\title{
HIGHER EDUCATION PATHWAYS
}

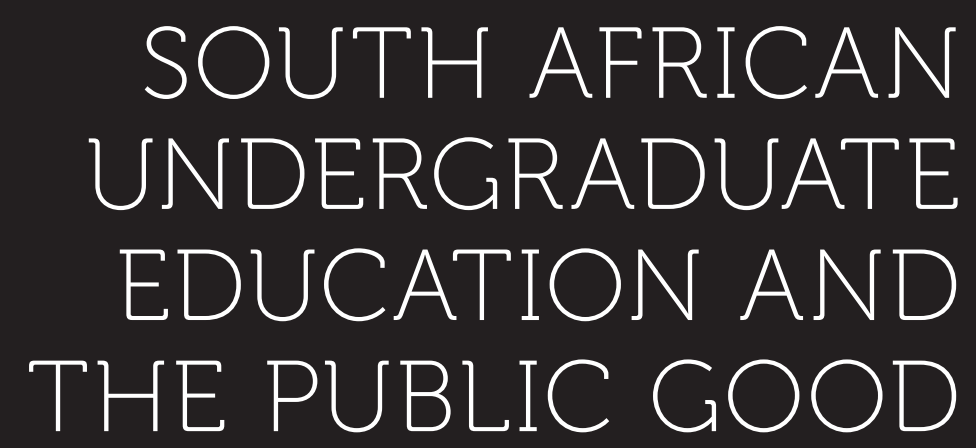




\section{Higher Education Pathways}

South African Undergraduate Education and the Public Good

Edited by Paul Ashwin and Jennifer M. Case 
First published in 2018 by African Minds

4 Eccleston Place, Somerset West 7130, Cape Town, South Africa

info@africanminds.org.za

www.africanminds.org.za

(c) 2018 African Minds

\section{(c) (1)}

This work is licensed under a Creative Commons Attribution 4.0 International License.

ISBN: 978-1-928331-90-2

eBook edition: 978-1-928331-91-9

ePub edition: 978-1-928331-92-6

\section{ORDERS:}

African Minds

4 Eccleston Place, Somerset West 7130, Cape Town, South Africa

info@africanminds.org.za

www.africanminds.org.za

For orders from outside Africa:

African Books Collective

PO Box 721, Oxford OX1 9EN, UK

orders@africanbookscollective.com 


\section{TABLE OF CONTENTS}

Acknowledgements $\quad$ vi

Notes on contributors vii

PART A: SeTting The SCEne 1

Chapter 1 Introduction 3

Paul Ashwin and Jennifer M. Case

Chapter 2 Transformation, the state and higher education: Towards a

developmental system of higher education in South Africa

Rajani Naidoo and Rushil Ranchod

Chapter 3 Subsidy, tuition fees and the challenge of financing higher education in South Africa

Gerald Wangenge-Ouma and Vincent Carpentier

Chapter 4 South African higher education, society and economy:

What do we know about the relationships?

Stephanie Allais

Chapter 5 Understanding the role of university graduates in society:

Which conception of public good?

Rosemary Deem and Tristan McCowan

PART B: WAYS OF UNDERSTANDING

Chapter 6 A multi-dimensional approach to fair access

Melanie Walker

Chapter 7 International perspectives on equality of higher education opportunities:

Models and strategies for accessibility and availability

Vincent Carpentier, Yann Lebeau and Jussi Välimaa

Chapter 8 How higher education research using the capability approach

illuminates possibilities for the transformation of individuals and society in South Africa

Monica McLean 
Chapter 9 The conceptualisation of students' personal transformation through their engagement in South African undergraduate education

Paul Ashwin and Janja Komljenovic

Chapter 10 Understanding the relationship between institutional cultures and pedagogical change

Rebecca Schendel

Chapter 11 The lenses we use to research student experiences

Amanda Hlengwa, Sioux McKenna and Thando Njovane

PART C: Situating: What We KNow about South African higher Education

Chapter 12 The rising challenge of university access for students from

low-income families

Langutani Masehela

Chapter 13 \#FeesMustFall: A media analysis of students' voices on access to universities in South Africa

Mikateko Mathebula and Talita Calitz

Chapter 14 Curriculum transformation: Looking back and planning forward Suellen Shay and Thandeka Mkhize

Chapter 15 Understanding student experiences through the lens of academic staff development practice and research

Sherran Clarence

Chapter 16 Students' experiences of university life beyond the curriculum Philippa Kerr and Thierry Luescher

Chapter 17 Post-graduation trajectories of young South Africans

Jennifer M. Case, Delia Marshall and Samuel Fongwa

Chapter 18 Exploring differences in South African graduate outcomes Samuel Fongwa, Delia Marshall and Jennifer M. Case

Chapter 19 Destination and outcome trends for graduates from sub-Saharan African countries: Implications for South Africa

Ibrahim Oanda and Siphelo Ngcwangu

Chapter 20 Engineering graduates in South Africa and Brazil: A common good perspective

Renato H. L. Pedrosa and Bruce Kloot 
PART D: CONCLUSION

Chapter 21 What have we learned about pathways to the public good from South African undergraduate education?

Paul Ashwin, Vincent Carpentier, Jennifer Case, Delia Marshall, Tristan McCowan, Sioux McKenna, Rajani Naidoo, Rebecca Schendel and Melanie Walker

Index 


\section{ACKNOWLEDGEMENTS}

We would like to acknowledge the support that was provided by the Economic Social Research Council (ESRC), UK, and National Research Foundation (NRF), South Africa, who funded the Newton Fund collaborative project 'Pathways to Personal and Public Good: Understanding access to, student experiences of, and outcomes from South African undergraduate higher education' (ESRC project reference: ES/N009894/1; NRF project reference: UID 98365). The chapters in this book were written as part of the collaborative work of this project.

We would also like to acknowledge the excellent administrative support that was provided to the project by Dee Daglish at Lancaster University and Carol Carr at the University of Cape Town. This project was part of the Centre for Global Higher Education (CGHE) (www.researchcghe.org) and we would also like to thank Simon Marginson, the Director of CGHE, and Anna Phillips, CGHE's Communications and Digital Engagement Officer, for their support for this project. 


\section{NOTES ON CONTRIBUTORS}

Stephanie Allais is the SARCHI Research Chair for Skills Development, and Professor of Education at the Centre for Researching Education and Labour at the School of Education, University of the Witwatersrand, South Africa.

Paul Ashwin is Professor of Higher Education in the Department of Educational Research, Lancaster University, UK.

Talita Calitz is Lecturer in the Department of Education Management and Policy Studies, University of Pretoria, South Africa.

Vincent Carpentier is Reader in the History of Education at the UCL Institute of Education, UK.

Jennifer M. Case is Department Head and Professor in the Department of Engineering Education at Virginia Tech, USA and Honorary Professor at the University of Cape Town.

Sherran Clarence is an Honorary Research Associate in the Centre for Postgraduate Studies at Rhodes University, Grahamstown.

Rosemary Deem is Vice-Principal (Education) and Professor of Higher Education Management, Royal Holloway, University of London, UK.

Samuel Fongwa is Post-Doctoral Fellow at the Human Sciences Research Council, South Africa.

Amanda Hlengwa is Senior Lecturer and New Generation of Academics Programme Manager, Rhodes University, South Africa.

Philippa Kerr is Post-Doctoral Researcher in the SARCHI Higher Education and Human Development Research Programme, University of the Free State, South Africa. 
Bruce KLOot is Academic Development Lecturer in the Department of Mechanical Engineering, University of Cape Town, South Africa.

Janja Komljenovic is Lecturer in Higher Education in the Department of Educational Research, Lancaster University, UK.

YanN Lebeau is Senior Lecturer in the School of Education and Lifelong Learning, University of East Anglia, UK.

Thierry Luescher is Research Director in the Education and Skills Development Department, Human Sciences Research Council, South Africa.

Delia Marshall is Professor in the Department of Physics at the University of the Western Cape, South Africa.

Langutani Masehela is Senior Educational Development practitioner and Head of Academic Development Unit at the University of Venda, South Africa.

Mikateko Mathebula is Senior Researcher in the SARCHI Higher Education and Human Development Research Programme, University of the Free State, South Africa.

Tristan McCowan is Professor of International Education at the UCL Institute of Education, UK.

Sioux McKenna is Professor in the Centre for Higher Education Research, Teaching and Learning and Director of Postgraduate Studies at Rhodes University, South Africa.

Monica McLean is Professor of Education in the School of Education, University of Nottingham, UK.

Thandeka Mкhize is based in the Quality Assurance Unit of Sur University College, Sultanate of Oman.

Rajani Naidoo is Professor of Higher Education Management in the School of Management at the University of Bath, UK.

Siphelo NgCwangu is Senior Lecturer in the Department of Sociology, University of Johannesburg, South Africa. 
Thando NJovane is a PhD candidate in the Department of Literary Studies in English, Rhodes University, South Africa.

Ibrahim OANDa is Senior Program Officer and Head of the Training, Grants and Fellowships Program at the Council for the Development of Social Science Research in Africa, Dakar, Senegal.

Renato H. L. Pedrosa is Professor in the Department of Science and Technology Policy, Institute of Geosciences, University of Campinas, Brazil.

RushiL RanCHOD is Fellow in International Development, University of Bath, UK.

Rebecca Schendel is Lecturer in Education and International Development at the UCL Institute of Education, UK.

Suellen Shay is Associate Professor in the Centre for Higher Education Development, University of Cape Town, South Africa.

Jussi VälimaA, is Director of the Finnish Institute for Educational Research and Professor in Educational Studies, University of Jyväskylä, Finland.

Melanie Walker is South African Research Chair in Higher Education and Human Development, University of the Free State, South Africa.

Gerald Wangenge-Ouma is Director of Institutional Planning, University of Pretoria, South Africa. 

PART A

\section{SETTING THE SCENE}





\section{CHAPTER 1 \\ INTRODUCTION}

Paul Ashwin and Jennifer M. Case

In what ways does higher education have a transformative impact on people and societies? What conditions are required for this impact to occur? What is the relationship between pathways through undergraduate education and the public good?

These questions, which are the focus of this book, have urgency across the globe and particular resonance in the South African higher education context, which is attempting to tackle the challenges of widening access and improving completion rates in an historically elite and racially segregated system. In this chapter, we first introduce the project that was designed to engage with these questions and then give a brief introduction to the South African higher education context. We then provide an outline of the remaining chapters in the book and show the different ways in which they engage with the relationship between undergraduate education and the public good.

\section{The project}

The chapters in this book are based on the Economic Social Research Council, UK, and National Research Foundation, South Africa, funded collaborative project 'Pathways to Personal and Public Good: Understanding access to, student experiences of, and outcomes from South African undergraduate higher education' (ESRC project reference: ES/N009894/1; NRF project reference: UID 98365). The project emerged from a collaboration between the Centre for Global Higher Education and a cluster of NRF projects in South Africa located at the University of Cape Town, University of the Free State and Rhodes University.

This partnership examined the relationship between undergraduate education and personal and public goods in South Africa through three interlinked themes: access to higher education; students' experiences whilst studying; and the economic and social contributions made by university graduates. Understanding that these themes describe undergraduate pathways through higher education, for this project we also conceptualised the relationship to the public good in terms of a pathway. In South Africa the issue of access to higher education is crucial, given the transformation imperative to redress the historical legacy of an unequal and segregated system resting on the systematic exclusion and political disempowerment of the majority of the 
population (Department of Education, 1997). The South African higher education system has expanded considerably, doubling overall enrolment since democracy, with just under a million students now in the system. However, some groups of students remain under-represented. For example, while about half of the white and Indian youth cohort participate in higher education, for black and coloured young people this is under a fifth of the cohort (Council on Higher Education, 2018).

Although questions of access are crucially important in their own right, any examination of the transformative potential of higher education must also consider the experiences of students within higher education. There is a pressing need to understand the forms of curriculum, pedagogy and social experiences that support 'epistemological access' for all students (Morrow, 2009). There is also a need to understand the ways in which transformative university experiences can lead to social change through the development of graduate professionals who are orientated to and contribute to the public good (Walker \& McLean, 2013). In terms of graduate outcomes, there remain concerns about the availability of graduate employment, particularly for certain groups (Bhorat, Mayet, \& Visser, 2012). This has also led to renewed interest in traditional arguments around the public good value of higher education. This perspective brings to the forefront the values, understandings and commitments that might be shaped by the university experience, in addition to 'skills', in order to build the essential elements for an engaged citizenry who can participate and contribute in a democratic community (Coetzee, Botha, \& Holtzhausen, 2012).

The project brought together internationally leading higher education researchers from the UK, South Africa and further afield in order to explore the relations between these themes (access, student experience and graduate outcomes). The partnership also sought to contribute to higher education research capacity building through the development of an internationally networked cadre of South African post-doctoral researchers, who had the opportunity to work with these internationally leading researchers in the field of higher education over a sustained period of time.

The project created a group of researchers to focus on each theme, and each group held meetings over a three-year period to discuss what we could glean from existing research into South African higher education. There were also meetings in which the work of the three theme groups was brought together and the overall project team discussed how integrating the work from these themes extended our understanding of South African higher education. The distinctive contribution of this work at its conclusion is thus to bring together empirical evidence and conceptual debates across these three domains of the higher education trajectory that are often considered in isolation.

South Africa has an active education research community with strong public funding, and a significant amount of higher education research has been conducted over the years. However, as is common in many other contexts, there is less critical review or synthesis of this work. As mentioned, this project had an objective to properly take stock on what is already known, and what is not known. 
With an unusually late transition to democracy and a racially offensive prior regime with notoriety on the world stage, it is easy to adopt a position of 'South African exceptionalism'; that is the view that this context is so unique that it does not permit comparison or even serious analysis. We do not align ourselves with this popular (and attractive, for some) view, but neither do we fall into universalism, especially of a Western inflected version. Thus, this project also worked closely with the potential for bringing South African research findings into conversation with an international literature, not only to bring new light to bear on South African challenges, but also to allow for potential impact of South African-derived insights into other contexts. In case study terminology, South Africa, while not unique as noted above, could potentially be termed a 'crucial case' - one which exhibits some unique characteristics but also shares a number of common characteristics with other higher education systems. This makes understandings of South African undergraduate education potentially valuable when thinking about other systems of higher education.

\section{The South African higher education context}

South Africa is a country defined by extreme inequality and this plays out in many ways across its social landscape, including higher education. Its history in colonialism and apartheid continues to structure the present. The university is situated within this broader socioeconomic context which includes significantly high levels of unemployment (most recently recorded as $26.7 \%$ ), particularly youth unemployment, with $32.4 \%$ of young people not in education, employment or training - the NEETs (Statistics South Africa, 2018). For the majority of young people, schooling outcomes are poor, even taking into account regional comparisons. This is arguably the major impediment for access to higher education. In terms of post-schooling options, the vocational sector is weak, and thus for many young people higher education is considered the only route to social mobility. There has been a dramatic growth of enrolments in higher education since the early 1990s, and the academic performance outcomes that have been recorded in terms of graduate rates are not strong: only $55 \%$ of students who register for three-year degrees at contact institutions have graduated five years after starting (Council on Higher Education, 2018).

Following a process around the turn of the century of institutional mergers, the public higher education sector currently comprises 26 public universities, currently classified by the Department of Higher Education and Training as 12 'traditional' universities, 8 universities of technology, and 6 comprehensive universities. The latter two categories offer both diplomas and degrees. Within the 'traditional' category there is considerable variation in how 'researchintensive' the institution is, with the racial inheritance of 'historically advantaged/white' and 'historically disadvantaged/black' tending to line up with resources and capacity to do research.

The book is located in the period when significant student protest rocked the South African higher education system. The two core cries of the student protest movement - \#RhodesMust Fall (RMF) and \#FeesMustFall (FMF) - exposed a disconnect between the policy based (and 
widely perceived) core role of higher education in facilitating social mobility and redress, and the realities facing many young people across the country. The protests highlighted barriers, both at the point of access and within higher education for those who were successful in gaining a place at university.

A key tension is between the aspirations of South African school leavers and the current arrangements for provision of undergraduate higher education. Public funding has not grown in accordance with growing enrolments in South Africa and thus an increasing share of the cost has been shifted to students and their families. A second tension relates to stratification of the higher education system: massification of higher education is typically, but not inevitably, accompanied by increased stratification. Stratification limits higher education's capacity to be an engine for social mobility because there are disparities in who has access to the most prestigious universities, which are seen to offer the highest economic and social returns. As such, even for students who gain an undergraduate degree, their possibilities for engaging in further higher education and entering the world of work are significantly structured by social background and geographical location. The many students who do not complete their degrees, regardless of which institution they attend, are left with substantial debts but little return from their engagement in higher education, and these students are more likely to be from poorer backgrounds. These tensions, crucially, have contributed to new patterns of inequality. The debate has thus expanded beyond that of access, by drawing attention to the ways in which the experiences and academic success of students in higher education differ in terms of their social and schooling background, as well as questions about the kinds of knowledge that universities offer students access to. At their core, these debates centre on questions around the purpose and focus of the university in a democratic society, as well as perceived uncertainties about employment prospects for graduates. They also raise the difficult question of whether we might be overestimating the power of higher education to change society.

This book tackles these complex issues by examining one key question underpinning all of these debates: to what extent does undergraduate education in South Africa support the public good? In engaging with this question, the chapters in this book draw on a wide range of theoretical resources and literature and data from both inside and outside of South Africa. The rationale behind this approach is that a variety of perspectives can offer us a number of different ways of understanding these pathways, rather than only examining them from a single viewpoint.

\section{The structure of the book}

The overall structure of the book first sets the scene for examining undergraduate education in South Africa, then looks at different ways of understanding the pathways to the public good that undergraduate education offers, and finally examines empirical evidence about particular aspects of these pathways. 
Part A of the book sets the scene, locating higher education within the broader context of relations to the state and to society. In Chapter 2, Naidoo and Ranchod focus on the relationship between higher education and the state, noting how in the democratic period in South Africa there have been distinctly different policy periods in terms of the stated commitment to a 'developmental state', and that this has worked through into the political economy of public higher education. In Chapter 3, Wangenge-Ouma and Carpentier review the system for the funding of higher education in South Africa, and how these arrangements link into ongoing concerns around accessibility, as well as international debates on cost-sharing. Allais, in Chapter 4, continues the exploration of relations between higher education, the state and society, showing the complexity especially of the relationship between higher education and the labour market. In Chapter 5, Deem and McCowan explore the concept of the 'public good' in reference to undergraduate education but also in relation to debates about the wider purposes of universities and the contribution made by university graduates.

In Part B of the book we gather a series of chapters that look further at ways of understanding key aspects of the relationship between higher education and the public good. In Chapter 6 , Walker shows how access to higher education is shaped by the complexity of the relationship between social inequalities, poverty, academic achievement, educational 'choices' and life chances. Walker notes that, compared to international findings, South African students from poor backgrounds are less put off by immediate costs of higher education because of the anticipated future returns. In Chapter 7, Carpentier, Lebeau and Välimaa take a comparative look at issues of accessibility, availability and attainability of higher education, looking at higher education systems in Finland, France, Senegal and Nigeria. McLean provides an overview of the Capability Approach in Chapter 8. This approach offers a normative framework for thinking about what kind of educational experiences support human well-being and fulfilment, focusing especially on firstly, those students who have accessed university against the odds because they are black and come from poor rural and township areas, and secondly, on how educational experiences might shape graduates oriented towards contributing to social transformation. In Chapter 9, Ashwin and Komljenovic present a review of literature examining the ways in which students' senses of identity are changed through their engagement with South African undergraduate education, with a focus on how this relationship between students and universities is conceptualised. Schendel, in Chapter 10, examines the assumed links between 'institutional culture' and processes of pedagogical change within universities, looking especially to see whether the theoretical assumptions present in the international literature are applicable to the South African context. Finally in this section, in Chapter 11, Hlengwa, McKenna and Njovane examine the ways that student experiences in South Africa are conceptualised in research by analysing postgraduate theses on this topic.

Part $\mathrm{C}$ moves in further to look at what the empirical evidence tells us about access to, students' experiences of, and graduate outcomes from South African higher education. Chapters 12 and 13 examine issues of access. In Chapter 12, Masehela explores how students from low-income families without any form of financial assistance manage to register and 
commence their academic studies. In Chapter 13, Mathebula and Calitz explore what student voices in the \#FeesMustFall protest reveal about questions of access to South African higher education, and universities in particular.

Chapters 14, 15 and 16 examine evidence about different aspects of students' experiences of undergraduate education in South Africa. Shay and Mkhize focus on issues of the curriculum in Chapter 14. They consider how curriculum structures and content might enable parity of participation, looking specifically at the extended degree which was introduced with this in mind, and exploring the features of a 'transforming curriculum' for the future. In Chapter 15, Clarence looks at academic staff development in South Africa, to identify how the student experience of higher education is represented in this field of practice. Kerr and Luescher, in Chapter 16, review the literature on South African student experiences of university life beyond the curriculum. They show a rather bleak picture of the student experience in which the university appears mainly as a place of personal struggle and campus life a source of anxiety for students. However, there are also some indications that the experience is positively transformative.

Chapters 17 to 20 offer differ perspectives on the experiences of graduates. In Chapter 17, Case, Marshall and Fongwa review the literature on the post-graduation trajectories of young South Africans, using both labour force surveys and graduate destinations studies, showing that while graduate unemployment on average is not a cause for concern, race continues to play a significant role in graduate employment. In Chapter 18, the same author team offer a more fine grained approach by looking in depth at two narrative studies of student experiences to interrogate what lies behind these differentiated outcomes, showing how students' experiences before and during university shape what graduates can aspire to and how they navigate, or not, through institutional structures to achieve diverse outcomes. In Chapter 19, Oanda and Ngcwangu take our understanding further by offering a comparative dimension and examining the graduate employment trends in a number of sub-Saharan African countries. In Chapter 20, Pedrosa and Kloot examine how focusing on the graduate outcomes from a single discipline in different countries (engineering in South Africa and Brazil) can further our understanding of how undergraduate education contributes to the public, or common, good.

The concluding section of the book, Part D, consists of a single chapter in which those who led the access, student experience and graduate themes of the project, consider what the book as a whole tells us about pathways to the public good from South African undergraduate education. They identify a number of tensions in our ways of thinking about these pathways and discuss the implications of the project for researching higher education and policies and practices in South African undergraduate education.

The chapters in the book thus provide a fresh engagement with the question of how undergraduate education contributes to the public good in the South African context. They also make a contribution to broader discussions about how universities are situated in society. These discussions are vital if we are going to develop richer understandings of the ways in which higher education can contribute to the transformation of society that is key to the future of a more inclusive and equitable South Africa. 


\section{References}

Bhorat, H., Mayet, N., \& Visser, M. (2012). Student graduation, labour market destinations and employment earnings. In M. Letseka, M. Cosser, M. Breier, \& M. Visser (Eds.), Student retention and graduate destination: Higher education \& labour market access and success (pp. 97-123). Cape Town: HSRC Press.

Coetzee, M., Botha, J.-A., \& Holtzhausen, N. (2012). Developing student graduateness and employability: Issues, provocations, theory and practical guidelines. Johannesburg: Knowres Publishing.

Council on Higher Education (2018). VitalStats: Public higher education, 2016. Pretoria: Council on Higher Education.

Department of Education (1997). White paper on higher education. Pretoria: Department of Education, Government of the Republic of South Africa.

Morrow, W. E. (2009). Bounds of democracy: Epistemological access in higher education. Cape Town: HSRC Press.

Statistics South Africa (2018). Quarterly Labour Force Survey.

Walker, M., \& McLean, M. (2013). Professional education, capabilities and the public good: The role of universities in promoting human development. London: Routledge. 


\title{
TRANSFORMATION, THE STATE AND HIGHER EDUCATION: TOWARDS A DEVELOPMENTAL SYSTEM OF HIGHER EDUCATION IN SOUTH AFRICA
}

\author{
Rajani Naidoo and Rushil Ranchod
}

\section{Introduction}

The concept of transformation in South African higher education has evolved as a powerful motif with historical roots in the struggle against apartheid projecting into different phases of the post-apartheid era. Transformation in higher education has been framed by wider aspirations for transformation linked to the public good role of higher education. We conceptualise the contribution of higher education to inclusive development in South Africa as a particular component of the public good; and characterise South Africa as an aspirant developmental state. This chapter focuses on changing conceptualisations of transformation in higher education in the context of the changing developmental role of the state; and the extent to which government policies combine to empower higher education to contribute to goals of inclusive social and economic development.

We begin by outlining the characteristics of South Africa as an aspirant development state by focusing on transformation through various periods in the post-apartheid era. Next, we outline the state-higher education policy nexus before focusing on key conceptualisations and policies related to transformation in higher education. We conclude by presenting an assessment of how these conceptions and policies come together to impact on the potential for higher education to contribute to inclusive development. 


\section{Transformation in an 'aspirational' developmental state}

Our understanding of the evolution of the concept of transformation in higher education is embedded in the state-higher education nexus, by which we mean the changing points of connection between the state and higher education, which are in turn related to the evolving political, economic and social strategies of the South African state economic. For the purposes of our chapter, we bracket out the relationship with civil society, as the state, higher education and society relationship is the focus of the next two chapters in this edition. The developmental role of the South African state, its relationship with national and global corporations, powerful governments, the trade union movements and its own citizens has, and continues to be, highly 'contested ideologically and politically' (Satgar, 2012, p. 34). We begin by introducing the notion of the developmental state in South Africa before focusing on three post-apartheid periods roughly divided by the Mandela, Mbeki and Zuma/Ramaphosa presidential regimes.

Ideological principles underlying the national liberation movement and popular democratic struggles envisioned an interventionist state which would play a central function in wholescale transformation leading to economic, political and social development. Encapsulated in the Freedom Charter, and then further operationalised through the Reconstruction and Development Programme (RDP), the democratic settlement was imbued with an activist role for the state in managing domestic and international pressures (Naidoo, 2017)

The notion of the developmental state first appeared in the African National Congress's (ANC) 1992 Ready to Govern document (Gwaindepi, n.d; ANC, 1992), but was given greater political and policy centrality by the ANC after 2007. At the ruling party's Polokwane Conference in 2007, the ANC noted that it was in the process of building a developmental state - this state form stood in counterpoint to the welfare state, 'given that in a welfare state, dependency is profound' (ANC, 2007). These 2007 ANC Conference resolutions permit an insight into the particular orientation and contours of an emergent South African development state. They display elements of both classic models of state intervention, but also critically aimed to play a capability-expanding role for citizens while building national and democratic consensus for development and economic growth. This conception of the developmental state was extended into South Africa's long-term National Development Plan (NDP), which had the explicit aim of '[b]uilding a capable and development state' (National Planning Commission [NPC], 2012). The NDP has recognised the centrality of capabilities-expansion for realising socio-economic and political development: 'A development state builds the capabilities of people to improve their own lives, while intervening to correct historical inequalities' (NPC, 2012, p. 27). The core capabilities identified are: 'Political freedoms and human rights; Social opportunities arising from education, health care, public transport and other public services; Social security and safety nets; An open society, transparency, disclosures and a culture of accountability; Economic facilities, work, consumption, exchange, investment and production' (NPC, 2012, p. 27). Critically, the NDP recognises the need for effective institutional capacity to function efficiently and recommends contending approaches to building a stronger and more efficient state apparatus. 
While these policy statements provide a clear outline of a developmental state 'in-themaking' (and hence it can be described as 'aspirational') (Routley, 2012), critics contend that the 'general approach to the developmental state in South Africa has been "propagandistic and declaratory"; it has "helped legitimate the state's contradictions" and that while it has subscribed to a developmental approach, the state is deeply embedded in neoliberalism' (Satgar, 2012, p. 37). To better understand the move towards a developmental state in democratic South Africa, we periodise its political economy by bounding state activity in different presidential administrations viz. the Mandela, Mbeki and Zuma/Ramaphosa periods. While such periodisation presents an artificial boundary between each presidential term, it nevertheless serves an analytical purpose to better understand the character of the South African state over time. Critically, however, it should not obscure the continuities across each of these periods.

\section{First period: Mandela presidential term}

The Mandela presidency saw the creation of a 'policy state' wherein the state undertook a 'wide ranging policy review and formulation' as it sought to rebuild a representative, inclusive and democratic policy and state apparatus (Naidoo, 2017, p. 13). The exigencies of post-apartheid state formation, and the awareness of the need to respond to 'pent-up public demands' saw both the reconstruction and expansion of the state apparatus to manage increased demands in an effective and efficient manner (Naidoo, 2017, p. 13). The Mandela presidency was expected to implement the social-democratic, corporatist Reconstruction and Development Programme (RDP), but by 1996, the RDP had been discarded and replaced by the more neoliberal Growth, Employment and Redistribution (GEAR) policy. Critics charged the ANC with duplicity of, in the words of the title of Bond's (2004) book, 'talk[ing] Left and walk[ing] Right', while other analysts point to a number of local and international pressures that had forced the state's hand in ensuring greater macroeconomic stability (Seekings \& Nattrass, 2016), albeit in a neoliberal mould.

The adoption of GEAR exposed the 'ambiguities' in South Africa's economic and social provisioning. While GEAR prescribed an orthodox set of tools to restrain public expenditure, the South African state also undertook a significant social protection agenda in which social transfers and welfare grants continued to function as important buffers against deepening poverty (Seekings \& Nattrass, 2016). This provisioning has created a universal, transfer welfare state which, despite the ANC government's reluctant implementation of pro-poor welfare programmes, has become 'more (not less) redistributive over time' (Seekings \& Nattrass, 2016, p. 169). Discursively, the state has maintained that such welfare provisioning would be part of an individual empowerment agenda in which an enabling environment would be created for capability-enhancement. However, in practise, the growing reliance on welfare as a means to stave off poverty, together with the lack of macro-economic reform and employment opportunities, undercut any viable claim to empowerment. 


\title{
Second period: Mbeki presidential term
}

The second period, the Mbeki presidency, did not see significant expansion in government departments to manage the functions of state; instead this period has been defined as one of 'fine-tuning' the existing configuration of the state with greater centralisation of functions and decision-making moved to the Presidency (Booysen, 2011). In addition, the shift to a 'wholeof-government' approach aimed to create a more functionally integrated state which could be better managed from the centre (Naidoo, 2017). Thus, greater emphasis was placed on the implementation capacity of the state and its ability to deliver on its developmental mandate. GEAR would maintain its centrality in economic policy; it was a precursor for a subsequent market-friendly economic policy agenda.

The interaction between the state and market was also more nuanced. Seekings and Nattrass (2016, p. 219) state that while the state was pro-market, it was less pro-business: white business was viewed with suspicion given their role during apartheid and thus, 'The state's priority ... was more to "discipline" and to "transform" existing business than to work with it.' The ambiguous nature of the state toward the market meant that

\begin{abstract}
[w] hile the state viewed markets with approval in various policy areas, not least because of the evident limits to state capacity, it also intervened in and subverted markets in other policy areas. ... it institutionalised corporatist collective bargaining over wages and employment conditions, provided minimum wage setting in sectors where workers were weak and introduced industrial and other growth path policies that benefitted unionised workers. (Seekings \& Nattrass, 2016, p. 220)
\end{abstract}

While adhering more toward these Scandinavian corporatist-style interventions, the state also undertook greater intervention in 'corporate ownership and management through Black Economic Empowerment (BEE) and affirmative action ('employment equity') policies' (Seekings \& Nattrass, 2016, p. 220). For the former, a preferential procurement framework aimed to support black business: rather than creating winners in key economic sectors, the state created winners through constituency politics. A clear, strong and symbiotic relationship between the state and capital was not established.

The capacity of the democratic state in this era to implement policy was uneven. While it succeeded largely in distributing social and welfare effectively, as well as undertaking critical economic functions such as tax collection efficiently, it 'lacked the developmental capacity to direct economic growth and change in the same way as ... the Korean developmental state' (Seekings \& Nattrass, 2016, p. 200). Instead, the creation of the aforementioned 'transfer welfare state' has been largely by 'default': the state's 'deficient policy and policy implementation in the areas of health and education leave its grants and social transfer policy as the effective social policies', and given the enduring problems of adequate provision in these social fields, 'there is little prospect for welfare-dependent 
households to acquire much needed human capital to escape their welfare-dependent living conditions' (Burger, 2014, p. 176).

The challenges to human capital development remain particularly acute, especially when consideration is given to the changing nature of the South African economy since the 1970s away from primary sectors and into secondary and tertiary sectors and compounded by a distinct skills bias in favour of higher end skills (Bhorat, Goga, \& Stanwix, 2013). While welfare provisioning may have supported some measure of capability-development, it did not go far enough in building a capability-expanding state.

Moreover, there has not been a singular, binding hegemonic vision that has driven a developmentalist orientation within the state. Policy shifts, historical and ideological differences within the party-political machinery, as well as a changing global context have functioned to nullify an overarching national vision to mobilise society. While the RDP and more recently, the NDP, have attempted to develop a binding vision, they have fallen short in articulating a clear developmental project with significant buy-in from all segments of society. In addition, the charges of neoliberalism have deepened fissures and factionalised the African National Congress, contributing to the lack of a cohesive developmental vision.

\section{Third period: Zuma/Ramaphosa presidential terms}

The third period, the Zuma administration, has attempted to give flesh to the bones of the developmental state, at least at a rhetorical level. The state has grown, and a number of new ministerial departments have been created in this period to effect greater implementation of key policy areas. A distinct politics was in play in the Zuma administration. Analysts have noted that patronage has functioned to shape the functional and organisational structure of the state (Naidoo, 2017). Departmental duplication and the lack of clear policy remits have led to a misalignment between the professed goals of greater developmentalism and the functional capacity of the state to deliver on it. Moreover, this expansionary state apparatus has also led to greater fiscal bloating. The South African state has been characterised as approaching a financial and political crisis, which has limited its ability to implement and reach its developmental goals (Southall, 2016). The Zuma period has been marked by a lack of distinct policy clarity, and while the overarching vision of the NDP attempts to provide a framework for a South African developmental state, there has not been sufficient, tangible progress on realising its core goals. Increasingly, the South African state is being hollowed out by a lack of leadership capacity and an inability to manage the economic, administrative and social levers required of a developmental state. It has also accelerated an enduring process of politicisation of the bureaucratic apparatus with negative consequences on capacity development and delivery (Cameron, 2010).

In February 2018, a change in the leadership of the ANC elevated Cyril Ramaphosa to the presidency of South Africa. Inaugurating the change as a 'moment of hope and renewal', Ramaphosa's agenda has been marked by attempts to arrest the decline of state institutions, to improve the governance and operation of large state-owned enterprises, and to drive economic 
growth and development through a renewed commitment to employment creation, increased foreign and domestic investment in productive sectors, and boosting industrialisation by stimulating the creation of black industrialists (The Presidency, 2018). The continued commitment to building 'a strong and capable state' informs these transformation processes. In response to Zuma's expansionary state, the new administration has resolved to 'initiate a process to review the configuration, number and size of national government departments' (The Presidency, 2018). While there is a recommitment to building state capacity and effectiveness, strong neoliberal drivers are being maintained or strengthened. An analysis of the budget shows that corporate taxes have been set at half the level they were in 1994, while social programmes have been cut, and general sales tax has been increased, with the potential to disproportionately hit the poorest in society, while exchange controls for the country's largest financiers have been liberalised.

The state in South Africa thus displays certain features of a developmental state, including being interventionist and shaping market-based policies as well as measures of redress and equity. However, these features are uneven and there are a number of challenges to the realisation of an effective democratic developmental state in South Africa. While the state has implemented a range of policies in the pursuit of economic growth, the interaction of such growth with poverty, inequality and unemployment has been complex. Structural and institutional factors have hampered state efforts at generating mass employment. The lack of a clear, hegemonic, developmentalist vision has hindered large-scale progressive societal mobilisation.

\section{The state-higher education nexus and the question of transformation}

We turn now to an analysis of the mutually constitutive relationship between the state and higher education in relation to the transformation imperative. Many of the tensions that exist in the state's own conflicts and issues with transformation are replicated both in the statehigher education relationship, as well as in the state's steering of higher education and the responses of higher education institutions across all three presidential regimes.

A key feature of a developmental state is the need to coordinate the different parts of the overall system, including higher education in order to ensure coherent policy formulation and implementation (Edigheji, 2007). In higher education, this process is facilitated by the Council on Higher Education (CHE), a coordinating body which interfaces between the universities and the government's Department of Higher Education and Training. The state-higher education relationship has been characterised as 'cooperative governance with state supervision' (Cloete, 2002, pp. 54-55) or as 'conditional autonomy'. This bi-directional relationship results in tensions with respect to autonomy and accountability. Changing alliances to accommodate or resist state steering are heavily dependent on historical hierarchies in the field of higher education and to university connections to dominant fractions in the field of political power (Lepori \& Naidoo, 2017).

An analysis of the shifts and contestations in transformation needs to start in the context of the specific post-apartheid historic juncture. Jansen $(2001,2002)$ has asserted that 
establishing the legitimacy and credentials of the government in the post-apartheid period required an overarching discourse about transformation which was largely symbolic and which would eventually undermine implementation when confronted with pressing local and global constraints. Thus the symbolism embedded in government policy generated unrealistic expectations about redress (Cloete, Fehnel, Maasen, Moja, Perold, \& Gibbon, 2002) and left the government open to criticism for half-hearted implementation (Jansen, 2001). Throughout the various transformation phases, tensions emerged which were not anticipated by the key players in South Africa (Cloete \& Moja, 2005; Kraak \& Young, 2001). Ideological and political differences and the realities of limited resources underlay such tensions. Further tensions were caused by the gap between the high expectations that followed from the end of apartheid, the difficulties of accommodating competing priorities and demands and limited government and institutional capacity (Thaver \& Thaver, 2009).

\section{Transformation as equity of access}

The Mandela presidential period was dominated by discussions of a break with the apartheid past and redress for past inequities. Government policies in this era, namely the NCHE Framework (1996), the Education White Papers and the Higher Education Act (1997) provided the rationale and the specific direction for the reconstruction of higher education. In the early years of the Mandela regime, emphasis was placed on achieving social justice through redress via a reconstruction and development programme which was envisaged to break with the apartheid past, achieve redress for past inequities and correct apartheid social engineering (Cloete et al., 2002). In higher education, the key transformative principle in this early period appears to be a narrow focus on demographic transformation particularly of the student body in relation to race, although this was extended to gender, age, and disability (Department of Education [DOE], 1997). As indicated in the report by the Council on Higher Education (Council on Higher Education [CHE], 2016), hegemonic discourses on transformation were equated with equity, and equity was equated with race. There appears to be the assumption that access to higher education for those who were previously excluded would automatically contribute to development in general and the public good in particular. In contemporary times, race is still a key factor in transformation debates, but this is infused with new debates on whether race should remain a criterion, given the development of a black middle class or whether other indicators of disadvantage, such as quintile of school, would be more equitable (for further discussion on this topic, see Chapter 6).

\section{Transformation as massification}

As we see in the sections above, the redress of apartheid's past in relation to equity of access in undergraduate education dominated the agenda in a relatively unmediated manner, particularly 
in the immediate post-apartheid era. In this context, discussions on what redress strategies would be most appropriate were raised. One suggestion was to award a disadvantage subsidy from the government block grant for each black student enrolled. However, this did not come to fruition (Cloete, 2014). Another concept linked to transformation focused on institutional rather than student redress. The intention here was to develop policy and funding mechanisms to transform the system so that the inherited inequalities between the historically black and historically white institutions were diminished rather than intensified (Badat, Barends, \& Wolpe, 1994). This approach was not wholly successful. Cloete, Pillay, Badat, and Moja (2004) have noted that a complex set of circumstances led instead to a widening gap between the historically black universities and the historically advantaged institutions, with only the historically advantaged Afrikaans institutions gaining any real benefit.

The second redress strategy proposed that was linked to transformation was that of massification. The concern was, however, that rapid massification in a situation in which school preparation was unequal, and in which the staff to student ratio in higher education would become even greater, could result in an overall reduction in quality. Instead, the Higher Education Plan of 2001 called for 'planned growth' and in May 2002 a phased series of mergers was proposed to reduce the number of institutions from 36 to 21 . The rationale for mergers was intended to transform the system to break historical patterns of advantage and disadvantage. It was noted that the historical legacy of apartheid, together with weak regulation and quasimarket competition, combined to entrench the crisis in historically black institutions, while historically white institutions 'creamed' off the best students and staff. This resulted in historically disadvantaged institutions retaining the bulk of the most disadvantaged and underprepared students (DOE, 2001). The rationale was that in a period of crisis, all institutions needed to be transformed to ensure that all take responsibility to redress past inequalities. Collaboration and combinations of institutions were thus two crucial mechanisms to transform the system (DOE, 2001). While funding levers to encourage collaboration have been developed, progress with mergers has been uneven (Arnolds, Stofile, \& Lillah, 2013), and there are some indications of the reinforcement of stratification.

\section{Transformation as differentiation}

In 2012, the National Development Plan (NDP) set a target of 30 per cent participation in higher education by 2030, calling for massification with differentiation, in combination with robust quality checks. This policy initiative had strong links with the CHE commissioned report Towards a new higher education landscape, released in 2000, which made a case for higher education as a public good, and argued that transformation required the creation of a diverse and differentiated higher education system. In 2012 it was proposed that the system include a mix of research-led universities, mainly undergraduate teaching universities, a vocationally driven further education and training college sector and a market-driven sector, as well as increasing distance education. In addition, a new funding and planning framework by 
the Department of Education called for a system-wide student enrolment planning exercise to facilitate the implementation of a new funding formula. The government's argument was that, in order to maintain a sustainable funding level per student, and improve efficiency, student numbers should be capped and institutions should increase graduate output, by increasing throughput rates rather than by taking in more students (DOE, 2005).

\section{Transformation of knowledge and culture}

Linked to the 'transformation debate' on equity are the fault lines arising from the past but gaining increasing traction in contemporary times around the issue of institutional culture and relevant curricula. Lessons from countries such as Singapore indicate the importance of education in developing social cohesion and responsible citizenship (Goh \& Gopinathan, 2008). In South Africa, many gains in relation to institutional culture and the Africanisation of the curriculum have been made. However, there remains a widespread perception amongst key stakeholders that elements of apartheid remain embedded in institutional cultures and in the curriculum, and that these vestiges of the past serve to alienate black and other disadvantaged students. Initiatives such as the institutional transformation forums have been set up with the aim of uprooting remaining vestiges of apartheid and transforming culture. However, success has been reported as uneven (Griffin, 2016). Protests by students demanding the decolonisation of the curriculum and the removal of apartheid symbols such as the statue of Rhodes has combined with high-profile cases to call for transformation charters for all institutions to 'defeat racism and patriarchy' at South African universities which is believed to be 'rife'. The Ministerial Committee Report on Transformation and Social Cohesion of 2008 served to place the issue of the transformation of institutional cultures firmly on the agenda and led to the development of a national policy on social cohesion in the post-school sector. In 2013, Higher Education South Africa (HESA) initiated a project facilitating the development of Integrated Transformation Plans in which institutions put forward their understandings of the challenges of transformation and how they planned to address it. This process is reported to have led to a more nuanced understanding of transformation in relation to institutional culture, inclusiveness, diversity and redress (CHE, 2016). Codified knowledge has always been characterised by power struggles and specific interests (Collins, 1998) and clearly the curriculum in South Africa has been utilised as an ideological device for protecting privilege. At the same time, as Muller (2000) and Young (2007) warn, there are grave dangers with an uncritical acceptance of highly relativistic conceptions of knowledge. Moore and Muller (1999) show that it is all too easy to reach the point where academic knowledge can be perceived as being unable to make any epistemological claim to validity since it can only ever be an ideological device for maintaining positions of dominance.

Researchers such as Peter Evans (2010), writing in the context of the developmental state, have highlighted the importance of expanding access to the existing stock of ideas, increasing the effective utilisation of this stock and generating new ideas suited to a country's specific 
circumstances. While high research performance and robust research infrastructure are present in elite institutions, this is not a characteristic of the South African system as a whole. The potential of research to contribute to inclusive development is hampered by the difficulty of maintaining a balance between research which focuses on the country's specific challenges and the contribution to global and blue-sky knowledge. While both aims can sometimes be simultaneously met, often a focus on one undermines the other. In addition, innovation models such as the 'triple helix' which advocate strong relations between universities, industry, and government may not work well in the South African context as corporations may be unwilling to fund research and training and may not have sufficient capacity to utilise research findings or high-skilled knowledge workers (Naidoo, 2011). Many higher education institutions may therefore face pressures to perform low-level, routine, consultancy-type activities with the aim of generating income (Arocena \& Sutz, 2005). In addition, in a national context where Mode 1 specialist disciplinary knowledge was never thoroughly institutionalised, high market demand for knowledge for narrow utilitarian purposes may constrain research to the point of squeezing out important explanatory and theoretical research (Holland, 2008).

\section{The contribution of higher education to development}

In this final section, we draw on the consequences of the policies related to transformation presented above to discuss the contribution of higher education to the overall social and economic development of the country. An analysis of higher education documents in the Mandela presidential period indicates that there was little focus on development (Cloete \& Moja, 2005). Where development, particularly economic development, was raised, it was often counterpoised, at least implicitly, to social equity. In other words, there was an analytical separation between economic development and racial equity, together with the potential for economic development to be perceived as 'anti-transformational'. However, initiatives such as GEAR introduced substantial shifts and brought South Africa more in line with international neoliberal trends emphasising economic development, the need for fiscal restraint and structural adjustment (Bond, 2004). In the National Development Plan stronger links have been made between knowledge and development. The ten-year innovation plan (2008-2018) has also set out the aim of driving South Africa's transformation towards a knowledge economy, in which the production and dissemination of knowledge is expected to lead to economic benefits and to enrich all fields of human endeavour. However, a close analysis reveals that there has been insufficient analysis of the role of higher education in such knowledgedevelopmental visions.

Various transformation discourses are related to important and visionary policies in higher education which have led to the successful integration of racially divided systems into one national system of higher education. Successes include an appropriate and relevant quality assurance system, established governance bodies, high research output in some universities and major achievements in relation to access with an $80 \%$ growth in the number of African 
students, as well as implementation of a financial aid scheme (Baijnath, 2016). These successes are even more impressive against the backdrop of a historical system that was segregated and unequal, inadequate funding, rising poverty and student protests. These achievements could not have occurred without the vision, commitment and hard work of national policy-makers, institutional leaders, academics, and administrative staff and students.

However, as is the case in many other countries, there is also considerable dis-articulation between various policies leading to tensions, imbalances and contradictions impacting on the system as a whole. These are likely to lead to adverse consequences and we outline some illustrative examples below.

The development of a higher education system comprising a diversity of institutions offering high-quality academic and vocational choices with inter-connected progression routes is an important step towards both greater equity as well as holding out great potential for the contribution of higher education to wider social and economic development. However insufficient attention has been paid to developing policy and funding instruments that are genuinely differentiated to steer and reward diverse sets of institutions. There are also inadequate incentives for different types of institutions to excel in different missions. These factors lead to rising isomorphism and militate against a more inclusive higher education system contributing to inclusive development. In relation to access, for example, the logic of policies, when taken together, appear to offer the greatest rewards to institutions that maximise research output and demonstrate student success and progression in the shortest time possible. Institutions which have not traditionally included widening participation in their missions are therefore unlikely to develop admission strategies to recruit students from under-represented groups. Such students are perceived to be time and resource intensive and are therefore expected to threaten institutional arrangements around activities, such as research, through which academic status and financial resources are accrued (Naidoo, 1998). In addition, such students are unlikely to enhance the institution's 'output' indicators. At the same time, as research in other contexts has shown, the institutions that absorb students from groups that are traditionally excluded from higher education are likely to be financially and reputationally penalised, since policy frameworks do not differentiate between categories of students with regard to social disadvantage and differences in prior educational attainment (Naidoo, 2000). Thus, while government measures are presented as devices for drawing diverse institutions into a horizontally differentiated system offering greater choice and quality, in reality, the impact will be to encourage the development of a sector in which status and resources are likely to be inversely proportional to institutional and student disadvantage.

Furthermore, expanding access to university whilst reinforcing a stratified higher education system could have negative effects on economic and social development. In highly stratified systems, the vast majority of students who face intersecting disadvantage could be recruited into low quality, cheap, standardised courses which would not provide an adequate base of skills in areas critically needed for development. Rather than gaining access to powerful forms of knowledge (Young \& Muller, 2013), the vast majority of students will continue to receive 
an education that has been reduced to narrowly defined core competencies. Disciplines such as Medicine, Engineering, Mathematics, Economics, as well as subjects in the Humanities and Social Sciences which are crucial to development may be placed in a vulnerable position, while degrees that are easier and cheaper to teach such as Business Studies may grow exponentially. In addition, programmes to build indigenous research capacity such as research degrees at postgraduate level or doctoral level work may be replaced by fee-based masters and postgraduate diploma programmes based primarily on coursework. Marginson (2001) has argued that such courses are often hard to distinguish from undergraduate courses and may in fact be augmenting credentialism rather than developing national capacity through the training of new generations of indigenous researchers. These factors could combine to lead to a shortage of programmes and graduates in key strategic areas which may be detrimental to development strategies.

An influential trend which has gained momentum worldwide is the competition for world class status. The assumption is that the transfer of the lion's share of resources into universities identified as world class will contribute in a direct manner to the social and economic development of the country as a whole. However, the jury is still out on whether the training of an elite social segment in elite universities automatically contributes to national development, particularly since world class universities are often embedded in global networks with multinational corporations and contribute to global rather than national innovation in developing countries. In addition, the argument that world class universities in highly stratified systems are the best route for higher education to contribute to national innovation is challenged by the success of the relatively non-hierarchical system of higher education in countries such as Finland and Germany. In addition, the research and prestige mission entrusted to elite universities is often diametrically opposed to enhancing equality. Few benefits trickle down to support institutions that admit large numbers of students from the most disadvantaged sectors of society.

Finally, there appear to be inadequate connections between higher education policy and wider economic and social policies of the country. Great faith is placed in the high skills thesis which contends that equipping higher levels of skill to the population as a whole, linked to technologically oriented mode of working, will unproblematically contribute to social mobility and economic development. However, researchers have pointed out that even in high-income countries, high performance production systems and high skills regimes are not all-pervasive and widely distributed (see, e.g. Kraak, 2004) and that in reality in most countries, mass producing manufacturing and low skill labour intensive production exist alongside high skill production techniques. Other analysts such as Keep (1999) go further to argue that Fordist and post-Fordist modes of production continue to flourish in advanced economies particularly in the United States of America and the United Kingdom as they are based on the expansion of low skilled, low cost jobs which give a certain competitive advantage. According to these analysts, the reality of high skill production strategies is that this only occurs in a few sectors, mainly in the leading advanced economies. The high skills rhetoric of the knowledge-based economy also prophesises that the growing importance of knowledge work would significantly 
raise the demand for educated workers, who would enjoy greater autonomy in their work. However, as Brown, Lauder, and Ashton (2011) show, bursts of creativity in capitalist countries are followed by the routinisation of work to enable profits to be made. Lauder, Brown, and Sin (in press) note that changes in the nature of capitalism, including skills replacing technology and the preference for corporations to move to high skilled low cost countries such as China, has fundamentally undermined the relationship between individual investments in education and higher paid employment. Thus, as Lloyd and Payne (2018) indicate, the policy preference for supply side approaches to skills for economic development based on human capital theory may be seen as more of a political device that acts as a poor substitute for more direct interventions in the economy and labour market which would genuinely enhance the demand for skills and job quality.

\section{Conclusions}

The uncertain and ambiguous approach to inclusive development adopted across various presidential periods in South Africa suggests major challenges to the realisation of a developmental state in South Africa capable of steering the country towards a model of inclusive development. While the state has implemented a range of policies in the pursuit of economic growth, the interaction of such growth with poverty, inequality and unemployment has been complex. The relationship between the state and higher education which has been characterised as cooperative governance with state supervision has in practice meant that universities have at times been faced with the state making far reaching decisions with no prior negotiation, such as President Zumas's decision in 2017 to implement free higher education for poor students. At the same time, there is the potential for university leaders to invoke the ideal of institutional autonomy at certain times to protect institutional interests, while proclaiming that state control has curtailed their ability to act in other periods of prolonged conflict with civil society.

Transformation merely perceived as enhanced access in the absence of support mechanisms aiding students in overcoming structural, social and individual level barriers (in the context of transformed institutional cultures) is unlikely to work. The question of transformed curricula has to be grasped by the horn (see Walker and McLean, 2013, for an example of the transformation of professional education) at the same time as acknowledging that equating knowledge in a simplistic manner to the national context or certain cultures may result in the detachment of higher education from powerful global knowledge structures and from wider procedures for generating better knowledge

In addition, undifferentiated governance and funding mechanisms are likely to lead to mission drift and isomorphism and the development of a dysfunctionally stratified system unable to contribute fully to inclusive development. An important paper by Carpentier (2018) drawing on historical data in comparative perspective suggests that the relationship between mission differentiation and social reproduction could be ameliorated by challenging 
the cultural heritage which tends to undervalue vocational higher education and to encourage transfers across the various parts of the system thereby contributing to social mobility. In addition, a balance needs to be found between funding and governance mechanisms that protect the existing quality of research and teaching while incentivising a diversity of missions across different types of institutions. Further attention on how policy and funding can shape the relationship between different types of domestic institutions, as well as foreign and private institutions, in order to build capacity is vitally important. An important area for research consideration is the extent to which policy fosters collaboration, competition or functional differentiation between the different sets of providers. In addition, the assumption that publicly funded institutions are likely to contribute in an unproblematic way to the public good is misplaced. Universities have historically played multiple roles, sometimes contributing to the transformation of societies and at other times reproducing unequal relations in society and more often than not, doing both simultaneously (Brennan, King, \& Lebeau, 2004). Research therefore needs to be conducted on which functions of the higher education system need to be publicly funded and protected. While regulation normally operates through rules and sanctions, it might also be useful to look at the provision of incentives so that institutions contribute to developmental goals. In most countries, governments have responded to the perceived insularity of higher education by implementing mechanisms to open up higher education to economic forces, to encourage higher education to contribute more directly to economic development and to foster closer relations with industry. However, while there has been a great deal of policy rhetoric, there has in general been little corresponding link between financial or performance incentives and the provision of public goods.

It is undoubtedly true that research-focused public institutions may be best able to succeed if the goal to provide certain levels of higher education on a mass scale can be met by other providers. However, at the same time for countries such as South Africa, given the national resources consumed, it could be argued that in addition to chasing prestige, elite universities should be tasked with a certain level of responsibility for building capacity in the South African higher education system as a whole. Scarce national resources could also be distributed to create world class systems of higher education that contribute to inclusive development, rather than world class universities that contribute to the development of an elite in higher education and to the reinforcement of stratification in the wider society (Naidoo, 2018).

Finally, a development strategy linking national, social and economic development strategies to higher education policy in the context of an appropriate measure of institutional autonomy is an important area to address. The idea of developing a skills strategy around the interlocking potential of low, intermediate and high skills to allow for greater variability and unevenness is persuasive (Kraak, 2004) and has implications for a mixture of investment strategies in higher and other levels of education, including vocational training. At the same time, such efforts to expand human capabilities through education have to be linked to the redistribution of material resources to South African citizens as a whole, while providing 
incentives for individuals to invest in their own capabilities through joined up macro industrial strategies linked to equitable and dignified forms of employment.

\section{References}

African National Congress (1992). Ready to govern: ANC policy guidelines for a democratic South Africa. Retrieved from http://www.anc.org.za/docs/pol/1992/readyto.html

African National Congress (2007). 52 nd National Conference: Resolutions. Retrieved from http://www.anc.org. $\mathrm{za} /$ content/52nd-national-conference-resolutions

Arnolds, C. A., Stofile, R. N, \& Lillah, R. (2013). Assessing the outcomes of the higher education mergers in South Africa: Implications for strategic management. Acta Commercii, 13(1), 175-189.

Arocena, R., \& Sutz, J. (2005). Latin American universities: From an original revolution to an uncertain transition. Higher Education, 50, 573-592.

Badat, S., Barends, Z., \& Wolpe, H. (1994). The post-secondary education system: Towards policy formulation for equality and development. In B. Kaplan (Ed.), Changing by degrees. Equity issues in South African tertiary education. Cape Town: UCT Press.

Baijnath, N. (2016). A word from the CEO. In CHE South African higher education reviewed: Two decades of democracy. Pretoria: Council on Higher Education.

Bhorat, H., Goga, S., \& Stanwix, B. (2013). Occupational shifts and shortages: Skills challenges facing the South African economy. Labour Market Intelligence Partnership Report 1. Retrieved from http://www.Imip. org.za/ sites/default/ files/events/ LMIP\%20Report\%201\%200ccupational\%20Shifts.pdf

Bond, P. (2004). Talk left, walk right: South Africa's frustrated global reforms. Scottsville: University of KwazuluNatal Press.

Booysen, S. (2011). The African National Congress and the regeneration of political power. Johannesburg: Wits University Press.

Brennan, J., King, R., \& Lebeau, Y. (2004). The role of universities in the transformation of societies: Synthesis report. London: Association of Commonwealth Universities and the Open University.

Brown, P., Lauder H., \& Ashton, D. (2011). The global auction: The broken promises of education, jobs and incomes. New York: Oxford University Press.

Burger, P. (2014). Facing the conundrum: How useful is the 'developmental state' concept in South Africa? South African Journal of Economics, 82(2), 159-180.

Cameron, R. (2010). Redefining political-administrative relationships in South Africa. International Review of Administrative Studies, 76, 676-711.

Carpentier, C. (2018). Expansion and differentiation in higher education: The historical trajectories of the UK, the USA and France. CGHE Working Paper No. 33, April 2018. London: Centre for Global Higher Education.

Cloete, N. (2002). Policy expectations. In N. Cloete, R. Fehnel, P. Maassen, T. Moja, H. Perold, \& T. Gibbon (Eds.), Transformation in higher education: Global pressures and local realities in South Africa (pp. 87-108). Cape Town: Juta.

Cloete, N. (2014). A new look at demographic transformation: Comments on Govinder et al. (2013). South African Journal of Science, 110(1/2), 1-6.

Cloete, N., Fehnel, R., Maasen, P., Moja, T., Perold, H., \& Gibbon, T. (2002). Transformation in higher education: Global pressures and local realities in South Africa. Cape Town: Juta.

Cloete, N., \& Moja, T. (2005). Transformation tensions in higher education: Equity, efficiency and development. Social Research, 72(3), 693-722.

Cloete, N., Pillay, P., Badat, S., \& Moja, T. (2004). National policy and a regional response in South African higher education. Cape Town: James Currey and David Philip.

Collins, R. (1998). The sociology of philosophies: A global theory of intellectual change. Cambridge, MA: Harvard University Press.

Council on Higher Education (2016). South African higher education reviewed: Two decades of democracy. Pretoria: Council on Higher Education. 
Department of Education (1997). White Paper 3: A programme for the transformation of higher education. Pretoria: Department of Education.

Department of Education (2001). National plan for higher education. Pretoria: Department of Education.

Department of Education (2005). Student enrolment planning in public higher education. Pretoria: Department of Education.

Edigheji, O. (2007). The emerging South African developmental state. Research Report No. 108, Centre for Policy Analysis, Gauteng. Retrieved from http://www.cps. org.za/cps\%20pdf/RR108.pdf.

Evans, P. (2010). Constructing the 21st century developmental state: Potentialities and pitfalls. In O. Edigheji (Ed.), Constructing a democratic developmental state in South Africa: Potentials and challenges (pp. 37-58). Cape Town: HSRC Press.

Goh, C. B., \& Gopinathan, S. (2008). The development of education in Singapore since 1965. In S. K. Lee, C. B. Goh, B. Fredriksen, \& J. P. Tan (Eds.), Toward a better future: Education and training for economic development in Singapore since 1965 (pp. 12-38). Washington, DC: The World Bank.

Griffin A.-M. (2016). Toward deliberative democracy: The institutional forum as an innovative shared governance mechanism in South African higher education (unpublished DBA dissertation). International Centre for Higher Education Management, University of Bath.

Gwaindepi, A. (n.d). The developmental state, social policy and social compacts: A comparative policy analysis of the South African case (unpublished masters dissertation). Department of Economics and Economic History. Rhodes University, South Africa.

Holland, D. G. (2008). Discipline in the context of development: A case of the social sciences in Malawi, Southern Africa. Higher Education, 55, 671-681.

Jansen, J. D. (2001). Rethinking education policy making in South Africa: Symbols of change, signals of conflict. In A. Kraak \& M. Young (Eds.), Education in retrospect: Policy and implementation since 1990. Pretoria: Human Sciences Research Council.

Jansen, J. D. (2002). Political symbolism as policy craft: Explaining non-reform in South African education after apartheid. Journal of Education Policy, 17(2), 199-215.

Keep, E. (1999). UK's VET policy and the 'third way': Following a high skills trajectory or running up a dead end street. Journal of Education and Work, 12(3), 323-346.

Kraak, A. (2004). Rethinking the high skills thesis in South Africa. In S. McGrath, A. Badroodien, A. Kraak, \& L. Unwin (Eds.), Shifting understandings of skills in South Africa: Overcoming the historical imprint of a low skills regime. Pretoria: Human Sciences Research Council Press.

Kraak, A., \& Young, M. (Eds.). (2001). Education in retrospect: Policy and implementation since 1990. Pretoria: Human Sciences Research Council.

Lauder, H., Brown, P., \& Sin, Y. (in press). Fractures in the education economy relationship : The end of the skill bias technological change research programme. Oxford Review of Economic Policy.

Lepori, B., \& Naidoo, R. (2017). Field interconnectedness and strategic action in South African higher education. Presented at the Academy of Management Conference, Organisation and Management Theory Division. Atlanta, Georgia, USA, 4-8 August 2017.

Lloyd, C., \& Payne, J. (2018). Response to reviews of skills in the age of over-qualification: Comparing service sector work in Europe. Work, Employment and Society, 32(2), 441-443.

Marginson, S. (2001). Knowledge Economy and Knowledge Culture. Presented at National Scholarly Communications Forum, Canberra, Australia, 9 August.

Moore, R., \& Muller, J. (1999). The discourse of 'voice' and the problem of knowledge and identity in the sociology of education. British Journal of Sociology of Education, 20(2), 189-206.

Muller, J. (2000). Reclaiming knowledge: Social theory, curriculum, and education policy. London: RoutledgeFalmer.

Naidoo, R. (1998). Levelling or playing the field: The politics of access to university education in post-apartheid South Africa. Cambridge Journal of Education, 28(3), 369-384.

Naidoo, R. (2000). The third way to widening participation and maintaining quality in higher education: Lessons from the United Kingdom. Journal of Educational Enquiry 1(2), 24-38.

Naidoo, R. (2011). Rethinking development: Higher education and the new imperialism. In R. King, S. Marginson, \&. R. Naidoo (Eds.), Handbook on higher education and globalisation (pp. 40-58). Cheltenham: Edward Elgar. 
Naidoo, R. (2018). World-class systems rather than world-class universities. University World News, April 2018, Issue No 502. Retrieved from http://www.universityworldnews.com/article.php?story=20180417162622337

Naidoo, V. (2017). Tracking the expansionary state: Machinery of government change in South Africa. Public Affairs Research Institute. Working Paper. Retrieved from https://47zhcvtiOul2ftip9rxo9fj9-wpengine.netdnassl.com/wp-content/uploads/2017/09/Machinery-of-govt-working-paper.pdf

National Planning Commission (2012). National Development Plan, 2030. Available online: https://www.gov.za/ sites/default/files/NDP-2030-Our-future-make-it-work_r.pdf

Routley, L. (2012). Developmental states: A review of the literature. Effective States and Inclusive Development Working Paper 3. Retrieved from https://assets.publishing.service.gov.uk/ media/57a08a9a40f0b6497400069c/esid_wp_03_routley.pdf

Satgar, V. (2012). Beyond Marikana: The post-apartheid South African state. Africa Spectrum, 47(2/3), 33-62.

Seekings, J., \& Nattrass, N. (2016). Poverty, politics and policy in South Africa: Why poverty has persisted after apartheid. Auckland Park: Jacana.

Southall, R. (2016). The coming crisis of Zuma's ANC: The party state confronts fiscal crisis. Review of African Political Economy, 43(147), 73-88.

Thaver, B., \& Thaver, L. (2009). State-in-society: The mutual constitutiveness of the developmental state and higher education in South Africa. African Sociological Review, 13(1), 57-74.

The Presidency (2018). State of the Nation Address by President of the Republic of South Africa, Mr Cyril Ramaphosa, 16 February 2018. Retrieved from http://www.thepresidency.gov.za/speeches/state-nationaddress-president-republic-south-africa\%2C-mr-cyril-ramaphosa

Young, M. (2007). Bringing knowledge back in: From social constructivism to social realism in the sociology of education. London: Routledge.

Young, M., \& Muller, J. (2013). On the powers of powerful knowledge. Review of Education, 1(3), 229-250.

Walker, M., \& McLean, M. (2013). Professional education, capabilities and the public good: The role of universities in promoting human development. London and New York: Routledge. 


\title{
SUBSIDY, TUITION FEES AND THE CHALLENGE OF FINANCING HIGHER EDUCATION IN SOUTH AFRICA
}

\author{
Gerald Wangenge-Ouma and Vincent Carpentier
}

\section{Introduction}

The funding of higher education is a hot topic in South Africa. During apartheid, higher education was deliberately steered to marginalise a significant section of society. The funding systems were instruments used in the implementation of the apartheid government's so-called 'separate but equal' policy. In the post-apartheid period, higher education is required to transform the legacy of the past, expand access, improve quality and respond to South Africa's broader societal and developmental objectives. Similar to the apartheid period, funding is a critical driver for the realisation of public policy objectives in the post-apartheid period, mainly in regard to adequate funding for the university system and affordability, especially for students from lower socio-economic backgrounds.

For many years, researchers have identified a number of challenges with the various aspects of the financing of higher education in South Africa, inter alia, the adequacy of public funding, mechanisms for allocating subsidy to universities, tuition fees (cost-sharing), student financial aid, student debt, and third stream income (Bunting, 2002; de Villiers \& Steyn, 2006; de Villiers \& Steyn, 2007; de Villiers, van Wyk, \& van der Berg, 2013; Wangenge-Ouma, 2010, 2012a, 2012b; Wangenge-Ouma \& Cloete, 2008). These challenges can be understood within the context of the often complex and evolving relationship between higher education institutions, the state and society, as captured by Clark's triangle of coordination (Clark, 1983). Clark's triangular space is characterised, inter alia, by tensions and evolving relationships among the three key actors (higher education institutions, the state and society). For instance, in the South African context, these tensions are manifested, among others, by a mismatch between state funding and political expectations on the one hand, and societal and institutional realities and 
expectations on the other hand. This chapter focuses on tensions related to two key elements: the adequacy of funding for the university system and tuition fees. Our approach is part of the political economy tradition, looking at higher education at the interface of political and economic processes. We review the financing of higher education in both the apartheid and post-apartheid periods, mainly to highlight the antecedents of the present challenges; examine the trends in the public appropriations for higher education within the context of enrolment growth and the performance of the South African economy, and finally, we engage the tuition fees question. Our empirical data were obtained mainly from official reports, treasury data and previous research.

We argue that the tensions are, to some extent, the product of a lack of a shared understanding of the needs, resources, challenges and visions of all three actors. For instance, universities have argued that the raising of tuition fees is a response to a decline in state funding. However, some analysts (for example, Pundy Pillay ${ }^{1}$ as reported in Scott, 2016) have argued that public funding of higher education has in fact been adequate, given the country's depressed economic circumstances vis-à-vis demands for public funding from other equally important priorities such as health, security, basic education and infrastructure development. On its part, the state has argued that while it has increased student financial aid significantly, the impact has been minimal because of the tendency by universities to increase tuition fees. Universities, especially historically advantaged universities, have countered this view by arguing that a significant portion of the income generated from tuition fees goes toward providing financial aid to indigent students, hence advancing the goal of enhancing equity of access (Higher Education South Africa [HESA], 2008; Wangenge-Ouma, 2010).

\section{Higher education funding during apartheid}

Bunting (2002) provides a detailed analysis of the manner in which the government funded higher education during the apartheid era. He identifies two broad types of government funding that were in place, namely, negotiated budgets that were associated with blacks-only universities and technikons (for example, the Universities of Fort Hare and Venda) and formula funding, associated initially with whites-only universities (for example Universities of Cape Town, Stellenbosch and Pretoria). The funding systems were instruments used in the implementation of the government's so-called 'separate but equal' policy.

Whereas whites-only universities enjoyed considerable autonomy in the manner in which they spent government subventions, and decisions regarding what their tuition fees should be, blacks-only universities did not have similar autonomy and freedom. Their tuition fees and the details of their expenditure had to be approved by the government (Bunting, 2002; WangengeOuma, 2007). The system of negotiated budgets involved the university or technikon

1 Presentation at a colloquium by the Council on Higher Education on funding in higher education in South Africa held on 3 December 2015. 
concerned submitting a 'needs' budget for expenditure and partial income to its controlling government department. The income side was the amount the institution expected to collect from student fees. The final amount which the institution was permitted to spend in that financial year would have been a net amount of approved expenditure, less student fees (Bunting, 2002; Council on Higher Education [CHE], 2004). The expenditure budgets finally approved were not determined by the student enrolments of the institution concerned but on assessments of current needs in the context of historical expenditure patterns. In many cases 'this amounted to adding a percentage to the allocation for the previous year, and did not overcome disparities with the more advantaged institutions or ensure adequate library, laboratory and computer facilities' (Bunting, 2002, p. 118). Expenditure by the institutions had to be strictly managed in terms of this budget, and any unspent balances on a negotiated budget would have to be returned to the national treasury. Further, institutions were not permitted to transfer these amounts to reserves under their control, hence leading to two consequences: unrestricted spending at the end of every year to discharge accumulated funds and no build-up of a reserve fund.

In 1982 the apartheid government started allocating subsidies and other financial resources to universities and technikons through the South African Post-Secondary Education (SAPSE) base formula funding (Bunting, 2002; Wangenge-Ouma, 2007). This formula was initially developed for whites-only universities. The overall amounts available for higher education were allocated to institutions in terms of a formula which contained as input variables fulltime equivalent (FTE) student enrolments and as output variables student success rates and research publications (CHE, 2004). Unlike blacks-only universities and technikons, these amounts could be spent at the discretion of the council of the higher education institution, and unspent balances could be retained.

Although the funding formula was originally intended for whites-only universities, by 1988, the formula was applied to all universities and technikons. The formula had the effect of generating and perpetuating institutional inequities such that larger amounts of subsidy were available to whites-only universities because they 'had larger numbers of natural science enrolments, produced better student success rates, had more postgraduate students, produced more research outputs, had better management capacities, and so on' (CHE, 2004, p. 190).

Bunting (2002) argues that the SAPSE funding formula satisfied several principles of higher education funding: the principles of effectiveness, efficiency, and sustainability and the principle of shared costs. He contends further that the formula directed government funding of higher education at ensuring that the system achieved its pre-determined goals at the lowest possible cost. An analysis by CHE (2004, p. 190) takes a different view:

The formula encouraged growth which was not financially sustainable-especially
as student enrolments increased from the mid-1980s-and which was not linked to
issues of quality. ..., the a-factors [adjustment factors] introduced to contain the
effects of growth created a climate of financial uncertainty for HEIs [Higher 


\begin{abstract}
Education Institutions], acting as disincentives to creative planning at institutional level and as incentives to expanding cash reserves, or devising strategies of crosssubsidisation, including distance learning activities. Finally, the formula encouraged larger numbers of cheaper enrolments in humanities, rather than in the more costly natural sciences.
\end{abstract}

One issue on which the various analyses of the SAPSE funding formula converge is the question of equity and redress. Bunting (2004, p. 132) perhaps captures the general consensus when he argues that the SAPSE funding formula 'explicitly rejected the principles of equity and redress, holding that it was not the business of the higher education system to deal with social inequalities which affected either individuals or institutions'. Following the regime shift in 1994, a change in the manner in which higher education was funded became a priority and was inevitable. The SAPSE funding framework was regarded as essentially an apartheid funding framework that could not be used to transform the higher education system in line with the new government's policies of equity, redress and development.

\title{
Changes to funding policies in the post-apartheid era
}

The apartheid era formula funding, adopted by blacks-only universities - which acquired the moniker 'historically disadvantaged universities' (HDUs) in the post-apartheid period - by 1988, remained in use up to 2003. The continued use of the funding formula, which was principally FTE driven, occasioned financial difficulty to a number of HDUs. After 1994, many black students enrolled in former whites-only universities (which later became known as historically advantaged universities [HAUs]) occasioning a decline in enrolments in the HDUs. Headcount enrolments in the HDUs fell from a peak of 111000 in 1995 to 83000 in 2000. This, combined with a range of other factors such as growing student debt, governance and management failures and general instability, resulted in the rapid erosion of the sustainability of a number of the HBUs (CHE, 2004; Cloete, 2002; Ministry of Education [MOE], 2001; Wangenge-Ouma, 2007).

Both the Education White Paper 3: A Programme for the Transformation of Higher Education, 1997 (Department of Education [DOE], 1997); and the 2001 National Plan for Higher Education in South Africa (MOE, 2001) emphasised the need for a new higher education funding framework that could serve as an effective steering mechanism for the attainment of transformation goals of the post-apartheid state. And in 2004, a new funding framework was introduced. The funding framework is generally consistent with some international accounts of the role which government funding can play in the implementation of national higher education policies (Merisotis \& Gilleland, 2000; Ziderman \& Albrecht, 1995). Unlike the apartheid era funding frameworks which rejected the principles of equity and redress, the present funding framework is generally aligned with government's policies of equity, redress and development. 
While the architecture of the funding framework has been maintained since its introduction in 2004, a number of changes have since been introduced. For instance, an HDI (historically disadvantaged institution) development grant, which would benefit the universities of Fort Hare, Limpopo, Venda, Walter Sisulu, Western Cape and Mangosuthu University of Technology and Sefako Makgatho Health Sciences University, was introduced in 2015/2016. The main purpose of this grant is to assist with establishing systems to develop and sustain the financial health of these universities and strengthen the academic enterprise. The introduction of this grant can be regarded as an acknowledgement of the inherent funding challenges faced by HDUs, inter alia, because of the historical, path-dependent factors referred to in the preceding section.

A review of the funding framework by the Ministerial Committee for the Review of the Funding of Universities (DHET, 2013), in terms of the goals that were set for it at its inception, suggests that many of the targets (set for 2010) were unmet. The unmet targets were in regard to gross participation rates, enrolments in science, engineering and technology fields, enrolments in masters and doctoral programmes, staff qualifications, throughputs, and research productivity. It should be pointed out, however, that there are many factors, beyond funding, involved in the achievement of university goals. Accordingly, the failure by the university system to achieve the targets cannot be attributed entirely to the funding framework. Having said that, the funding framework is not entirely blameless: one of the key critiques of the funding framework is that it is not driven by the actual costs of higher education provision, but by the amount of funds made available in the national higher education budget, which makes it a mechanism for dividing a pre-determined total grant allocation (de Villiers \& Steyn, 2006; Wangenge-Ouma, 2010).

The manner in which public funding is allocated to universities is known to have a major impact on their behaviour, institutional performance, sustainability and their long-term success. While the collapse of apartheid occasioned dramatic transformative changes in the government's approach to the allocation of resources to universities, for many HDUs, the changes have not gone far enough to remedy their long history of underfunding

\section{State appropriations for higher education}

Allocations to the university system can be examined using indicators such as the percentage of total public expenditure that is devoted to higher education, public higher education expenditure as a percentage of gross domestic product (GDP), public higher education expenditure's share in relation to total government budget expenditure, public higher education expenditure's share of the overall education budget, and per student expenditures. In this section, we focus on public expenditure per student, which is a measure of public investment adjusted for full-time-equivalent students enrolled in the university system. It reflects the general purchasing power (or standard of living) given up (through public sources) to support the education of each university student. 
Table 1 provides an important set of data regarding the funding of higher education in South Africa. The key observation from this table is that, while state funding for universities increased year on year in nominal terms and also in real terms (with the exception of 2007/08 and 2009/10), the rate of growth in funding did not however match the growth in the number of students as shown by the per capita growth in real terms (i.e. adjusting for inflation). With the exception of three years (2007/08, 2008/09 and 2009/10), the per capita growth in real terms shows a declining trend. Overall, over the ten years, per capita FTE allocation declined by $1.35 \%$.

Table 1 Block grant allocations to universities from 2004/5 to 2014/15

\begin{tabular}{|c|c|c|c|c|c|c|c|c|c|}
\hline Year & $\begin{array}{l}\text { Block grant } \\
\text { for } \\
\text { universities } \\
\text { in nominal } \\
\text { terms } \\
\text { (ZAR million) } \\
\text { (A) }\end{array}$ & $\begin{array}{l}\text { Growth in } \\
\text { nominal } \\
\text { terms } \\
(\%)\end{array}$ & $\begin{array}{l}\text { Inflation } \\
(\mathrm{CPI})^{\star}\end{array}$ & Deflator (B) & $\begin{array}{c}\text { Block grant } \\
\text { for } \\
\text { universities } \\
\text { in real terms } \\
\text { (ZAR million) } \\
\text { (C) = (A/B) }\end{array}$ & $\begin{array}{c}\text { Growth in } \\
\text { real terms } \\
(\%)\end{array}$ & $\begin{array}{l}\text { HEMIS } \\
\text { Student FTES } \\
\text { (D) }\end{array}$ & $\begin{array}{l}\text { Per capita in } \\
\text { real terms } \\
\text { using FTE } \\
\text { students } \\
\text { (ZAR) } \\
\text { (C/D) }\end{array}$ & $\begin{array}{c}\text { Per capita } \\
\text { growth in } \\
\text { real terms } \\
(\%)\end{array}$ \\
\hline $2004 / 05$ & 8568 & - & $2.0 \%$ & 1.00 & 8568 & - & 505473 & 16950 & - \\
\hline $2005 / 06$ & 9145 & $6.7 \%$ & $3.6 \%$ & 1.02 & 8966 & $4.6 \%$ & 500931 & 17899 & $5.6 \%$ \\
\hline $2006 / 07$ & 9956 & $8.9 \%$ & $5.2 \%$ & 1.06 & 9421 & $5.1 \%$ & 497772 & 18926 & $5.7 \%$ \\
\hline $2007 / 08$ & 10234 & $2.8 \%$ & $8.1 \%$ & 1.11 & 9205 & $-2.3 \%$ & 518560 & 17751 & $-6.2 \%$ \\
\hline $2008 / 09$ & 11550 & $12.9 \%$ & $11.2 \%$ & 1.20 & 9614 & $4.4 \%$ & 538457 & 17854 & $-0.6 \%$ \\
\hline $2009 / 10$ & 12701 & $10 \%$ & $6.9 \%$ & 1.34 & 9511 & $-1.1 \%$ & 569708 & 16694 & $-6.5 \%$ \\
\hline $2010 / 11$ & 14533 & $14.4 \%$ & $3.8 \%$ & 1.43 & 10176 & $7.0 \%$ & 600002 & 16960 & $1.6 \%$ \\
\hline $2011 / 12$ & 16387 & $12.8 \%$ & $5.6 \%$ & 1.48 & 11051 & $8.6 \%$ & 628409 & 17586 & $3.7 \%$ \\
\hline $2012 / 13$ & 17434 & $6.4 \%$ & $5.6 \%$ & 1.57 & 11134 & $0.7 \%$ & 634548 & 17546 & $-0.2 \%$ \\
\hline $2013 / 14$ & 18439 & $5.8 \%$ & $5.8 \%$ & 1.65 & 11151 & $0.2 \%$ & 665856 & 16747 & $-4.6 \%$ \\
\hline $2014 / 15$ & 19561 & $6.1 \%$ & $5.6 \%$ & 1.75 & 11181 & $0.3 \%$ & 668705 & 16721 & $-0.2 \%$ \\
\hline \multicolumn{2}{|c|}{$\begin{array}{l}\text { Net \% change in nominal } \\
\text { terms in block grant from } \\
2004 / 5 \text { to } 2014 / 15\end{array}$} & $128.3 \%$ & \multicolumn{3}{|c|}{ Net real change in block grant } & $30.5 \%$ & \multicolumn{2}{|c|}{$\begin{array}{l}\text { Net change in per capita } \\
\text { FTE student allocation }\end{array}$} & $-1.35 \%$ \\
\hline
\end{tabular}

Source: DHET (2015)

In 2004, the South African government acknowledged that, despite increasing appropriations, little improvement was being made in the real resources expended per student. University student enrolments were exerting unsustainable pressure on the fiscus. Partly to address this situation, the government introduced enrolment caps, thus limiting the number of students that individual institutions could sign up. In introducing the caps, the government argued that

the [South African] higher education system has grown more rapidly than the available resources. The resultant short-fall in funding has put severe pressure on 


\begin{abstract}
institutional infrastructure and personnel, thus compromising the ability of higher education institutions to discharge their teaching and research mandate. (DOE, 2004, p. 3)
\end{abstract}

The quote above acknowledges the need for adequate funding for universities to deliver on their mandate; specifically, the need to align funding with enrolment growth. However, the continued pattern of underfunding, even after the introduction of enrolment caps, requires some explanation. We suggest three possible explanations: the failure of enrolment planning, that is, the inability to align enrolment growth with the available resources; strong demand for university education which could not be channelled to alternative opportunities within the post-school sector; and poor economic growth vis-à-vis the demands from other equally important public needs, such as infrastructure development, basic education, security and health.

During the 2016 mid-term review of the enrolment plans of universities for the period 2014-2019, and while the \#FeesMustFall students protests ${ }^{2}$ were raging, the Department of Higher Education and Training (DHET) attempted to remedy the misalignment between enrolment planning and funding, by encouraging universities to pursue slower enrolment growth in the remaining three years (2017-2019). The national enrolment growth was adjusted to $1.0 \%$ from the originally set growth target of $1.9 \%$. It should also be pointed out that the university system in South Africa is notoriously inefficient in terms of student success and throughputs, which, inevitably, adds to the pressure on public funding. While throughput rates have improved, they remain poor. For instance, the throughput rate for the 2009 cohort, after five years, was $53.5 \%$, an improvement on the 2000 cohort, whose throughput rate, after five years, was $44.2 \%$ (Green, 2016). The high levels of internal inefficiency in the university system have reinforced the view that the public is paying more for less. In response, universities have argued, inter alia, that the funding received is inadequate to provide sufficient academic support for the many underprepared students who join universities.

Cloete, Sheppard, \& van Schalkwyk (2016), among others, have identified the 'shape' of the post-school system as one of the challenges with implications for public funding in South Africa. Unlike many post-secondary systems, for example, the United States of America (USA), where the majority of students are enrolled in technical institutions and colleges below the university level, the bulk of students in the South African post-school system are enrolled in the university system. In 2016, 975837 students were enrolled in public universities in South Africa, compared to 705397 who were enrolled in technical and vocational education and training colleges (DHET, 2018).

The 'decline' in state funding for higher education needs to be understood in the context of South Africa's economic performance. We seek to demonstrate that trends in the allocation

2 In October 2015, student protests erupted across South African universities against, among others, high levels of tuition fee increases and inadequate funding support from student financial aid. The protests intensified in 2016, leading to the closure of many universities. 
of financial resources to higher education cannot be interpreted adequately in isolation from the economic and social contexts in which higher education is located. As shown in Figure 1 below, the past decade was an economic nightmare for South Africa. Economic growth was sluggish and inflation rates were high. Persistent low growth has led to the stagnation of GDP per capita compared to other economies, especially from 2010.

Figure 1 South Africa's GDP growth, 2000-2016

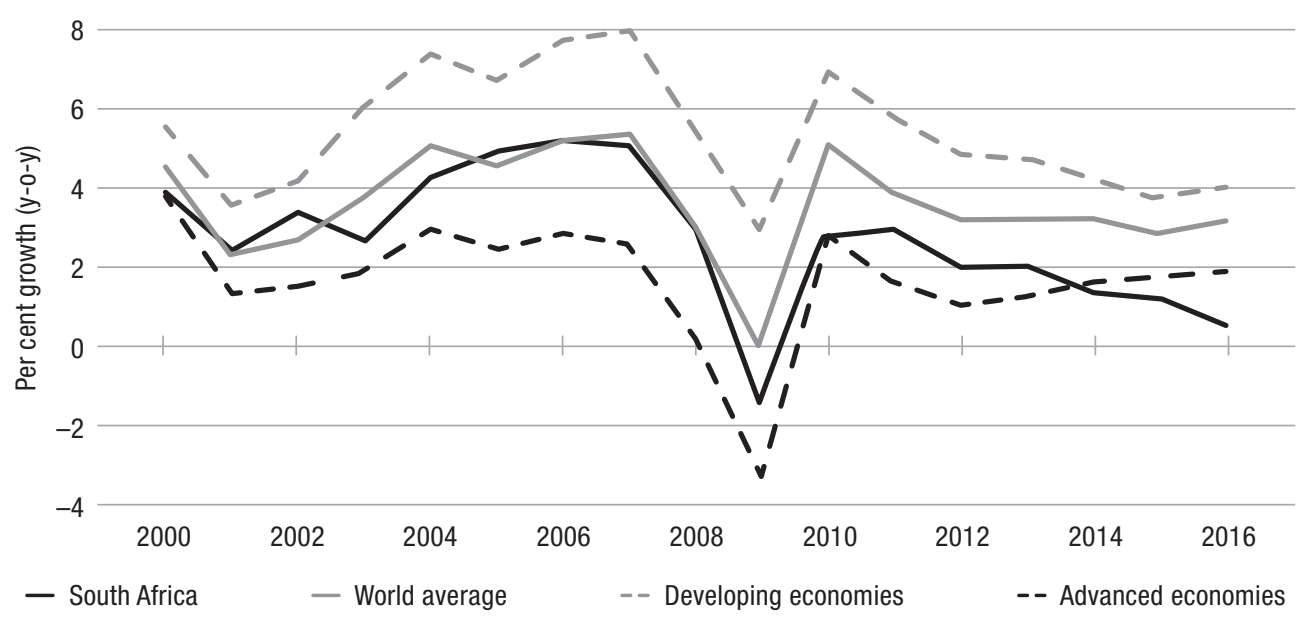

Source: Makhanya (2016)

The poor economic growth has had a number of implications, among them, lower tax revenue collections (falling revenue growth - see Figure 2), increasing deficit, and borrowing by government. It therefore seems defensible to conclude that the decline in per capita FTE allocation shown in Table 1 reflects the economic challenges experienced by the country. In fact, compared to other sectors, the university sector seems to have fared better. For instance, the report of the presidential Commission of Inquiry into Higher Education and Training (2017) states that the shortfall in budget allocations to Technical and Vocational Education and Training Colleges (TVET) increased from 19\% in 2013/2014 to a projected shortfall of 47\% in 2017/2018. Regarding basic education, Spaull (2018) reports that funding per schoolchild has declined by $8 \%$ in the last seven years. This decline is projected to increase to $10 \%$ by 2019 .

\section{Tuition fees}

The overriding principle in South Africa's public higher education funding is that costs must be shared between government and students (or their families). Van Harte (2002) notes that South Africa, even before it became a republic, charged tuition fees at those postsecondary 
institutions that over time fully evolved into the modern universities of today. However, there were provisions made for some students to attend for free at the discretion of the governor (Cape of Good Hope Ordinance 11 of 1837, cited in van Harte, 2002). In 1922, van Harte (2002) reports, an amendment was passed that set into motion a system that continues today in which charging tuition fees is acceptable, and in which government signals its support of public higher education by providing financial support to it. During apartheid, government did fully fund both the tuition and living costs of students studying for careers deemed to be for the public benefit, for example police officers, nurses and teachers, through direct government allocations or through bursaries directly to the students (van Harte, 2002). All the programmes in this category were offered in the college sector. So, though the dominant thinking regarding higher education funding was that which emphasised private investment, in some cases, where public benefit was deemed to surpass private benefit, government met all the costs of higher education training.

South African individual universities set their own fees, unlike many African countries, for example Tanzania, Mozambique and Uganda, where tuition fees are controlled by government, are often undifferentiated across institutions and programmes, and are frozen. Accordingly, fees at South African universities are differentiated by programmes and institutions. The differences in tuition fee levels between universities, even for similar programmes, can be considerable. Every year, except in 2016 when a freeze on tuition fee increases was implemented, South African universities increase their tuition fee levels. For a long time, students, government and the general public, lamented the high tuition fee increases, but the practice persisted. Universities argued that the tuition fee increases were necessitated by existential needs - to mitigate inadequate public funding and avoid institutional decline. This argument regarding the need to increase tuition fee levels speaks to the balanced budget constraints experienced by universities, whereby their costs must be offset by the sum of tuition fee revenue and non-tuition fee revenue. The gist of this perspective is that tuition fee levels have to be increased whenever costs rise by a larger amount than non-tuition fee revenue (Cheslock \& Hughes, 2011).

The continued increase in tuition fee levels resulted in tuition fees becoming the fastest growing source of university income, compared to state funding. Bunting's (2016) analysis (see Figure 2) shows that the growth rate in tuition fee levels not only surpassed that of state funding for universities (subsidy), but also tax revenue to the state. From 2007 to 2009, fees, subsidy and taxes increased at roughly equivalent (and therefore sustainable) rates. However, in 2010, tax revenues declined sharply, but state funding remained relatively stable. From 2011 onwards, despite the country's economic challenges (see Figure 1), fee revenue continued to increase steadily while subsidy slowed down.

The strong growth in tuition fee levels resulted in tuition fees accounting for a significant proportion of the income of universities. As illustrated in Figure 3 below, from 2000 to 2014, the share of tuition fees in the income of universities increased by 11 percentage points while that of subsidy (state funding) declined by 8.1 percentage points. 
Figure 2 Growth in tuition fee revenue, subsidy income, and tax revenue, 2007-2016

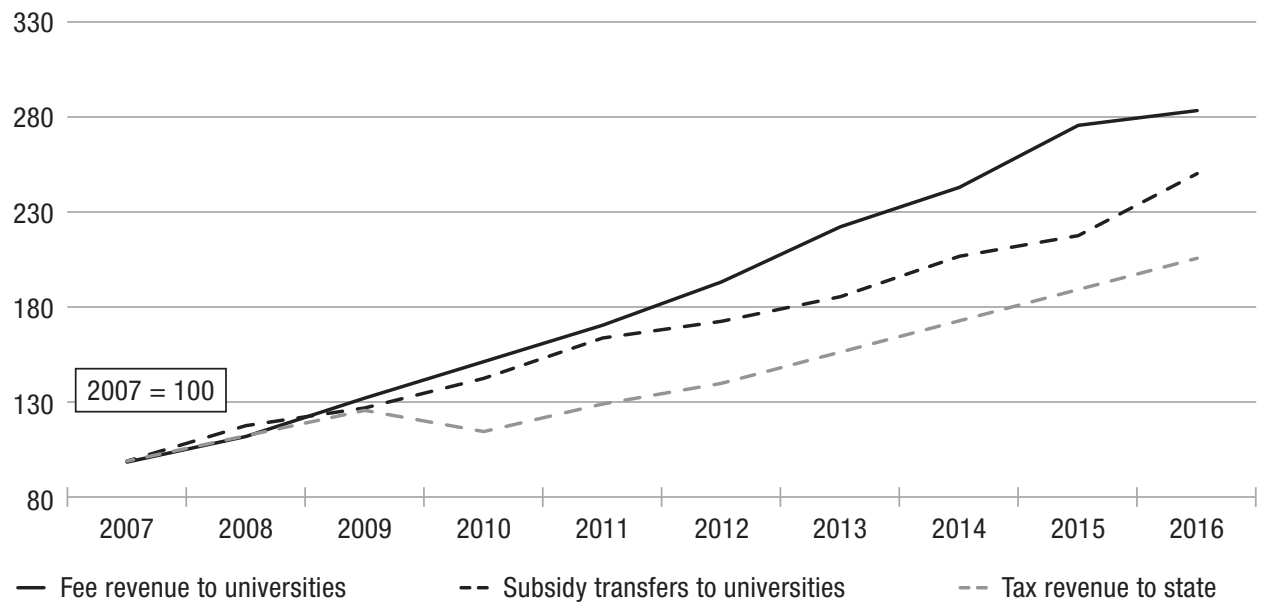

Source: Bunting (2016)

Figure 3 University income sources 2000 and 2014 (nation-wide), ZAR billion

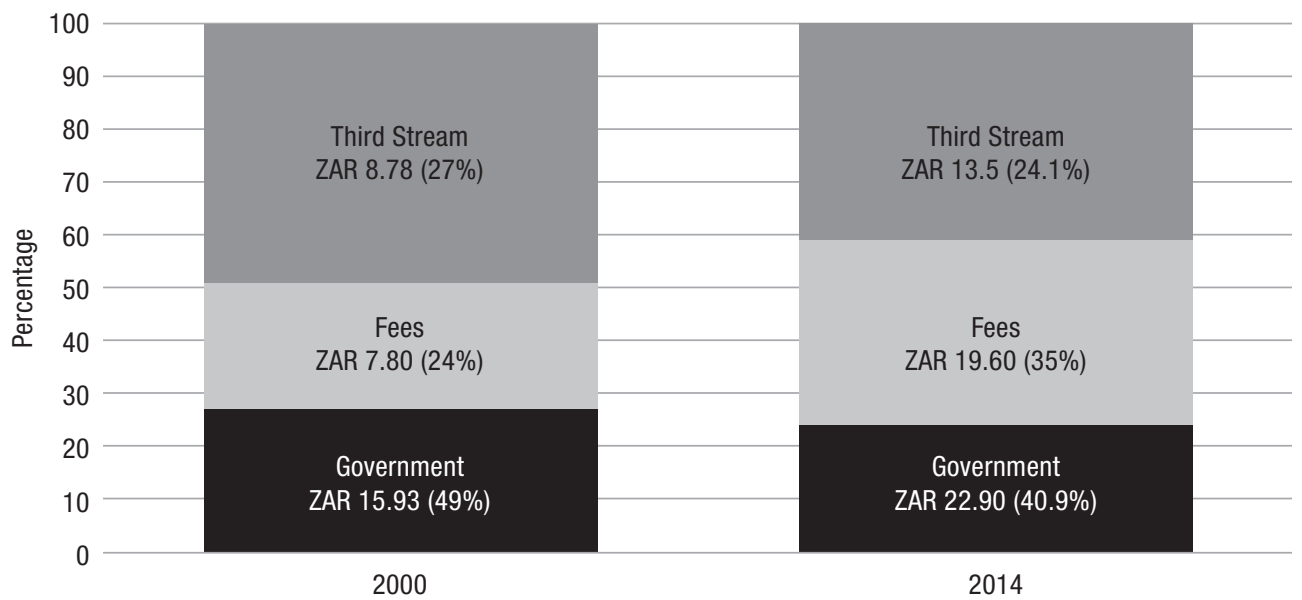

Source: DHET (2015)

The increased reliance on tuition fees by universities to mitigate the effects of decreased government investment in higher education, in the context of an ineffectual student financial aid scheme and declining economy, triggered various responses prior to the \#FeesMustFall student protests of 2015 and 2016. In 2006, the Minister of Education lamented the high levels of tuition fee increases. In her budget speech to the National Assembly on 19 May 2006 the Minister protested that: 


\begin{abstract}
Student tuition fee collections have become a critical resource issue in the higher education sector. Institutions have funded increases in their volumes of activity by raising student tuition fees to 'unreasonably' high levels. In turn this has put pressure on state funding to NSFAS. While fees have doubled over the last five years, the increase in funding to NSFAS has risen by 30 percent. (quoted in Wangenge-
\end{abstract} Ouma \& Cloete, 2008, p. 910)

In the same budget speech, the Minister announced that she was considering the introduction of a mechanism for regulating tuition fees. In 2007, the Department of Education, which then also had responsibility for universities, made the following proposals aimed at regulating tuition fee increases by universities (HESA, 2008):

a) Placing upper limits on the levels of tuition fees collected by universities;

b) Determining what shares institutions will receive of the joint block grant and tuition fees totals; and

c) Requiring universities to keep the sum of their individual tuition charges within the limits of their approved total tuition fee income.

The response by universities to these proposals was both defensive and insular. Universities invoked the principle of institutional autonomy and reminded the DOE that the determination of tuition fees was their (universities') prerogative (HESA, 2008). Further, universities argued that:

a) They increased tuition fees to mitigate declining state funding and therefore tuition fee regulation, without enhancing state funding, would have a negative impact on educational delivery by universities;

b) Universities would introduce additional charges that were notionally optional (e.g. notes levies and charges for sports facilities) hence negating the purpose of capping tuition fees; and

c) Capping tuition fees would have an impact on equity of access since universities, mainly HAUs, utilised some of the revenue generated from tuition fees to finance university bursary schemes. In other words, high tuition fee levels were having a redistributive effect whereby the fees paid by students from well to do families was used to support poor students (HESA, 2008). According to this logic, fee increases did not affect poor students or harm equity since the high charges were offset by bursaries.

However, given the context of declining public funding and the inability by universities to alter public funding in their favour, it can be argued that the response by universities was geared at guaranteeing financial stability. It is generally agreed that, in contexts of uncertainty, 
organisations actively seek to create for themselves environments that are better for their interest (Pfeffer \& Salancik, 1978).

The response by universities maintained the status quo. As demonstrated in Figure 2, tuition fee levels continued to rise steeply, which created new patterns of dependence - the universities became increasingly dependent on tuition fees (see Figure 3). Unfortunately, the rise in tuition fee levels was not matched by a concomitant rise in financial aid and household incomes, which impacted on the ability of students to pay. As several analyses (DHET, 2010; DHET, 2015; Wangenge-Ouma, 2012a) have shown, many students who qualified for financial aid did not receive funding support from the National Student Financial Aid Scheme (NSFAS). An important point, which South African universities seemed to have failed to consider, is that given the country's history of exclusion and marginalisation of a significant section of society, the expansion in higher education participation rates brought with it cohorts of students who required financial support. Unfortunately, the rapidly rising tuition fee levels were not matched with a concomitant increase in financial aid.

Overall, while the raising of tuition fees may be described as an adaptive response by universities to declining resource support, the \#FeesMustFall student protests of 2015 and 2016 demonstrated that the response was out of step with the broader socio-economic contexts in which South African universities are located. The new patterns of resource dependence produced consequences: the significant dependence on tuition fees made the universities vulnerable to shifts in this funding source. In response to the \#FeesMustFall student protests in 2015, a decision was taken not to increase fees in 2016, which contributed to a number of universities becoming financially distressed. An analysis by the Council on Higher Education (CHE, 2016) projected that 19 of the 26 universities could have become financially unstable by 2018 if the $0 \%$ increase was extended to 2017 . In addition, the student protests invited a political and regulatory response, which was hitherto 'impossible'. The non-interventionist policy environment with autonomy to set tuition fees, which universities hitherto enjoyed, came to an end. As already mentioned, in 2016 tuition fees were frozen ( $0 \%$ fee increase) and in 2017 and 2018, increases were capped at 8\%. More importantly, despite the presidential Commission of Inquiry into Higher Education and Training (2017) finding that there was 'insufficient financial capacity in the state to provide totally free higher education and training to all who are unable to finance their own education, let alone to all students, whether in need or not...', the government decided in December 2017 that the state would provide free university education for poor and working class students. This decision will have a number of potential implications for universities: (a) given the prevailing circumstances of slow economic growth, which is expected to continue, competing public spending needs and slow growth in tax revenue to the state, it is unlikely that public funding for universities will improve, unless the state increases its borrowing or cuts spending on other priorities; (b) there will be more pressure on tuition fee levels that universities can charge considering that the state will be paying the fees for a significant number of students. 
The de facto regulation of tuition fees, together with the decision to provide fee-free university education for poor and working class students, has framed the higher education funding challenge in South Africa in terms of affordability and accessibility. The state's actions have placed emphasis on the importance of minimising costs to students and their families, and enhancing the participation of students from poor families. The changes to the higher education cost-sharing model in South Africa illustrate the complex and unpredictable interaction of politics and economics in the making of policy decisions. Despite economists, higher education policy experts, universities, the National Treasury and the presidential Commission of Inquiry into Higher Education and Training warning that South Africa did not have sufficient resources to provide fee-free higher education, a decision was taken to the contrary largely to satisfy political pressure to do something and prevent a possible recurrence of the $2015 / 16$ disruptions.

\section{The South African reality versus global trends}

The South African case offers key lessons for understanding the tensions between funding and affordability, which have generated worldwide debates (Carpentier, 2012; Oketch, 2016; Schendel \& McCowan, 2016; Wangenge-Ouma, 2012a). Furthermore, the South African context can be informed by these global trends and debates. Although it is difficult to compare and contrast countries with different histories, and impossible to characterise a generic pattern of funding higher education, an overall global trend in the funding of higher education can be discerned, with varied impacts across various national settings. We take seriously Cowen's warning about the circulation of ideas, policy and initiatives in education when he argues 'as its moves, it morphs' (2009, p. 315). It goads us to base our understanding of these debates contextually, to reflect on the variety of economic, social, political, and cultural factors that explain the connections and tensions between expansion, affordability, and funding of higher education in specific settings. The following looks at several global trends in relation to South Africa.

First, the key debates and tensions regarding funding higher education should be understood as the result of a historical trend with an increase of public funding in higher education after the Second World War, followed by a decrease after the crisis of the 1970s (Carpentier, 2012). These post-1970s trends should be seen as part of a wider retreat of state spending associated with, among others, a shift of most economies towards a low taxation agenda (Piketty, 2014). Higher education debates are thus part of wider debates on the funding of the social sphere, which did not start with the post-2008 global economic downturn, but with the crisis of the 1970s (Carpentier, 2015). The South African case confirms the acceleration of the policy of public austerity observed in other countries.

Secondly, this retreat of public funding is connected to another key historical trend, which is the increase of private funding in higher education and especially tuition fees, which started in the 1980s (Carpentier, 2012; Wangenge-Ouma, 2008, 2018). This development has been 
driven by a variety of rationales, ranging from a pure neoliberal marketisation agenda to a more or less moderate version of what came to be defined as cost-sharing (Carpentier, 2018). The principle of cost-sharing is based on the idea that students and their families should, in the name of equity and sustainability, contribute to the cost of their studies alongside the state (Johnstone, 2004). The impact of the various models of cost-sharing is widely debated. Those models differ according to the types of fees, and financial mechanisms in place to support students. Fees can be upfront or deferred, uniform or variable, paid by grants, loans or graduate tax. Loans can be commercial as in the USA, or backed by the government as in England. A number of university systems are still free, while others, for example South Africa, have decided to move to free education for a particular segment of students, or are considering reducing the tuition fee levels (England).

Thirdly, the implication of cost-sharing differs according to its design and the contexts, and depends on the links between the public and private dynamics of funding and especially whether private funding is additional or substitutive (Carpentier, 2012, 2018). In some countries, cost-sharing started in a period of higher economic growth during which the rise in fees coincided with relatively slow but still resilient public spending. The post-2008 world has led to a change of context where the acceleration of tuition fees has coincided with a sharp decline in public funding, leading to a shift in the main driver of cost-sharing - from generating additional resources to public/private substitution in the USA and England (Carpentier, 2018). The diminution of spending per capita after 2008 observed in Table 1 confirms this trend in the South African context where substitution seems to have clashed with expansion.

Fourthly, the impact of those changes in the trends and structure of funding higher education have implications for access and equity. At the same time, it is key to acknowledge inequalities at the society and school levels, as well as the intersection of socio-economic background with other forms of inequality such as gender, race and ethnicity (Burke, 2012; Morley \& Lugg, 2009; Wangenge-Ouma, 2012a). For example, the trends towards public/ private substitution have produced a shift in cost-sharing policies where the rising fees are increasingly funded by loans rather than grants (Carpentier, 2012). Since the 2008 crisis which has been described as a crisis of inequalities (Stiglitz, 2012) - this shift has been connected to the question of student debt. This raises not only equity issues, as debt aversion has been shown to be connected to social class (Callender \& Mason, 2017), but also systemic issues regarding the sustainability of the funding of higher education. The current debates and policy changes in South Africa are at the heart of these trends with key tensions between the level of fees, grants and student debt.

The consequence of public private substitution on increased institutional stratification (Carpentier, 2018) and the question of the funding of the public good are also important to consider (Lebeau, Stumpf, Brown, Lucchesi, \& Kwiek, 2012; Marginson, 2011). A key question raised in this paper is the contingency across space and time. The effect of costsharing in one particular time might be different from another. Moreover, the consequences of cost-sharing might be different according to the level of socio-economic development and 
stage of development of the higher education system of a country. This is probably why there has been a backlash in many countries, including South Africa.

\section{References}

Bunting, I. (2002). Funding. In N. Cloete, R. Fehnel, P. Maassen, T. Moja, H. Perold, \& T. Gibbon (Eds.), Transformation in higher education: Global pressures and local realities in South Africa (pp. 115-146). Cape Town: Juta.

Bunting, M. B. (2016). The financial condition of South African public universities: A framework for nonprofit financial analysis in a small-n context. Retrieved from https://ssrn.com/abstract=2790758

Burke, P. J. (2012). The right to higher education: Beyond widening participation. Abingdon: Routledge.

Callender C., \& Mason, G. (2017). Does student loan debt deter higher education participation? New evidence from England. Annals of American Political and Social Science, 671(1), 20-48.

Carpentier, V. (2012). Public-private substitution in higher education: Has cost-sharing gone too far? Higher Education Quarterly, 66(4), 363-390.

Carpentier, V. (2015). State education, crisis and austerity: An historical analysis through the lens of the Kondratiev cycles. In C. Aubry, M. Geiss, V. Magyar-Haas, \& J. Oelkers (Eds.), Education and the state: International perspectives on a changing relationship (pp. 78-102). Abingdon: Routledge.

Carpentier, V. (2018). Expansion and differentiation in higher education: The historical trajectories of the UK, the USA and France. Centre for Global Higher Education Working Papers, No. 33. London: UCL Institute of Education.

Clark, B. (1983). The higher education system. Academic organisation in cross-national perspective. Berkeley: University of California Press.

Cheslock, J. J., \& Hughes, R. P. (2011). Differences across states in higher education finance policy. Journal of Education Finance, 36(4), 369-393.

Cloete, N. (2002). New South African realities. In N. Cloete, R. Fehnel, P. Maassen, T. Moja, H. Perold, \& T. Gibbon (Eds.), Transformation in higher education: Global pressures and local realities in South Africa (pp. 414-446). Cape Town: Juta.

Cloete, N., Sheppard, C., \& van Schalkwyk, F. (2016). Fees and sustainable development. Moving the higher education fees debate from ideology to evidence. Presentation to the Presidential Commission of Inquiry into Higher Education and Training.

Commission of Inquiry into Higher Education and Training (2017). Report of the Commission of Inquiry into higher education and training. Pretoria: Department of Justice.

Council on Higher Education (2004). South African higher education in the first decade of democracy. Pretoria: Council on Higher Education.

Council on Higher Education (2016). Advice to the minister of higher education and training on fee adjustments at public universities. Pretoria: Council on Higher Education.

Cowen, R. (2009). The transfer, translation and transformation of educational processes: And their shape shifting? Comparative Education, 45(3), 315-327.

de Villiers, P., \& Steyn, G. (2006). Income and expenditure trends of higher education institutions in South Africa: 1986-2003. Perspectives in Education, 24(2), 35-48.

de Villiers, P., \& Steyn, G. (2007). The changing face of public financing of higher education, with special reference to South Africa. South African Journal of Economics, 75(1), 136-154.

de Villiers, P., van Wyk, C., \& van der Berg, S. (2013). The first five years project - a cohort study of students awarded NSFAS loans in the first five years 2000-2004. Stellenbosch Economic Working Papers: 11/13. Bureau for Economic Research: Stellenbosch University.

Department of Education (1997). Education White Paper 3: A programme for the transformation of higher education. General Notice 1196 of 1997. Pretoria: Department of Education.

Department of Higher Education and Training (2010). Report of the ministerial committee on the review of the National Student Financial Aid Scheme. Pretoria: Department of Higher Education and Training. 
Department of Higher Education and Training (2013). Report of the ministerial committee for the review of the funding of universities. Pretoria: Department of Higher Education and Training.

Department of Higher Education and Training (2015). Report of the presidential task team on student funding challenges at universities. Pretoria: Department of Higher Education and Training.

Department of Higher Education and Training (2018). Statistics on post-school education and training in South Africa: 2016. Pretoria: Department of Higher Education and Training.

Green, W. (2016). Access and success from a transformation perspective. Enrolment plan mid-term review. Presented at the Workshop on Mid-term Review of Enrolment Planning Efficiency Targets for 2017/182019/2020, Kopanong hotel and conference centre, Benoni. 15-16 March 2016.

Higher Education South Africa (2008). Tuition fees. Higher education institutions in South Africa. Report submitted to the Department of Education.

Johnstone, B. (2004). The economics and politics of cost-sharing in higher education: Comparative perspectives. Economics of Education Review, 23(4), 403-410.

Lebeau, Y., Stumpf, R., Brown, R., Lucchesi, M. A. S., \& Kwiek, M. (2012). Who shall pay for the public good? Comparative trends in the funding crisis of public higher education. Compare, 42(1), 137-157.

Makhanya, N. (2016). Sustainability of the higher education system: Discal review. Presentation at the Workshop on Mid-term Review of Enrolment Planning Efficiency Targets: 2017/18-2019.

Marginson, S. (2011). Higher education and public good. Higher Education Quarterly, 65, 411-433.

Merisotis, J. P., \& Gilleland, D. S. (2000). Funding South African higher education: Steering mechanisms to meet national goals. Washington, DC: The Institute for Higher Education Policy.

Ministry of Education (2001). National plan for higher education in South Africa. Pretoria: Department of Education.

Morley, L., \& Lugg, R. (2009). Mapping meritocracy: Intersecting gender, poverty and higher educational opportunity structures. Higher Education Policy, 22(1), 37-60.

Oketch, M. (2016). Financing higher education in sub-Saharan Africa: Some reflections and implications for sustainable development. Higher Education, 72(4), 525-539.

Pfeffer, J., \& Salancik, G. R. (1978). The external control of organisations: A resource dependence perspective. New York: Harper \& Row.

Piketty, T. (2014). Capital in the 21st century. Cambridge, MA: Harvard University Press.

Schendel, R., \& McCowan, T. (2016). Expanding higher education systems in low- and middle-income countries: The challenges of equity and quality, Higher Education, 72(4), 407-411.

Scott, I. (2016). A report on the colloquium. In Student funding (pp. 7-37), Kagisano (10). Pretoria: Council on Higher Education.

Spaull, N. (2018, 16 April). Basic education thrown under the bus - and it shows up in test results. Businesslive. Retrieved from https://www.businesslive.co.za/bd/opinion/2018-04-16-basic-education-thrown-under-thebus--and-it-shows-up-in-test-results/

Stiglitz, J. (2012). The price of inequality: How today's divided society endangers our future. New York, WW Norton.

van Harte, M. (2002). Can student loan schemes ensure access to higher education? South Africa's experience. The International Comparative Higher Education Finance and Accessibility Project, Graduate School of Education, State University of New York, Buffalo.

Wangenge-Ouma, G. (2007). Reducing resource dependence on government funding: The case of public universities in Kenya and South Africa (unpublished doctoral dissertation). School of Education, University of Cape Town.

Wangenge-Ouma, G. (2008). Globalisation and higher education funding policy shifts in Kenya. Journal of Higher Education Policy and Management, 30(3), 215-229.

Wangenge-Ouma, G. (2010). Funding and the attainment of transformation goals in South Africa's higher education. Oxford Review of Education, 36(4), 481-497.

Wangenge-Ouma, G. (2012a). Tuition fees and the challenge of making higher education a popular commodity in South Africa. Higher Education, 64(6), 831-844. 
Wangenge-Ouma, G. (2012b). Improvement in access, but participation rates still a problem. In J. Hofmeyr (Ed.), The youth dividend: Unlocking the potential of young South Africans (pp. 63-67). Wynberg: Institute for Justice and Reconciliation.

Wangenge-Ouma, G. (2018). Financing higher education in Africa: An overview. In J. C. Shin \& P. Texiera (Eds.), Encyclopedia of international higher education systems and institutions. Dordrecht: Springer.

Wangenge-Ouma, G., \& Cloete, N. (2008). Financing higher education in South Africa: Public funding, nongovernment revenue and tuition fees. South African Journal of Higher Education, 22(4), 906-919.

Ziderman, A., \& Albrecht, D. (1995). Financing universities in developing countries. Washington, DC: The Falmer Press. 


\title{
SOUTH AFRICAN HIGHER EDUCATION, SOCIETY AND
} ECONOMY: WHAT DO WE KNOW ABOUT THE RELATIONSHIPS?

\author{
Stephanie Allais
}

\section{Introduction: Development versus sorting roles of education}

This chapter reflects on relationships between higher education, society and the economy in South Africa today, with a focus on undergraduate education. I suggest that we can gain some insight into these relationships by looking at the nature of research and evaluation of higher education outcomes - how research is conducted, what are the main kinds of research, how the research understands the relationship between education and the economy, and what inferences, analyses, and policy implications are drawn out from research. Instead of assuming that they give us useful information about higher education (to some extent they do), and instead of considering what we can learn from the results of these studies and forms of evaluations (which is also important), here I seek to explore them as phenomena which are part of the systems they seek to understand and evaluate.

I suggest that relationships between higher education, society and the economy are more complex than is generally understood. I argue that much of the focus of research and systemic evaluation of graduate outcomes is focused on benefits, and not on interrelationships or interactions, and therefore can easily trap us in a fairly superficial set of debates and analyses about how higher education interacts with society. What is needed, then, is more analysis of relationships between different institutions in society in a way that provides insight into the wider system, that is revealing systemic issues and tendencies beyond the confines of one set of institutions. This entails research that does not attempt to quantify the individual (contingent) and social (not easily quantifiable) benefits of higher education, but rather tries to understand better the relationships between universities, society and the economy in 
different contexts today. Education exists relationally. It changes when the context changes, and the roles that it plays change.

To make this case, I use an analytic distinction between the developmental and the screening roles of education (Halliday, 2015). Education plays a role in screening (or signalling) and sorting individuals according to academic criteria, within education and training systems, and from education and training systems into labour markets and workplaces. This is completely separate from the developmental role that the learning which happens through education plays: the substantive goods of education play a role in preparing children for autonomous life as adults; enriching children, young people, and adults; preparing people to do different kinds of work; contributing to well-being; preparing young people for citizenship; and enabling them to share in the bodies of knowledge that have been developed over thousands of years, across continents. I suggest that much South African (and to some extent international) literature on the role of higher education in society does not adequately pull out the differences between these two roles, which need to be understood in their own right in order to attempt to gain insight into the complexity of interrelationships between higher education and the rest of the education and training system, as well as between the education and training system and the labour market. What is also important is to look at the ways in which these relationships shape each other. This is of concern not only analytically, but also because the act of measurement and of evaluation shapes the nature of higher education.

In the next section, I discuss the large body of research that aims to consider the impact of undergraduate education on society in terms of graduate outcomes. This includes return studies and tracer studies which attempt to understand labour market outcomes of graduates. I argue that although they are used to extrapolate analyses of the skills needs of the economy as well as funding priorities for education, they are suggestive of labour market stratification - with education functioning as a screening device. I then consider another major type of evaluation and research in higher education which reveals a similar pattern - ranking systems, which seem focused on facilitating distinctions between graduates. I also consider quality assurance systems that try to gain systemic insight into the nature of universities. Both the graduate outcomes research and the systemic evaluations focus on the benefits that higher education produces whether to society or to individuals, and both assume implicitly that these benefits are due to the developmental role of higher education. I conclude this chapter by arguing that this results in inadequate attention being paid to the complexity of interrelationships between higher education and the rest of the education and training system, as well as between the education and training system and the labour market, and the ways in which these relationships shape each other.

\section{Graduate outcomes}

Rates of return studies are a major source of insight into graduate outcomes. These are done using labour force data, aggregating the individual incomes of people who hold different levels 
of educational qualifications; the idea is that this reveals the private returns to education (Psacharopoulos, 1994; Psacharopoulos \& Patrinos, 2004; Woodhall, 1987). In South Africa, this type of research reveals that graduates are dramatically better off than their non-graduate counterparts (Bhorat, Cassim, \& Tseng, 2016; Cloete, 2015a; van den Berg, 2015).

The South African literature on graduate outcomes is reviewed in detail in Chapter 17. In short, their review demonstrates that in South Africa graduates have good labour market outcomes, in a context in which general labour market outcomes are very poor. This is confirmed by Haroon Bhorat et al. (2016), who show that the long-run average unemployment for degree holders is $4.2 \%$. This is in a context of extremely high unemployment: the official rate is currently $26 \%$, and $36.9 \%$ for youth according to Statistics South Africa. ${ }^{3}$ An expanded definition of unemployment puts youth unemployment at around 68\% (National Youth Development Agency, 2015). My interest here is the use to which this kind of information is put.

One key argument that is made based on rates of return analyses is that South Africa is observing skill-biased economic growth, which means we need more higher education graduates. Bhorat et al. (2016) argue that the South African economy increasingly requires workers with higher levels of skills. They base this argument on two main data sets: labour force surveys, which show a consistent trend whereby the more educated are improving their labour force positions relative to the less educated; and analyses of the sectoral composition of the economy, which show growth in capital-intensive industries and a growing finance sector. They describe this as 'skill-biased economic growth'. In other words, rates of return to graduates are used to extrapolate about the kinds of education the country is believed to need, which should then inform various policy levers. Of course, funding is a key policy lever which is affected by this kind of analysis. In South Africa currently there is significant contestation about the proportion of funds that should be spent on the small college sector (vocational and adult education) that is intended to service the huge percentage of adults without access to university education, relative to the proportion of funds that goes to the university sector, which currently vastly dominates the post-school sector (Department of Higher Education and Training, 2016).

Rates of return are used to make other arguments about funding policy as well. For example, some researchers argue that the high benefits that accrue to graduates suggest that the state should not contribute to the full cost of study for wealthy individuals, and even poor individuals should repay some of the costs of their study. For example, Nico Cloete (2015b) surveys the graduate outcome literature in order to make an argument about higher education funding. He argues that there is a relationship between inequality and returns to higher education - the higher the inequality, the higher the returns to individuals. He demonstrates that in a highly unequal society such as South Africa, the rate of return from higher education is of a dramatically higher order than that in more egalitarian societies. The high rates of return

3 www.statssa.gov.za accessed 21st September 2016 
enjoyed by graduates at an aggregate level in South Africa are bolstered by a system in which there are weak transition systems from technical and vocational education, and technical and vocational education (TVET) graduates tend to obtain poorly paid and poorly rewarded work - often no better than their counterparts with a school leaving qualification (Bhorat et al., 2016). Cloete concludes, then, that a higher education system in which wealthy individuals were not expected to pay something at the door would be unfair.

Analysts such as Cloete (2015a) argue that fiscus-based funding is regressive because all South Africans contribute to the fiscus, through value added tax. So Cloete's argument is that even if those who earn in the formal labour market contribute much more, the life time private benefits that are obtained from higher education are dramatically higher than those who don't access higher education, and the implication is that a higher education system which is fee-free at the point of access would mean that the poor, whose children do not attend higher education, are subsidising the rich. This line of argument can be seen as reinforced by van den Berg's (2015) analysis that $80 \%$ of those who qualify to apply for higher education attended schools in the top two income quintiles, and van Broekhuizen, van den Berg, and Hofmeyer's analysis (2016) that for every 100 individuals, the state already spends substantially more on the roughly 10 individuals from a particular age cohort who graduate compared to their 90 counterparts who don't.

A third, and again different argument made by van den Berg and colleagues (2011) based on analyses of rates of return analyses, is that labour market outcomes are driven by education, and therefore, improving education levels will improve the labour market outcomes of South Africans. They argue that $80 \%$ of inequality in South Africa is driven by wages, and wages are strongly related to levels of education.

In other words, rates of return studies demonstrate that university graduates do better than non-graduates in the labour market. Some researchers point out that in addition to this ultimate better performance, in general, those who enter higher education are more wealthy than those who don't, and that the relative amount of funds spent by the state on the former group is dramatically larger. Some of the implications that these researchers then draw out is that the economy needs higher levels of skills; the state should encourage more people into more higher education; that individuals who can afford to should pay directly for at least some of the cost of higher education; that raising education levels will improve labour market outcomes in general. I suggest that the picture is much more complex than this.

Rates of return and analysis of labour market statistics simply point to aggregate outcomes - and often obfuscate important trends (Lauder, Brown, \& Ashton, 2017). Part of the problem is that there is not sufficient analytic separation of the screening versus developmental role of education. Take the first argument: Bhorat et al. (2016) argue that economic growth in South Africa is skill-biased by showing that in areas that do not require education, workers with no education are being replaced by those with education. But this does not prove their argument. Rather, it provides insight into hiring practices. Hiring practices often reflect the screening or signaling role of education: employers select potential employees with the highest possible level 
of qualifications relative to the potential pool of applicants. Similarly, they point out that there is growth in the 'technical' category, but add that this category has mainly been absorbing people with degrees. Their explanation for this is that there is inadequate preparation at TVET college level - and employers are therefore selecting graduates instead. It is just as likely that this phenomenon is caused by qualification inflation in the context of a large reserve army of the unemployed: employers have a pool of graduates to draw on, and therefore ignore technically trained workers. What is at stake here is how employers use qualifications in hiring decisions: whether qualifications are seen as a proxy for skill, or a proxy for ability relative to other job applicants. Different labour markets operate differently in this regard (van de Werfhorst, 2011).

Take the third argument - that raising education levels would improve labour market outcomes in general. Giving more people more education would only improve labour market outcomes if the developmental aspect of education was what was leading to improved labour market outcomes. In classical economics terms, this would mean that human capital theory would apply: education would provide people with skills and knowledge that would make them more productive at work; their good labour market outcomes would be the result of this. But if the good labour market outcomes of those with more education are as a result of signalling in the labour market, raising levels of education will not make a difference. To the extent that education is used for screening in labour markets, it is a positional good. Positional goods have absolute limits on their supply. Supplying more education to more people can increase the role education plays developmentally - by providing more people with the opportunity to learn. But increasing the supply of education cannot increase the positional gains made by achieving particular educational levels. Put differently, in labour markets what matters is often not so much 'the type of education that different groups receive (whether defined through formal content, the hidden curriculum or the social relations of education), but the relative differences between the amounts and status of education regardless of content or form' (Moore, 2004, p. 101). This helps to make sense of the fact that world education levels are converging far faster than economic levels:

This implies that the average developing country adult in 2010 had more years of schooling completed (7.2) than developed country adults had in 1960 (6.7). Developing country stocks of schooled adults have already (in 2010) exceeded the levels of schooling that the current developed countries had when they already were, in every meaningful sense, fully developed. For instance, the Barro and Lee $e^{4}$ data shows that the adult population in France, an undeniably developed economy/ society/nation-state in 1965, had only 4.71 years of schooling in 1965, a level exceeded in 2010 by many of the poorest places on the planet: Haiti at 5.16, Uganda at 5.36, and even Afghanistan at 4.75. (Pritchett, 2018, p. 6)

$4 \quad$ Barro and Lee (2011) 
Fredriksen and Fossberg (2014, p. 248) make a similar point that 'at the start of the 20th century, the majority of the labour force in most of today's "old" industrialised countries had made the transition out of agriculture, at a time when the coverage of their secondary education was well below that of SSA [sub-Saharan Africa] today'.

One implication of this is that extrapolating the value of higher education for individuals may be accurate only for a moment in time. Thus degree holders do currently, in South Africa, reap substantial rewards in labour markets. But this tells us little that is helpful in terms of the nature and shape of education provision required by a particular society, because the relationships between education and labour markets are far more complex than a simple function of the increased productivity of educated workers. The economists cited above argue that skill-biased economic growth means that economies need more skilled people. A public policy response that attempts to increase levels of higher education participation would then be correct. But in the main education levels have risen much faster than knowledge requirements in most jobs, and technological change has not been the driving force in rising credential requirements (Collins, 1979, 2013; Livingstone, 2012). Increasing participation in higher education around the world (Collins, 2013; Meyer, St John, Chankseliani \& Uribe, 2013; Schofer \& Meyer, 2005) has coincided with rising inequality (Piketty, 2014). So skill-biased growth is at best a highly partial explanation for the observed trends in education/labour market interaction. It is particularly implausible in sub-Saharan Africa where there has been a weak association between economic growth and education: between 1960 and the mid-1980s, this region experienced the fastest education expansion in the world but, on average, sluggish economic performance (Languille, 2014). Similarly, changing the mix of graduates to nongraduates may do very little for labour market outcomes, if there is no absorptive capacity in the economy. This kind of analysis, therefore, should also be treated with caution in the making of policy decisions, including of funding policy.

There are a range of issues in a given society which shape these relationships. For example, Lauder et al. (2017) show that rates of return depend on the industrial development path taken - they show that South Korea and Republic of Ireland have made similar investments in higher education, but with very different results for individual labour market outcomes, because of different industrial development trajectories that require different actual skill mixes (developmental role of education). These interrelationships are discussed further in the conclusion to this chapter. For now the point is that where employer demand for skilled workers is shaped by the relative availability of different types of qualified workers, the structure of the labour market, and conditions of employment for different levels of workers, it is less focused on the specific knowledge and abilities of graduates.

Graduate tracer studies in South Africa, reviewed in detail in Chapter 17, confirm the basic gist of the rates of return studies, but provide more nuanced insights, telling us what precise benefits are obtained by particular individuals - the types of jobs that different groups of graduates get, how fast they get them, and sometimes, their experiences within them. In South Africa, they reveal other factors which are at work in labour markets, as they show that race and 
gender are a substantial predictor of labour market success within the graduate group, while field of study, predicted by socio-economic status, is also significant (Cape Higher Education Consortium [CHEC], 2013; Cosser, 2015; Koen, 2006; Rogan \& Reynolds, 2016; Rogan, Reynolds, du Plessis, Bally, \& Whitfield, 2015).

So for example, in the Eastern Cape province of South Africa, students from the historically white university, Rhodes, fare better in general than their counterparts from the historically black university, Fort Hare. This raises inevitable questions about stratification: is it just perception, or are there grounds for believing that the former institution on the whole offers better education than the latter? Are Rhodes graduates better equipped for the labour market because the institution is able to take in school leavers who are better prepared for higher education study? Or is their intake simply better networked? All of this starts to suggest the complexity of the myriad interactions between race, socio-economic success, and educational success in South Africa, which cannot be unravelled through tracer studies. Charlton Koen (2006, p. 3) argues in his analysis of 46 such studies in South Africa that they frequently do not tell us more than what a plausible guess would have predicted:

\section{Key graduate employment problems relate to the demographics of graduates, mismatches between graduate skills and labour market needs, graduate shortages in key fields, bias in terms of institutions attended, and crucial differences in time-to- employment across economic sectors.}

So we know that in South Africa, white men generally have the faster paths to employment and that once employed, they get better salaries and job satisfaction. African women have the worst labour market outcomes. We know that the vast majority of graduates are better off than their non-graduate counterparts. We also know that race, gender, geography and poverty continue to be key factors in determining who enters higher education, as well as who enters the world of work and how. Indirect effects are also at play: a recent $\mathrm{PhD}$ thesis found that students from wealthy backgrounds tend to enrol in the natural, mathematical, engineering and health sciences, while poorer students are more likely to be enrolled for diploma programmes in business, commerce and the human or social sciences (Cosser, 2015). Predictably, wealthier students had considerably higher success rates in their chosen course of study (Cosser, 2015), in line with findings from other countries. Many schools serving poor communities don't even offer the subjects required to gain entrance to studying engineering or medicine. If they do offer these subjects, good performance in subjects such as mathematics, physical science and first language English is required. Socio-economic background is highly correlated with attainment in these subjects (van den Berg et al., 2011). This is in line with much sociological and economic analysis of the role of higher education, which shows that it is unable to counteract stratification because both access and success in higher education are substantially shaped by socio-economic status (for a recent argument about this issue in developing countries, see Ilie \& Rose, 2016). 
All of this seems to tell us as much, if not more, about the changing nature of work and labour markets than about the quality and nature of higher education and the nature of the goods - public or private - that it might provide. The tracer studies also provide some insights into the ways in which stratification within higher education interacts with a stratified labour market.

Another major set of research and analysis of our university system - quality assurance or systemic evaluation - reveals a similar pattern: while the outcomes of research are used to inform funding and other policy decisions, we seem to learn as much about the nature and functioning of South African labour markets. I now turn to a brief discussion of systemic evaluation of South African universities.

\section{Systemic information}

Quality assurance, systemic research and rankings systems are some of the key mechanisms for system-wide research and analysis about higher education. Looking at what is measured and to what use such measurements are put, can be telling.

The more market-oriented form of systemic evaluation is ranking systems which operate nationally and internationally and compare composite scores of universities on teaching, research, student experience and interaction with industry (Shin, Toutkoushian, \& Teichler, 2011). There is a large body of literature engaging with and critiquing rankings, both in terms of how they are done and the role that they play within higher education systems (for example, Hazelkorn, 2015). For the purpose of considering what they tell us about interactions between universities, society and economies, there are four points to draw out.

First, while the hierarchies that they present cannot be completely dismissed - it seems plausible that the institutions at the top are offering better quality education than those at the bottom - the fine grained distinctions that they claim to provide about the hierarchy between universities is spurious (Castells, 2009).

Second, while rankings provide some, limited, information about quality of education and by implication 'value for money' for those paying fees - they tell us more about the nature of labour markets than they do about universities.

Third, because they are in the main driven by a focus on benefits, and not on interrelationships or interactions, they can easily trap us in a fairly superficial set of debates and analyses about how higher education interacts with society.

Fourth, universities feel compelled to compete in ranking systems, and therefore shape their activities towards those that will improve their status in the rank, regardless of the intrinsic benefit of such a pursuit. This is classic of any target-based system - the pursuit of the target, which is a proxy, can distort the practice and ultimately not ensure that the end goal is reached.

The reason ranking systems are so important, despite all the convincing critiques of them, is because higher education systems are increasingly treated as markets, but they are markets in which 'consumers' (the role that both students and employers are placed in, in different ways, 
by marketisation logics) have extremely weak information about the market value of what is being purchased. Rankings offer a solution to this problem, however problematic they may be in terms of the substance of teaching and learning. To the extent that higher education is valued for its signalling role in the labour market, signals need to be as differentiated as possible. Ranking systems offer ways for 'consumers' to differentiate amongst higher education systems. Rankings can be understood primarily as a consumer service and advertisement mechanism, and it is for this reason that institutions are keen to participate; they are there not to provide hierarchies of meaningful fine-grained distinctions between universities, but to respond to labour markets that want some way of making finely-grained distinctions from a growing pool of graduates. Add to this that graduate outcomes are often included as a factor in such rankings, and we have a circular system whereby employers perceive that certain institutions produce better graduates, leading to stronger or better prepared applicants favouring these institutions, leading to good outcomes, leading to them being likely to be employed. This is reminiscent of the 'beauty competition' described by Brown, Lauder, \& Ashton (2011) in their description of the mutually reinforcing hiring patterns between elite universities and multi-national employers. To this extent, the increasing focus on higher education measurement can be seen as a symptom of labour markets characterised by growing inequality and fragmentation. And its effects on the ability of universities to deliver the 'goods' or the developmental aspects of education is undermined - as universities focus on meeting criteria that will boost their rankings, to the detriment of thinking about the actual education offered (Hazelkorn, 2012, 2015).

The negative side effects of measurement are also visible in government attempts to assess universities systematically through quality assurance systems, which originate from governments attempting to manage institutions and systems to ensure value for money and effectiveness, as well as to regulate possible new entrants (Brown, 2013; Vidovich \& Slee, 2001).

Quality assurance systems generally attempt to measure institutional performance against institutional or national goals, through national systems of audit, evaluation and accreditation. South Africa's system is relatively new but established, and provides a great deal of data and analysis about institutions and systems (CHE, 2015).

Unsurprisingly, like the graduate outcome studies discussed above, they are also mobilised in funding policy debates. Chapter 3 has already provided an overview of the complexities of the funding debate. For now, my focus is on how these systems are used, and what we can learn by considering them as part of the phenomena that they seek to evaluate.

One of the long-standing debates in South Africa is whether more money should be given to strong institutions (they are giving good value for money) or to weak institutions (we need to help them to do better) (Department of Higher Education and Training, 2013, 2014; NCHE, 1996). This is in the context of a fragile system with a small number of institutions in almost constant crisis, and many institutions that are unstable, with falling enrolments, high failure rates and management crises (Department of Higher Education and Training, 2014). Another debate is the mechanism for funding - should individuals be levied fees on registration, 
or through a graduate tax, for example. Currently, in South Africa the fee component, paid by students and government bursaries for poor students, creates a system with differential income. A tax-based funding model is easier to administer than a sliding arrangement of fees and financial aid, and avoids the stigmatisation of means-testing; all of these are significant considerations in the South African context. A model which incorporates a component of direct fees offers protection against fiscal erosion, which is likely over time, both considering research in other African countries (Cloete, 2015a) and also given that it is what led to the $2015 / 2016$ funding crisis in the first place. It also enables universities to extract additional payments from the rich directly at the point of interface with the system, where they are more likely to be willing to pay, which could be decisive in preventing a seriously underfunded system over time. Robust insight into the universities, but also into issues such as tax politics, is important for the resolution of such debates.

There are many other considerations, such as fairness of access. The Department of Higher Education and Training estimates, ${ }^{5}$ on the basis of data from Statistics South Africa, that about $30 \%$ of South African university undergraduate students can comfortably pay fees; about $25 \%$ are supported through public financial aid. About $45 \%$ of students come from households that currently face some degree or a high degree of economic difficulty. A fair system would support these students to undertake studies without financial anxiety.

The point for this chapter is not to further unpack these complex debates, or to provide policy recommendations on funding models. Rather, it is to consider how the information that we have about the role of higher education is used in national and economic policy decisions, and what the limitations of this kind of information are. One limitation of much quality assurance or systemic research is that it evaluates institutions and systems in terms of the goals that they set for themselves. These goals tend to be things such as enrolment and output numbers, as well as throughput times, but, like all target driven systems, they can have positive or negative effects, depending on how attempts are made to meet the targets. It is difficult for any society, but particularly a highly unequal one, to fund a mass higher education system. The bigger the system, the more pressure there will be for accountability mechanisms - and proof that the tax payer is getting 'value for money'. But the systems which attempt to obtain such proof distort the nature of the very system they are claiming to examine. This is not to argue in favour of small elite systems, but simply to point out that trade-offs may be inevitable. If a system grows to the extent that it places a heavy burden on the fiscus, there is more need for government systemic evaluation. But this evaluation is costly, and can have negative side effects. So the larger system which results is never going to be substantively the same thing - when considered from the developmental aspect of education - as the elite system. And, as argued above, it is never going to change labour market outcomes to the extent that they are driven by education's screening role. All of this can have a range of negative effects. For example, employers who feel that education doesn't prepare people adequately for work could find firstly, that their new employees have an increasing

5 Personal communication with Diane Parker, the official in charge of higher education at the DHET. 
disconnect - because they are driven to acquire higher education qualifications that are not substantively required to do the job. Secondly, universities under pressure to increase throughput and increase enrolment could also increasingly cut corners - and thereby reduce the substantive education obtained by their students.

\section{Preliminary conclusions}

Currently in South Africa we know something amount about who gets access to what, how, and in what contexts, and how it benefits them in terms of labour market rewards. There is much more to learn about these crucial questions, and better data systems would enable far more analysis. Much of the current findings are put to use in policy debates about funding, because the research is focused on who benefits from higher education and how, and who should pay and how payment should be allocated. Despite this focus, funding policy remains unresolvable because, as elaborated in Chapter 3, there is no convincing way of quantifying public and private benefits of higher education in relation to each other. More fundamentally, this focus, as well as the systemic focus on value for money and efficiency, leads to a focus on the quantifiable, in a context where we have poor analysis of the bigger picture, or of long-term relationships. This focus, and the increasing types of measurement, can affect systems in highly undesirable ways.

But we can also learn from the ways in which higher education systems are evaluated, assessed, and researched, and the uses to which findings from these evaluations are put, and gain some insights into the relationships between universities, society and the economy. I have argued above that one major learning from higher education evaluation - and its increasing dominance - can be understood when considering the screening role of education. Employers are increasingly looking for higher levels of qualifications as well as ways of distinguishing between graduates. Another implication that can be drawn from a consideration of the various arguments above is that the ways in which education relates to work is far less direct than is generally held to be the case. Much better insight is needed not only to unpack relationships in terms of how the economy shapes the education system, but also how different parts of the education system interact with each other.

Much analysis of the South African higher education system suggests that there is an inverted pyramid with too many students at university and two few in TVET, and further, that this situation puts strain on universities. There is much focus on how the poor quality of basic education creates problems for higher education in South Africa. Where the relationships are reversed, and the effects of higher education on basic education are considered, the main issue under the spotlight is teacher training, with small pockets of research into the role of universities in contributing to knowledge about education improvement. There is much less interrogation of how the nature of higher education and its interaction with labour markets in South Africa shapes the rest of the education system in terms of who attends what kind of institution, motivation to continue to study, and so on. 
If we look historically and globally, there is a relatively small set of countries that have built vocational education systems that have attracted a majority or even reasonably large percentages of upper secondary students, and that have been supported by industry. In these countries, relationships between secondary education and higher education, as well as between education and the economy, are different to those in which academic education is the only valued educational pathway.

One key set of countries, the ones that are generally regarded as the most successful in ensuring that a significant share of the typical youth cohort chooses to pursue vocational education instead of academic upper secondary and then higher education, are referred to in the literature as 'collective skill formation systems' (Busemeyer \& Trampusch, 2012). These countries are referred to as 'collective skill formation systems' because they are collectively organised: 'firms, intermediary associations, and the state cooperate in the process of skill formation in initial vocational training' (Busemeyer $\&$ Trampusch, 2012, p. 4). In particular: firms are strongly involved in financing and administering workplace-based training; intermediary associations play an important role in administration and reform of these systems; the systems provide portable, certified occupational skills; and training takes place not only in schools but also in companies.

There are other examples of countries that have developed relatively successful TVET, even if without the systemic success and relative stability of the collective skill formation countries. For example, in the late industrialising countries of Asia, strong state coordination of the education and training system ensured that the industrialisation, which was also being strongly driven by the state, got the skills it needed (Ashton, Green, James, \& Sung, 1999; Ashton, Green, Sung, \& James, 2002; Park, 2013). In Latin America, what can be seen is industry developing strong national systems for the development and provision of TVET at a point in time at which economies were growing and there was strong growth of industries - in other words, the import substitution period (Cintefor \& the ILO, 1991; de Moura Castro, 1979, 2000).

Key in all instances was demand for intermediate skills. It is present across all, whether there is strong coordination between employers, workers and the state, or strong centrally driven industrialisation and the TVET system, or strong industry-driven provision of TVET. Successful upper secondary level TVET systems grew and developed in response to industrialising economies (Ashton \& Green, 1996; Ashton et al., 2002; Bosch, 2017; de Moura Castro, 1979, 2000). They also grew before or jointly with the worldwide trend to massification of secondary education and the more recent massification of higher education (Pritchett, 2018).

In the absence of some combination of these factors, the pattern which emerged over the course of the twentieth century was of general education playing more of a role in the economy, and being used more as selection for work. This forced TVET into a residual role. There are many countries in which general education is the key component of skill formation for the economy. In these contexts, there are often relatively small TVET systems, with pockets of 
excellence, and pockets of good relationships between education and work, but in the main weak relationships. In other words, during the 20th century period in which education systems have massified, in the absence of specific factors, populations tend to push for higher levels of general education (Foster, 1965; Hall \& Soskice, 2001; Nherera, 2000; Wolf, 2002).

This is not necessarily a bad thing. Hall and Soskice (2001) argue that in the developed world high levels of general education have led to self-reinforcing virtuous cycles in terms of economic growth, and that liberal market economies are more likely to be home to radical innovation, enabling substantial shifts in production lines or the development of completely new goods. However, this has generally been accompanied by a negative pattern for those people who don't achieve well at school, and who don't make it to university education (or who realise early on that they won't make it). In other words, more people are left behind. The notion of an educational arms race (Halliday, 2015; Livingstone, 2009) captures the situation whereby labour markets respond to the demand for positional consumption - as more people get higher levels of education, demand for ever higher educational levels is proliferated more and more, a process which leads to no real economic gains, and has a range of effects on school systems, including undermining the motivation of those who are not at the top of the academic achievement spectrum. The demand for non-positional or developmental education - such as the actual knowledge needed to do work, or for the intrinsic value of learning - then remains relatively weak and unstimulated. Arms races in education are self-reinforcing, making education disproportionately about screening, and less about development.

The point is that there is a large body of literature that considers the complex interrelationships in the organisation of occupations as well as in the labour process on the one hand, and the organisation of education and training systems on the other (Busemeyer \& Trampusch, 2012; Hall \& Soskice, 2001; Iverson \& Stephens, 2008; Warhurst, Mayhew, Finegold, \& Buchanan, 2017). All of these intertwine with broader social policy - social welfare spending, labour market regulation, employment protection, and industrial strategies. Very little of this type of analysis has been done in South Africa or indeed any African countries. But some preliminary analysis can be made by considering the political economy of skill formation in South Africa.

The education arms race described above seems to have a particularly detrimental effect in economies with only a very small percentage of good, well-paying, protected jobs. South Africa has a weak TVET system, and students seem to attempt to complete upper secondary education in school, rather than electing to move to TVET (DHET, 2018). South Africa also has a very small (by middle income country standards) formal and industrial sector. As shown by the economists who analyse labour market outcomes (Bhorat et al., 2016; van den Berg, 2015; van den Berg et al., 2011), the best jobs within this sector go to graduates. My preliminary analysis suggests that the tiny size of the formal and industrial sectors in South Africa - and the small number of good jobs - as well as the extreme difference between options inside and outside of these sectors, and the desirability of getting a job outside of the country, seems to make 
'screening' dominate the functioning of education and training. The small number of good well-paying protected jobs available could be aggravating the ways in which education is used for screening (gaining access to a good job or place at university), which then undermines the developmental roles of education (learning). As discussed above, the two functions are not the same, and they can interfere with each other. In other words, it could be argued that the relationship between the higher education system and the labour market that is a factor hampering the development of a stronger TVET system, with perverse outcomes for individuals and the development trajectory of the economy.

This makes it difficult for policy-makers who are involved with developing educational institutions and educational curricula for mid-level skills - that is, TVET colleges and apprenticeships - to develop curricula which contain the knowledge and skills needed to perform mid-level skilled work. No matter what they do, it seems that the offerings developed are low status, in low demand, attract poorly prepared students, which then aggravates the limited possibilities of such programmes. While there are pockets of success despite these extreme structural challenges, the possibilities for building dynamic skill formation systems are highly constrained. The possibility for changing this by changing aspects of the education and training system seem very remote because the dynamics which are driving it don't emanate from the education system. And yet, lack of mid-level technical skills, lack of basic general education, and lack of high level skills, are all argued to be critically undermining efforts for industrialisation and economic development, and flooding universities with students who are poorly prepared and equipped for success. These kinds of relationships need far more research and analysis.

Besides the irony of the growing necessity and rising cost of higher education, another irony is the growing focus on the need for higher education to inculcate 'employability'. If university education is in fact so necessary for work, it must then be doing a good job of preparing people for work, so it seems paradoxical that universities should also have to change their curricula in untried ways to ensure employability. This apparent paradox is, I suggest, symptomatic of shrinking good employment (Mohamed, 2017) combined with qualification inflation. Similarly, debates about 'graduateness' are symptomatic of the soul-searching caused by massification. These debates emerge just at a time when the role we believe higher education to play in society is increasingly not the role that it really plays. In South Africa, these play into debates about decolonisation which are furious precisely because higher education has become the default gatekeeper of good jobs, albeit still in the racialised, gendered ways discussed in Chapter 17.

We need more critical approaches to the range of different institutions, political systems, and policy environments that interrelate with each other, and analysis of higher education needs to be located in such a broader sociological and political economy approach which takes a long-term perspective. Better information along the lines described above would not only be crucial for sociologists trying to understand the social world, but could also help policy-makers in a range of different ways, including on priorities for funding policies. 


\section{Acknowledgements}

This paper draws on Allais, S. (2017) Towards measuring the economic value of higher education: Lessons from South Africa. Comparative Education, 53(1), pp. 147-163; and Allais, S. (2018). Analysis must rise: A political economy of falling fees. In Khadiagala, G., Mosoetsa, S., Pillay, D., \& Southall, R. (Eds.), New South African review 6: The crisis of inequality. Johannesburg: Wits University Press, pp. 152-166.

\section{References}

Ashton, D., \& Green, F. (1996). Education, training and the global economy. Cheltenham: Edward Elgar.

Ashton, D., Green, F., James, D., \& Sung, J. (1999). Education and training for development in East Asia: The political economy of skill formation in newly industrialised economies. London: Routledge.

Ashton, D., Green, F., Sung, J., \& James, D. (2002). The evolution of education and training strategies in Singapore, Taiwan and S. Korea: A development model of skill formation. Journal of Education and Work, 15(1), 5-30.

Barro, R. J., \& Lee, J. W. (2011). A new set of educational attainment in the world, 1950-2010 (NBER Working Paper No. 15902).

Bhorat, H., Cassim, A., \& Tseng, D. (2016). Higher education, employment and economic growth: Exploring the interactions. Development Southern Africa, 33(3), 312-237.

Bosch, G. (2017). Different national skill systems. In C. Warhurst, K. Mayhew, D. Finegold, \& J. Buchanan (Eds.), The Oxford handbook of skills and training (pp. 424-443). Oxford: Oxford University Press.

Brown, P., Lauder, H., \& Ashton D. (2011). The global auction. The broken promises of education, jobs, and incomes. Oxford: Oxford University Press.

Brown, R. (2013). Mutuality meets the market: Analysing changes in the control of quality assurance in United Kingdom higher education 1992-2012. Higher Education Quarterly, 67(4), 420-437.

Busemeyer, M. R., \& Trampusch, C. (Eds.). (2012). The political economy of collective skill formation. Oxford and New York: Oxford University Press.

Cape Higher Education Consortium (2013). Pathways from university to work. A Graduate Destination Survey of the 2010 cohort of graduates from the Western Cape universities. Wynberg: Cape Higher Education Consortium Study.

Castells, M. (2009). The role of universities in development, the economy and society. Lecture, University of the Western Cape.

Cintefor, \& the ILO. (1991). Vocational training on the threshold of the 1990s Volume 1. Montevideo: Education and Employment Division Population and Human Resources Department The World Bank.

Cloete, N. (2015a). The ideology of free higher education in South Africa. The poor and middle class subsidising the rich (Kagisano No. 10. Student Funding.) (pp. 115-124). Pretoria: Council on Higher Education.

Cloete, N. (2015b). The third force in South African higher education activism. Cape Town: Centre for Higher Education Trust.

Collins, R. (1979). The credential society. New York: Academic Press.

Collins, R. (2013). The end of middleclass work: No more escapes. In I. Wallerstein, R. Collins, M. Mann, G. Derluguian, \& C. Calhoun (Eds.), Does capitalism have a future? (pp. 37-70). Oxford and New York: Oxford University Press.

Cosser, M. (2015). Differential pathways of South African students through higher education: Settling for less, but learning to like it (unpublished doctoral dissertation). University of the Witwatersrand, Johannesburg.

Council on Higher Education (2015). VitalStats: Public higher education 2013. Pretoria: Council on Higher Education. 
de Moura Castro, C. (1979). Vocational education and training of industrial labour in Brazil. International Labour Review, 18(5), 617-629.

de Moura Castro, C. (2000). Vocational training at the turn of the century. Frankfurt: Peter Lang.

Department of Higher Education and Training (2013). White Paper for post-school education and training. Building an expanded, effective and integrated post-school system. Pretoria: Department of Higher Education and Training, Republic of South Africa.

Department of Higher Education and Training (2014). Report of the ministerial committee for the review of the funding of universities. Pretoria: Department of Higher Education and Training.

Department of Higher Education and Training (2016). Submission to the Presidential Commission on the feasibility of fee-free higher education and training. Pretoria: Department of Higher Education and Training.

Department of Higher Education and Training (2018). Statistics on post-school education and training in South Africa 2015. Pretoria: South African Department of Higher Education and Training.

Foster, P. J. (1965). The vocational school fallacy in development planning. In J. Karabel \& A. H. Halsey (Eds.), Power and ideology in education. New York: Oxford University Press.

Fredriksen, B., \& Fossberg, C. H. (2014). The case for investing in secondary education in sub-Saharan Africa (SSA): Challenges and opportunities. International Review of Education, 60, 235-259.

Hall, P. A., \& Soskice, D. (Eds.). (2001). Varieties of capitalism: The institutional foundations of comparative advantage. Oxford: Oxford University Press.

Halliday, D. (2015). Private education, positional goods, and the arms race problem. Politics, Philosophy \& Economics, 15(2), 150-169.

Hazelkorn, E. (2012). Striving for excellence: Rankings and emerging societies. In D. Araya \& P. Marbert (Eds.), Emerging societies. London and New York: Routledge.

Hazelkorn, E. (2015). Rankings and the reshaping of higher education: The battle for world-class excellence. London, New York, and Shanghai: Palgrave Macmillan.

\|lie, S., \& Rose, P. (2016). Is equal access to higher education in South Asia and sub-Saharan Africa achievable by 2030 ? Higher Education, 72(4), 435-455.

Iverson, T., \& Stephens, J. D. (2008). Partisan politics, the welfare state, and three worlds of human capital formation. Comparative Political Studies, 45(4/5), 600-637.

Koen, C. (2006). Higher education and work: Setting a new research agenda (Occasional Paper 1). Cape Town: HSRC Press.

Languille, S. (2014). Secondary education expansion in Tanzania, 2004-2012: A political economy perspective (unpublished doctoral thesis). Department of Development Studies School of Oriental and African Studies University of London, London.

Lauder, H., Brown, P., \& Ashton, D. (2017). Theorizing skill formation in the global economy. In C. Warhurst, K. Mayhew, D. Finegold, \& J. Buchanan (Eds.), The Oxford handbook of skills and training (pp. 401-423). Oxford: Oxford University Press.

Livingstone, D. W. (2009). Education and jobs: Exploring the gaps. Toronto: University of Toronto Press.

Livingstone, D. W. (2012). Debunking the 'knowledge economy'. The limits of human capital theory. In D. W. Livingstone \& D. Guile (Eds.), The knowledge economy and lifelong learning. A Critical Reader. (pp. 85-116). Rotterdam: Sense.

Meyer, H.-D., St John, E. P., Chankseliani, M., \& Uribe, L. (Eds.). (2013). Fairness in access to higher education in a global perspective. Reconciling excellence, efficiency, and justice. Rotterdam: Sense.

Mohamed, S. (2017). Financialization of the South African economy. Development. https://doi.org/10.1057/ s41301-017-0065-1

Moore, R. (2004). Education and society: Issues and explorations in the sociology of education. Cambridge: Polity.

National Youth Development Agency (2015). National youth policy 2015-2020. Pretoria: The Presidency, Republic of South Africa.

NCHE. (1996). National Commission on Higher Education report: A framework for transformation. Pretoria: NCHE.

Nherera, C. M. (2000). Globalisation, qualifications and livelihoods: The case of Zimbabwe. Assessment in Education: Principles, Policy \& Practice, 7(3), 335-362. https://doi.org/10.1080/09695940050201343 


\section{Higher EDUCATION PATHWAYS}

Park, S.-Y. (2013). The political and institutional basis of Korea's skill formation system. Journal of Education and Work, 26(3), 291-308.

Piketty, T. (2014). Capital in the twenty-first century. (A. Goldhammer, Trans.). Cambridge, Massachusetts and London, England: The Belknap Press of Harvard University Press.

Pritchett, L. (2018). The politics of learning: Directions for future research (RISE-WP-18/020). Oxford and Washington, DC: Research on Improving Systems of Education.

Psacharopoulos, G. (1994). Returns to investment in education - a Global update. World Development Update, 22(9), 1325-1343.

Psacharopoulos, G., \& Patrinos, H. A. (2004). Returns to investment in education: A further update. Education Economics, 12(2), 111-134.

Rogan, M., \& Reynolds, J. (2016). Schooling inequality, higher education and the labour market: Evidence from a graduate tracer study in the Eastern Cape, South Africa. Development Southern Africa, 33(3), 343-360.

Rogan, M., Reynolds, J., du Plessis, U., Bally, R., \& Whitfield, K. (2015). Pathways through university and into the labour market. Report on a graduate tracer study from the Eastern Cape (Labour Market Information Project Report 18). Pretoria: Human Science Research Council.

Schofer, E., \& Meyer, J. W. (2005). The worldwide expansion of higher education in the twentieth century. American Sociological Review, 70, 898-920.

Shin, J. C., Toutkoushian, R. K., \& Teichler, U. (2011). The past, present, and future of university rankings. Dordrecht: Springer.

van Broekhuizen, H., van den Berg, S., \& Hofmeyr, H. (2016). Higher education access and outcomes for the 2008 national matric cohort (Stellenbosch Economic Working Papers: 16/16). Stellenbosch: Stellenbosch University.

van de Werfhorst, H. G. (2011). Skills, positional good or social closure? The role of education across structural-institutional labour market settings. Journal of Education and Work, 24(5), 521-528.

van den Berg, S. (2015). Funding university studies: Who benefits? (Kagisano No. 10. Student Funding.) (pp. 173-186). Pretoria: Council on Higher Education.

van den Berg, S., Burger, C., Burger, R., de Vos, M., du Rand, G., Gustafsson, M., ... von Fintel, D. (2011). Low quality education as a poverty trap. Stellenbosch University.

Vidovich, L., \& Slee, R. (2001). Bringing universities to account? Exploring some global and local policy tensions. Journal of Education Policy, 17(5), 431-453.

Warhurst, C., Mayhew, K., Finegold, D., \& Buchanan, J. (Eds.). (2017). The Oxford handbook of skills and training. Oxford: Oxford University Press.

Wolf, A. (2002). Does education matter? Myths about education and economic growth. London: Penguin.

Woodhall, M. (1987). Human capital concepts. In G. Psacharopoulos (Ed.), Economics of education: Research and studies (pp. 21-24). Oxford: Pergamon Press. 


\section{UNDERSTANDING THE ROLE OF UNIVERSITY GRADUATES IN SOCIETY: WHICH CONCEPTION OF PUBLIC GOOD?}

Rosemary Deem and Tristan McCowan

\section{Introduction}

This chapter examines how concepts of public good can be utilised to understand what happens to South African graduates after graduation, which at present is a quasi-marketised higher education system highly stratified by 'race' and social class. We draw mainly but not exclusively on concepts of public good developed in the Global North which are extensively present in the literature but also recognise the gradual emergence of Global South perspectives. One consequence of the introduction of substantial fees in public as well as private universities around the world is that taking a degree is now regarded in such countries as something which benefits only those who graduate and not society at large. That is, higher education has come to be perceived as a consumption good in which students position themselves primarily as consumers, not learners, particularly in subjects such as business and management (Naidoo, Shankar, \& Veer, 2011). However, as Budd (2016) notes in a recent comparison of undergraduate views in the UK (mainly market-driven) and Germany (feefree), it can be more complex than that and responses tend to be specific to particular higher education systems. This consumerist lens can shape attitudes to teaching, with responsibility for learning passed from student to teachers, and is oriented around enabling graduates to enter graduate jobs. Also, in theory, a degree raises life-time earnings, though the 'graduate premium' is decreasing as higher education continues to massify and formerly 'graduate' professional jobs become deskilled or even replaced by technology (Cooke, Watson, \& Webb, 2018; Naylor, Smith, \& Telhag, 2015). Furthermore, the kind of job obtained by graduates is heavily dependent on gender, ethnicity, social class and discipline studied, as well as the prestige of the institution attended (Behle et al., 2015; Macmillan, Tyler, \& 
Vignoles, 2015; Purcell \& Tzanakou 2016), rather than the quality of teaching. But more importantly, the 'higher education as consumption' debate tends to see degrees as having little or no wider social benefit beyond the student and their immediate families. Yet universities still train many professionals from doctors and nurses to teachers and social workers, many of whom choose their jobs in order to significantly benefit the wider society and who still mostly work in public-service professions.

The contestation in South African higher education, following the \#RhodesMustFall and \#FeesMustFall protests, is predicated on a fundamental difference of view about the purpose of higher education and its role in eradicating inequality. On the one hand, there are those who perceive that higher education should be a fundamental right for all, funded by the state, and that it should address historical and continuing injustices of recognition (political, cultural and epistemological). The widespread corruption and luxurious living of those in power in South Africa do little to support claims that funds could not be found to support such a free higher education system, given political will. On the other hand, some in government, university staff and society more broadly (e.g. Cloete, 2015), tend to see the idea of universal free higher education as overly idealistic, given the constraints on public finances. Furthermore, the latter group assert that taxpayer funding of free-of-charge places is really a subsidy for the privileged, given the social class-demographic currently accessing higher education. The demands for decolonisation are generally seen to be justified, but requiring time and regarded as a lower priority than other aims, such as producing employable graduates.

However, to a large extent, this deadlock is based on a misconception about higher education: namely, that the returns to higher education are predominantly, or even exclusively, private. In a system in which benefits of attending a higher education institution are solely for the individual, it would be perverse for the state to pay, particularly if this level of study was not related to either personhood or citizenship. A state concerned with equality of opportunity may, in line with this logic, intervene to ensure that all people have the potential to access these benefits, and mitigate the effects of a free market: but this intervention might be in the form of loans or a graduate tax, repaid in relation to the benefits directly gained (which implies an income threshold when repayment kicks in). Furthermore, it is problematic to assume that society is comprised of discrete individuals, with largely separate interests, or that the purpose and benefits of higher education are largely economic. This chapter takes these assumptions to task, arguing that a much broader role for the university in society needs to be acknowledged, alongside significant public benefits. On this basis, a proposal is put forward as to how the public role of higher education can be better acknowledged and supported, creating a virtuous cycle.

There has been substantial work on higher education and the public good (e.g. Marginson, 2011, 2018; Nixon, 2011; Singh, 2014; Walker \& McLean, 2013), and this chapter concurs with much of these previous analyses. The distinctive characteristic of the contribution presented in this chapter is the focus on graduates: rather than addressing the totality of functions of university (including research and community engagement), the chapter develops 
a more extensive analysis of the teaching function, which expresses itself in society through the work and lives of graduates. As will be outlined more fully, the analysis is relevant to reasoning around policies on student fees, but also to questions of access to higher education and the openness or otherwise of university curricula. Furthermore, there are implications for those conducting research on graduates, involving a broader set of concerns than might conventionally be included in graduate destination surveys and other forms of data collection.

Conceptualising and measuring the public good dimension of higher education is essential for current debates on international development. While higher education was largely absent from the Millennium Development Goals, the debates around the post-2015 agenda and the Sustainable Development Goals subsequently agreed give the sector a more prominent role (Boni, Lopez-Fogues, \& Walker, 2016; McCowan, 2016a; United Nations, 2015). However, in order for the rhetoric to become reality, a much clearer understanding of the benefits that universities provide to society (beyond the improvement of career opportunities for individuals) is needed.

This chapter presents an exploration and conceptual mapping of higher education and the public good, serving as a base for the subsequent chapters in this book in the application of the ideas to the specific challenges of contemporary South Africa. The chapter starts with a general outline of notions of public good, before assessing the positions of key theorists and finally drawing out the specific implications relevant to the contribution of graduates to society.

\section{The notion of public good}

A good in this sense is something of benefit to people, and a good is public when its benefit extends beyond the confines of an individual or group. Yet that is where the consensus ends. Contestations over public goods in higher education involve questions of how they manifest themselves, whether and how they can be produced by universities, which goods should be prioritised, and how funded and distributed. This section presents an initial foray into this complex area, presenting some basic conceptual distinctions and outlining the ideas of some of the key theorists in political philosophy and education rooted in the Western tradition.

The central divide in uses of the term public good is between countable and uncountable versions. The notion of a public good or public goods is used in economics, drawing on Samuelson's (1954) work, to signify those products or services that are non-rivalrous and nonexcludable and which cannot be used to generate profit. In relation to higher education, the clearest example is knowledge generated through research and scholarship: it is not possible to exclude certain people from the benefit of a mathematical theorem and use of it by one person does not detract from its use by another. In a singular uncountable sense, public good has a different meaning, signifying collective benefit, a state of affairs in the interests of all. Marginson's (2011) well-known account distinguishes between these two, and adds a third conceptualisation - that of the public sphere, drawing on Habermas's work, and historical reference points such as the English coffeehouses of the 17th and 18th centuries. The third 
conception of higher education as a public sphere also draws on Kant's ideas on critical reason, and the need for universities to maintain autonomy from the state in order to critically scrutinise society.

Global public goods are those public goods that are able to pass beyond national boundaries. Stiglitz (1999) provided an influential analysis of knowledge as a global public good, and the idea has also been applied to basic education by Menashy (2009). The idea of global public goods has generated significant interest in recent years, and has been endorsed by agencies such as the World Bank (2007), consequently seen by some as tarnished by their neoliberal associations.

A close correlate to the public good is the 'common good', a notion that has a long history in Western political philosophy, from Plato and Aristotle, through Rousseau, Adam Smith, to Rawls in the 20th century. In much of its usage, common good is equivalent to public good. However, there is a dimension of the common good that is distinctive, namely its indication of a shared space of collective construction - thereby having a procedural, in addition to a substantive, meaning. Deneulin and Townsend (2007, p. 25) state:

\section{[T] he common good is not the outcome of a collective action which makes everybody better off than if they acted individually, but is the good of that shared enterprise itself. It is the good of the community which comes into being in and through that enterprise.}

The idea of 'common good' has been applied to education to indicate a shared space for community construction (see UNESCO, 2015 and Locatelli, 2017) and serves as a critique of the individualist conception of public goods. Marginson (2016, p. 17) defines common good in relation to higher education as 'formation of common relationships and joint (collective) benefits in solidaristic social relations within a country', although how this would work in heavily divided societies such as South Africa is not fully addressed.

Linked to the idea of common good, but with distinct elements is the 'commons', an open, cooperative and non-hierarchical space, where people come to use a commonly owned resource. This idea has been extended from its original usage as shared agricultural land to include the cultural and political, thereby having extensive applications in education in relation to digital knowledge, online learning and open access courseware (Hess \& Ostrom, 2007).

Conceptions of public good, therefore, vary along two key axes: first, unitary versus multiple (the extent to which there is a single public good, or alternatively many goods from which individuals benefit); and second, substantive versus procedural (whether the public good is an outcome that is beneficial for all, or a process of collective sharing and construction).

\section{The 'public good' and higher education}

There have been many debates about the public good, some directly applicable to higher education. The concept of public in social science owes much to the work of Habermas in relation to his discussion of the public sphere, a space or area where people can openly 
discuss social problems, shape public opinion and consider how to solve societal challenges through political activity (Habermas, 1989, 1992). The notion of a 'public sphere' presupposes some kind of public authority such as the state, but also a civil society 'private' realm. The relevance of a 'public sphere' to universities lies partly in the possibility of universities acting as an arena for discussing public problems and the possible political actions that could be undertaken. Though clearly before the massification of higher education, higher education institutions were elite organisations offering little public access to anyone other than academics and (selected) students. In contemporary South Africa, students have used university campuses to debate whether the cost and content of higher education should change (Keet, Nel, \& Sattarzadeh, 2017; Pennington, Mokose, Smith, \& Kawanu, 2017), although the 2016 student uprisings were marked by sporadic acts of violence which were at odds with the more orderly and peaceful public debate Habermas imagined. In contemporary UK, some students have tried to exclude certain speakers from campuses (the 'No-platforming' approach). Furthermore, the English government counterterrorism 'Prevent' regime, designed to detect young people who may be attracted to terrorism (Ramsey, 2017), has threatened to identify and even arrest people who are simply studying controversial political topics at university, rather than identifying those at risk by absorbing 'Islamic State' ideology. Additionally, the use of 'trigger warnings' to students in class about potentially disturbing texts seems to suggest that rather than opening minds, universities might actually be closing them (Cares, Franklin, Fisher, \& Bostaph, 2018; Halberstam, 2017). A controversy was sparked in the UK in 2017 when a Conservative Member of Parliament, who was in favour of the UK leaving the European Union (Brexit), sent a letter to all universities demanding to know what their lecturers were teaching students about this topic. The recently formed Office for Students in England has, however, vowed to retain free speech in universities.

While Habermas traces the public sphere back to the 18th century, recent changes to societies, to what we understand as democracy, and the rise of social media and their role in politics (Fenton, 2016; Highfield, 2016) have significantly altered what might be understood as 'public' and 'private' spheres. Much of the conceptualisation of public good and even the notion of 'public' itself are relevant only to certain political conjunctures and climates. We face a world dealing with the implications of increased tensions in conflict-torn countries such as Syria, the instability of countries such as Turkey, with arrests and sacking of academics and journalists on the basis of flimsy charges and increasing numbers of violent terrorist incidents both in Turkey and in mainland Europe, as well as dramatically divided and new forms of political opinions (such as the alleged post-truth era), even in what had hitherto been described as stable democracies. The last was evidenced in the UK in June 2016 with the UK referendum vote to leave the EU and the election of Donald Trump as President of the United States in November 2016. Added to this, we have the student movement protests against fees and a colonial curriculum in South African higher education. This might lead us to ask whether the concept of public good can survive anywhere and if so whether it has much meaning left in it. 
Singh (2014), in questioning how useful the notion of public good is, contends that the very idea of public good is a precarious one, given that universities worldwide have adopted a corporate and sometimes overtly neoliberal approach (Harris, 2007), making any other radical change very challenging, both ideologically and practically. Nevertheless, Singh also indicates that there may be some mileage in continuing to resist what could be seen as public 'bad' and in striving for continued interventions in higher education focused on public good, however difficult that may be (Singh, 2014). Nixon (2011) argues that the concept of public good is critical to the future of universities, particularly in the post-2008 Eurozone financial crisis, as efforts to alleviate national public debt arising from the failures of the banking system denude public services and increase the likelihood (as has happened in many Western higher education systems) that there will be not just indirect payment for public services through taxation, but also direct payment of fees or charges.

Nixon identifies commercialisation (in universities and other organisations with an interest in higher education), commodification (of student learning, of knowledge, of degrees), competition (between institutions in the same system as well as in other systems) and classification (as in national and international league tables and rankings) as the new 'core' businesses of universities, all of which need addressing if higher education is to continue as a public good (Nixon, 2011). Nixon suggests that it is possible to resurrect the university as a base from which to foster human capability, reason and purpose. From the perspective of either the current student movement in South Africa or the high-fee-paying students in UK higher education systems, reason and purpose may be a long way from what they seek. But this idealistic view of what universities should be about perhaps requires a different type of university, one with a distinct but non-consumerist rationale, a student-centred approach and a more collaborative and collective organisational form than the standard Western university currently has (Boden, Ciancanelli, \& Wright, 2012; Wright, Greenwood, \& Boden, 2011), such as cooperatives or trust/partnership models. Though debates about this are starting to gain momentum, there are as yet few examples of such institutions. Those that do exist, such as Mondragon in the Spanish Basque country (a cooperative university) or Berea in the USA which charges no fees but expects students to work on campus, often have very specialist roots and purposes. In Latin America, these alternative forms of university organisation are more common, many drawing on Paulo Freire's ideas of conscientisation and dialogue, and Ivan Illich's ideas of deschooling (Esteva, 2007; McCowan, 2016b), although only some award degrees.

Other writers who have tackled the public good concept in respect of universities include Dill, Calhoun and Marginson. Dill and Calhoun explore the broader issues of how the idea of public good affects the university per se. Calhoun (2006) enquired into the challenges to the idea of public good that recent changes to universities such as greater privatisation, increases in social inequality and a change in how people access knowledge have brought about. He suggests we also need to ask of supposedly 'public' universities where all their funding comes from, who is on their governing bodies, who benefits from what those universities do and what the conditions are under which knowledge is produced and disseminated. In particular, Calhoun says we need to examine how and to what extent academics act as public intellectuals or translators of academic 
knowledge for the public, rather than for private organisations (Calhoun 2006). The answers for universities in the systems we are examining here suggest that the idea of 'public' universities may be under some strain. As Calhoun (2006, p. 8) expresses it:

\begin{abstract}
Two tacit Enlightenment premises have underwritten much thinking about the public roles of science and scholarship, teaching and research. They are that knowledge can be at once authoritative and democratic and can simultaneously inform expert instrumental use and public debate but ... the two dimensions could readily come into tension or even contradiction ... intensified inequalities and new patterns of instrumental evaluation of universities as providers of private goods are making the integration of the two ideals all but unsustainable.
\end{abstract}

There are also, Calhoun suggests, tensions between the best universities being highly selective, the use of public money to fund higher education and questions about access to knowledge for a wider social group and a broader set of societal purposes. Indeed, this is exactly what is one of the tensions in South Africa about the cost of higher education is focused upon. There is also another contemporary tension present, between 'expert' knowledge so derided by Brexit campaigners in the UK EU referendum and pro-Trump supporters in the American presidential election and other forms of knowledge or 'common sense':

On the one hand, higher education and research produce esoteric knowledge to be deployed by experts. On the other hand, they produce accessible knowledge to inform public discussion. (Calhoun, 2006 p .14)

Universities are valued both for their contribution to specialised excellent knowledge and for also being open and making knowledge publicly available. But these do not always sit well together, particularly when, as in South Africa, the current student unrest is raising questions about the nature of the knowledge produced in universities and in whose interests that knowledge is created and disseminated, given the highly unequal nature of South African society and the continuing sharp divide in life chances between black and white populations. Calhoun also points out that sometimes the private interests of academics and university students can get in the way of universities serving wider public purposes, a point not always made in the public good debate. Dill (2011) also concentrates on ideas of which public and for whose good and how universities can best be organised to ensure that teaching and research serve the public purpose. He advocates both a system of markets and a series of quality checks on teaching and research to ensure that universities work effectively and efficiently (Dill, 2011). This highly market-oriented view reflects exactly what Calhoun notes about the global dominance of an American model of higher education in which even private universities benefit significantly from public money. Dill suggests that it makes no difference whether universities are public, for-profit or not-for-profit, since all three can contribute to public good, but many would disagree with him. 
Finally, Marginson has made a number of contributions to the debate on higher education and public good (Marginson, 2007, 2011) but here for reasons of brevity the focus is on his most recent paper on the topic at the time of writing (Marginson, 2016). The approach taken on this occasion is to produce a synthesis of two different conceptions of the public good, an economic and a political definition, both of which look at the costs of public expenditure on public goods. Samuelson (1954) made a distinction between public non-market-produced and distributed goods and market-produced and market-distributed goods; only the former form part of public expenditure. Public goods are both non-rivalrous and non-excludable. Dewey's (1927) approach is based on political theory and a notion that 'public' relates to state ownership and control. Social transactions are seen by Dewey as 'public' when they have effects on people other than those directly involved and thus are relevant to the state. Dewey therefore included but distinguished between those activities controlled by the state and those not. Marginson develops a model utilising both approaches, developing an almost Parsonian (see Parsons, 1951) categorisation with four quadrants (civil society, social democracy, quasi markets and commercial markets) which he applies to both education and research, which perhaps does not fully recognise how research and teaching are linked. This diagram uses both state/non-state distinctions (vertical axis) and non-market/market distinctions (horizontal axis). Higher education activities are located in this diagram according to the extent that they are market-driven or non-market driven (derived from Samuelson's theory) and whether public (or not) in Dewey's sense of being of common relevance and state-controlled.

Figure 1 Public and private goods: The four variations

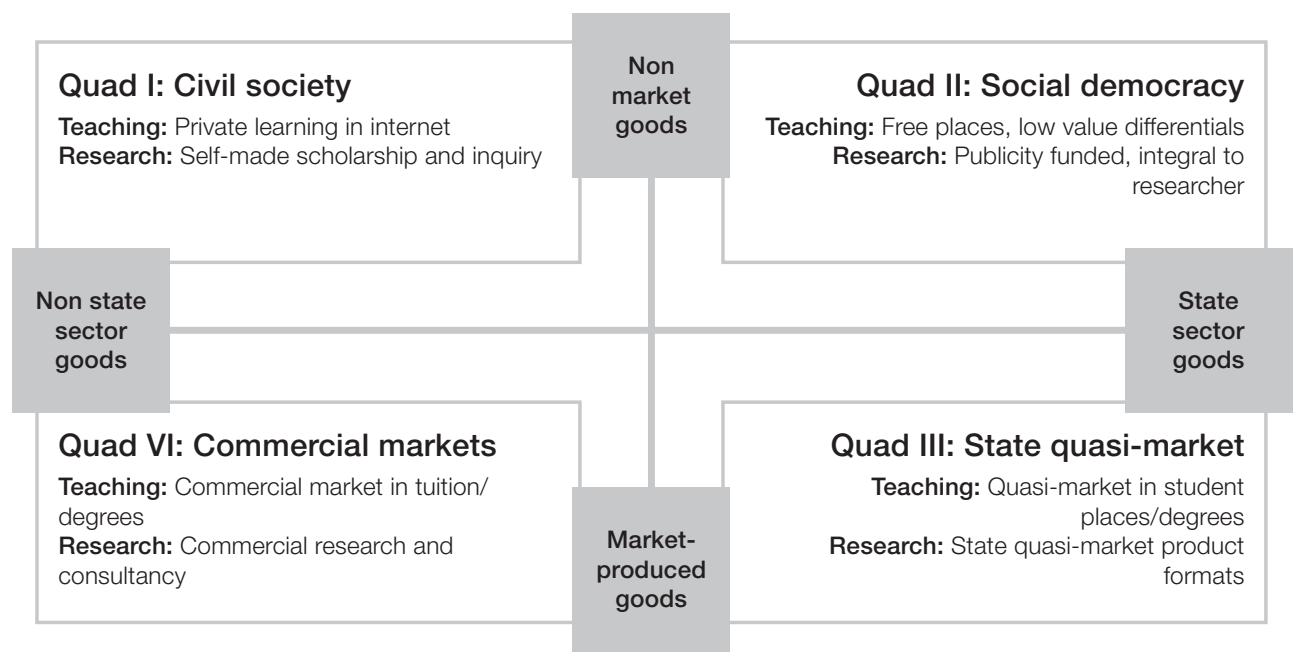

Note: State, institutions and individuals are active agents in 4 quadrants

Source: Marginson (2016, p. 10) 
The diagram is useful because it avoids some problems with defining public and state higher education activity and what counts as market-driven higher education, but just as Talcott Parsons (1951) sometimes had trouble putting everything into four boxes, this is also a challenge for Marginson's model. It does, however, serve to illustrate some of the problems that South Africa and countries such as Scotland (where higher education is still largely free) face as they try to decide which model/quadrant to fit into. Also, it poses some of the difficulties for universities and students of trying to have a fee-free regime, however desirable free higher education may seem in other ways: for example, under-funding of institutions, treating everyone the same whatever their socio-economic status and so giving more advantage to middle class white students, dealing with international students, funding research etc.

One possible problem with using these theories of public good is also that most of them have been developed in relation to the Global North and it may be more difficult to apply them to the Global South. There is emerging literature on non-Western conceptualisations of the public good, in particular Ubuntu in the southern African context, emphasising the interconnectedness of individuals (Murove, 2014; van der Walt, 2010), and buen vivir in Latin America, a holistic view of human society and natural environment (Brown \& McCowan, 2018; Villalba, 2013). Yet there is as yet limited literature on a distinctively African concept of public good in relation to higher education. Examples of developing thinking around this issue can be seen in Unterhalter, Allais, Howell, McCowan, Morley, Oanda, and Oketch (2017) and Walker (2018), as well as in contributions to this book.

We have already explained that this chapter is largely based on perspectives about the public good and universities developed in the Global North, drawing on an extensive literature. As the work underpinning the chapters in this book arises from networks which bring together both Northern and Southern perspectives in order to develop a deeper analysis of the current situation of universities and students, as well as the outcomes for black and white graduates in South Africa, this seems a justifiable approach. There are the beginnings of a Southern perspective in the work of some South African and other writers such as Walker and McLean (2013), Singh (2012), Leibowitz (2012) and others. However, we want to suggest that Northern and Southern perspectives are not completely separate from each other, particularly since some of those putting forward Southern perspectives have worked in both the Global North and Global South (Hall, 2012; Walker, 2012; Wisker, 2012). Also, the Southern approach put forward by the group of writers already mentioned focuses mainly on South Africa itself and is not always applicable even to the rest of Southern Africa, so it is itself far from comprehensive or all-encompassing.

The main elements of a Southern approach, as developed in the context of South Africa, include emphasising the pursuit of social justice and reduction of economic and cultural inequality, especially among young black people; encouraging wider participation of disadvantaged and under-represented groups in higher education; developing decolonialised and inclusive curricula across all disciplines and subjects in higher education (Walker, 2012); using non-oppressive pedagogies (Subreenuth, 2012) and assessment strategies; thinking about 
how to remove or reduce the dominance of privileged, relatively uncritical, middle class white academics (Leibowit \& Holgate, 2012); nurturing a holistic, critical and democratic approach to higher education; encouraging those entering the professions after university to be alert to de-emphasising privilege; tackling inequality and remaining critically reflective; stressing agency and participation and enabling an emphasis on reconciliation. Though some of these arise from the specific situation of post-apartheid South Africa, a number of these strategies are also found in the Global North, such as the current UK National Union of Students campaign on 'Why is my curriculum white?' (El Magd, 2016). Feminists and others have been discussing radical and anti-oppressive pedagogies since at least the 1970s. Critical thinking is heavily emphasised in many Global North universities. Intersectional inequalities are pursued in relation to both students and staff, though of course not by everyone. So perhaps instead of polarising Southern and Northern perspectives on what constitutes public good in higher education and employment contexts, both sets of protagonists would benefit from more of a sustained dialogue?

\section{Graduates' contributions to the public good}

A good deal has been written on the general contribution of the university to the public good, particularly through its research and community engagement functions. But what about the impact its teaching has, through the lives and actions of graduates? In relation to this question, Locatelli (2017) makes an important distinction between education as a public good and education for the public good, highlighting in turn its intrinsic and instrumental value. Education as a public good is close to the notion of a (human) right, referring to the opening of access to education to all. Yet education also has a role in promoting other goods - for example, employment or political participation - constituting an instrumental rather than a constitutive role in relation to the public good.

The ideas of equity of access are central to the first theme of this project, and are amply discussed in other chapters. This chapter has focused primarily on the second of these questions, higher education for the public good, and as outlined at the start, concentrates specifically on education (at undergraduate level), rather than research. Teaching and learning are commonly associated with the private benefits of higher education. Those graduating in medicine, for example, accrue private benefits in the form of a high salary and a rewarding livelihood. Nevertheless, as will be explored further below, there are also public benefits resulting from undergraduate education - in the case of a doctor, the positive impact on others' health.

The private benefits of the university go in substantial measure to its graduates in the form of increased earning potential, more fulfilling livelihoods and a range of other social, economic and cultural benefits. However, graduates also 'produce' or 'deliver' a range of public benefits for society and the communities with which they come into contact. These public goods will be outlined below, in relation to three principal areas: employment, citizenship and personal lives. 
Of course, we cannot claim that the actions and destinations of graduates are entirely the result of their university education - their values, skills and knowledge have been formed through a much longer trajectory of formal education, and fundamental influences from family, peer group and so forth in a complex process (Allais, 2017). Nevertheless, the learning obtained within the formally taught component of universities, as well as the significant learning experiences more broadly on the campus and beyond the gates of the institution, are substantial.

\section{Employment}

Improved employment opportunities are generally considered to be a primary good generated by higher education - indeed it is conceptualised exclusively in these terms by many. However, there is international concern that the increase in the percentage of young people entering higher education is decreasing the extent to which graduates earn a premium compared with non-graduates (Rospigliosi, Greener, Bourner, \& Sheehan, 2014). The UK Institute for Fiscal Studies (Blundell, Green, \& Jin, 2016) found that the gap between graduate and non-graduate salaries was reducing as the proportion of graduates increased (about 40\% of 23-29 year olds in the UK now have a degree; in 1993 it was 13\%). About 40\% of graduates in the UK workforce in 2013 worked in public services (Jenkins, 2013), but this is equivalent to only $16-17 \%$ of the workforce.

Changes in the labour market, along with the marketisation of the higher education system and consequent pressure placed on universities to attract prospective 'customers', have led to an increasing emphasis on employability in many countries' higher education systems. Higher education institutions now commonly provide a range of courses and other experiences for students to enhance their employability, and publicise their positive performance in terms of employment outcomes. However, there is a highly problematic side to these initiatives, in that they very often promote 'zero-sum game' employability - enhancing some students' opportunities without a net gain - they rarely include an ethical dimension, and serve regularly to reproduce and exacerbate initial inequalities (McCowan, 2015).

Nevertheless, there are other ways of looking at employment and work that go beyond these narrow, individualised and economistic conceptions. Part of the shift back towards higher education in international development has been the realisation that it is not possible to provide basic services (primary schools, healthcare etc.) without a robust higher education system, given the need to train professionals for these services. It is clear, therefore, that maintaining an adequate proportion of graduates going into public sector work is important, as well as attracting those with the commitment and capacity to make a significant contribution.

Furthermore, the values held by professionals are critically important. Allegiance to one's immediate employer with little sense of responsibility for other communities and the broader society is problematic, given the destructive impacts that many corporations have had on human populations and the natural environment. In this respect, the work of Melanie Walker 
and colleagues (e.g. Walker \& McLean, 2013) on 'pro-poor' and 'public good' professionals is important, analysing the extent to which the work of graduates such as engineers is oriented towards poverty reduction in highly unequal societies such as South Africa.

\section{Citizenship}

The civic dimension is startlingly absent from much discussion of higher education in contemporary times, and when it is included in policy, institutional mission statements and graduate attributes, there is often a disjuncture between rhetoric and practice (Ahier, Beck, \& Moore, 2003; Lange, 2012). Primary and secondary education may be more important in this regard, in part because of the importance of childhood and adolescence for formation of values, and also because of the almost universal enrolment at these levels in many countries. Nevertheless, higher education does have a strong impact on civic identity, practices and values, and indeed should be a place for strengthening of these attributes.

There is ample evidence of the influence of higher education in strengthening citizenship amongst graduates, including in Africa (Luescher-Mamashela, Kiiru, Mattes, Mwollontallima, Ng'ethe, \& Romo, 2011). Research in high-income countries has shown statistically significant associations between higher education and a range of positive attitudes and practices, for example in relation to diversity and democracy (Bynner, Dolton, Feinstein, Makepeace, Malmberg, \& Woods, 2003). Findings from a recent four-country study in subSaharan Africa found that higher education had a crucial role in fostering respect and dialogue between different racial/ethnic groups (McCowan et al., 2015). The Developmental Leadership Programme has produced innovative work in Ghana showing the role of secondary and higher education in forming ethical leaders committed to the public good (Jones, Jones, \& Ndaruhutse, 2014).

Nevertheless, there are limits to the role that higher education institutions can play in a direct sense in promoting active engaged citizenship, beyond developing criticality and a broad understanding of society (McCowan, 2012). To a large extent, political participation is learned through the act of participating. The essential experiential elements can be facilitated by universities, however, in providing opportunities for students to engage in volunteering, community work, campaigning and political debate.

\section{Personal life}

While divisions of public and private spheres can be problematic, we can also point to influences of higher education on the lives of graduates outside of their work and citizenship. In part, these factors make life richer and more meaningful for the graduates themselves, but they also serve to enrich the environment for those people around them. Most significant of the attempts to measure these broader impacts of higher education has been those of Walter McMahon (2009), who has tried to examine them on the basis of a study using data from the 
USA and other OECD countries, examining the non-market benefits which accrue to graduates as a result of their higher education experiences and knowledge. This approach has been much less used than the alternative economic valuing of degree level study in relation to lifetime earnings compared with non-graduates. McMahon estimates that if we factor in all the positive impacts of higher education that are not directly economic (e.g. lower crime rates etc.), then the returns to higher education are actually double the level conventionally estimated.

In the African context, and in many other locations, it is important also to acknowledge that individuals are part of family networks that provide support but also present responsibilities. The rewards of higher education are very often shared amongst extended family members, thereby problematising the individualistic discourse of returns to higher education. Gender also has a big influence in almost all countries but especially in the Global South, with 33 million girls of primary education age not in school (compared to 28 million boys), 9.7\% of the global cohort, with significantly higher rates in some regions (UNESCO, 2017). In all countries, graduate job access is mediated by gender and social class as well as institutional prestige (Behle et al., 2015; Purcell \& Tzanakou, 2016), even though globally, women undergraduates outnumber men, and particularly in non-STEM disciplines. This effect is exacerbated in the Global South where women graduates get lower paid jobs than men or are inveigled by family networks into returning home to carry out unpaid caring roles.

There are a number of ways, therefore, in which graduates use the precious opportunity to have studied at university to make contributions broadly to society - termed by some as 'paying it forward', as opposed to repaying a past debt solely to the creditor. Nevertheless, the public good impact of universities through graduates is not guaranteed, and depends on the nature and quality of the provision - hence the importance of looking at access, experiences and outcomes together, as shown in this research project.

\section{Some concluding comments}

The apparent conundrum of fees in higher education - that free higher education ends up subsidising the privileged, while introducing fees further excludes the less privileged - can be seen in a different light if we move away from viewing universities primarily or exclusively in terms of private returns. An investment in higher education is not just a gift for the individual students who are lucky enough to study there, but additionally a benefit for the whole of society. In this way, we can reconceptualise the repayment that graduates make for the investment that has been made in them in terms of their contribution to public good. Instead of repaying a monetary loan (one that may - depending on the system - debilitate them financially, never be repaid, deter them from studying at university in the first place, or provide distortions in relation to choice of area of study), the graduate would repay society through their subsequent work in the public benefit. A number of countries (e.g. Nigeria and Ghana) have institutionalised public service schemes of this type, through which graduates are obliged to one or more years after completion of their studies working 
in a publicly beneficial area. South Africa has also adopted this for certain health sciences professions (e.g. doctors, nurses and physiotherapists). However, it is not of course at all straight forward to assess what the economic and public benefits of higher education are (Allais, 2017) and how they might be better aligned. A public service work requirement immediately after graduation might provide some amelioration of this but alternatively might simply lead to some South African students leaving the country on graduation and others dragging their families into further poverty.

There are a range of questions which are still unanswered by this chapter and which regrettably we do not have space to fully engage with. These include the relationship between perspectives from the North and South: the extent to which conceptions of public good are culturally specific is a complex one, and further analyses would be needed to tease out, politically and epistemologically, what kinds of divergence there might be. There is also Dill's (2011) argument that any kind of higher education institution can promote the public good, even if it is for-profit. In the context of some higher education systems it is difficult to untangle the fact that, as in the USA, where Dill is based, for-profit and not-for-profit both end up with significant public funds. It seems highly likely, as argued by Marginson (2011), that any kind of HEI can produce both public and private goods, sometimes from the same programme (given the varying proportions of medics or dentists, for example, who go into the public compared with the private sector in different countries, including South Africa). Nevertheless, while private institutions can produce some public goods, the ability of for-profit ones to do so is inevitably curtailed by their requirements for making profit in cases of tensions or trade-offs. Furthermore, just assuming that public universities do prioritise and promote the public good is contestable. Even where this is so, there is almost certainly more that can be done to promote notions of public good in teaching through a more inclusive curriculum, and develop students' exposure to the public sphere in classes, in student societies and in extra-curricular activities such as volunteering, even prior to graduation.

\section{References}

Ahier, J., Beck, J., \& Moore, R. (2003). Graduate citizens? Issues of citizenship and higher education. London and New York: RoutledgeFalmer.

Allais, S. (2017). Towards measuring the economic value of higher education: Lessons from South Africa. Comparative Education, 50(1), 147-163.

Behle, H., Atfield, G., Elias, P., Gambin, L., Green, A., Hogarth, T., ..., Warhurst, C. (2015). Reassessing the employment outcomes of higher education. In J. Case \& J. Huisman (Eds.), Researching higher education (pp. 114-131). New York: Routledge.

Blundell, R., Green, D., \& Jin, W. (2016). The puzzle of graduate wages. Institute for Fiscal Studies, London. Retrieved from https://www.ifs.org.uk/uploads/publications/bns/bn185.pdf

Boden, R., Ciancanelli, P., \& Wright, S. (2012). Trust universities? Governance for post-capitalist futures. Journal of Co-operative Studies, 45(2), 16-24.

Boni, A., Lopez-Fogues, A., \& Walker, M. (2016). Higher education and the post 2015 agenda. A contribution from the human development approach. Journal of Global Ethics, 12(1), 17-28. 
Brown, E., \& McCowan, T. (2018). Forum. Buen vivir: Reimagining education and shifting paradigms. Compare: A Journal of Comparative and International Education, 48(2), 317-323

Budd, R. (2016). Undergraduate orientations towards higher education in Germany and England: Problematizing the notion of 'student as customer'. Higher Education, 73(1), 23-37.

Bynner, J., Dolton, P., Feinstein, L., Makepeace, G., Malmberg, L., \& Woods, L. (2003). Revisiting the benefits of higher education: A report by the Bedford Group for Lifecourse and Statistical Studies, Institute of Education. Bristol: Higher Education Funding Council for England.

Calhoun, C. (2006). The university and the public good. Thesis Eleven, 84(1), 7-43.

Cares, A. C., Franklin, C. A., Fisher, D., \& Bostaph, L. G. (2018). 'They were there for people who needed them': Student attitudes toward the use of trigger warnings in victimology classrooms. Journal of Criminal Justice Education, 1-24.

Cloete, N. (2015) The ideology of free higher education in South Africa: The poor, the rich and the missing Middle. Paper published by the Centre for Higher Education Trust (CHET).

Cooke, S., Watson, D., \& Webb, R. (2018). 'It's just not worth a damn!' Investigating perceptions of the value in attending university. Studies in Higher Education, 1-12.

Deneulin, S., \& Townsend, N. (2007). Public goods, global public goods and the common good, International Journal of Social Economics, 34(1/2), 19-36.

Dewey, J. (1927). The public and its problems. New York: H. Holt. Reprinted by Ohio University Press.

Dill, D. D. (2011). Assuring the public good in higher education: Essential framework conditions and academic values. In SRHE seminar on higher education as a public good: Critical perspectives, New College, Oxford, July (pp. 4-5).

El Magd, N. A. (2016). Why is my curriculum white? - Decolonising the academy. NUS Connect. Retrieved from https://www.nusconnect.org.uk/articles/why-is-my-curriculum-white-decolonising-the-academy

Esteva, G. (2007, November). Reclaiming our freedom to learn. Yes Magazine.

Fenton, N. (2016). Left out? Digital media, radical politics and social change. Information, Communication \& Society, 19(3), 346-361.

Habermas, J. (1989). The structural transformation of the public sphere: An inquiry into a category of bourgeois society. Cambridge: Polity Press.

Habermas, J. (1992). Further reflections on the public sphere. In C. Calhoun (Ed.), Habermas and the public sphere. Cambridge, MA: MIT Press.

Halberstam, J. (2017). Trigger happy: From content warning to censorship. Signs, 42(2), 535-542.

Hall, M. (2012). Public good and private benefits of higher education. In B. Leibowitz (Ed.), Higher education for the public good - views from the south (pp. 17-30). Stellenbosch: Sun Media.

Harris, S. (2007). The governance of education in neoliberal times. London: Continuum.

Hess, C., \& Ostrom, E. (2007). Understanding knowledge as a commons: From theory to practice. Cambridge, MA: MIT Press.

Highfield, T. (2016). Social media and everyday politics. Malden, MA: Polity.

Jenkins, J. (2013). Graduates in the UK labour market: 2013. London: City Office for National Statistics.

Jones, A., Jones, C., \& Ndaruhutse, S. (2014). Higher education and developmental leadership: The case of Ghana. Development Leadership Programme, Research Paper 26. Retrieved from http://publications. dlprog.org/Higher\%20Education\%20and\%20Developmental\%20Leadership\%20-\%20The\%20Case\%20 of\%20Ghana.pdf

Keet, A., Nel, W., \& Sattarzadeh, S. D. (2017). Retreating rights : Human rights, pre-theoretical praxes and student activism in South African universities. Southern African Journal of Higher Education, 31(6), 79-95.

Lange, E. (2012). The public purposes of the university: A historical view, 1995-2010. In B. Leibowitz (Ed.), Higher education for the public good - views from the south (pp. 45-57). Stellenbosch: Sun Media.

Leibowitz, B. (2012). Introduction: Reflections on higher education and the public good. In B. Leibowitz (Ed.), Higher education for the public good - views from the south (pp. xviii-xxvii). Stellenbosch: Sun Media.

Leibowitz, B., \& Holgate, D. (2012). Critical professionalism: A lecturer attribute for troubled times. In B. Leibowitz (Ed.), Higher education for the public good - views from the south (pp. 165-178). Stellenbosch: Sun Media. 


\section{HigheR EDUCATION PATHWAYS}

Locatelli, R. (2017). Education as a public and common good: Revisiting the role of the state in a context of growing marketisation (unpublished doctoral dissertation). University of Bergamo.

Luescher-Mamashela, T. M., Kiiru, S., Mattes, R., Mwollo-ntallima, A., Ng'ethe, N., \& Romo, M. (2011). The university in Africa and democratic citizenship: Hothouse or training ground? Wynberg: Centre for Higher Education Transformation.

Macmillan, L., Tyler, C., \& Vignoles, A. (2015). Who gets the top jobs? The role of family background and networks in recent graduates' access to high-status professions. Journal of Social Policy, 44(3), 487-515.

Marginson, S. (2007). The public/private divide in higher education: A global revision. Higher Education, 53(3), 307-333.

Marginson, S. (2011). Higher education and public good. Higher Education Quarterly, 65(4), 411-433.

Marginson, S. (2016). Higher education and the common good. Melbourne: Melbourne University Press.

Marginson, S. (2018). Public/private in higher education: A synthesis of economic and political approaches. Studies in Higher Education, 43(2), 322-337.

McCowan, T. (2012). Opening spaces for citizenship in higher education: Three initiatives in English universities. Studies in Higher Education, 37(1), 51-67.

McCowan, T. (2015). Should universities promote employability? Theory and Research in Education, 13(3), 267-285.

McCowan, T. (2016a). Universities and the post-2015 development agenda: An analytical framework. Higher Education, 72(4), 505-523.

McCowan, T. (2016b). Forging radical alternatives in higher education: The case of Brazil. Other Education, 5(2), 196-220.

McCowan, T., Ananga, E., Oanda, I., Sifuna, D., Ongwenyi, Z., Adedeji, S., ... James, Z. (2015) Students in the driving seat. British Council. Retrieved from https://www.britishcouncil.org/sites/default/files/2.5_studentsin-the-driving-seat_report_overview.pdf

McMahon, W. W. (2009). Higher learning, greater good: The private and social benefits of higher education. Baltimore: Johns Hopkins Press.

Menashy, F. (2009). Education as a global public good: The applicability and implications of a framework. Globalisation, Societies and Education, 7(3), 307-320.

Murove, M. F. (2014). Ubuntu. Diogenes, 59(3-4), 36-47.

Naidoo, R., Shankar, A., \& Veer, E. (2011). The consumerist turn in higher education: Policy aspirations and outcomes. Journal of Marketing Management, 27(11-12), 1142-1162.

Naylor, R., Smith, J., \& Telhag, S. (2015). Graduate returns, degree class premia and higher education expansion in the UK. Oxford Economic Papers, 68(2), 525-545.

Nixon, J. (2011). Higher education and the public good: Imagining the university. London, New York: Continuum.

Parsons, T. (1951). The social system. New York: Routledge and Kegan Paul.

Pennington, A., Mokose, M., Smith, M. N., \& Kawanu, Z. (2017). Neoliberalism and the crisis in higher education in South Africa: Student voice. New Agenda: South African Journal of Social and Economic Policy, 64(March), 28-32.

Purcell, K., \& Tzanakou, C. (2016). Life after higher education: The diversity of opportunities and obstacles in a changing graduate labour market. In J. Cote \& J. Furlong (Eds.) Handbook of the sociology of higher education. London: Routledge.

Ramsey, P. (2017). Is prevent a safe space? Education, Citizenship and Social Justice, 12(2), 143-158.

Rospigliosi, A. P., Greener, S., Bourner, T., \& Sheehan, M. (2014). Human capital or signalling, unpacking the graduate premium. International Journal of Social Economics, 41(5), 420-432.

Samuelson, P. (1954). The pure theory of public expenditure. Review of Economics and Statistics, 36(4), 387-389.

Singh, M. (2012). Re-inserting the 'public good' into higher education transformation. In B. Leibowitz (Ed.), Higher education for the public good - views from the south (pp. 1-16). Stellenbosch: Sun Media. 
Singh, M. (2014). Higher education and the public good: Precarious potential. In R. Munck, L. Mcllrath, B. Hall, \& R. Tandon (Eds.), Higher education and community-based research: Creating a global vision (pp. 199-216). New York: Palgrave Macmillan.

Subreenuth, S. (2012). Disrupting mainstream discourse in teacher education through decolonising pedagogies. In B. Leibowitz (Ed.), Higher education for the public good - views from the south (pp. 127-138). Stellenbosch: Sun Media.

Stiglitz, J. E. (1999). Knowledge as a global public good. Global Public Goods, 1(9), 308-326.

UNESCO (2015). Rethinking education. Towards a global common good? Paris: UNESCO.

UNESCO (2017). Accountability in education: Meeting our commitments. (Global Education Monitoring Report 2017-18). Paris: UNESCO.

United Nations (2015). Transforming our world: The 2030 agenda for sustainable development. Retrieved from https://sustainabledevelopment.un.org/post2015/transformingourworld

Unterhalter, E., Allais, S., Howell, C., McCowan, T., Morley, L., Oanda, I., \& Oketch, M. (2017). Higher education and the public good: Concepts, challenges and complexities in Africa. Working Paper on Higher Education and the Public Good in Four African Countries.

van der Walt, J. L. (2010). Ubuntugogy for the 21st century. Journal of Third World Studies, 27, 249-266.

Villalba, U. (2013). Buen Vivir vs development: A paradigm shift in the Andes? Third World Quarterly, 34(8), 1427-1442.

Walker, M. (2012). The role of curriculum: Advancing capabilities and functionings for a public-good education. In B. Leibowitz (Ed.), Higher education for the public good - views from the south (pp. 74-86). Stellenbosch: Sun Media.

Walker, M. (2018). Dimensions of higher education and the public good in South Africa. Higher Education, DOI 10.1007/s10734-017-0225-y

Walker, M., \& McLean, M. (2013). Professional education, capabilities and the public good: The role of universities in promoting human development. Routledge.

Wisker, G. (2012). Educational development for the public good. In B. Leibowitz (Ed.), Higher education for the public good - views from the south (pp. 203-216). Stellenbosch: Sun Media.

World Bank (2007). Global public goods: A framework for the role of the World Bank. In Global Programs and Partnerships. Washington, DC: World Bank.

Wright, S., Greenwood, D., \& Boden, R. (2011). Report on a field visit to Mondragón University: A cooperative experience/experiment. Retrieved from devsoc.cals.cornell.edu/sites/devsoc.cals.cornell.edu/files/ shared/Wright\%20Greenwood\%20and\%20Boden\%20Report\%20on\%20a\%20field\%20vist\%20to\%20 Mondragón\%20University.pdf 

PART B

\section{WAYS OF UNDERSTANDING}





\title{
CHAPTER 6
}

\section{A MULTI-DIMENSIONAL APPROACH TO FAIR ACCESS}

\author{
Melanie Walker
}

The goal in this chapter is to sketch the access terrain in order to understand what may be missing in relation to equity and to research so that we can work towards university access opportunities and outcomes which are more just. It is proposed that these are evaluated in terms of the actual lives that persons are able to choose by advancing their valued opportunities (their human capabilities), their achievements and their agency freedoms (Sen, 2009). The chapter notes the strong correlation between socio-economic status and educational outcomes (Moses, van der Berg, \& Rich, 2017), suggesting inadequate opportunities for many to shape their own futures. Yet who goes to university, who benefits and whose social mobility is advanced are important public-good questions in a highly unequal country. In 2015, the median income for people with a degree was ZAR 17000 per month compared to ZAR 3000 for those without a degree (Makgetla, 2018), while the unemployment rate of graduates with a degree is around $6 \%$ compared to $27 \%$ for other adults (Makgetla, 2018). Indeed, at the time of writing, South Africa was reported to have the highest rates of private return from higher education (Montenegro \& Patrinos, 2014). If we understand higher education in South Africa as benefitting both a person but also her family, and if we understand higher education as advancing social mobility for low-income families, then access is a rather crucial first step in this direction.

If social mobility opportunities are not available to all, then who actually gets in to higher education and to which university and programme is a question for policy and practice. The universities and programmes into which students are admitted, the structural constraints which get in the way - despite the heroic efforts some low-income students make in the face of massive adversity (see for example reporting by Nombembe, Nair, \& Macanda, 2018) require critical scrutiny and debate.

\section{Sketching research on access}

Space allows for only a brief sketch of the considerable body of international research on access which is relevant to South Africa. This research has investigated how working class and middle 
class students make different choices about higher education (Reay, David, \& Ball, 2005), revealing a complex intersection of personal aspirations, parental education and economic capital (Hart, 2013). Often individual aspirations are reduced to fit what someone (or their school teachers) thinks is suitable for 'a person like me'. Anders (2012) found that a greater proportion of people in the top income quartile in the UK apply to university, compared to those in the bottom quintile. Ball, Maguire, and Macrae (2002) suggest that in families where one or more members have been to university, it is assumed that others will follow; this effect of parental level of education is also confirmed by Oliveira and Zanchi (2004). More broadly, and even accepting that there are wide variations among the club of well-off countries, the OECD (2013, p. 3) reported that amongst its member countries, students from a more educated family are 'almost twice' as likely to attend university than their peers.

Educational stratification is not only imposed upon the student but also may be 'selfimposed', with young people making choices that are similar to those of their peers and their families, including choosing more familiar institutions - generally lower status universities for working class students and lower status degree programmes, while middle and upper class students choose higher status universities (Reay, Crozier, \& Clayton, 2009). Reay et al. (2005, p. 85) thus comment that for a majority of 'non-traditional' students, choosing to go to university and to which university 'involve[s] either a process of finding out what you cannot have, what is not open for negotiation and then looking at the few options left, or a process of self-exclusion'. They argue that what appears to be an individual choice is 'a social process which is structured and structuring' (p. 160), informed by one's social position and educational background. For many, this means only one choice rather than many possible pathways. Spiegler and Bednarek (2013) further affirm that decisions about which subjects to study at school, ${ }^{6}$ what degree to aim for, which universities to apply to, and so on are influenced by social class background and the type of secondary school attended.

Finally, universities may also themselves look for students who are the 'best fit'. Pitman (2015), using Australia as the context, considers university status as the elephant in the higher education room, arguing that the better off are simply more skilled at playing the access and admissions game, loading the dice with their own cultural capital. University status must then be factored into access policies for a 'more democratic distribution of its benefits' (Pitman, 2015, p. 290 and see Stevens, 2007).

\section{What do we mean by access?}

In the South Africa's case, access is understood in this chapter as getting into university across four key stages which are not necessarily sequential: 1) Grade 12 marks and subjects; 2) choosing a university, including getting information from family, friends, schools, teachers, the

6 In South Africa students must select their Grade 12 subjects at the end of Grade 9 and will do so under varying conditions of agency and equality. The subjects they select will shape possible university options, for example if they take mathematics literacy this will rule out a number of degree options. 
media; 3) being accepted into a programme; and 4) registration, with access to funding. ${ }^{7}$ These moments may be more or less agentic, more or less secure or unstable, and more or less equitable. They may be serendipitous or carefully planned and aspirations to go to university may be formed early or quite late (when Grade 12 results suggest this possibility) (Walker, forthcoming; also see Walker \& Fongwa, 2017). The end point is achievement of a university place and not just the formal opportunity.

Understanding how these moments work is helped by McCowan's (2016) three dimensions of equity: availability (number of places), accessibility (can the student actually take up a place, are they selected and admitted and do they have funding), and horizontality (to which university does a student get access, high status, low status, rural, urban, and so on), ${ }^{8}$ shaped by wider socio-economic variables). In short: is there is a place, is it accessible, and which university and programme is the student able to access? In practice there is considerable overlap between the three dimensions.

Achieving access is further helped if we consider the capability approach (Robeyns, 2017). The approach points to the effect of: 1) (adequate) resources as the means to achieve (income, wealth, schooling and so on); and 2) each person's set of conversion factors (structural conditions such as race, gender and class, and so on) which shape the freedoms to achieve access - what we can call the person's capability set and her functioning. Thus we consider both the achieved outcomes but also the opportunities to achieve. Based on research in the Free State, Wilson-Strydom (2015) has proposed an access capability set which includes: practical reason; knowledge and imagination; learning disposition; social relations and social networks; respect, dignity and recognition; emotional health and reflexivity; and, language competence and confidence. This would sit inside a capability set 'box' emerging from personal conversion factors, preference formation, character, and so forth (see Robeyns, 2017). Access is thus shaped by contextual and conversion variables, working through the biographies of students and the intersections of structures.

Choosing higher education, choosing a university and choosing a programme of study are then not simply personal decisions but sit at the intersection of the person, her schooling, her family, university policy and actions and government policy, and in turn intersect across McCowan's three equity dimensions. How these factors intersect will either give the green light for genuine choice in access (achieving a place of choice at the university of choice), or the red light for exclusion or constrained choices. Given the importance of access it is surprising that there is limited research, for example on secondary school actions, on how universities engage

7 In South Africa, universities require an upfront registration fee, usually around $10 \%$ of the total fee. Students can register if they can find this money, which is why we see registration rather than only the offer of a place as the end point of getting in. Progressing to the following year requires that students pay the balance of their fees or they are 'deregistered' and exam results are withheld. Free (government funded) university education fees for students from low-income families will reshape the access terrain, at least for now, and only for first-time entering students from 2018. In itself it does not increase the number of available places or smooth out prior inequalities that affect choice or even eliminate accessibility and horizontality, given that only fees will be covered by government, leaving a student and her family to cover all the other costs of higher education.

8 The DHET Green Paper (2012, p. 11) notes persistent apartheid effects: 'While our leading universities are internationally respected, our historically black universities continue to face severe financial, human, infrastructure, and other resource constraints.' 
with schools to enable fair access, or on how race intersects with social class to influence educational access, patterns of educational stratification, and patterns of advantage and disadvantage. We also need more research on how universities, and which universities, make a difference with regards to fair access. Overall, how do our universities enable or constrain the development of the public good in relation to access? What are the policy implications and policy levers that then follow? We need to know more about selection and admissions processes at the university end and choosing processes at the individual end across different types of schools. We know that students who get in have high aspirations, but we do not know about students who do not make it and what their aspiration pathways look like.

Given this gap, the paper suggests a conceptual framing of equity dimensions, capability formation and the functioning achievement of a university place, and maps this over what we do know.

\section{Equity dimensions}

\section{Availability}

Lack of places for all who qualify is an availability constraint. In 2018, South Africa's 26 public universities had 208308 first-year places for a total of 153610 students with bachelors passes, which allow entry to a degree, and 161133 with diploma passes allowing entry to a higher education diploma programme usually in a comprehensive university of technology (Africa Check, 2018). Thus more qualify than there are available places. For instance, in 2017 to take just two urban universities, the University of Johannesburg (a comprehensive university offering degrees and diplomas) had 135500 applications for 10500 first year places, while the University of Cape Town (an elite research and teaching university) had 26000 applications for 4200 places (Fengu, 2017). In short, as things stand currently in 2018 , not every student that graduates with a bachelor or diploma pass will be able to go to university; there are simply not enough places. Of course where spaces are scarce, availability will articulate with accessibility factors - better qualified candidates will stand a better chance of getting in. According to the 2008 cohort study by van Broekhuizen, van der Berg, and Hofmeyr (2016) approximately $33.3 \%$ of Grade 12 students who qualify never enrol in university in the next six years. Of these around $33.3 \%$ attended quintile one to three schools $s^{9}$ and around half were black (African). ${ }^{10}$ The point here is that many students who qualify do not enter university. We do not know if this is because there are insufficient places or something else.

9 In South Africa schools are divided into five quintiles as a rough but imperfect proxy for SES. Quintiles one to three do not charge fees, while quintiles four and five (former white schools) do. On the whole quality is low and uneven in quintile one to three schools.

10 Racial terms remain problematic in South Africa. African is used in official higher education statistics reporting. The paper uses black to mean African students. 
National policy planning certainly has an effect on availability. According to the Department of Higher Education and Training (DHET, 2016), the enrolment planning process includes bilateral discussions between DHET and each university in order to arrive at agreed upon funded student numbers. Institutional projections and targets are decided according to 'a strategy of differentiated growth for each university in line with their institutional capacity' (DHET; 2016, p. 5). A 2\% deviation is allowed. While it is recognised that the higher education system needs to expand and enable access, over- or under enrolment of students in relation to the agreed-upon target results in funding penalties for universities. DHET further noted, however, that while targets are being exceeded in the undergraduate degree, universities were not providing access at undergraduate certificate and diploma levels, even though half of qualifying applicants can only enter diploma and certificate programmes. Nor has there been sufficient focus on enabling access through distance education programmes. In 2014 only ten universities enrolled students via distance mode and this resulted in a deviation of just under $10 \%$ from the projected DHET number.

Nonetheless, overall, there is not a place for every student who qualifies and who wants to go to university and both policy-makers and universities could do more. Moreover, wanting to go and being able to choose to go may not coincide for all students. Not wanting to go, even if spaces are available, cannot be assumed to be a genuine choice if conditions do not support aspirations to access higher education.

At the same time post-1994 government policy has effectively widened access by its focus on redress, while previous laws which prevented black students from accessing historically white universities formally fell away. Headcount numbers of black students continue to steadily increase. For example, from 640442 out of 938200 students in 2011 to 701482 out of 975837 in 2016 (CHE, 2016, p. 3). However, without a socio-economic measure we do not know if participation is widening for low-income students, and we do not yet know the effect for these students of fees-free higher education. Participation rate (or Gross Enrolment Ratios, GER) as a total headcount enrolment over the national population of 20-24 years old has increased slightly for African students from 14\% to 16\%, but remains much higher for white students at 50\% in 2016 (although falling from 57\% in 2011) (CHE, 2016, p. 6). Thus participation, and we can assume access, is uneven based on the numbers.

Overall, then, along McCowan's availability dimension the picture is mixed.

\section{Accessibility}

From what we know accessibility is shaped by multiple intersecting factors, each of which may constrain or enable on its own or working with others. According to van Broekhuizen et al. (2016) these include Grade 12 attainment (including gateway subjects such as Mathematics and English as first language; quintile of school attended; quality of school; relative wealth of the school; structures of race, gender, age; and geography. From this study we know that there are huge differences in Grade 12 pass rates across race groups. 
Only $57 \%$ of black learners passed the 2008 NSC exams, compared with $99 \%$ of whites. Among whites who passed Grade 12, 71\% achieved bachelor passes (for degree entry), but in the case of black learners this was only $24 \%$. Their evidence shows that the best schools significantly enhance accessibility. Thus the proportion of learners from quintile five schools who passed Grade 12 is more than double (93\%) that of learners from quintile one schools (46\%). While only about $12 \%$ of learners from quintile one to three schools enrolled in undergraduate programmes at some point between 2009 and 2014, the corresponding proportions for learners from quintile 4 and 5 schools were roughly $24 \%$ and $45 \%$ respectively. Further, van Broekhuizen et. al.'s wealth index for each school confirms that university access and completion are positively associated with the wealth of the schools that learners attended. They found that increases in this wealth index are more closely associated with increases in university access rates. Age and race also affects access: whether or not learners are of the appropriate age in Grade 12 (and this is related to socioeconomic factors and school quality).

Moreover, they point to a regional dividend and rural 'gap' to accessibility. Van Broekhuizen et. al. (2016) show that the proportion of learners achieving an average grade of above $50 \%$ in Grade 12 varied widely: roughly 40\% for the Western Cape, less than 20\% for both Limpopo and the Eastern Cape, both provinces with large rural populations. The provincial differences in the proportions of learners who achieved an average Grade 12 grade of $60 \%$ or above are just as striking: roughly $21 \%$ of learners from the Western Cape achieved this grade, while only about $6 \%$ and $7 \%$ of learners from Limpopo and Eastern Cape did so. Given these provincial differences in Grade 12 performance, one might also expect provincial differences in university access and success. Thus, while Gauteng and the Western Cape have the highest access rates, Limpopo and Mpumalanga have the lowest.

Focusing on gender, van Broekhuizen and Spaull (2017) show that girls and women are doing better educationally than boys and men. Based on the 2008 Grade 12 cohort, they found a female advantage that continued to grow at each stage of the higher education process. Relative to their male counterparts, they found that $27 \%$ more females qualified for university, and $34 \%$ more enrolled in university than male learners. After controlling for pre-university achievement, females are $20 \%$ more likely to access university and graduate with an undergraduate degree in six years than are their male counterparts. They also point out that of 100 white female learners who passed Grade 12, 50\% enter university. However, in quintile one schools only $2 \%$ of female Grade 12 students went to university and graduated with a degree, compared to $24 \%$ from quintile five schools. While overall there is a persistent numerical female advantage, the poorest females are the only group not to exhibit an advantage in accessing university. They therefore acknowledge how race and wealth intersect to act either as barriers or opportunities to accessibility, especially affecting low-income black girls.

In South Africa there is not much in the way of research on alternative pathways at the access end, nor on access articulations between technical and vocational colleges and universities - particularly universities of technology. Much of the work in the area of accessing university 
within the South African context has been done only after students get into university through academic development $(\mathrm{AD})$ programmes and extended programmes which stretch the curriculum over an additional year for students with lower entry points. For example, at the University of the Free State the extended programme in commerce is compulsory for students with an AP score of between 25 and 29, and Grade 12 Mathematics at least at Level 3 (40\%), compared to a minimum of 30 points for the mainstream programme. The University's Access Programme (UAP) admits students with an AP score (see Table 2) lower than that needed for the extended route, often as low as 19 AP points. On successful completion, the student moves into the relevant extended degree. Such access programmes seem to depend on the universities themselves and the UAP is not funded by government. One study of nine extended programmes (Shay, Clarence-Fincham, \& Wolff, 2016, p. iii) did find that these 'have played a significant role in terms of providing access ... to South Africa's most talented and capable but underprepared black students', suggesting that the availability and accessibility (students need to know that the UAP, for example, exists) of alternative pathways might widen access.

Significantly shaping accessibility is the issue of funding, of which fees are a major dimension (see Chapter 3). In the face of declining government funding, which has dropped by about one third in spending per student since 1997 (Makgetla, 2018), South African universities regularly increase tuition fees to compensate. The effect of fees on choice has been brought into sharp relief and will be shaped, we can assume, by the introduction of fees-free higher education for families who qualify. Nonetheless, the new policy does not apply to existing students nor to students whose family income is slightly above the threshold, but who may not be especially well-off.

Table 1 Sample of university fees

\begin{tabular}{l|c|c|c|c|c}
\hline University & BA & BCom & BSc & LLB & BEng \\
\hline University of Cape Town & ZAR 53 440 & ZAR 64 890 & ZAR 58 400 & ZAR 54 350 & ZAR 61 220 \\
\hline University of the Witwatersrand & ZAR 44 890 & ZAR 46 795 & ZAR 47 920 & ZAR 43 640 & ZAR 61 810 \\
\hline Stellenbosch University & ZAR 39 696 & ZAR 41 030 & ZAR 48 096 & ZAR 47 270 & ZAR 55 296 \\
\hline University of Pretoria* & ZAR 36 000 & ZAR 42 000 & ZAR 44 000 & ZAR 37 000 & ZAR 46 000 \\
(ZAR 38 880) & (ZAR 45 360) & (ZAR 47 520) & (ZAR 39 960) & (ZAR 49 680) \\
\hline University of Johannesburg* & ZAR 36 650 & ZAR 37 500 & ZAR 44 000 & ZAR 34 150 & ZAR 41 600 \\
(ZAR 39 580) & (ZAR 40 500) & (ZAR 47 520) & (ZAR 36 880) & (ZAR 44 930) \\
\hline North-West University & ZAR 39 300 & ZAR 39 300 & ZAR 42 600 & ZAR 46 100 & ZAR 49 900 \\
\hline
\end{tabular}

* 2017 fees with adjustments. The fees in parentheses represent the indicative $8 \%$ increase on 2017 rates for students whose household income is above ZAR 600000 per annum, for UP and UJ.

Source: https://businesstech.co.za/news/lifestyle/219191/university-fees-2018-how-much-it-costs-to-studyin-south-africal 
To put this in context, in 2015 average monthly earnings were ZAR 16506 - or less than half the required fees even for the cheaper programmes, while a skilled worker earned an average of ZAR 35000 (Institute for Race Relations, 2016, pp. 305-307). Many poor students may come from families which are dependent on social grants and these are low, for example ZAR 1500 per month for the state pension and ZAR 380 per month for the child grant. While they will no longer pay fees, money must still be found to fund accommodation, food, books, technology and transport. In poor families there may be no discretionary funding and the hardships from home will travel with students in completing their access journeys. At even earlier stages, money has to be found to attend an open day, or borrowed from a sympathetic teacher for a bus to get to the university, for example. Family wealth still matters.

Information wealth matters too. We know from international research that university access is strongly shaped by the right kind of information from the right people, by good schooling and supportive teachers who form and encourage higher education aspirations, and by families who know about higher education. Availability of information is needed in order to apply for a place at university. While the information on university websites regarding application procedures, admission requirements, tuition fees, bursaries and funding is easily accessible - if you have a smart phone or internet access - there appears to be less information about university open days, and even less regarding what respective universities are doing (if anything) through community engagement and outreach programmes to increase access to their institutions for low-income youth.

A small number of studies confirm the importance of access to a wide range of information. Thus, Wiese, van Heerden, Jordaan, and North (2009) looked at why relatively high achieving and better-off students chose particular universities. Sources of information that were valuable were university publications, followed by word-of-mouth, while campus visits, open days and university web sites were all helpful. Less useful were visits by universities to their schools, although this may be much more important to poorer students with no or very little information and no access to the internet. Nonetheless, the study confirms the importance of access to multiple sources of information and at least some correlation of middle class-ness and wide information. Walker and Mkwananzi (2015) conducted a small-scale study in an informal settlement (Orange Farm), and found that, while the young people had higher education aspirations, they lacked knowledge about what this entailed. They were aware of only two universities and did not know how to get hold of their brochures. In promoting the apply now campaign' launched by the DHET, the then Deputy Minister Manana (2013), noted that students could apply to universities as early as Grade 11 to avoid late applications. Yet the young people interviewed were in Grade 11, and did not know that they could already apply to university. They were influenced by other students at school, some teachers, and their guardians, even though these informants may not have reliable knowledge about higher education. In a study of undergraduate sociology students, Manyonga (2017) found evidence of student choice being constrained by a number of social factors, such as lack of parental support and knowledge. He also found that the participants in his study ended up in the 
Humanities not because of choice or aspirations, but because of low school-leaving scores and as a result, limited choice of degrees and future careers. Walker's (forthcoming) study on access compares quintile one to three informants with quintile five students and finds significant differences in choosing a secondary school, choosing subjects and knowing how to access university. In Ball and Vincent's (1998) terms, low-income students are doubly disadvantaged in that they both lack 'hot' knowledge residing in close family members who have been to university and from teachers or university outreach. They do not even have much in the way of 'cold' knowledge in the form of reliable information from university brochures, the internet, and so forth.

All this comes together to result in many choices, or one choice. For example, Rebecca attended a Model C school in the north of Johannesburg. She comes from a family of civil engineers, her father and uncles and her sister, all studied or worked at Wits. Wits is an easy choice for her, and her parents are able to pay her university fees. Ramagoma attended a rural school in the Limpopo area. She applied to Univen and Limpopo - only Univen replied. She chose Univen because it is close to home and she thought she could study viticulture (not offered at Univen). She would have chosen radiography if she could have. She ends up in Animal Sciences and has a government loan to pay for her studies (from Walker \& Fongwa, 2017).

Along this equity dimension the picture is mixed. The new fees regime should go some way to removing basic financial barriers to access, but along intersectional and cumulative factors of wealth, social class, race, gender and geography, barriers still reduce the opportunities of many students from low-income and/or rural backgrounds.

\section{Horizontality}

Turning to horizontality and university status, it is tricky to tease apart accessibility and horizontality so the focus here is on university status and its effects on access and admissions. It is hardly coincidental that the best universities tend to have the lowest numbers of students on government loans (as a rough proxy for socio-economic status or SES), nor that the best schools have the highest achieving students, or that advantaged universities have more of these kinds of students. Cooper (2015) in his account of the 'stalled revolution' points out that the five most elite universities in South Africa had around 30\% black students compared to $85 \%$ attending the lower status universities. With regard to selection by universities, according to van Broekhuizen et al. (2016) there are large differences in the average Grade 12 performance of students who are admitted. Learners from the 2008 Grade 12 cohort who enrolled at high status universities in 2009 had average Grade 12 achievement levels of 75\%, while those from the same cohort who enrolled at lower status universities achieved closer to $55 \%$.

Even with fees now waived from 2018 to entering low-income students, the minimum qualification of a bachelors pass may still not ensure access to the best universities or the most prestigious programmes such as medicine, the health sciences and law. The admissions programme score (APS) which is calculated based on subjects studied, as well as subject grades, 
sets requirements over and above the basic bachelors pass. Some degrees, for example medicine and accountancy, will also require that students have a good pass in mathematics. However, there is no nationally agreed way of calculating AP scores and no common AP requirement for each degree; universities calculate weighting differently of Grade 12 subjects and set varying score requirements. Elite universities can then set high or higher AP scores (see Table 2).

Table 2 APS required for admission across three universities of different status, 2016 entry

\begin{tabular}{l|c|c|c}
\hline Status & $\begin{array}{c}\text { High } \\
\text { (historically white): } \\
\text { WITS }\end{array}$ & $\begin{array}{c}\text { Mid-ranking } \\
\text { (historically white): } \\
\text { UFS }\end{array}$ & $\begin{array}{c}\text { Low } \\
\text { (historically black): } \\
\text { University of Venda }\end{array}$ \\
\hline Education Faculty & $34+$ & 30 & 26 \\
\hline Natural Sciences Faculty & $40-43$ & $30-24$ & $23-26$ \\
\hline Law Faculty & $43+$ & 33 & 26 \\
\hline
\end{tabular}

Source: Authors' own calculations

We can assume from the limited South African research that selection-admission processes are underpinned by an unproblematised discourse of meritocracy and 'homophily'. ${ }^{11}$ Yet merit is not a neutral means of making decisions and, even when claimed to be fair, places emphasis on individual achievements rather than the conditions that supported the achievement. Naidoo's (2004) study of access and admissions practices at two contrasting universities in the 1990s explains the problem well. Here I consider her case of the elite university (Mount Pleasant) whose admission judgements as implemented by 'powerful agents' did not appear to be consciously unfair in deliberately excluding black students from the institution that was (at that time) predominantly white. Instead 'academic potential' became part of the institutional narrative, and Naidoo argues that this focus on potential to succeed re-inscribed academic merit and reproduction effects, while still claiming the virtuous inclusion of disadvantaged students. The judgements implemented by powerful agents indicated that how students were classified 'appeared to be part of an orientation to conserve institutional arrangements' (2004, p. 463). New criteria (other than academic) were resisted because academics were concerned that more students from low quality schools would 'threaten' institutional arrangements such as time for research and the status of the university in the intellectual field, as well as reduce the student progression rate. The worry was that admissions shifts might require dominant and elite universities to change, even though years after the research was concluded Mount Pleasant had - if anything - reinforced its merit-based admissions policy.

11 In the 1950s, sociologists coined the term 'homophily' - love of the same - to explain our inexorable tendency to link up with one another in ways that confirm rather than test our core beliefs. In short we look for people (students) like us. 
Naidoo's analysis of the legitimate academic capital of what were considered 'typical' students coincided closely with qualities possessed by students from advantaged schools. The exclusion of poor and working class students was perhaps not malign; however, the exclusionary effects were the same. Indeed, the apparent objectivity of the criteria and the transparency of the process and the apparently just deserts that resulted might make it harder for those on the outside to fathom or challenge. Persistence, hard work and resilience will never then suffice, except for a few exceptional students, without knowing the precise rules of the admissions game. What results is an 'aristocracy of [class-based] merit' (Stevens, 2007, p. 242); elite colleges 'get just what they are looking for' (p. 247). On the other hand, she suggests that one could argue that Mount Pleasant was enabling an elite minority of African students to access more privileged positions in society, and this might be considered transformative.

Along this dimension, too, equity is not doing well and the stratification of the higher education system is reinforcing social inequalities, even if small numbers of disadvantaged individuals manage to break through. Take for example Marshall and Case (2010) who use one student narrative to rethink disadvantage. According to Mandla (from a large and poor family) at a critical point he began to take a longer term view of his future. It seems he took an individual decision to consider where his academic studies might take him, read about 'a black guy like me' working at a paper mill, did some research, and found out that this was connected to engineering. He decided on this as a career path and secured an industry-financed scholarship at an elite university. What we do not know is anything about the social conditions under which his choice was made or his aspirations formed or encouraged. Kapp et al. (2014) consider how their black and working class students at an elite university had negotiated high school contexts and neighbourhoods which were not socially conducive to learning and academic attainments, but which were also not over-determining. These students constructed themselves as 'hard-working' people who did not give up and sought out equally serious peers to form study groups. They also sought out community organisations which could provide support, including churches. Thus student agency emerges as important, but the research does not show how some students were agency-enabled and others were not, in the face of the same constraining opportunity structures.

\section{Going forward}

Of course there are students like the above who defy the odds and each life is unique in its bundles of qualities, effort, talents and capabilities. We should celebrate students such as Mandisa Xaba from a poor township in rural KwaZulu-Natal who obtained seven distinctions in 2017 at her no-fees school, and has a place to study computer science at UCT (Nombembe et al., 2018). But as Lareau (2003) reminds us, we should not be blinded to the fact that membership in a social group matters in the creation of inequality and structures life opportunities. When we look across the life chances of low-income South African youth, we 
are some way off the kind of multi-dimensional equitable access which does not allow circumstances to limit opportunities. Across all three dimensions there are amber warning lights indicating equity challenges, with each dimension having a knock-on effect for the others. There is no unambiguous green for go.

Access is constrained by the availability of sufficient places for qualifying Grade 12 students. Accessibility is unequal across race, socio-economic class, rural/urban, quality of schools, field of study chosen and elite or non-elite university admissions criteria. Horizontality preserves stratification and status and is unequal across different types of universities and fields of study. Thus, higher education enables mobility - for some - but also reproduces social privilege and intergenerational inequality across income groups. Different people have different resources which they can convert to the capabilities to access university; all do not compete fairly. Achieving a place and being satisfied with that achievement choice are affected by multiple factors in each person's life, including uneven capability sets shaped by resources, social conversion factors, preference formation and individual talents and qualities. Yet unequal endowments and resources make it urgent that university access is inclusive for those who qualify. In addition, access pathways which allow students entry with lower entry scores would enable a chance at higher education for students from low quality schools.

There is much we do not yet know enough about and more research on the access end is needed as noted earlier. We need action on multiple fronts - by universities, by government, by student movements and by individuals working in different and multiple ways to foster the formation of students' capability sets and agency, using McCowan's dimensions as a helpful equity grid. As Dreze and Sen (2002, p. 82) say, the basic approach to access ought to be 'an overarching interest in the role of human beings - on their own and in cooperation with others - in running their own lives and expanding their freedoms'. In this way we might operationalise the capability to access higher education inclusively, thereby contributing to comparatively greater justice and more of the public good.

\section{References}

Africa Check (2018). FACTSHEET: Funding \& the changing face of SA's public universities. Retrieved from https://africacheck.org/factsheets/factsheet-funding-changing-face-sas-public-universities/

Anders, J. (2012). What's the link between household income and going to university? Department of Quantitative Social Science, Institute of Education, London. Retrieved from http: repec.ioe.ac.uk/RePEc/ pdf/qsswp1201.pdf

Ball, S. J., \& Vincent, C. (1998). I heard it on the grapevine: Hot knowledge and school choice. British Journal of Sociology of Education, 19(3), 377-400.

Ball, S., Maguire, M., \& Macrae, S. (2002). Choice, pathways and transitions Post 16. London: Routledge.

Cooper, D. (2015). Social justice and South African university student enrolment data by 'race', 1998-2012: From 'skewed revolution' to 'stalled revolution'. Higher Education Quarterly, 69(3), 237-262.

Council on Higher Education (2016). VitalStats 2016. Pretoria: Council on Higher Education.

Department of Higher Education and Training (2016). Annual monitoring report on the projected 2014 targets of the ministerial statement on student enrolment planning, 2014/15-2019/20. Pretoria: Department of Higher Education and Training. 
Dreze, J., \& Sen, A. (2002). India: Development and participation. (2nd ed.). Oxford: Oxford University Press.

Fengu, M. (2017). Matrics, take note: Most universities are already full. Retrieved from https://www.news24. com/SouthAfrica/News/matrics-take-note-most-universities-are-already-full-20170107

Hart, C. (2013). Aspirations, education and social justice. Bloomsbury: London.

Institute of Race Relations (2016). South Africa survey 2016. Johannesburg: Institute of Race Relations.

Kapp, R., Badenhorst, E., Bangeni, B., Craig, T., Janse van Rensburg, V., Le Roux, K., Prince, R., Pym, J., \& van Pletzen, E. (2014). Successful students' negotiation of township schooling in contemporary South Africa. Perspectives in Education, 32(3), 50-61.

Lareau, A. (2003). Unequal childhoods. Berkeley: University of California Press.

Makgetla, N. (2018, 16 January). Funding can be found to implement free education plan. Business Day.

Manyonga, B. (2017). The sociology curriculum, pedagogy and capabilities formation: A case study in two South African universities (unpublished doctoral dissertation). University of the Free State.

Marshall, D., \& Case, J. M. (2010) Rethinking disadvantage in higher education: A paradigmatic case study using narrative analysis. Studies in Higher Education, 35(5), 491-504.

McCowan, T. (2016). Three dimensions of equity of access to higher education. Compare, 46(4), 645-665.

Montenegro, C. E., \& Patrinos, H. A. (2014). Human development reports comparable estimates of returns to schooling around the world. Washington, DC: The World Bank. Retrieved from http://dx.doi. org/10.1596/1813-9450-7020

Moses, E., van der Berg, S., \& Rich, K. (2017). A society divided. How unequal quality education limits social mobility. Synthesis Report for the Programme to Support Pro-Poor Policy Development (PSPPD). Retrieved from http://resep.sun.ac.za/wp-content/uploads/2017/03/2372-Resep_PSPPD_A-society-divided_WEB.pdf

Naidoo, R. (2004). Fields and institutional strategy: Bourdieu on the relationship between higher education, inequality and society. British Journal of Sociology of Education, 25(4): 457-471.

Nombembe, P., Nair, N., \& Macanda, S. (2018, 7 January). Commitment conquers all for township achievers. Sunday Times.

OECD (2013). Education indicators in focus (September). Paris: OECD. Retrieved from http://www.oecd.org/ education/skills-beyond-school

Oliveira, T., \& Zanchi, L. (2004). Participation in higher education in Britain: The effect of ability and parental income. Leeds: University of Leeds Business School. Retrieved from http://www.le.ac.uk/economics/to20/ heeea.pdf

Pitman, T. (2015). Unlocking the gates to the peasants: Are policies of 'fairness' or 'inclusion' more important for equity in higher education? Cambridge Journal of Education, 45(2), 281-293.

Reay, D, Crozier, G, \& Clayton, J. (2009). 'Strangers in paradise': Working class students in elite universities. Sociology 43(6), 1103-1121.

Reay, D., David, M. E., \& Ball, S. (2005). Degrees of choice: Social class, race and gender in higher education. Stoke-on-Trent: Trentham Books.

Robeyns, I. (2017). Wellbeing, freedom and social justice: The capability approach re-examined. UK: Open Book Publishers.

Sen, A. (2009). The idea of justice. Oxford University Press: Oxford.

Shay, S., Clarence-Fincham, J., \& Wolff, K. (2016). New generation extended curriculum. Cape Town: University of Cape Town.

Speigler, T., \& Bednarek, A. (2013). First-generation students: What we ask, what we know and what it means: An international review of the state of research. International Studies in Sociology of Education, 23(4): 318-337.

Stevens, M. L. (2007). Creating a class: College admissions and the education of elites. Cambridge, MA: Harvard University Press.

van Broekhuizen, H., van der Berg, S., \& Hofmeyr, H. (2016). Higher education access and outcomes for the 2008 national Grade 12 cohort. Stellenbosch Working Papers 16/6, Stellenbsch University.

van Broekhuizen, H., \& Spaull, N. (2017). The 'Martha effect': The compounding female advantage in South African higher education. Stellenbosch Economic Working Papers: WP14/2017. Retrieved from www.ekon. sun.ac.za/wpapers/2017/wp142017

Walker, M. (forthcoming). The achievement of university access: Conversion factors, capabilities and choices. 


\section{HigheR EDUCATION PATHWAYS}

Walker, M., \& Fongwa, S. (2017). Universities, employability and human development. New York and London: Palgrave.

Walker, M., \& Mkwananzi, F. (2015). Challenges in accessing higher education: A case study of marginalised young people in one South African informal settlement. IJED, 40, 40-49.

Wiese, N., van Heerden, Y., Jordaan, M, \& North, E. (2009). A marketing perspective on choice factors in selecting a higher education institution. Southern Africa Business Review, 13(1), 39-60.

Wilson-Strydom, M. (2015). University access and success: Capabilities, diversity and social justice. London: Routledge. 


\section{INTERNATIONAL PERSPECTIVES ON EQUALITY OF HIGHER EDUCATION OPPORTUNITIES: MODELS AND STRATEGIES FOR ACCESSIBILITY AND AVAILABILITY}

Vincent Carpentier, Yann Lebeau and Jussi Välimaa

\section{Introduction}

Issues of access to higher education have long been discussed in the context of a worldwide move towards a massification of higher education systems. The data reveal persisting inequalities of access to and of success within higher education, even in high participation systems (Marginson, 2016) which raises the question of equity in the management of availability and accessibility of higher education opportunities and of other factors of inequality operating within and beyond higher education systems. Depending on their resources and ideological positions, governments around the world have generally opened up their higher education sector by either allowing the private sector to absorb new demands or by funding the expansion of public higher institutions through various strategies responding to local circumstances or to donors' agendas. The increase in the number of study places has usually gone hand in hand with a diversification of higher education systems vertically (reputational differentiation among organisations of formally the same type) and/or horizontally (sectoral diversification), concealing in most cases the reproduction of prior inequalities within stratified systems (Marginson, 2016).

The chapter examines different strategies adopted in both high- and low-income countries to counter the deepening of inequalities of access within contexts of expansion of higher education systems. Initiatives related to institutional diversification, funding paradigms, and 
the diversification of pathways into higher education, will be analysed in their capacity to address the challenge of reaching a balance between accessibility and availability and in their implications on the attainability of higher education opportunities for all segments of societies.

We first discuss the conceptual challenges posed by the notion of social justice underlying policies improving access opportunities to higher education for disadvantaged groups. We propose a framework for conceptualising the connections and tensions between policies of greater accessibility and availability on the one hand and, on the other, empirical observation of the effective attainability of courses and institutions. We then use four national contexts ranging from postcolonial low participation to highly inclusive 'universal' systems in order to emphasise the significance of contexts and historical trajectories in the formation and application of social justice agendas of access and participation in higher education.

\section{Conceptualising and mapping the determinants and forms of participation in higher education}

\section{Equity and equality and the prospect of high participation systems of bigher education}

Equality and equity are often mixed with each other as concepts or used interchangeably. However, these concepts are linked to different, but interrelated social phenomena, in addition to having their own academic traditions and political interpretations and uses. According to Oscar Espinoza, the 'equity' concept is associated with fairness or justice in the provision of education and takes individual circumstances into consideration, while 'equality' 'usually connotes sameness in treatment by asserting the fundamental or natural equality of all persons' (Espinoza, 2007, p. 345). Equity is thus a problematic concept and policy paradigm because people understand fairness and justice differently (McCowan, 2016). Politically, the question may be formulated as fairness to whom, and justice in relation to what? According to Espinoza (2007), equity can be approached from three different perspectives. Equity for equal needs puts emphasis on giving the same amount of financial, social and cultural resources to all students with the same needs. It may also be interpreted as an aim to provide equal level of educational attainment or with equal educational achievements for students with equal needs. The principle of equity for equal potential is related, in turn, to the broad idea that individuals should maximise their potential and therefore, all individuals with similar abilities and skills should have access to higher education. However, the main problem with this approach is how to define 'potential' or 'ability' of a student. Typically this problem is addressed through standardised testing which, however, favours students from dominant groups, resulting in elitist policies which, in turn, increase inequality (Au, 2009; Bourdieu \& Passeron, 1990). The third approach, equity for equal achievement, is maybe the most meritocratic approach because it ties students' past achievements to access to higher education and to their educational performance during their studies. 
Equality and equity are therefore rooted in political ideologies underpinning decisions about how to allocate the resources of a society to higher education. Historically, the first comes with the belief that human beings have innate differences which cannot be changed. This reasoning supports a clear distinction between elite (academic) and lower (vocational) educational institutions. A liberal perspective on equity, in turn, is based on the conviction that society should help talented students to advance in their studies. In practical terms, however, liberal policies have often led to policies aiming to impact on the perceived attainability of university education, and to change students' working class values into middle class educational values (Nori, 2011; Reay, David, \& Ball, 2005). According to Husén (1974) the most advanced approach to equity is represented by the radical definition of equality based on the idea that society guarantees both the quality of education and the equality of educational outcomes to every citizen, regardless of their socio-economic backgrounds. According to this definition, popular in Nordic countries such as Finland, the role of society is to provide equal educational opportunities and help to guarantee good educational outcomes for every citizen, regardless of gender, socio-economic background or geographical location (Husén, 1974; Nori, 2011). These different perspectives to equality and equity, sometimes classified as 'sufficitarian' and 'egalitarian' (Brighouse \& Swift, 2006; McCowan, 2016) are helpful to understand the variations in the principles and modalities of expansion of higher education systems across the world and their social implications.

Marginson (2016) shows that high participation systems are growing in numbers, with substantial transformative effects on both higher education and society. The relationship works both ways as the structures of societies, and in particular their dynamics of social reproduction, impact on and shape the expansion of higher education systems. In this chapter we argue that the connections and sometimes tensions between social structures and expansion policies of higher education are historically situated and country-contingent and that their evolution is complex, rather than reflecting stages of economic development in a linear and static way. We explore them through the lenses of accessibility, availability and attainability.

\section{Operational concepts: Accessibility, availability and attainability (AAA) of higher education}

Accessibility refers to opportunities available to enrol in tertiary education programmes and institutions. The expression 'equity of access' refers to policies ensuring that such opportunities are available to all (Salmi \& Bassett, 2014) and is used by international organisations and researchers with reference to public interventions geared at eliminating 'disadvantages from circumstances that lie largely beyond the control of the individual but that powerfully shape both the outcomes and actions in pursuit of those outcomes' (World Bank, 2006, p. 78). This approach, based on what Piketty (2014) refers to as the 'illusory nature of merit', still dominates public policies of widening participation, as well as discourses of the dominant groups seeking to defend their privileged status (Burke, 2013; van Zanten \& Maxwell, 2015). 
The accessibility of higher education in a given country is raised by establishing initiatives to increase the enrolment of students from disadvantaged backgrounds, for example outreach activities in communities with poor higher education participation rates (Archer, 2007; Burke, 2013; James, Bexley, Anderson, Devlin, Garnett, Marginson, \& Maxwell et al., 2008) or by providing students and their families with the necessary means to counter the effects of their disadvantage. In many countries, governments have introduced policies designed to eliminate identified barriers faced by potential students from lower income strata or other categories of the population facing significant barriers to access higher education through measures such as targeted scholarships and admission quotas (Long \& Kavazanjian, 2012).

Availability refers to the number of places within a higher education system (through investments in public sites or the multiplication of alternative providers), and increasing availability often goes together with measures to broaden access to higher education. Because they operate at the point of entry of higher education systems, these strategies translate into growth without necessarily generating equalisation (Marginson, 2016). In Chile for instance, an increased availability at local level was thought to have enabled growth in participation from the lowest household income quintile; there was a 'rapid expansion of the private sector, which today accounts for about 70 per cent of overall enrolment' (Salmi \& Bassett, 2014, p. 367). Yet, it has been found that the tertiary level enrolment rate for the wealthiest quintile is almost four times higher than the rate for the poorest, and the gap has widened over the last decade (Salmi \& Bassett, 2014).

Countries such as the UK and France also present wide gaps between socio-economic groups despite showing higher participation rates than Chile. Participation rates of lower income groups have increased under a combination of widening participation measures and increased availability, but the gap with higher income groups in the attainability of the most rewarding qualifications is not showing signs of narrowing due to the stratification that accompanied the expansion of both systems (Carpentier, 2018; van Zanten \& Maxwell, 2015).

Thus, the availability measured in terms of overall provision of places only tells one side of the story. Attainability is a further key concept. A study by the Higher Education Funding Council for England (HEFCE) on the geographical distribution of higher education institutions in England and Wales, indicated some significant 'cold spots' (HEFCE, 2014) and revealed how universities and colleges play a key role as economic and social 'anchors' in their local and wider communities: students from lower socio-economic backgrounds are less likely to travel long distances and the regional proximity is therefore an important dimension of the availability of higher education. Attainability refers to how the perceived selectivity of universities by secondary school leavers affects participation, as applicants tend to 'judge the attainability of a place in higher education on the basis of their grades and subjects' (HEFCE, 2015, p. 2).

The unequal attainability of courses and institutions within a system (achievement barriers) usually reflects its level of stratification, as well as significant differences in socio-cultural perceptions of the relevance and likely success of higher education to career plans (James, 
2002; Lee, 2014). As will be shown in this chapter, the more higher education systems evolve towards a universalisation of access to higher education (total accessibility), the more stratified and hierarchical they tend to become because the greater availability of places masks striking differences of status among institutions. The attainability of institutions and degrees is therefore in large part generated from within the higher education systems, except where, as in the case of Finland discussed below, a 'determined effort is made by government to match growth with equalisation' (Marginson, 2016, p. 422). But those unequal perceptions and realities of achievement are also products of broader dynamics of class or cultural inequalities. Higher education strategies of access and growth can only partially redress these if designed in isolation from broader policies tackling wealth and income inequalities.

\section{Trajectories of accessibility and availability: How the question of attainability has been addressed in different contexts}

Contemporary higher education systems are the historical products of common or specific economic, political, social and cultural forces. Our intention here is to highlight and contextualise the policies and practices that influence accessibility, availability and attainability in selected countries and to locate some elements of convergences and divergences. The cases presented below reflect unique configurations historically constructed by the evolving connections and tensions between social, economic, political and cultural rationales (Carpentier, 2018). They include an archetypical high participation system (Finland), centralised republican models in contrasting environments (Senegal, France), a market orientated approach (UK) and a system combining aspects of centrally controlled quotas (positive discrimination) in a competitive and increasingly deregulated higher education landscape (Nigeria). The countries are intentionally chosen in contrasting groupings along economic development and higher education participation rates. The postcolonial perspective introduced in the cases of Nigeria and Senegal is an invitation to question the relevance of comparative concepts on matters of equity in educational opportunities, and also the underlying modernisation theories still dominating discourses on higher education development.

\section{The Nordic model and the case of Finland: The alignment between AAA}

Politically the main challenge in Nordic societies is to create egalitarian societies (EspingAndersen, 2015). In the field of higher education this Nordic value basis translates into policies supporting equal educational opportunities for all citizens, regardless of their gender, socio-economic background or geographical location. Consequently, Nordic governments have aimed to create higher education systems which have small (or no) institutional stratification, high participation rates and a general good quality of HEIs (Isopahkala-Bouret et al., 2018; Marginson, 2016). Nordic higher education systems have similar basic 
structures, with a distinction between universities and vocationally oriented and more regional HEIs, the latter called either Universities of Applied Sciences (UAS) in Finland or University Colleges in Denmark, Norway and Sweden.

In Finland, key differences between universities and UASs relate to the degree structure (only universities are allowed to confer doctoral degrees) and to research capacities (UASs are expected to do applied research). The Finnish state has been supporting this dual system and aiming to reduce competition between them, with clearly defined visions for UASs and universities. However, for students, universities and UASs are de facto competitors because practically all students are qualified for both sectors after completing their secondary education and because both universities and UASs seek to have the best students. However, 'the best student' for universities means a student with an academic orientation, whereas for UASs it means a student with a professional orientation.

The most important factor describing the Nordic approach to higher education is the strong role played by the state in the steering of higher education through funding, legislation and ministerial interventions (Tarkiainen, 2016). Ethically and politically, education, including higher education, is understood and defined as a public service and a civil right, rather than a consumer good. This means that education is free of charge to all citizens from the European Union. Furthermore, in Nordic countries, the proportion of public funding of higher education institutions is among the highest among OECD countries and all institutions are predominantly funded through public sources (approximately $85-95 \%$ of the budget). When compared to the OECD average of $30 \%$ of higher education budgets covered by private investments, it is evident that Nordic countries are thus rather exceptional cases of publicly supported systems (see OECD, 2014). According to the OECD, public expenditure per student on both public and private tertiary institutions 'varies from about USD 2000 in Chile to more than USD 17000 in Denmark, Finland, Norway and Sweden' (OECD, 2014, p. 243).

The 'odds ratio', which 'reflects the relative likelihood of participating in tertiary education of individuals whose parents have upper secondary or tertiary education' (OECD, 2014, p. 93), also indicates the level of commitment of policies aiming to provide equal educational opportunities for all citizens. In Finland, having parents with tertiary level education only increases one's odds of attaining a university degree by 1.4 . The ratio is 2.0 in Norway, 2.3 in Sweden and 3.0 in Denmark, while the OECD average is at 4.5. However, there is a big difference between universities and UASs in Finland. The odds ratio for universities is 6.8, whereas for UASs it is very close to one, meaning that universities are more socially selective than UASs (OECD, 2014).

Reflecting on accessibility, attainability and availability of higher education in the Finnish context requires paying attention to the lower levels of the system of education. Finnish basic education is offered in public comprehensive schools where the level of education is said to be uniformly good - at least if we believe PISA studies (Simola, 2015; Varjo, Simola, \& Rinne, 2013). This means that all pupils have equal opportunities to continue their studies either in general upper secondary schools or in vocational upper secondary schools. Importantly, both 
of these school sectors qualify pupils to continue their studies in higher education (both in UASs and in universities).

Good basic education is important for the attainability and accessibility of higher education and in Finland access to higher education is not restricted by the lower levels of the system of education. The availability of higher education is also influenced by the fact that there is a higher education study place offered to over $80 \%$ of the relevant age cohort. However, access to higher education is also based on numerus clausus, with limited places per field, and entrance examinations mean that there is hard competition, especially in popular fields. Concerning the impact of the socio-economic background on attainment, the Nordic state seems to successfully mitigate class factors by supporting all students at all levels of higher education. As for gender, Finland has had one of the highest female participation rates since the 1920s and currently more than 50\% of the students are female. Accessibility and availability are also related to geographical proximity of higher education institutions. An important Finnish education policy goal has been the establishment of a university or a UAS or both in every corner of the country. This policy goal has been important because Finland is a rather large country $\left(338000 \mathrm{~km}^{2}\right)$ with a relatively small population (5.5 million). Taking these matters into consideration, it is fair to present Finland, and to a large extent the Nordic model, as an exception among the high participation systems, with horizontal rather than vertical stratification characterising a well-resourced system geared towards ensuring equitable access to wealth for all.

\section{The French republican model: AAA and the tensions between principles and practice}

Contemporary statistics show that in France, having parents with tertiary education increases one's odds of attaining a university degree by 6 (OECD, 2014). This is not the most flattering illustration of a republican model of equality built on a meritocratic access to higher education (Charle \& Verger, 2012). Two contemporary debates are particularly helpful to understand this French paradox and its implications for the accessibility, availability and attainability of higher education opportunities. The first debate questions the role of the baccalauréat (Bac) in regulating access to higher education. The second questions the institutional differentiation between nonselective universities, the selective Grandes Ecoles, and the selective two-year vocational sector (Carpentier, 2018). At the time of writing, the French government is looking at reforming both the Bac content and the automatic access to university it provides, generating intense debates about the mechanisms of access to and selection within higher education.

The Bac was not only created as the examination sanctioning the end of secondary education but also as a qualification guaranteeing access to public universities. The Bac results are therefore a reliable indicator of access to higher education in France. Table 1 shows that participation in the Bac, initially limited to a small elite, grew exponentially in line with the massification of secondary education. 
Table 1 The \% of age group accessing the baccalauréat 1920-2015

\begin{tabular}{l|c|c|c|c|c|c|c}
\hline Year & 1920 & 1950 & 1960 & 1968 & 1985 & 1995 & 2015 \\
\hline$\%$ of age group & 2 & 5 & 11 & 20 & 30 & 63 & 77 \\
\hline
\end{tabular}

Sources: Carpentier (2018); INSEE (various years); Ministry of National Education (DEP) (2016)

The ratio reveals undeniable progress but masks persistent inequalities between social groups with substantial implications for accessibility to higher education (Beaud, 2002). Firstly, while overall gender parity has been reached (with differences between disciplines), variations in access between socio-economic groups remain important. Respectively $90 \%$ and $40 \%$ of the population of the higher and lower income categories hold a Bac (National Institute of Statistics and Economic Studies [INSEE], 2015). Secondly, the generalisation of access to the Bac has been driven by a differentiation between the traditional 'general' and 'technological' Bacs on one hand, and the more recent 'professional' Bacs whose share rose from 6\% in 1990 to $29 \%$ today. This academic/vocational divide is not socially neutral as $40 \%$ of enrolment in the professional Bac are from lower socio-economic categories compared to $10 \%$ from higher income groups. This is important as the professional Bac traditionally leads to less selective higher education institutions. Thus the generalisation of the Bac has improved accessibility to higher education while putting significant pressure on availability. Moreover, the differentiation between the types of Bac signals a perpetuation of the social reproduction through the stratification of the higher education system.

The transition to mass higher education has transformed the structures of availability as evidenced by the decline of the non-selective sector in the share of enrolment from $82 \%$ in 1970 to 59\% in 2016 (Carpentier, 2018) and the growth of the selective sector affecting both ends of the system. The selective Classes préparatoires and Grandes Ecoles, as well as the business schools and paramedical and social schools have increased their share in enrolment from $12 \%$ to $28 \%$ (amongst that group the Grandes Ecoles remained stable at $8 \%$ reflecting their continuous role in the selection of the elite). The share of the selective two year shorter vocational programmes such as University Institute of Technology (IUT) and the Higher Technical Sections (STS) rose from 6\% in 1969 to 14\% in 2016 (Carpentier, 2018).

The tensions between accessibility and availability are reflected in attainability. Students from low and high socio-economic categories represent respectively $11 \%$ and $30 \%$ of enrolment in non-selective universities, 6\% and 50\% in Grandes Ecoles, 15\% and 29\% in IUT and 20\% and $14 \%$ in STS which traditionally enrol more students with the professional Bac (Ministry of National Education [DEP], 2016). The socio-economic disparities in attainability are reinforced by the tensions between intake and resources. Funding per student in Grandes Ecoles is 50\% higher than in universities where the ratio of completion of a bachelor degree within the prescribed three years is just 30\%, far lower than in any of the selective sector courses (Ministry of National Education $[\mathrm{DEP}], 2016)$. Completion rates are also strongly correlated to the types of Bac (and 
therefore to social class), revealing a unique tension between accessibility, availability and attainability in the non-selective sector. There is a stark contrast between the multiple demands made on universities and their lack of resources (Carpentier, 2018). Bodin and Orange (2018) argue that university drop out is actually a mechanism of regulation of accessibility to the system. Another significant change in the structures of availability is the increase in private provision to nearly $20 \%$ of overall enrolment, suggesting that fees are indeed constraining attainability according to social groups (Carpentier, 2018). The French system of relatively high accessibility (ensured by the Bac) is articulated to a highly differentiated availability with a mix of open and highly selective institutions whose practices and resources tend to make attainability highly dependent on pre-existing socio-economic inequalities.

\section{The British model: The shift from a binary to a unitary marketised system and the tensions between AAA}

The connections and tensions between accessibility, availability and attainability of higher education in England have been particularly affected by three key historical changes accompanying the drive towards high participation from the 1960s. The first is a dynamic of expansion with two key phases in the 1960s and 1990s leading to a high participation system with persistent inequalities between social groups (Reay et al., 2005). The second change relates to the process of institutional differentiation of the higher education system. The first phase of expansion was driven by a binary system, while the second phase saw a transition towards a unitary but highly stratified system (Carpentier, 2018). The third key change relates to changes in the level of funding and its public/private distribution. The first expansion was driven by a trend of increasing public funding started after the Second World War, while the second was contemporaneous of the gradual rise in private resources (especially fees) (Carpentier, 2012).

The conditions of access to higher education are historically contingent, depending on government policies and practices towards widening access and participation, as well as the criteria and entry tariffs adopted by institutions during the student admission process. The fact that some universities select using achievements in secondary education (A level results) and extracurricular criteria, while many others recruit students through access courses or with further education qualification, sums up well the impact of differentiation on the accessibility of institutions and courses, also reflected in commonly used expressions such as the distinction between 'recruiting' and 'selecting' universities. The initial participation rate measuring the number in the age group of 18-30 years who entered a higher education course was $32 \%$ in 1995 and is around 50\% today (Carpentier, 2018). However, the differences between expansion and democratisation have been revealed by the persistence of extensive inequalities in terms of access, participation and outcomes for different social groups. In short, the traditional image of the young, fulltime, white male middle class student has vacated space for more diverse forms of enrolment. However, it is important to note that while social, ethnic and 
gender participation rates have all gone up, some important gaps remain. One explanation behind these mixed results might be linked to the question of availability.

Availability of higher education places in Britain has historically been dependent on a system of student number controls, whereby universities were allocated a number of places by the government with substantial fines issued to over-recruiting institutions. As such, availability has at times been alternatively stimulated and constrained by public funding. During the first phase of expansion of the 1960s, the expansion was driven by both sectors of the binary system through the creation by the government of new universities and the increase in places at existing ones, as well as the expansion of the non-university sector run by local authorities. The second phase of expansion from the 1990s was marked by the merger of both sectors in a unified system from 1992 and by the introduction of market logics in higher education (the gradual replacement of block public grants with tuition fees, and eventually to the removal of a number controls in 2015 - the deregulation for international students had occurred earlier). Since that period, availability has not only been driven by supply and upfront public funding, but increasingly by demand with a system of fees and income-contingent loans (especially in England). This regulation of availability by the market was complemented by the government's strategy to encourage private provision. However, it is worth noting that the focus on public debt, which was behind such a policy move, masks the issue of private debt and its potential consequences on sustainability and future availability (the non-repayment of loans which are backed by government might indeed fuel future public debt).

The historical tensions between policy and accessibility and availability have been reflected in differentials in attainability under both free and marketised systems. First of all, there is strong correlation between the secondary school attended, the access route to higher education and the type of university attended. For example, attending a state school or an elite independent school strongly determines destinations within higher education ('access to what?'). Secondly, those inequalities of access are channelled through and reinforced by the stratification of the system. Ross (2003, p. 49) claims that beyond the local sector/university divide, the binary system was also about 'access to a different form of higher education and to offer it to different kinds of students'. This was evidenced by the strong correlation between the background of students and their destination in the binary system (with higher income groups over-represented in universities). The transition from a binary to a unitary system has not altered the strong variations in the attainability of courses and institutions as reflected by the greater concentration of lower socioeconomic groups in post-1992 universities. The unitary system maintained a stratification based on the reputation and resources of institutions (Carpentier, 2018). Boliver (2011, p. 240) argues that 'qualitative inequalities in the odds of enrolment in more prestigious higher education programmes and institutions, that is on degree programmes and specifically those at "Old" universities, proved persistent throughout the expansion of both the 1960s and the early 1990s'. Brennan (2013, p. 194) argues that 'the differentiation of higher education in the UK allows the performance of an elite reproduction within a mass system', recognising social mobility but also the key importance of vertical differentiation. 
The influence of changes in funding must also be acknowledged. The increased accessibility which characterised the first phase of expansion was driven by the adoption in 1962 of free higher education with fees and grants paid to universities by local education authorities. This coincided with a rise of public funding whose share of income to higher education increased from 50 to $90 \%$ from 1945 to 1973 , fuelling the construction of new institutions and more places in existing ones in both the university and public sector of higher education (Carpentier, 2012). Free higher education led to undeniable progress in terms of accessibility, although enrolment rates were still low and regulated by differentials in attainability across the populations. This was a rationale used by the supporters of cost-sharing who claimed that free higher education was reproducing inequalities by financing the access of the most advantaged groups through the taxation of all. The shift away from free education started with the introduction of fees for international students in 1967 and full costing in 1981. Cost-sharing was subsequently applied to domestic students with the introduction of upfront fees of $£ 1000$ in 1998 and grants. In 2006, fees in England were increased to $£ 3000$ but deferred and paid through income-contingent loans and grants. In 2012, fees in England rose to $£ 9000$, still deferred but entirely paid by income-contingent loans as grants were abolished. Although the design of those funding systems was geared towards improving attainability, recent developments are asking difficult questions. The simultaneous fee hike and suppression of block funding suggests a shift towards public/private substitution in funding, raising key tensions between funding and attainability (Carpentier, 2012, 2018). Important issues include debt aversion from lower income categories, as well as the collapse of part-time student numbers (Callender \& Mason, 2017). The consensus on cost-sharing might have broken down with the tensions it generated between these 3 'A's, as shown by the recent Labour Party U-turn on tuition fees in undergraduate education and by the recent commissioning by the government of a report on student finance.

\section{Postcolonial experiences of equity of access: Nigeria and Senegal}

The postcolonial condition extends well beyond the context of the official decolonisation of universities in the 1960s and early 1970s, and covers the development of particularly hybrid forms of higher education in contexts marked by resilient forms of economic and intellectual dependencies and strong tendencies of extraversion of systems and individuals (AssieLumumba, 2006; Lebeau, 2008). This confluence generates a new order where imperialism, globalisation and emancipation combine in a new historically located 'geometry of power that is inherently unequal' (Rizvi, Lingard, \& Lavia, 2006, p. 255). 'Colonial residues' such as the conditionalities imposed by donors on higher education systems of the Global South until the late 1990 s remind us of the contemporaneity of postcolonial realities.

As suggested earlier, the concepts of equality and equity are deeply rooted in the 20th century ideologies underpinning 'modern' policies of expansion of higher education systems. Their universality is questioned here, using trends and characteristics of higher education systems in Nigeria and Senegal. First, the higher education trajectories of those countries have 
not followed the steady rise of the worldwide trend. Secondly, when this expansion started to happen, the process of massification showed little evidence of tackling social inequalities of access and participation (Hornsby \& Osman, 2014).

\section{The colonial legacy: Extraversion and dependence}

When considered from a world comparative perspective, Nigeria and Senegal are immediately striking by their overall low levels of enrolment (currently below 10\% GER), despite the early establishment of their higher education opportunities (1930s) by regional comparison, and of strong ties between the first universities established in the 1940s and 1950s and their accrediting institutions in the metropoles.

During its first year of operation in 1957, the University of Dakar enrolled 1069 students, comprising 368 'French' and 628 'Africans'. African students, organised in the Association Générale des Etudiants de Dakar (AGED), began to question the quality of the teaching on offer and the level of qualification of the academics appointed (Singaravélou, 2009). A similar climate of suspicion had accompanied the parsimonious development of higher institutions across British West Africa up until the formal opening of the University of Ibadan in 1948. In both cases the colonial powers had resisted the introduction of the type of universities established decades earlier in the colonies of North Africa and Asia. This had resulted in a steady flow of 'educated elites' towards the metropoles for further education. Returning home with 'proper' higher education qualifications, the elites were unimpressed by what was about to be offered at home. No higher education would be accepted that did not match the standard of qualifications offered in the metropole.

Among other things, this colonial dynamic externalised the values upon which the system was expected to be built (Steiner-Khamsi \& Quist, 2000), and made it more receptive to international pressure, and dependent on donor resources. The internalisation of the notion that improvement and change require external support, advice, and often personnel (Samoff \& Carrol, 2004) has had a determining impact on policy choices made by countries such as Senegal and Nigeria in the postcolonial era.

\section{Access to what?}

The colonial origin of the two systems can be said to have shaped their 'model' of management of access to higher education, with Senegal adopting a republican model of access built upon the Baccalaureate and Nigeria operating highly selective and meritocratic - although diverse and decentralised - routes into higher education.

However, the postcolonial agendas of the period 1960-1970 (state consolidation and the 'developmental university') and the gradual imposition of new forms of external dependencies by international organisations and bilateral donors progressively eroded the prospect of public equitable higher education systems accessible to the masses. 
Nigeria and Senegal have since opened their higher education sector to private providers in an attempt to alleviate the huge political tensions generated by the unavailability of places. In both countries, public universities now sit at the top of impressive pyramids of eclectic types of institutions (public, private, hybrid, international franchises) attracting international students, but are still incapable of absorbing the local demand.

Research has showed that the efforts of the Senegalese government to open up its system of higher education have remained focused on economic measures (bursaries, student accommodation, non-fee policy in public universities) and on a better distribution of higher education institutions across the country in order to address the gender imbalance and the low participation outside the urban environments of Dakar and Saint Louis (Ly, Diallo, Yade, Mbaye, \& Biaye, 2007). The Baccalaureate remains the only acceptable access route to universities and as in the French case discussed earlier, the principle of formal equality attached to the 'Bac' restricts the possibilities of broadening the accessibility of higher educational institutions through alternative access routes.

By contrast, Nigeria has always shown more openness towards multiple access routes to higher education, leaving it to universities, and to some extend to state-level administrations, to decide on their requirements. This pragmatic approach benefitted the 'state universities' established from the 1980s, particularly in the most remote parts of the country, while preserving the more elitist recruitment of the federal universities. A model of positive discrimination towards applicants from certain parts of the federation has dominated the admission policy of federal and state universities since 1979 as part of the 'federal character' policy requesting that public authorities, semi-government agencies, institutions of learning and even the private sector should ensure fair and effective representation of states or local government areas or ethnic groups in positions of power, authority, placement in enrolment into schools and so on (Adeosun, 2011).

Despite - or as a result of - this centrally controlled strategy of positive discrimination, the university system has never been able to absorb more than $10 \%$ of the qualified applicants since the late 1970s (Salihu \& Jamil, 2015). A rigid conception of an 'equity' agenda restricted largely to state-based quotas and ignoring huge inequalities within states led to a situation where the educationally 'disadvantaged' states targeted by the policy have so far been unable to fill in their quota, while candidates from other states were left to seek in the private sector or abroad the educational opportunities denied at home by the policy (Salihu \& Jamil, 2015).

It is fair to say that the redistributive logic of the Nigerian equity policy produced limited results as far as reducing the gap in educational achievement between the rich and the poor, urban and rural populations, and between men and women are concerned (Agboola \& Ofoegbu, 2010). The gross rate of access to higher education remains at $10 \%$, with parts of the country already well into mass higher education when others barely have any higher education statistical presence. These patterns of inequality also dominate Senegal despite a very different strategy for tackling inequalities of access to higher education. 
A study systematically linking wealth, gender and access to higher education in the low and lower-middle income countries of South Asia and sub-Saharan Africa shows how strongly restricted access to higher education is correlated to wealth and gender, and even more to the combination of wealth and gender (Ilie \& Rose, 2016). The study shows how the higher education participation rates of the poorest groups have barely risen over three decades in these countries (including Senegal and Nigeria).

Thus, while both countries have been hosts of the earliest colonial initiatives in higher education in sub-Saharan Africa, they find themselves in the pool of the lowest participation rates in the world. Malthusian colonial policies on education and the continuities of dependence in matters of university education (Samoff, \& Carrol, 2004), combined with broader developmental challenges, have led to a situation where the patterns of gender and social inequalities have remained unchanged in rural areas. Elsewhere, the availability of public higher education continues to pose a challenge to measures of accessibility and it is the rise of the private sector in both cases that fills the gap of attainability at the lower end of the demand spectrum.

\section{Discussion}

Scott notes (1995, p. 33) that 'the transition from elite to mass higher education is a global phenomenon comprising not only the inner dynamics of higher education systems but also deeply rooted secular trends in the character of the states, society, the economy, science and culture'.

The French, English and Nordic models show how the connections, tensions and also contradictions between accessibility, availability and attainability reflect the evolving arbitrations and compromises between political, social and economic rationales. The French and English cases in particular show that the 'universalisation' of higher education involves important access and funding strategies, and in turn new patterns of inequality associated with institutional stratification and diverse routes into higher education. These two cases highlight two major tensions between policies of accessibility and availability and their impact on attainability for the most disadvantaged groups: the dilemma of system selectivity in France and the question of reputational stratification in the UK. The Finnish experience, in turn, reveals that public education policies emphasising equality with state intervention can allow high academic quality, be egalitarian in the accessibility of higher education opportunities, and ensure genuine horizontality across qualifications and institutions by ensuring 'high quality and recognition of diplomas in the broader society' (McCowan, 2016, p. 15). Historical and spatial contingencies question the inevitability that 'not all participation in HPS is of equal value' and that higher education provides a 'stratified structure of opportunity, from elite universities and high-status professional degrees to the much larger number of places in mass education with uncertain outcomes' (Marginson, 2016, p. 421). 
The cases of Nigeria and Senegal are further challenging the ideas of linearity and ineluctability of stages in the long march towards high participation, and in particular the view that universal expansion occurs when social demands for higher education surpass policydriven expansion strategies. In colonial West Africa, social demand pre-existed the availability of higher education, and colonial policies actually restrained the attainability of universities and high-level qualifications by developing all sorts of 'adapted' educational opportunities dissuading local populations from seeking mainstream higher education opportunities. Ever since, governments have been playing catch-up with social demand in the most urban and economically developed areas, while constraining attainability elsewhere due to ineffective measures of accessibility or inadequate public resources. In a number of contexts discussed in this chapter, marketisation (in the form of private provision or tuition-based funding of public higher education) appears to be appeasing the tension between accessibility and availability, but without challenging the socio-economic determinants of attainability because they fit in, rather than upset the 'hierarchy of value' generated by the stratification process (Marginson, 2016, p. 422). These are important issues to consider for countries seeking to equalise opportunities and redress deeply unequal patterns of social mobility through higher education.

\section{References}

Adeosun, A. B. (2011). Federal character principle and national integration: A critical appraisal. International Journal of Politics and Good Governance, 2(2.4), 1-13.

Agboola, B. M., \& Ofoegbu, F. I. (2010). Access to university education in Nigeria: A review. Working Paper, Faculty of Education, University of Benin (Nigeria). Retrieved from http://files.eric.ed.gov/fulltext/ED511051.pdf

Archer, L. (2007). Diversity, equality and higher education: A critical reflection on the ab/uses of equity discourse within widening participation. Teaching in Higher Education, 12(5-6), 635-653.

Assie-Lumumba, N. T. (2006). Higher education in Africa: Crisis, reforms and transformation. Working Paper Series. Dakar: CODESRIA.

Au, W. (2009). Unequal by design: High-stakes testing and the standardization of inequality. New York: Routledge.

Beaud, S. (2002). 80 \% au bac ... et après? Les enfants de la démocratisation scolaire. Paris: La Découverte.

Bodin, R., \& Orange, S. (2018). Access and retention in French higher education: Student drop-out as a form of regulation. British Journal of Sociology of Education, 39(1), 126-143.

Boliver, V. (2011). Expansion, differentiation and the persistence of social class inequalities in British higher education. Higher Education, 61(3), 229-242.

Bourdieu, P., \& Passeron, J. (1990). Reproduction in education, society and culture (2nd ed.). (R. Nice, trans.). Thousand Oaks, CA: Sage Publications (Original work published 1970).

Brennan, J. L. (2013). Higher education differentiation and the myth of meritocracy: The case of the UK. In P. Zgaga, U. Teichler, \& J. L. Brennan (Eds.), The globalisation challenge for higher education: Convergence or diversity; centres or peripheries. Frankfurt: Peter Lang.

Brighouse, H., \& Swift, A. (2006). Equality, priority, and positional goods. Ethics, 116(3), 471-497.

Burke, P. J. (2013). The right to higher education: Neoliberalism, gender and professional mis/recognitions. International Studies in Sociology of Education, 23(2), 107-126.

Callender, C., \& Mason, G. (2017). Does student loan debt deter higher education participation? New evidence from England. Annals of American Political and Social Science ,671(1), 20-48.

Carpentier, V. (2012). Public-private substitution in higher education: Has cost-sharing gone too far? Higher Education Quarterly, 66(4), 363-390. 


\section{HigheR EDUCATION PATHWAYS}

Carpentier, V. (2018). Expansion and differentiation in higher education: The historical trajectories of the UK, the USA and France. Centre for Global Higher Education Working Papers, No.33. London: UCL Institute of Education.

Charle, C., \& Verger, J. (2012). Histoire des Universités. XIlème-XXlème siècles. Paris: Presses Universitaires de France.

Esping-Andersen, G. (2015). Welfare regimes and social stratification. Journal of European Social Policy, 25(1), 124-134.

Espinoza, O. (2007). Solving the equity-equality conceptual dilemma. A new model for analysis of the educational process. Educational Research, 49(4), 343-363.

Higher Education Funding Council for England (2014). Higher education provision in England pre-2015. Retrieved from http://www.hefce.ac.uk/analysis/maps/archive/heprovision/

Higher Education Funding Council for England (2015). Young participation in higher education: A-levels and similar qualifications (Report 2015/03). Retrieved from http://www.hefce.ac.uk/pubs/year/2015/201503/

Hornsby, D. J., \& Osman, R. (2014). Massification in higher education: Large classes and student learning. Higher Education, 67(6), 711-719.

Husén, T. (1974). Talent, equality and meritocracy. The Hague: Martinus Nijhoff.

llie, S., \& Rose, P. (2016). Is equal access to higher education in South Asia and sub-Saharan Africa achievable by 2030? Higher Education, 72(4), 435-455.

Isopahkala-Bouret, U., Börjesson, M., Beach, D., Haltia, N., Jónasson, J. T., Jauhiainen, A., Nori, H., \& Vabø, A. (2018). Access and stratification in Nordic higher education. A review of cross-cutting research themes and issues. Education Inquiry, 9(1), 142-154.

James, R. (2002). Socioeconomic background and higher education participation: An analysis of school students' aspirations and expectations. Canberra: Australian Government Publishing Service.

James, R., Bexley, E., Anderson, A., Devlin, M., Garnett, R., Marginson, S., \& Maxwell, L. (2008). Participation and equity: A review of the participation in higher education of people from low socioeconomic backgrounds and indigenous people. Centre for the Study of Higher Education: University of Melbourne.

Lebeau, Y. (2008). Universities and social transformation in sub-Saharan Africa: Global rhetoric and local contradictions. Compare, 38(2), 139-153.

Lee, J. S. (2014). The attainability of university degrees and their labour market benefits for young Australians. Higher Education, 68(3), 449-469.

Long, B. T., \& Kavazanjian, L. (2012). Affirmative action in tertiary education: A meta-analysis of global policies and practices. World Bank Report.

Ly, P. B., Diallo A., Yade A., Mbaye, C. T., \& Biaye, A. (2007). La responsabilité sociale de l'université sénégalaise. Rapport de Recherche. Réseau Ouest et Centre Africain de Recherche en Education (ROCARE).

Marginson, S. (2016). The worldwide trend to high participation higher education: Dynamics of social stratification in inclusive systems. Higher Education, 72(4), 413-434.

McCowan, T. (2016). Three dimensions of equity of access to higher education. Compare: A Journal of Comparative and International Education, 46(4), 645-665.

Ministry of National Education [DEP] (2016). Repères et références statistiques sur les enseignements, la formation et la recherche. Paris: Direction de l'évaluation et de la prospective, Ministère de l'Education.

National Institute of Statistics and Economic Studies [INSEE] (various years). Annuaire statistique de la France. Paris : Institut National de la Statistique et des Etudes Economiques.

Nori, H. (2011). Keille yliopiston portit avautuvat? Tutkimus suomalaisiin yliopistoihin ja eri tieteenaloille valikoitumisesta 2000-luvun alussa. Turku: Annales Universitatis Turkuensis, Ser. C, tom 309.

OECD (2014). Education at a glance 2014: OECD indicators. OECD Publishing. Retrieved from http://dx.doi.org/10.1787/eag-2014-en

Piketty, T. (2014). Capital in the 21st century. Cambridge, MA: Harvard University Press.

Reay, D., David, M., \& Ball, S. (2005). Degrees of choice: Class, race, gender and higher education. Stoke-onTrent: Trentham Books. 
Rizvi, F., Lingard, B., \& Lavia, J. (2006). Postcolonialism and education: Negotiating a contested terrain. Pedagogy, Culture \& Society, 14(3), 249-262.

Ross, A. (2003). Access to higher education: Inclusion for the masses? In L. Archer, M. Hutchings, \& A. Ross (Eds.), Higher education and social class: Issues of exclusion and inclusion (pp. 45-74). London: RoutledgeFalmer.

Salihu, M. J., \& Jamil, H. (2015). Achieving equality of educational opportunity on access to university education in Nigeria: A case of policy implementation. Hiroshima University Institutional Repository, 17(2): 3-22.

Salmi, J., \& Bassett, R. M. (2014). The equity imperative in tertiary education: Promoting fairness and efficiency. International Review of Education, 60(3), 361-377.

Samoff, J., \& Carrol B. (2004). Conditions, coalitions and influence: The World Bank and higher education in Africa. Institute of Development Studies.

Scott, P. (1995). The meanings of mass higher education. Buckingham: Open University Press.

Simola, H. (2015). The Finnish education mystery: Historical and sociological essays on schooling in Finland. New York, NY: Routledge.

Singaravélou, P. (2009). L'enseignement supérieur colonial. Un état des lieux. Histoire de l'éducation, 122, 71-92.

Steiner-Khamsi, G., \& Quist, H. O. (2000). The politics of educational borrowing: Reopening the case of Achimota in British Ghana. Comparative Education Review, 44(3), 272-299.

Tarkiainen, A. (2016). Extending equity in higher education in an equitable society: The Finnish dilemma. In G. Atherton (Ed.), Access to higher education: Understanding global inequalities (pp. 68-76). New York: Macmillan International Higher Education.

van Zanten, A., \& Maxwell, C. (2015). Elite education and the state in France: Durable ties and new challenges. British Journal of Sociology of Education, 36(1), 71-94.

Varjo, J., Simola, H., \& Rinne, R. (2013). Finland's PISA results: An analysis of dynamics in education politics. In H. D. Meyer \& A. Benavot (Eds.), PISA, power, and policy: The emergence of global educational governance (pp. 51-76). Oxford: Symposium Books.

World Bank (2006). World development report 2006: Equity and development. A co-publication of The World Bank and Oxford University Press. 


\title{
HOW HIGHER EDUCATION RESEARCH USING THE CAPABILITY APPROACH ILLUMINATES POSSIBILITIES FOR THE TRANSFORMATION OF INDIVIDUALS AND SOCIETY IN SOUTH AFRICA
}

\author{
Monica McLean
}

\section{Introduction}

The capability approach offers a normative framework for thinking how higher education can support human well-being and fulfilment. It was developed with a focus on poverty reduction by the economist Amartya Sen during the 1980s (see, inter alia, 1985 and 1999). Originating in welfare economics, it is underpinned by a commitment to human development and social justice. Following on, Martha Nussbaum collaborated with Sen, bringing in a perspective from philosophy. (Nussbaum \& Sen [1993] and 1997, 2000, 2003, 2010, 2011). Over the last two decades, the approach has been taken up by scholars across the disciplines to research a broad range of topics related to human development and flourishing. This community is served by the Human Development and Capabilities Association (HDCA) which was established in 2004 and by a dedicated journal entitled the Journal of Human Development and Capabilities (JHDC). While empirical work from a capabilities approach perspective is often carried out in poorer countries, including those in sub-Saharan Africa, comparatively little deals with education per se and even less with higher education. Work in this area was pioneered by Melanie Walker, who directs the South African Research Chairs Initiative (SARChI) Chair in Higher Education, \& Human Development Research Programme at the University of the Free State. 
Several chapters in this book identify how higher education in South Africa is expected to contribute to the policy agenda of social transformation by reducing deep social and economic inequalities and how reality is falling far short of policy aspiration. In the light of this contradiction, this chapter discusses how the capability approach illuminates how university education might transform both individuals and South African society. This discussion is presented in two parts. The first part shows how the central concepts of the capability approach focus on reducing poverty, conceptualised as depriving people of life's opportunities and freedoms. The second part considers two strands of higher education research based in South Africa and informed by what Ingrid Robeyns (2017) calls 'capabilitarian' theory or analysis. The first strand is about those students who have accessed university against the odds because they are black and come from poor rural and township areas; the second is about how higher education can shape graduates oriented towards contributing to social transformation, whatever their background.

\section{The capability approach and poverty reduction}

Several key texts offer overviews of the capability approach and the work that it does (e.g. Alkire, 2005; Deneulin \& Shahani, 2009; Ibrahim \& Tiwari, 2014; Nussbaum, 2011; Otto \& Schafer, 2014; Robeyns, 2016, 2017; Sen, 1985, 1999). Here I draw from them to identify key ideas and concepts (identified by italics when first introduced) to show how they relate to poverty, well-being and social justice.

Human capital is a measure of the skills, education, capacity and attributes of labour which influence peoples' productive capacity and earning potential (Becker, 1964). For the capability approach, the human capital emphasis on material resources is unidimensional. Rather, poverty is seen as multi-dimensional, limiting opportunities in many areas of life for individuals to choose to be and do what, with good reason, they value. In parallel, poverty reduction and human development are understood as the expansion of life choices. The approach is concerned with what constitutes a flourishing life: for example, enough to eat, sound health, supportive relationships and good quality education. Opportunities (also called 'freedoms') to eat, be healthy, have supportive relationships and be well educated are termed 'capabilities'. The realised states of being and doing, that is, the actual practices of individuals in their everyday lives are called 'functionings'. Individuals flourish when they are free to choose how they want to function in all areas of life. So, the capability approach promotes agency whereby individuals are free to choose lives (beings and doings) that express their own values and objectives. The social justice goal is that people lead free and dignified lives in a position of equality with others. Structural constraints are accounted for in the concept of 'conversion factors' which are the social, political, policy and economic arrangements that interact with personal biographies to enable or constrain capabilities for well-being and a flourishing life.

In the capability approach, justice focuses on the extent to which people have the same opportunities to be the kind of person they want to be and to do what they want. Inequality 
is challenged when political, economic or social developments expand peoples' opportunities or capabilities. Each 'person as an end' is a principle and, in this approach, individual choice is given a central place (Robeyns, 2017, p. 57). Yet, choice of what to be or do is often constrained economically, socially or culturally and the term 'adaptive preferences' refers to the phenomenon of people being socialised to accept unconsciously the constraints of their deprived circumstances: they might not aspire to what they do not expect or think achievable.

Much debate in such fields as welfare economics, development studies, gender studies and political philosophy centres on operationalising the approach and drawing up 'capability sets' (or lists) as guides, both to evaluating whether people have the capabilities to lead valued, good lives and to making changes to expand capabilities. On the one hand, Nussbaum (2000, 2003) proposes a set of ten 'central' 'universal', 'comprehensive' capabilities ${ }^{12}$ as a threshold to which all humans are entitled, which has been criticised for not allowing people living in poverty to specify what they themselves value (Clark, 2013). On the other hand, Sen (2004) rejects the specification of capabilities because it denies the role of democracy. He foregrounds participation and informed reasoning so that those people who are concerned can come to agreements about what capabilities matter.

While empirical research taking a capability approach often develops an 'ideal-theoretical' set of capabilities drawn from literature, including previous similar studies, it is essential that those whose capabilities are of concern have a voice. In an iterative, interrogative process, the ideal-theoretical set and empirical data from participant stakeholders about what is valued are brought together. The combined set can then be adjusted for relevance and feasibility and in some cases used for evaluation in different, similar settings with similar groups of people. There are now numerous empirical applications of the approach aimed at evaluating people's freedoms and opportunities in many different contexts and in diverse ways, for example, to evaluate gender inequalities and the effects of health programmes; or to assess the level of human development in different countries (see Robeyns, 2006, 2017). Education is a sub-field of the applications of the capability approach.

\section{The capability approach and higher education}

Generally, education applications of the capability approach are few but increasing. In human development, education has a specific relationship to poverty:

The human development approach recognizes education primarily not as an instrument or means of development, but as development itself, while lack of the same constitutes not just a cause of poverty, but poverty itself. Educational deprivation or poverty of education becomes an integral part of human poverty. Accordingly,

12 Nussbaum's ten universal capabilities are: life; bodily health; bodily integrity; senses, imagination and thought; emotions; practical reason; affiliation; other species; play; and control over one's environment. 
standard of living, quality of life, human development, human poverty, and so on, are measured in terms of, inter alia, educational status of the population. (Tilak, 2002, p. 195)

Melanie Walker and Elaine Unterhalter's edited book 'Amartya Sen's capability approach and social justice in education' (2007) shows conceptually and empirically the potential of the capability approach in education. The editors point out that for both Sen and Nussbaum education is itself a basic capability (to be educated) that affects the development and expansion of other capabilities. However, in the same volume, Terzi (2007) warns that evaluations should not assume that education is transformative: if it is of poor quality, it can close opportunities, for example, by instilling a sense of failure. So, she tentatively proposes a sub-set of capabilities without which an individual cannot be said to be educated: literacy; numeracy; sociality and participation; learning dispositions; physical activities; science and technology; and practical reason. Arguably, these capabilities are the starting point for someone coming to university. Yet, there is strong evidence that the quality of schooling in South Africa is so poor for many students ${ }^{13}$ that they arrive under-prepared for university education, despite working hard, holding high aspirations and being determined in the face of many structural barriers (Calitz, 2018; Spaull, 2013; Wilson-Strydom, 2015, 2017).

Applications of the capability approach to higher education specifically are few; nevertheless they illustrate what can be illuminated. Nussbaum $(1997,2010)$ (who, as a philosopher, does not undertake empirical research) makes a case for university humanities and arts producing world citizens because they teach empathy and critical thinking. In the UK, Caroline Hart (2014) has combined the capabilitarian and Bordieuan theory to explore hope and aspiration in the lives of working-class young people as they leave school and go to university.

However, it is Melanie Walker who has arguably broken new ground, interpreting Sen and Nussbaum to explore empirically and to think about higher education and social justice. In the UK, as well as in South Africa, she has used a capability lens to discuss pedagogies to support under-privileged students, who can feel alienated by university (Walker, 2003, 2006, 2010). She proposes participatory research methods to generate, implement and evaluate capability sets for higher education (2005, 2006, 2018a). With Alejandro Boni (Boni \& Walker, 2013), she edited a book with global reach dedicated to the capabilities approach and higher education. It positions universities (if 'reimagined') as potentially powerful sites for achieving human development by challenging the status quo and entrenched interests. Her research programme produces a steady stream of doctoral theses and publications, which form the basis of this chapter.

The rest of this chapter discusses capability research which first focuses on how underprivileged students in South Africa access and participate in higher education; and, secondly, focuses on how to produce graduates oriented towards the public good. The two sets of studies

13 The Economist (7 January 2017). 'Bottom of the class', https://www.economist.com/news/middle-east-and-africa/21713858-why-itbottom-class-south-africa-has-one-worlds-worst-education, accessed 26 February 2018. 
are not discrete because the capabilities and functionings that are generated often overlap, as will be shown. At this point, it should be noted that little is known about students in rural universities in South Africa because higher education research tends to be undertaken in historically white universities where the researchers work (cf. footnote 14).

\section{A capabilities approach to evaluating and addressing unequal access to and participation in universities in South Africa}

The body of capability approach studies that has been undertaken in South Africa confirms structural inequalities (Calitz, 2017, 2018; Calitz, Walker, \& Wilson-Strydom, 2016; WilsonStrydom, 2015, 2016, 2017). Someone born into poverty competes for access and success in higher education with those from socio-economically advantaged circumstances. Students from rural and township areas usually attend poorly resourced schools without access to technology, have difficulty finding information and being well-advised about choosing and applying for university, and often cannot afford university (from 2018 the government will pay poor students' tuition fees, though not accommodation, food or other living expenses). Nevertheless, students from poor backgrounds do gain access to university. But equitable participation often does not follow. The same studies reveal that once at university, students from disadvantaged backgrounds usually have insufficient and precarious financial resources (often going without food or toiletries); sometimes feel they do not 'belong'; and do not always experience teaching and learning which is confidence-enhancing and imparts critical knowledge. These students do not have substantive equality compared to better-off or racially privileged students.

Despite the intractability of the material poverty of these students, capabilities studies reveal how institutional and pedagogical discursive practices can both expand and constrain capability formation. Often the first from their impoverished communities to come to university, they have worked extremely hard to achieve access and are shown to be agentic, resilient and resourceful. They are also often full of hope for themselves, their families and communities which they want to benefit from their education. Yet, the studies also reveal that the transition to university is often punishing for a range of economic, academic, linguistic and social reasons. Curricular and pedagogical arrangements can mitigate or exacerbate difficulties, and many do not complete their course.

In capability approach studies 'participation' in higher education is understood normatively to be capability expanding. As explained above, capabilities are the opportunities or freedoms to be or act as one chooses, and realised capabilities are called functionings. For researchers, functionings are often the focus because they are more likely to be observable. Sets of educationally based capabilities and associated functionings are produced by exploring student perspectives with mixed and participatory methods (Bridges, 2015; Calitz, 2018; Crosbie, 2014; Flores-Crespo, 2007; Walker, 2006; Walker \& Fongwa, 2017; Wilson-Strydom, 2015). There is much overlap in the sets of capabilities that higher education should expand; most include a version of the following capabilities: 
- Knowledge of the field or (inter) discipline being studied: for example, having opportunity to be critical from a specific perspective;

- Practical reason: being free to make well-informed, independent choices about one's life;

- Deliberative participation: having opportunities to enter into dialogue and come to agreements with others;

- Affiliation: having the opportunities to develop social relationships and networks for the benefit of oneself and others;

- Respect and dignity: being free from denigration and not denigrating others;

- Emotional health: being free from fear or anxiety that might constrain learning; and

- Resilience: to be persevering in difficult circumstances.

While expansion of capabilities can be understood as an educational goal, the capability approach also focuses on conversion factors. To possess a capability often requires functioning or practise; learning to read is an obvious example. For this reason, curriculum (what students learn) and pedagogy (how they are taught and learn) are key conversion factors: their quality influences whether or not students possess the capabilities for successful participation (McLean, Abbas, \& Ashwin, 2013). A frequent example in the literature is that for students to have the capability for deliberative participation, classrooms need to be democratic, participatory spaces where students are included in collaborative decision-making (Calitz, 2017; Walker \& McLean, 2013; Wilson-Strydom, 2015).

Providing further principles and examples for enabling pedagogic arrangements is work by June Pym, Rochelle Kapp and colleagues based on small-scale case studies in different disciplines in South Africa (Bangeni \& Kapp, 2017; Pym 2017; Pym \& Kapp, 2013; van Rensburg \& Kapp, 2014). These papers are not explicitly framed by the capability approach but invoke it in their definition of student agency: '[A]n individual's capacity to act purposively to make choices about how they wish to live and to act on those choices' (Pym \& Kapp, 2013, p. 274). The focus is on formation of identity and agency: supporting students to gain confidence and to be and do what they value. The authors show how compensatory provision can make underprepared students feel stigmatised by foregrounding white, middle class values and norms and by ignoring the social and psychological aspects of becoming a university student (Pym, 2017; Pym \& Kapp, 2013). They argue for interventions which connect to students' home identities and foster a supportive social community and culture of learning. Such interventions include: 'visible' pedagogies where values and expectations are made explicit; increasing interactions between lecturers and students and small group work; flexible entry and exit points; time for reflection; and dedicated academic and psychological support.

Before concluding this section, I want to address an important question I have been asked: how does a set of higher education capabilities differ from a set of graduate attributes? Vivienne Bozalek (2013) answers it directly in relation to developing graduate attributes for an historically black university (the University of the Western Cape, UWC). She argues that the 
capability approach offers an enlarged view of the purpose of a university education, a broader conception of the graduate's 'good life', pointing out that it has at its heart social good, whereas graduate attributes might or might not. Moreover, she identifies the significance of the concept of conversion factors:

\begin{abstract}
The [capability approach] offers a way of taking into account where students and institutions are positioned and what they are able to do with personal, material and social resources, rather than merely looking at what resources people have and assuming that people are equally placed in relation to these resources. (Bozalek, 2013, p.74)
\end{abstract}

Although UWC uses the term 'graduate attributes' in its institutional documentation, the capability approach informed three overarching attributes to encompass human flourishing and social concern, which are based on an investigation of the needs of students and staff and collaborative deliberation. They are scholarship, critical citizenship, and lifelong learning.

Currently, there is limited evidence regarding the outcomes of university education for people from low-income backgrounds in South Africa. In the capability approach, the outcomes of education are understood as 'achieved functionings': that is, what graduates actually do and actually are in ways they value and choose. Little is known from any perspective about what happens to students from rural and township backgrounds in South Africa when they leave university: their numbers are small; research does not follow students after they leave; and data about employment and other destinations is patchy. ${ }^{14}$

To summarise this section: studies of higher education in South Africa that are shaped or influenced by capabilitarian theory are based on rich data usually including methods which give participants a voice. They reveal (1) how academic under-preparation, poverty and an alien environment constrain capabilities for access and participation; (2) how successful participation in university emerges in the interaction between agency and social context: students from deprived and difficult backgrounds who have managed to access university show agency, determination, often identify as academically able and have high hopes, but are often still living in extreme poverty; (3) that successful transition to and participation in university involves a varied, multi-dimensional set of freedoms and opportunities (including enough resources); (4) that unequal participation is an injustice which can be remedied by institutional and pedagogical arrangements which provide opportunities for specific

14 The Miratho project (www.miratho.com) aims to address this lacuna. It is an ESRC/Dfid and NFR-funded project based in HEHD (University of the Free State) led by Melanie Walker and part of the 'Inclusive Learning Outcomes in Challenging Contexts' research programme. It is a four-year (2016-2020) mixed methods research project, including interviewing students over the course of their degrees and into employment in both city and rural universities. It has two main aims: 1) to investigate how complex biographical, socio-economic, policy, and educational factors interact to enable or inhibit pathways for rural and township youth to get in, get on, and get out of higher education, in terms of the formation of their capabilities and how fair and inclusive are the 'learning outcomes' or functionings achieved; 2) and to produce a normative, multi-dimensional human capabilities-based index for evaluating the extent to which capabilities are expanded by a university education. 
capabilities and functionings, if only imperfectly, especially when students do not have sufficient material resources.

In this section of the chapter, I have presented the capability approach as offering purchase on how university education might expand the freedoms of graduates who have grown up in poverty to live rich, fulfilling lives. In the next, I focus on what has been written about how university education might develop graduates with the capabilities for public good.

\section{Higher education for making contributions to social transformation in South Africa}

Sen (2008, p. 335) proposed that: '[I]f someone has the power to make a change that he or she can see will reduce injustice in the world, then there is a strong social argument for doing just that (without having to dress all this up in terms of some imagined cooperative benefits enjoyed by all).' So, being advantaged, which university graduates are, brings 'inescapable' responsibilities: '[C]apability is a kind of power, and it would be a mistake to see capability only as a concept of human advantage, not also as a central concept in human obligation' (p. 336). This argument justifies capabilitarian higher education scholars' interest in producing graduates oriented to the public good.

In South Africa, the literature on this topic is small. First, there are studies exploring whether and how the capabilities for political agency and critical citizenship are formed through university education. ${ }^{15}$ Some were based on participatory action research in which students develop as political agents by taking part in projects related to gender (Boni \& Walker, 2016; Walker, 2018b; Walker \& Loots, 2018). Two further studies were based on interviewing students to explore how taking part in specific extra-curricular programmes expanded their capabilities for 'citizen agency'. Walker and Loots (2016, p. 63) found that for a mixed race and gender group of 50 students going abroad as part of a leadership programme, 'Confidence emerged as the basic platform for changing selves: taking on new knowledge, finding their own (informed) critical voices and participating in discussions.' Moreover, there was evidence that the students had come to value four functionings in relation to race (critical awareness of race, racism and history; affiliation; critical reasoning; to act for change) which Walker (2016, p. 1284) judges as 'capabilities formation to support a non-racist campus and society, emerging from inauspicious circumstances.' Conversely, Mtawa and Wilson-Strydom (2018, pp. 9-10) found that taking part in community service programmes led students (at an historically white university) to unquestioningly 'position community members as disempowered individuals in need of assistance', which entrenched paternalistic attitudes.

15 There is also a small South African capabilitarian higher education literature which focuses on gender and disability. For this chapter I am bracketing it, although it deals with the how institutional and pedagogical arrangements can be capability constraining or expanding (Loots, \& Walker, 2015, 2016; Mutanga, 2016; Mutanga \& Walker, 2015, 2017; Unterhalter, 2003; Walker 2018a; Walker \& Loots, 2017). 
Secondly, there is a small body of literature from the capability perspective about professional education in South Africa. This includes a book by Mikateko Mathebula (2018) on engineering university education in South Africa and Germany; and a book and papers based on a research project ${ }^{16}$ in South African universities (two historically white and one historically black) of five professional education departments: engineering, theology, social work, law and public health (McLean \& Walker, 2012; McLean \& Walker, 2016; Peppin Vaughan, \& Walker, 2012; Walker \& McLean, 2013). In both studies, there was an explicit focus on what kind of university education would produce public-good professionals interested in poverty reduction conceptualised in the broad capability sense of expanding clients' freedoms and opportunities beyond the economic (in the case of Mathebula's engineering study, the interest was in professionals oriented and able to act for sustainable development). For both studies a wide range of stakeholders (students, educators, alumni and employers) were interviewed and workshops held to explore collaboratively what was valued and what the contextual constraints were, so that the sets that emerged were not overidealised. There were overlaps in the capability sets that finally emerged. The capabilities for a public-good engineer were: solving problems; being confident and feeling empowered; being resilient and having a sense of affiliation; and working in diverse fields. For the other study the capabilities for professional public-good which spanned the professions were: knowledge and skills; informed vision (for the country and profession); affiliation; integrity; resilience (these five were strongly encouraged in university departments); social and collective struggle; emotional reflexivity; and assurance and confidence (these three were differently inflected or disappeared according to profession).

Both these studies engaged with what kinds of universities, departments and pedagogical arrangements would be likely to support students' formation as public-good professionals. Peppin, Vaughan, and Walker (2012) note that the findings provided examples of how education can either ignore poverty awareness and engagement or enable students to value and choose pro-poor professional work. The latter was done by: exposure to the realities of poverty in South Africa; the development of critical reasoning, giving students the ability and opportunity to explore their own underlying values; and imparting certain skills and capacities (resilience, relevant professional knowledge, understanding of collective effort and struggle), so that those who chose a 'pro-poor' professional path would be better equipped to do so. But even when pedagogy was enabling, some students cared more about social transformation than others. The authors conclude that pedagogy itself should respect individual's freedom to choose what is valuable, despite Sen's insistence on the obligations of someone with expanded capabilities.

16 ESRC/Dfid (Award No. RES-167-25-0302) 


\section{Conclusion}

I have brought together capabilitarian higher education research from South Africa which, on the one hand, explores the access and participation experiences of black students from poor rural and township backgrounds; and, on the other, engages with both black underprivileged and privileged people (black or white) to explore how universities might produce graduates oriented to and able to act as public-good professionals. I have done this because the transformation of individuals and society in South Africa will take both the full educational inclusion of people who experience extreme poverty and professionals who want to address the multi-dimensional problems associated with the poverty in which most black South Africans live and want to contribute to social transformation in a highly unequal society. Although there is still only a small number of students from impoverished backgrounds getting to university, it is growing, and the evidence is that, while they certainly want to support their families out of poverty, they also want to 'give back'. Many of the capabilities for inclusion and for public-good professionalism are often the same (knowledge and skills; affiliation; respect and so on).

The capability approach offers a contribution to higher education in South Africa primarily because it derives from a normative framework which places human flourishing as its primary goal, chiming with the country's transformation goals. Though the field is relatively small it offers contextualised, collaborative and feasible ways of thinking about university education goals; for designing and evaluating curriculum and teaching methods; and for making recommendations about policies and practices. The focus of capability higher education research is on how South African universities might expand graduate capabilities for choosing valuable functionings for success at university and for productive, fulfilling work and life after university.

However, the South African studies discussed are also cognisant of societal and material constraints, often attributable to the legacy of apartheid: for example, under-resourced and often poorly managed public services; a brain drain of skilled professionals either into private practice or jobs abroad; and a dearth of black professionals in some fields because of race-based discrimination. While there is a small body of evidence about some graduates developing as public-good professionals, as noted above, little is known about what happens in work and life to graduates who come from poor backgrounds. We do not know whether their dreams are being fulfilled. ${ }^{17}$ University education cannot do everything: graduates might expand their capabilities as students, but they need conditions in employment and as citizens to convert capabilities to achieved functionings.

17 See the 'photovoice' project with students from the University of the Free State talking about their aspirations: https://www.ufs.ac.za/ docs/librariesprovider34/default-document-library/photo-voice-project_crhed_2018.pdf?sfvrsn=9f96a621_0 


\section{References}

Alkire, S. (2005). Valuing freedoms. Oxford: Oxford University Press.

Bangeni, B. \& Kapp. R. (2017). Negotiating learning and identity in higher education: Access, persistence and retention. London: Bloomsbury.

Becker, G. (1964). Human capital: A theoretical and empirical analysis with special reference to education. Chicago: University of Chicago Press.

Boni, A., \& Walker, M. (2013). Human development and capabilities: Re-imaging the university of the twenty-first century. London: Routledge.

Boni, A., \& Walker, M. (2016). Global human development: Theoretical and empirical insights for social change. London: Routledge.

Bozalek, V. (2013). Equity and graduate attributes. In A. Boni \& M. Walker (Eds.), Human development and capabilities: Re-imaging the university of the twenty-first century (pp. 69-81). London: Routledge.

Bridges, S. J. (2015). Conceptualising cosmopolitan values in internationalised higher education: A capabilities approach. Paper given at the SRHE Annual Research Conference, December.

Calitiz, T. (2017). Designing capability-informed pedagogy using participatory student research. In M. Walker \& M. Wilson-Strydom (Eds.), Socially just pedagogies, capabilities and quality in higher education: Global perspectives (pp. 153-176). London: Palgrave MacMillan.

Calitz, T. (2018). Enhancing the freedom to flourish in higher education: Participation, equality and capabilities. London: Routledge.

Calitz, T., Walker, M., \& Wilson-Strydom, M. (2016). Theorising a capability approach to equal participation for undergraduate students at a South African university. Perspectives in Education, 34(2), 57-69.

Clark, D. A. (2013). Creating capabilities, lists and thresholds: Whose voices, intuitions and value judgements count? Journal of Human Development and Capabilities, 14(1), 172-184.

Crosbie, V. (2014). Capabilities for intercultural dialogue. Language and Intercultural Communication, 14, 91-107.

Deneulin, S. \& Shahani. L. (Eds.). (2009). An introduction to the human development and capability approach: Freedom and agency. London: Routledge.

Flores-Crespo, P. (2007). Education, employment and human development: Illustrations from Mexico. Journal of Education and Work, 20(1), 45-66.

Hart, C. (2014). Aspiration, education and social justice: Applying Sen and Bourdieu. London: Bloomsbury.

Ibrahim, S., \& Tiwari, M. (Eds). (2014). The capability approach: From theory to practice. London: Palgrave MacMillan.

Loots, S., \& Walker, M. (2015). Shaping a gender equality policy in higher education: Which human capabilities matter? Gender and Education, 27(4), 361-375.

Loots, S., \& Walker, M. (2016). A capabilities-based gender equality policy for higher education: Conceptual and methodological considerations. Journal of Human Development and Capabilities, 17(2), 260-277.

Mathebula, M. (2018). Engineering education for sustainable development: A capabilities approach. New York: Routledge.

McLean, M., \& Walker, M. (2012). The possibilities for university-based public-good professional education: A case-study from South Africa based on the 'capability approach'. Studies in Higher Education, 37(5), 585-601.

McLean, M., \& Walker, M. (2016). A capabilities approach to educating the deliberate professional: Theory and practice. In F. Trede \& C. McEwen (Eds.), Educating the deliberate professional: Preparing for future practices (pp.141-156). New York: Springer.

McLean, M., Abbas, A., \& Ashwin, P. (2013). Human development and pedagogic rights. In A. Boni \& M. Walker (Eds.), Human development and capabilities (pp. 30-43). London: Routledge.

Mtawa, N., \& Wilson-Strydom, M. (2018). Community service learning: Pedagogy at the interface of poverty, inequality and privilege. Journal of Human Development and Capabilities, 19(2), 249-265.

Mutanga, O. (2016). Experiences of disabled students at two South African universities: A capabilities approach (unpublished doctoral dissertation). Faculty of Economic and Management Sciences, University of the Free State, Bloemfontein, South Africa. 
Mutanga O., \& Walker M. (2015). Towards a disability-inclusive higher education policy through the capabilities approach. Journal of Human Development and Capabilities, 16(4): 501-517.

Mutanga, O., \& Walker, M. (2017). Exploration of the academic lives of students with disabilities at South African universities: Lecturers' perspectives. African Journal of Disability (Online), 6, 1-9.

Nussbaum, M. (1997). Cultivating humanity. A classical defence of reform in liberal education. Cambridge, MA: Harvard University Press.

Nussbaum, M. (2000). Women and human development. Cambridge: Cambridge University Press.

Nussbaum, M. (2003). Capabilities as fundamental entitlements: Sen and social justice, Feminist Economics, 9(2/3), 33-59.

Nussbaum, M. (2010). Not for profit. Princeton, NJ: Princeton University Press.

Nussbaum, M. (2011). Creating capabilities. The human development approach. Cambridge, MA: The Belknap Press.

Nussbaum, M., \& Sen, A. (Eds.). (1993). The quality of life. Oxford: Clarendon Press.

Otto, H.-U., \&. Schafer, S. (Eds.). (2014). New approaches towards the 'good life': Applications and transformations of the capability approach. Verlag Barbara Budrich.

Peppin Vaughan, R., \& Walker, M. (2012). Capabilities, values and education policy. Journal of Human Development and Capabilities, 13(3), 495-512.

Pym, J. (2017). Voice, identity and belonging: Making a difference. In M. Walker \& M. Wilson-Strydom (Eds.), Socially just pedagogies, capabilities and quality in higher education: Global perspectives (pp. 177-200). London: Palgrave MacMillan.

Pym, J., \& Kapp. R. (2013). Harnessing agency: Towards a learning model for undergraduate students. Studies in Higher Education, 38(2), 272-284.

Robeyns, I. (2006). The capability approach in practice. Journal of Political Philosophy, 14(3), 351-76.

Robeyns, I. (2016). Capabilitarianism. Journal of Human Development and Capabilities, 17(3), 397-414.

Robeyns, I. (2017). Wellbeing, freedom and social justice: The capability approach re-examined. Cambridge: Open Book Publishers.

Sen, A. (1985). Commodities and capabilities. Oxford: Oxford University Press.

Sen, A. (1999). Development as freedom. Oxford: Oxford University Press.

Sen, A. (2004). Capabilities, lists, and public reason: Continuing the conversation. Feminist Economics, 10(3), 77-80.

Sen, A. (2008). The idea of justice. Journal of Human Development, 9(3), 331-342.

Spaull, N. (2013). South Africa's education crisis: The quality of education in South Africa 1994-2011. Johannesburg: Centre for Development and Enterprise.

Terzi, L. (2007). The capability to be educated. In M. Walker, \& E. Unterhalter (Eds.), Amartya Sen's capability approach and social justice in education (pp. 25-44). London: Palgrave MacMillan.

Tilak, J. B. (2002). Education and poverty. Journal of Human Development, 3(2), 191-207.

Unterhalter, E. (2003). The capability approach and gendered education: An examination of the complexities of South Africa. Theory and Research, 1(1) 7-22.

van Rensburg, V. J., \& Kapp, R. (2014). 'So I have to be positive, no matter how difficult it is': A longitudinal study of first generation occupational theory students. South African Journal of Occupational Therapy, 44(3), 29-33.

Walker, M. (2003). Framing social justice in education: What does the 'capabilities' approach offer? British Journal of Educational Studies, 5(2), 168-187.

Walker, M. (2005). Amartya Sen's capability approach and education. Educational Action Research, 13(1), 103-110.

Walker, M. (2006). Higher education pedagogies. Maidenhead: Society for Research into Higher Education and The Open University Press.

Walker, M. (2010). Critical capability pedagogies and university education. Educational Philosophy and Theory, 42(8), 898-917.

Walker, M. (2016). Context, complexity and change: Education as a conversion factor for non-racist capabilities in a South African university. Race, Ethnicity and Education, 19(6), 1275-1287. 
Walker, M. (2018a). Aspirations and equality in higher education: Gender in a South African university. Cambridge Journal of Education, 48(1), 123-139.

Walker, M. (2018b). Political agency and capabilities formation through participatory action research. Journal of Human Development and Capabilities, 19(1), 53-69.

Walker, M., \& Fongwa, S. (2017). Universities, employability and human development. New York: Palgrave.

Walker, M., \& Loots, S. (2016). Social citizenship formation at university: A South African case study. Compare, 46(1), 48-68.

Walker, M., \& Loots, S. (2017). Human capabilities and gender equality: What do higher education students have reason to value? In M. Cin \& A. Fogues (Eds.), Capabilities, youth and gender: Rethinking opportunities and agency from a human development perspective. London and New York: Routledge.

Walker M., \& Loots., S. (2018). Transformative change in higher education through participatory action research: A capabilities analysis. Educational Action Research, 26(1), 166-181.

Walker, M., \& McLean, M. (2013). Professional education, capabilities and the public good: The role of universities in promoting human development. London: Routledge.

Walker, M., \& Unterhalter, E. (Eds.). (2007). Amartya Sen's capability approach and social justice in education. London: Palgrave MacMillan.

Wilson-Strydom, M. (2015). University access and success: Capabilities, diversity and social justice. London: Routledge.

Wilson-Strydom, M. (2016). A capabilities list for equitable transitions to university: A top-down and bottom-up approach. Journal of Human Development and Capabilities, 17(2): 145-160.

Wilson-Strydom, M. (2017). Disrupting structural inequalities of higher education opportunity: 'Grit', resilience and capabilities at a South African university. Journal of Human Development and Capabilities 18(3), 384-398. 


\title{
THE CONCEPTUALISATION OF STUDENTS' PERSONAL TRANSFORMATION THROUGH THEIR ENGAGEMENT IN SOUTH AFRICAN UNDERGRADUATE EDUCATION
}

\author{
Paul Ashwin and Janja Komljenovic
}

\section{Introduction}

The chapters in this book are all concerned with the role that higher education plays in promoting the personal and public good. Underlying this way of viewing higher education is the assumption that higher education is personally transformational. Watson (2014) argues that discussing expectations of higher education to have a transformative impact on students highlights a number of questions, for example: What is it about higher education that is supposed to change students? How do these changes come about? What is needed for these changes to occur?

These questions are relevant to all higher education systems. For example, the European Ministers Responsible for Higher Education (2015) highlighted the importance of the personally transformative nature of higher education and its role in building 'inclusive societies, founded on democratic values and human rights'. However, these questions have a particular resonance and urgency in the South African context, given its history and that higher education is recognised in legislation as playing a distinctive and crucial role in transforming society (Department of Education, 1997) and as a key driver of 'equity, social justice and democracy' in the state's vision for 2030 (National Planning Commission, 2013).

There is an interesting contradiction in this positioning of higher education. On the one hand universities are identified as important actors of social change (McLean, 2015; Smith \& Bauling, 2013); while on the other hand they are heavily criticised for not delivering results on 
improving social justice in the country (Ellery, 2011). This again highlights questions about the meaning of the personal transformation that universities are expected to offer. In this chapter, we examine the empirical evidence relating to South African universities' contribution to student transformation. We review research published from 2007 to 2017 that analyses the ways in which students' senses of identity and the world are changed through their engagement with South African undergraduate education. We map where this research has been conducted and the student populations involved, as well as the outcomes of the studies. In the chapter, we will thus examine the following questions:

- How is the relationship between students and universities conceptualised in this research?

- How is the process of transformation conceptualised?

- What are the implications of these conceptualisations for our understanding of students' experiences of studying in South African universities?

In what follows, we will first review the concept of personal transformation and the position it holds in the South African context. We then introduce our approach to analysing the literature and present the findings. We conclude by identifying the main insights that are supported by our analysis of the literature.

\section{Higher education and personal transformation}

As Smith and Bauling (2013) argue, understanding the ways in which higher education supports personal transformation involves thinking about the relations between the political project of transformation at a societal level and personal changes that individuals undergo in their values, beliefs, assumptions and the ways they understand themselves and their society.

In the international literature on the transformative nature of higher education for students, there are two broad approaches that are taken (Ashwin, Abbas, \& McLean, 2016). First, some studies focus on the formal educational elements of students' experiences and implicitly assume that it is the educational aspects of these experiences that lead to changes in students' sense of who they are and their relations to the world. These studies tend to focus on the extent to which aspects of programme design support students in going through the stages of transformative experiences (Mezirow, 1991; Slavich \& Zimbardo, 2012; Taylor, 2007, 2008) or they focus on how students' experiences support students in becoming 'independent' (Christie, Tett, Cree, Hounsell, \& McCune, 2008; Christie, Tett, Cree, \& McCune, 2016; Scanlon, Rowling, \& Weber, 2007) or 'ideal' learners (Gale \& Parker, 2014; Reay, Crozier, \& Clayton, 2009, 2010). This approach thus tends to be narrowly focused on the formal elements of the university experience, rather than the holistic experience of being a student and tends to focus on the extent to which students meet the expectations of their educational environments.

A second approach encompasses students' wider university experiences by analysing students' orientations to university (e.g. Beaty, Gibbs, \& Morgan, 1997; Brint, 2012; Clark, \& 
Trow, 1966; Morgan \& Beaty, 1997; Spronken-Smith, Bond, Buissink-Smith, \& Grigg, 2009). However, this approach tends to assume that students are either mainly focused on the economic value of their degree; or on knowledge for its own sake. It tends to present these two binary orientations as fixed rather than dynamic and subject to change. These binary distinctions oversimplify the complexities of students' experiences and tend to be based on differences in the social class of students, rather than differences in their commitment to their education (Hurst, 2010, 2013).

Recognising the problems with these two approaches, Ashwin et al. (2016) examine students' personal transformation through engagement with undergraduate degrees by drawing on Dubet's (2000) approach to understanding student engagement. This was further developed in relation to higher education by Jary and Lebeau (2009). This involves three elements. The first element is the students' 'personal project', which reflects students' views of the value and usefulness of what they are studying. The second element is students' level of social integration into university life, which looks at the extent to which students feel a part of a community during their time at university. The third element is students' level of intellectual engagement with their studies, which can be seen as the extent to which they are personally engaged with the knowledge, ideas and concepts that they encounter during their studies. Based on an empirical examination of this proposed framework, Ashwin et al. (2016) argue that the transformational nature of undergraduate degrees might lie in the relations between these three elements, where students' sense of self is changed through their engagement with university and with knowledge. This involves students relating their personal projects to the world and seeing themselves implicated in knowledge. This process does not always happen; it requires students to be intellectually engaged with their courses, which is dependent on both students and the quality of their educational experience.

It is clear that this approach to understanding students' personal transformation through engagement in higher education was developed outside of the context of South African higher education. In this chapter, we examine how the process of personal transformation through engagement in undergraduate education has been researched in South Africa and consider the usefulness of Dubet's (2000) approach to student engagement for understanding personal transformation in the South African context.

\section{Approach to the literature}

In this chapter, we base our analysis on literature published from 2007 to 2017 that examines personal transformation in undergraduate education in South Africa. We searched for publications on Sabinet, an online database of full text South and southern African journals, and two global databases: Google Scholar and Primo Central Index. These databases were selected to give us a wide range of material from a variety of sources.

The terms that were used as search criteria were 'personal transformation', 'South Africa', 'undergraduate', 'student', 'identity' and 'identity change'. The search string applied to each 
specific database was based on the following query ('personal transformation' AND 'South Africa' AND undergraduate), ('personal transformation' AND 'student' AND 'South Africa'), ('identity change' AND 'South Africa' AND undergraduate) and ('identity' AND 'South Africa' AND undergraduate). The searches were done between October 2016 and January 2017.

In our search we focused on identifying books and papers published between 2007 and 2017, which reported on empirical studies at the undergraduate higher education level in South Africa. The following exclusion criteria were applied:

- Publications outside of our selected timescale (e.g. Bangeni \& Kapp, 2005; McKenna, 2004);

- Publications focused on postgraduates (e.g. Naudé, 2015);

- Non-empirical publications such as literature reviews, conceptual studies and general reviews (Essa \& Hoffman, 2014; Smith \& Bauling, 2013; van Schoor, 2011);

- Publications not focused on transformation that occurred through students' higher education experiences (Ndimande \& Neville, 2015; Sonday, 2015).

In total, 21 texts were included in our final sample and analysed. It is important to note that we deliberately use the word 'text' rather than 'study' because in two cases there were texts that appeared to be based on the same overall study (Rohleder, Swartz, Bozalek, Carolissen, \& Leibowitz, 2008 and Leibowitz, Bozalek, Rohleder, Carolissen, \& Swartz, 2010; Kapp \& Bangeni, 2009, 2011). We decided to include these as separate texts rather than merging them because, as separate texts, they add to the weight of what we know about students' personal transformation through engagement in higher education. We wanted to maintain this sense of how much has been published about different aspects of this transformation in the discussion of our analysis.

Each of the final 21 texts was carefully read and analysed in terms of three broad categories. First, the approach to researching personal transformation was analysed in terms of the institutional and disciplinary location of the research and the sources of data for the text in terms of the method of data generation and the size of the sample. Second, the process of transformation was analysed in terms of the site of transformation (the structure or experience through which transformation happened) and the primary object of transformation (was it student identities or student understanding that was intended to be transformed). Third, we drew these elements together to develop three overall models of student personal transformation through engagement with their undergraduate education.

\section{The approach to researching personal transformation}

The vast majority of texts (over $80 \%$ ) were focused within a single institution. Only three texts included two institutions; and one text focused on students' experiences across three 
institutions. Where the type of institution could be identified, over three quarters of these were focused on historically white institutions (HWIs). This means that the evidence we have about students' transformation through engagement with undergraduate education largely excludes the experiences of students from historically disadvantaged institutions. In terms of the academic subjects, around a third of the texts were focused on students studying the social sciences and a third on students studying medical sciences. The remaining texts were split equally between the arts and humanities, the natural sciences and engineering and projects that were not focused on particular academic subjects.

In relation to the sources of data for the texts, over $80 \%$ of the texts were based on the qualitative analysis of interview data, although in most cases these were supported by the qualitative analysis of other forms of data such as student assignments or written accounts. Only three of the texts were based on the analysis of survey data, although this is not surprising given the dynamic nature of students' transformational experiences. In terms of sample size, two thirds of the texts involved data generated from fewer than thirty students.

Overall, the picture that these texts offer us of students' transformative experiences through South African higher education is mainly based on small qualitative studies in HWIs, with a tendency to focus on the social and medical sciences. It is important that the partial picture that this creates is recognised in the next section where we discuss the way in which the processes of personal transformation are conceptualised.

\section{The process of personal transformation}

In examining the process of transformation, we looked at the site of personal transformation and the object of personal transformation.

In terms of the site of the personal transformation, around two thirds of the texts focused on how students were transformed by their engagement with a particular course or module that was an integral part of their overall programme. The other third of texts analysed how students were transformed by their engagement in service learning or a collaborative project that was in some way separate from their overall degree programme. Whilst these could be modules that formed part of the programme, they were explicitly positioned as something outside of the mainstream of the programme students were studying. The site of personal transformation tended to vary by academic subject, with $80 \%$ of the texts focused on the medical sciences examining service learning or collaborative projects, and with over $80 \%$ of those focused on the social sciences, engineering and the natural sciences examining students' engagement with particular courses or modules.

In examining the object of students' transformation, around two thirds of texts primarily analysed changes to students' identity, with over half of these relating to these changes in identity to changes in students' understanding of society, and a third primarily examined changes to students' academic knowledge. All but one of the texts examining medical sciences primarily focused on identity, whereas in the other subjects there was an equal split between a 
primary focus on knowledge and a primary focus on identity. This appeared to be related to the medical sciences tendency to focus on service learning and collaborative projects, as all of the texts examining service learning and collaborative projects were focused on changes to students' identities.

\section{The overall models of students' personal transformation}

Drawing together the analysis on the research approach and process of personal transformation, we constructed three overall models of personal transformation from the literature. The first foregrounds the changes to students' identities when they come to university; the second is focused on how students' engagement with knowledge is supported by the institutional arrangements of their education; while the third foregrounds the ways in which students' views of the world are changed by their engagement in unusual educational settings.

The first model of personal transformation tends to be found in texts that focus on the social sciences and examines how students' identities change when they come to the university (Kapp \& Bangeni, 2009, 2011; Leibowitz et al., 2005; Makalela, 2014; Vincent \& Idahosa, 2014). These texts examine how students from underprivileged backgrounds engage with a process of identity change. They tend to focus on black students, who are first generation at university, from rural areas and for whom English is not their first language. In these texts, identity is understood as complex, multiple and fluid, while the process of identity change is positioned as hard, full of struggles and challenges. The broad narrative in this model is that at the beginning of their academic studies, disadvantaged students are normally positioned as 'other' by their academic environment. Struggling with the English language as well as with the academic discourse, they often feel under stress. If they persist and conform to the academic environment, they increasingly integrate with academic and urban identities over time. These two identities (the 'home' and the 'academic' ones) are seen as separated and importantly different. These texts highlight how students' home environments (pre-university friends and family) start rejecting the students in time as they are seen to be 'becoming white' and 'becoming the other', which even further alienates students to their home environments. As a consequence, students develop nomadic and hybrid identities as they integrate elements from both their home and new environments, and often feel that they are foreign to both of them. Language and identity are strongly connected. Students increasingly use English when they go to the university, but their own language(s) stay an important part of who they are. 'Translanguaging' is the concept that can accommodate practices when students use several languages at the same time in thinking, writing, communicating and so on. In this broad approach, academic success is very much connected to identity change and compliance with academic and disciplinary discourses (more than to motivation, for example). The texts find that while students resist academic and disciplinary discourses, they also adopt them and increasingly in time become integrated with the academic 
discourse. This means that this group of texts tends to focus on the ways in which students are changed by the process of going to university, but are less focused on examining alternative institutional arrangements that might better support students' personal transformation.

The second model of personal transformation is similar to the first, and again is primarily located in the social sciences. However, this model is more focused on the role students' engagement with knowledge plays in their personal transformation and on the kinds of institutional arrangements that would better support this transformation (Calitz, 2018; Case, 2013; Ellery, 2011; Green-Thompson, McInerney, Manning, Mapukata-Sondzaba, Chipamaunga, \& Maswanganyi, 2012; Leibowitz et al., 2010; McLean, 2015; Manyonga, 2016; Rohleder et al., 2008; Walker, 2016). These texts examine the ways that the education environment and pedagogic practices can positively impact on students' interpretations, understandings and beliefs and the practices that inhibit students' opportunities to engage productively with their educational settings. A number of these studies look at the ways in which educational settings support or inhibit the development of key capabilities that can help to address inequalities in South African society (Calitz, 2018; McLean, 2015; Manyonga, 2016; Walker, 2016), including questions around the ways in which students can recognise themselves in the knowledge that makes up their curricula.

The third model, which was found primarily in texts looking at the medical sciences, is focused on how personal transformation comes from unusual situations or special educational practices, as are found in service learning and collaborative projects. In a number of studies these are positioned as only coming from outside the traditional curriculum and experiences of students (Berman \& Allan, 2012; Efthimiadis-Keith, 2007; Janse van Rensburg, Poggenpoel, \& Myburgh, 2012; Moagi, van Rensburg, \& Maritz, 2013; Stears, 2009; Sutherland, 2013). As the innovations explored in these texts are largely situated outside of the academic curriculum, they tend to focus on how students' experiences help them to develop a new understanding of South African society, rather than how this is informed by their engagement with academic knowledge. Within these texts there can be a tendency to adopt an implicit positon that exposing students to a wider range of people and circumstances will lead to them developing more inclusive outlooks, rather than considering whether this might also lead to the confirmation of attitudes that perpetuate exclusion.

\section{Framework of students' personal transformation in South Africa}

If we examine the three models of personal transformation using Dubet's (2000) concepts of personal project, social integration and intellectual engagement, it becomes clear that whilst they offer a useful way of framing personal transformation, they are in need of some extension to make sense of the South African research.

All three of the models can be understood in terms of Dubet's concepts. The first model is focused on the development of students' personal projects as they enter university, the 
second model foregrounds the relationship between students' intellectual engagement and their social integration into their universities. The third model examines how students' personal projects are developed by engagement in unusual education settings. However, there are important elements of the South African research that are not covered by Dubet's concepts. The first model of personal transformation highlights the ways in which students have an ongoing relationship with their 'home' environments during their time as university students. This relationship goes beyond what is captured by their personal projects and appears to play an important role in students' experiences of university. The second model of transformation highlights the ways in which students can recognise themselves in the knowledge they engage with at university. This goes beyond intellectual engagement with knowledge to raise questions about whose identities are included and excluded by this knowledge. The third model of personal transformation highlights the ways in which students' understanding of their wider society is shaped by their educational experiences. Whilst this is partly captured by the idea of social integration, it goes beyond students' integration into their university context to highlight students' understanding of how they are positioned and integrated in South African society.

All of these ways of extending Dubet's (2000) concepts highlight the dangers of considering students' engagement with higher education separately from their engagement with their lives and societies outside of higher education. Whilst the stark inequalities within South African society bring these issues to the foreground, they are likely to be equally relevant to an understanding of students' experiences of personal transformation in other higher education systems. The tendency to consider higher education and universities as separate from society rather than an integrated part of society, can be seen to limit the kinds of questions that we ask about the role of higher education in personal transformation. It is highlighted in the tension identified earlier between the presentation of the higher education system as negative and conservative, whilst the transformation of students through higher education largely is positioned as positive and radical. It also means that across the international and South African literature there is very little consideration of the ways in which students might be transformed that reinforce, rather than challenge, existing inequalities.

This separation of higher education from society also highlights the difficulties in linking personal transformation to the wider political project of the transformation of South African society. Whilst some studies examine the ways in which graduates might develop capabilities that contribute to the development of a more equal society, this tends to be focused at an individual level, rather than examining what structures might be developed that support personally transformed graduates to contribute to the development of a more equal society. The tendency for research to be conducted in single, historically advantaged institutions further exacerbates the sense that we only know about the experiences of personal transformation for students within a small number of relatively privileged South African universities and do not know how engagement with higher education impacts on the identities of students from other institutions. 


\section{Conclusion}

In concluding this chapter, we want to consider both how the research into students' personal transformation might be developed further, both in terms of extending what is currently done in South Africa and in terms of approaching this research in ways that that does not separate higher education from society.

In relation to the South African research, there is clearly a need for more studies that examine students' experiences across a range of institutions and academic subjects, rather than within single institutional and disciplinary settings. There is also a need for more studies that examine the nature of curriculum and the challenges of offering students access to academic knowledge in ways that do not deny or ignore who they are in terms of their backgrounds and identities. It is notable that most of the existing studies that tackle these questions are in the humanities and social sciences. It is far more difficult to develop a sense of what it might mean to develop a curriculum that accepts who students are, but also gives them access to academic knowledge in the natural sciences and engineering.

In relation to approaching this research in ways that do not separate higher education and society, there is also a need to examine the consequence of going to university by studying exactly that - how graduates engage with society after their higher education. Whilst recent studies have begun to examine this with positive findings about graduates' commitment to the public good (e.g. Case, Marshall, McKenna, \& Mogashana, 2018; Ndimande \& Neville, 2015), there is a need to consider the ways in which graduates and non-graduates come together in society. Doing so would allow a consideration of whether higher education primarily represents a way of insulating individuals from the challenges of their society or can offer a way of addressing these challenges for the benefit of all members of that society.

\section{References}

Ashwin, P., Abbas, A., \& McLean, M. (2016). Conceptualising transformative undergraduate experiences: A phenomenographic exploration of students' personal projects. British Educational Research Journal, 42(6), 962-977.

Bangeni, B., \& Kapp, R. (2005). Identities in transition: Shifting conceptions of home among 'black' South African university students. African Studies Review, 48(3), 1-19.

Beaty, L., Gibbs, G., \& Morgan, A. (1997). Learning orientations and study contracts. In F. Marton, D. Hounsell, \& N. Entwistle (Eds.), The experience of learning (pp. 72-86). (2nd ed.). Edinburgh: Scottish Academic Press.

Berman, K., \& Allen, L. (2012). Deepening students' understanding of democratic citizenship through artsbased approaches to experiential service learning. South African Review of Sociology, 43(2), 76-88.

Brint, S. (2012). Undergraduate student orientations in the United States: Academically adrift? Bildung und Erziehung, 65(2), 195-207.

Calitz, T. (2018). Enhancing the freedom to flourish in higher education: Participation, equality and capabilities. London: Routledge.

Case, J. (2013). Researching student learning in higher education: A social realist approach. London: Routledge. 


\section{HigheR EDUCATION PATHWAYS}

Case, J., Marshall, D., McKenna, S., \& Mogashana, D. (2018). Going to university: The influence of higher education on the lives of young South Africans. Cape Town: African Minds.

Christie, H., Tett, L., Cree, V., Hounsell, J., \& McCune, V. (2008). 'A real rollercoaster of confidence and emotions': Learning to be a university student. Studies in Higher Education, 33, 567-581.

Christie, H., Tett, L., Cree, V. E., \& McCune, V. (2016). 'It all just clicked': A longitudinal perspective on transitions within university. Studies in Higher Education, 41, 478-490.

Clark, B., \& Trow, M. (1966). The organisational context. In T. Newcomb \& E. Wilson (Eds.), College peer groups: Problems and prospects for research (pp. 17-70). London: Aldine Publication.

Department of Education (1997). White paper on higher education. Pretoria: Department of Education, Government of the Republic of South Africa.

Dubet, F. (2000). The sociology of pupils. Journal of Education Policy, 15, 93-104.

Efthimiadis-Keith, H. (2007). Personal transformation and leadership: Student responses to the Life-skills module at the University of Limpopo, 2003-2006. South African Journal of Higher Education, 21 (7), 858-869.

Ellery, K. (2011). Knowing, acting and being: Epistemological and ontological access in a Science Extended Studies course. South African Journal of Higher Education, 25(6), 1077-1090.

Essa, I, \& Hoffman, J. (2014). Exploring development of leadership capacities in undergraduate nursing students through transformative learning: A narrative review. African Journal for Physical, Health Education, Recreation and Dance (AJPHERD) Supplement 1:1, 217-214.

European Ministers Responsible for Higher Education (2015). Yerevan Communiqué. May 14-15. Yerevan. Retrieved from http://www.ehea.info/Uploads/SubmitedFiles/5_2015/112705.pdf

Gale, T., \& Parker, S. (2014). Navigating change: A typology of student transition in higher education. Studies in Higher Education, 39(5), 734-753.

Green-Thompson, L. P., Mclnerney, P., Manning, D. M., Mapukata-Sondzaba, N., Chipamaunga, S., \& Maswanganyi, T. (2012). Reflections of students graduating from a transforming medical curriculum in South Africa: A qualitative study. BMC Medical Education, 12(49), 1-9.

Hurst, A. (2010). Schoolcraft vs. becoming somebody: Competing visions of higher education among workingclass college students. Qualitative Studies, 1(2), 75-90.

Hurst, A. (2013). Student types as reflection of class habitus: An application of Bourdieu's scholastic fallacy. Theory and Research in Education, 11(1), 43-61.

Janse van Rensburg, E. S., Poggenpoel, M., \& Myburgh, C. P. H. (2012). Student nurses' experience working with mentally challenged individuals in South Africa. Journal of Psychiatric and Mental Health Nursing, 19(9), 761-769.

Jary. D., \& Lebeau, Y. (2009). The student experience and subject engagement in UK sociology: A proposed typology. British Journal of Sociology of Education, 30, 697-712.

Kapp, R., \& Bangeni, B. (2009). Positioning (in) the discipline: Undergraduate students ' negotiations of disciplinary discourses. Teaching in Higher Education, 14(6), 587-596.

Kapp, R., \& Bangeni, B. (2011). A longitudinal study of students' negotiation of language, literacy and identity. Southern African Linguistics and Applied Language Studies, 29(2), 197-208.

Leibowitz, B., Adendorff, H., Daniels, S., Loots, A., Nakasa, S., Ngxabazi, N., ... van Deventer, I. (2005). The relationship between identity, language and teaching and learning in higher education in South Africa. Per Linguam, 21(2), 23-37.

Leibowitz, B., Bozalek, V., Rohleder, P., Carolissen, R., \& Swartz, L. (2010). 'Ah, but the whiteys love to talk about themselves': Discomfort as a pedagogy for change. Race Ethnicity and Education, 13(1), 83-100.

Makalela, L. (2014). Fluid identity construction in language contact zones: Metacognitive reflections on Kasi-taal languaging practices. International Journal of Bilingual Education and Bilingualism, 17(6), 668-682.

Manyonga, B. (2016). The sociology curriculum, pedagogy and capabilities formation: A case study in two South African universities (unpublished doctoral dissertation). University of the Free State.

McKenna, S. (2004). The intersection between academic literacies and student identities. South African Journal of Higher Education, 18(3), 269-280.

McLean, M. (2015). 'Promising spaces': Universities' critical-moral mission and educative function. Critical Studies in Teaching and Learning, 3(2), 1-22. 
Mezirow, J. (1991). Transformative dimensions of adult learning. San Francisco: Jossey-Bass.

Moagi, M., van Rensburg, E. J., \& Maritz, J. (2013). Student nurses' experiences of the clinical psychiatric learning environment in an education institution. Journal of Psychology in Africa, 23(2), 359-362.

Morgan, A., \& Beaty, L. (1997). The world of the learner. In F. Marton, D. Hounsell, \& N. Entwistle (Eds.), The experience of learning (pp. 217-237). (2nd ed.). Edinburgh: Scottish Academic Press.

National Planning Commission (2013). National Development Plan: Vision for 2030.

Naudé, L. (2015). On (un) common ground: Transforming from dissonance to commitment in a service learning class. Journal of College Student Development, 56(1), 84-102.

Ndimande, B. S., \& Neville, H. A. (2015). Urban education and black racial identity in South Africa. Urban Education, 1-28.

Reay, D., Crozier, G., \& Clayton, J. (2009). 'Strangers in paradise?' Working-class students in elite universities. Sociology, 43(6), 1103-1121.

Reay, D., Crozier, G., \& Clayton, J. (2010). 'Fitting in' or 'standing out': Working-class students in UK higher education. British Educational Research Journal, 36(1), 107-124.

Rohleder, P., Swartz, L., Bozalek, V., Carolissen, R., \& Leibowitz, B. (2008). Community, self and identity: Participatory action research and the creation of a virtual community across two South African universities. Teaching in Higher Education, 13(2), 131-143.

Scanlon, L., Rowling, L., \& Weber, Z. (2007). 'You don't have like an identity ... you are just lost in a crowd': Forming a student identity in the first-year transition to university. Journal of Youth Studies, 10(2), 223-241.

Slavich, G., \& Zimbardo, P. (2012). Transformational teaching: Theoretical underpinnings, basic principles, and core methods. Educational Psychology Review, 24(4), 569-608.

Smith, S., \& Bauling, A. (2013). Aiming for transformation: Exploring graduateness in South Africa. Stellenbosch Law Review, 24, 601-617.

Sonday, A. (2015). A case study of professional role transition for occupational therapists in specialised education in post-apartheid South Africa: A critical narrative (unpublished doctoral dissertation). University of Cape Town.

Spronken-Smith, R. A., Bond, C., Buissink-Smith, N., \& Grigg, G. (2009). Millennium graduates' orientations to higher education. College Student Journal, 43(2), 352-365.

Stears, M. (2009). Incorporating service-learning in science education: The impact on students and teachers. South African Journal of Higher Education, 23(2), 386-397.

Sutherland, A. (2013). The role of theatre and embodied knowledge in addressing race in South African higher education. Studies in Higher Education, 38(5), 728-740.

Taylor, E. (2007). An update of transformative learning theory: A critical review of the empirical research (1999-2005). International Journal of Lifelong Education, 26(2), 173-191.

Taylor, E. (2008). Transformative learning theory. New Directions for Adult and Continuing Education, 119, 5-15.

van Schoor, W. (2011). You can lead a horse to water but you can't make it drink: The development of transformed situated agency to facilitate the integration of students into institutions. First Year in Higher Education Conference, Fremantle, 28 June-1 July.

Vincent, L., \& Idahosa, G. E. (2014). 'Joining the academic life': South African students who succeed at university despite not meeting standard entry requirements. South African Journal of Higher Education, 28(4), 1433-1447.

Walker, M. (2016). Context, complexity and change: Education as a conversion factor for non-racist capabilities in a South African university. Race Ethnicity and Education, 19(6), 1275-1287.

Watson, D. (2014). The question of conscience: Higher education and personal responsibility. London: Institute of Education Press. 


\title{
UNDERSTANDING THE RELATIONSHIP BETWEEN INSTITUTIONAL CULTURES AND PEDAGOGICAL CHANGE
}

\author{
Rebecca Schendel
}

In the South African context, the notion of higher education 'for the public good' is inextricably linked with the concept of 'transformation'. Having been actively involved in the racialised social organisation of the apartheid era (i.e. through the classification of institutions along racial lines), higher education institutions are now expected to overcome their historical legacies and work to transform South Africa into a more democratic and equitable society. Although the research and service functions of the sector play an important role in social transformation, it is the teaching function that is seen to play the most significant role in this process, by supporting students to develop into 'enlightened, responsible and constructively critical citizens' (Department of Education [DOE], 1997, p. 4) who are committed to rectifying the country's historical ills through their lives and work.

Despite these lofty ambitions for the sector, it is apparent that higher education institutions across South Africa are not yet fulfilling this ideal, as outlined in Chapter 1. Indeed, higher education remains implicated in the perpetuation of deep inequalities in South African society. Amongst a raft of possible reasons that have been proposed for this inertia within the sector, one persuasive possibility that is often advanced is the limited uptake of the kinds of 'transformational' pedagogies that are most likely to inspire students to work on behalf of the public good. Many have argued that the kind of personal development necessary for the achievement of the country's social transformation goals requires a radically different kind of university pedagogy than the kind that has traditionally been provided by universities - one that explicitly exposes students to the 'socio-economicpolitical-historical contexts in which they (will) work' (McLean, Walker, Dison, \& Vaughan, 2008 , p. 11) - encourages them to imagine alternative futures and, crucially, fosters the disposition to act upon those imaginings following graduation (Unterhalter, 2010). 
In 2007, a paper published by the Council on Higher Education (CHE) placed the blame for the unfulfilled promise of higher education transformation on entrenched 'institutional cultures' within universities (Higgins, 2007). Myriad accounts published in the years following the $\mathrm{CHE}$ report have supported this argument, by highlighting elements of both the overt and the hidden curriculum that continue to perpetuate racist attitudes within university classrooms (e.g. McKinney, 2007) and contribute to inequalities in completion and graduation rates across the sector (Bhorat, Mayet, \& Visser, 2010). This account of institutional culture as a barrier to pedagogical change stands in marked contrast to the 1997 White Paper on South African higher education, which - although also acknowledging the damaging impact of entrenched cultures of racism within many of the country's universities - positioned institutional culture as a key catalyst for change, positing that it was possible to develop new institutional cultures capable of 'facilitat[ing] behaviour aimed at peaceful assembly, reconciliation, respect for difference and the promotion of the common good (DOE, 1997, p. 37, emphasis added). The result of this conceptual tension is confusion around the particular role that institutional cultures play in processes of pedagogical transformation (despite broad consensus around their importance) and a related limited understanding of how institutions might work to challenge the entrenched aspects of culture that work against the possibility of positive change.

A key question is whether further theoretical discussion about what institutional culture is (or what institutional cultures are), how culture relates to pedagogical change, and how institutions might go about engaging with this relationship, would help higher education institutions in South Africa to address the deeply entrenched inequalities that persist in the sector. In other words, to what extent might theoretical understandings of the relationship between institutional culture(s) and pedagogy help to explain the limited uptake of transformational pedagogies in the South African context - and how might the development of shared understandings help the sector to move forward?

This chapter engages with this question by honing in on one particular source of such theoretical understandings in the South African context, the South African Journal of Higher Education (SAJHE), which is the most widely read journal publishing research on South African higher education (Deacon, Osman, \& Buchler, 2009). Although the work of any one journal is necessarily limited in its scope, analysis of the ways in which the relationship between institutional cultures and pedagogical change have been conceptualised within the SAJHE offers useful insights into the understandings that are likely to have guided both policy and practice in South Africa, given its broad local readership and its mission to 'provide institutions of higher education and professional readers with scholarly information on major innovations in higher education, research projects and trends' (SAJHE, n.d.). The chapter, which relies on a review of SAJHE articles published between 2007 and 2017, shows that discussions of institutional culture in the journal have become more locally specific over this period, with earlier articles broadly reflecting understandings derived from the Western contexts which tend to dominate the literature (i.e. the USA and UK) and more recent articles beginning to 
propose more localised understandings. Although the emergence of a more contextually relevant understanding of institutional cultures is a positive development, the picture presented by the SAJHE literature remains quite partial, with only certain institutions (and certain individuals within those institutions) being represented. Given the journal's influence within the sector, these gaps are likely to have had a significant impact on the ability of those working within higher education institutions to fully comprehend the ways in which attempts to change pedagogy might be undermined by institutional cultures and, as such, may have limited the impact of many attempts at pedagogical change within the sector.

The chapter begins with a brief discussion of the assumed links between institutional culture(s) and pedagogical change, before presenting the results of the SAJHE review. It concludes by, first, drawing out some important implications of the analysis for the broader international literature on change within higher education institutions and, second, highlighting the practical implications of this theoretical discussion for those working to reform pedagogy within South Africa’s universities.

\section{Unpacking the assumed links between institutional culture(s) and pedagogical change}

Early definitions of institutional culture in higher education (e.g. Schein, 1985) first emerged in the USA in the 1980s and were largely influenced by the more general literature on organisational culture, which originated in the fields of organisational psychology and business management. This tradition emphasises norms, values, perceptions and shared understandings as the key components of culture and, as such, often focuses on the myriad symbols and representations of assumed values and norms present within an institution. Although this tradition retains a high profile in the contemporary literature, many theorists have moved beyond this largely symbolic understanding of culture to include the behaviours of individuals within institutions. Tierney's (2008) framework, for instance, incorporates elements such as 'socialisation' (i.e. the process by which individuals learn about the values and practices of the institution) and 'mission' (which Tierney describes as having both a technical definition - that is, the stated purpose of an institution - and a sociological dimension - that is, the priorities reflected by the behaviour of individuals within the institution). Indeed, Tierney's definition of organisational culture as 'what is done, how it is done, and who is involved in doing it' (p. 24) reflects an understanding of culture as being largely enacted, not simply represented through symbols and rituals. Some more recent work, largely from the UK, has added further nuance to the discussion by acknowledging that individuals within institutions (and, indeed, institutions themselves) simultaneously inhabit multiple worlds and are differentially affected by those worlds in ways that affect ongoing interactions within an institution. Ashwin's work, which positions the 'field' of higher education as a 'game in which different players compete in order to maintain and develop different types of capital' (2009, p. 110), is indicative of this latter body of literature. 
A key tension in the literature is the question of whether one monolithic institutional 'culture' can ever be identified within a university, given the 'loosely coupled' nature of higher education (Weick, 1976). Clark's notion of the 'organisational saga' (1972) is representative of one end of the spectrum, as he argues that at least some institutions have strong unifying cultures, typically due to a particularly influential founding myth or charismatic leader (or leaders). Although Clark's work maintains some influence, much of the contemporary literature has moved away from the idea of universities having one central culture, with most theorists at least acknowledging that there are multiple 'cultures' within any university. Indeed, the existence of multiple (sometimes competing) cultures within institutions is often advanced as one of the key characteristics of higher education, which renders it different from other kinds of organisations in society. Even within the multiple cultures discourse, however, differences remain, with some theorists highlighting the various levels of the institution, i.e. the institution as a whole, the subgroups within it, and the individuals themselves (e.g. Martin, 1992), and others focusing largely on the disciplinary cultures present within universities (e.g. Becher, 1989). To some extent, these differences are nationally specific, with American theorists being more likely to discuss multiple cultures within institutions in terms of structures and British theorists being more likely to focus on the role of the disciplines, but this is not a universal pattern.

It is possible to identify literature based on all of these different definitions of institutional culture when examining writing on pedagogical change within higher education. From the 'culture as a barrier' end of the spectrum comes work examining the ways in which the dominant norms and values within an institution inhibit attempts to change pedagogy. At the other end of the spectrum is work which advocates for explicitly changing the culture of an institution (or a sub-unit within an institution) in order to embrace a particular orientation towards, or 'culture of', teaching (e.g. Cox, McIntosh, Reason, \& Terenzini, 2011). Other work maintains an understanding of culture as being largely resistant to change but still allows for the possibility of change to occur. Kezar (2014), for example, argues that, in general, leaders are more effective at creating change when they explicitly structure their change strategies to work with, rather than against, the dominant institutional culture, although she does acknowledge that pedagogical change is particularly difficult for leaders to effect, given that it 'involves unlearning the values associated with the existing mode of teaching' (p. 33). Trowler's work on 'teaching and learning regimes' (e.g. Knight \& Trowler, 2000; Trowler, 2005; Trowler \& Cooper, 2002) also falls within this category, but with a particular focus on the academic department as a key institutional sub-unit in this regard.

The literature also varies in terms of the particular mechanisms through which institutional culture is assumed to influence pedagogy. Much of the work of teaching and learning which acknowledges the influence of culture presents the relationship between culture and pedagogy as one in which one concept is simply subsumed by the other, for example work which focuses on the norms and values related to teaching within an institution's culture or cultures (e.g. Cox et al., 2011). However, some writing - particularly by those theorists focused on the sociological dimensions of culture - explicitly acknowledges the behaviour of academics as the link between 
cultural norms and pedagogical practice (e.g. Trowler, 2005). In this tradition, pedagogy is not merely assumed to 'be' part of an institution's culture; rather, culture is seen to affect academics' behaviour and/or attitudes toward teaching, which then translates into pedagogical choices within university classrooms. Another body of literature further nuances this understanding by acknowledging the role of academic identities in the enactment of pedagogy (e.g. Schendel, 2016a, 2016b). This perspective acknowledges the influence of cultural norms and values on the identities of academic staff, which then influence academic behaviour and pedagogical choices. A particularly valuable contribution of this latter body of literature is the theoretical framework it provides for explaining the decisions of academics to move between institutions, as it acknowledges that there can be tensions between individual academic identities and institutional cultures, which can push academics to seek other institutions where there is better 'identity coherence' (as discussed in Henkel, 2000).

\section{Understandings within the SAJHE}

As higher education systems around the world grapple with the challenges of transforming more 'traditional' forms of pedagogy within their institutions, the literature on pedagogical change within universities has become increasingly international in scope and, as such, it is now possible to find a broad geographic diversity of literature focused on institutional culture as a barrier or a catalyst for pedagogical change within higher education. However, theoretical understandings of how institutional cultures interact with institutional change processes, including those focused on pedagogy, remain heavily influenced by the best-known theories of institutional culture, nearly all of which originated in the USA or the UK. Although some of these theories may be broadly applicable, others rest on a number of assumptions which may not hold in other systems of higher education. In order to probe whether South Africa's institutions of higher education might be suffering from an over-reliance on inapplicable theoretical understandings of the relationship between institutional cultures and pedagogical change, a review was undertaken of the literature on institutional culture and pedagogy published by the South African Journal of Higher Education (SAJHE) between 2007 and 2017. Although the SAJHE is not representative of all literature related to South African higher education, it is the most widely read journal publishing research on the subject (Deacon et al., 2009), and, as such, the theoretical understandings that it promotes are likely to have an important formative influence on a) other writing on institutional cultures and pedagogy in the South African context; and b) policy and practice within the South African higher education sector. An analysis of the ways in which this relationship has been conceptualised within the journal can therefore offer important insights into the ways in which international understandings of this relationship have shaped, but also may differ from, local writing on the topic.

A review of the titles of all SAJHE articles published between 2007 and 2017 yielded a sample of 42 articles which relate to issues of curriculum and/or pedagogy. After these 42 were read in full, 30 articles were retained for analysis, due to their inclusion of at least some 
discussion, or description, of institutional culture. The content of these 30 articles was then examined, with a specific focus on: a) any links with - or differences from - key themes and understandings present in the 'international' (i.e. Western) literature, and b) any evidence of change in the discourse over the ten-year period of the review.

As would perhaps be expected, the 30 articles represent a broad range of viewpoints as to the end goal of pedagogical 'change' in South African higher education, with some articles presenting technical goals (e.g. the adoption of 'outcomes-based' curricula) and others explicitly engaging with the political dimensions of pedagogical transformation (e.g. the adoption of 'socially just pedagogies', designed to counter entrenched inequalities in South African society). Diversity in the level of analysis can also be identified, with some authors discussing culture at an institutional level (e.g. Garnett \& Pelser, 2007) and others focusing in on particular departments or, in some cases, academic programmes (e.g. Bozalek \& Dison, 2013; Duthie \& Freeman, 2015; Heydenrych \& Case, 2015).

Similar to the American and British literature, the articles also represent a broad range of understandings of what institutional culture is and whether it can be changed. However, the first key finding from the review is that these understandings of institutional culture appear to have developed considerably over the ten-year period, with some locally specific definitions gaining traction over time.

The earliest articles on the topic at least implicitly rely on some of the early theories of institutional culture coming out of the USA and the UK. Many of the early articles, for instance, either explicitly state or implicitly assume that leaders can change the culture of teaching, either across an institution as a whole or within institutional 'sub-units', such as faculties or departments (e.g. Leibowitz \& Adendorff, 2007). Many that identify cultural barriers to change (e.g. Garnett \& Pelser, 2007; Ntshoe, Higgs, Higgs, \& Wolhuter, 2008; Par \& van der Merwe, 2009; Rothmann, Barkhuizen, $\&$ Tytherleigh, 2008) do so with a pragmatic purpose (i.e. in order to outline the cultural constraints that institutional leaders will need to address in order to improve their change strategies). They also tend to resemble similar work from the USA and the UK in the barriers that they identify (e.g. institutional missions which do not prioritise teaching; limited resources available for teaching; institutional norms, such as academic workload models, which inhibit the adoption of time-intensive pedagogies; etc.).

However, key differences begin to emerge around 2009, possibly in response to the 2007 Council on Higher Education (CHE) report which explicitly acknowledged the particular position of institutional culture in the history of South African higher education. From 2009 onwards, it is possible to identify two broad themes in the SAJHE literature which differ significantly from British and American understandings of institutional culture and its relationship with pedagogy.

First, the literature from 2009 onwards engages much more explicitly with the entrenched nature of racialised institutional cultures in the South African context. Institutional culture (often used euphemistically to refer to racially distinct institutional histories) is acknowledged as directly affecting pedagogical transformation through, for example, the maintenance of 
particular language of instruction policies (Walker \& McLean, 2010) or the perpetuation of detrimental racialised attitudes regarding the academic ability of black students (Hemson $\&$ Singh, 2010; Mgqwashu \& Bengesai, 2015). Discussion of the impact of institutional culture on academic identity and, relatedly, motivation to improve teaching also features strongly in the SAJHE literature post-2009 (e.g. Hemson \& Singh, 2010; Leibowitz, 2016b; PithouseMorgan, Masinga, Naicker, Hlao, \& Pillay 2016; Vandeyar, 2010).

Institutional history is discussed as an important component of culture throughout the international literature (Kezar, 2001). However, the particular role of higher education in perpetuating the apartheid regime - and, indeed, the particular position of pedagogy in that perpetuation (Badat, 2009) - problematises the possibility of applying foreign understandings of how institutional culture affects pedagogical change to the South African context. It is, therefore, unsurprising that locally specific understandings of the link between culture and pedagogy have started to emerge in the South African literature.

The second key theme is how the institutional mergers, which were implemented across the country in the post-apartheid era as a way to redress historical inequalities of funding between historically white and historically black institutions, have problematised the notion of 'institutional culture' in the South African context. As a result of the merger process, institutions had to undergo a long and sometimes painful process of reconciling their histories, their perceptions of their role in the sector, and their strategic visions for the future in order to develop a new image of themselves (both externally and internally). In many cases, the power relations between the merging institutions was such that one institution essentially 'lost' its identity to the other, rather than forging a truly new identity, with inevitable impacts on staff identity and morale (Baloyi \& Phago, 2012; Reddy, 2007). In others, the merger process served to exacerbate, rather than address, the entrenched racial identities of the former institutions (Hemson \& Singh, 2010). Although the literature on merged institutions in the South African context is somewhat reminiscent of international literature which focuses on competing norms and values within the same institution, the particular purpose of the institutional mergers in South Africa (i.e. to 'create' new institutional cultures capable of driving social transformation) necessitates a localised understanding of how such fragmented cultures affect pedagogy. The SAJHE articles, which consider pedagogical change within merged institutions, contribute to such an understanding by highlighting various ways in which the merger process has limited the possibility of productive pedagogical change within institutions, for example by preventing the development of a unified strategy for curriculum reform (Bester \& Scholtz, 2012; Sattar \& Cooke, 2012) or by introducing logistical impediments to pedagogical innovation (see, for example, Roy, 2007, on the difficulties in establishing Centres for Teaching, \& Learning at universities in the Eastern Cape).

An additional finding of the review is that representations of institutional culture in the literature somewhat differ by institutional type. The majority of SAJHE articles about the entrenched racialised nature of institutional culture in South Africa, for instance, rely on evidence from merged institutions, with one additional article (Vandeyar, 2010) focusing on 
the experience of black academics within a historically white, Afrikaans-medium institution. This is unsurprising, given that merged institutions have had to explicitly contend with the integration of at least two racially-differentiated institutional histories. It also reflects Higgins' (2007) contention that 'institutional culture' is simply code for 'whiteness' within many of South Africa's historically advantaged institutions. A key caveat to this point, of course, is that racialised histories and cultures are often differentially perceived by different individuals within institutions. In her study, for instance, Vandeyar (2010) also interviewed a white Afrikaansspeaking academic who did not perceive any racial dimension to the socialisation processes operating within her institution (a finding which stood in marked contrast to the perceptions of black academics within her sample). A limitation of the SAJHE literature reviewed for this chapter is how few articles explicitly engage with the multiple cultures within institutions or with the different experiences of particular groups of individuals within those diverse cultural contexts.

Meanwhile, those articles reflecting a less static understanding of institutional culture (i.e. those which position institutional culture as something that can be changed, provided that those leading the change strategy work within the cultural norms of the institution) mostly reflect the experiences of better resourced universities. Although there are examples of literature in this vein coming from English-medium, Afrikaans-medium, historically black and historically white institutions (e.g. Bitzer, 2010, regarding Stellenbosch University; Small, Smith, Williams, \& Fataar, 2011 and Bozalek \& Dison, 2013, re the University of the Western Cape; and Duthie \& Freeman, 2015 and Heydenrych \& Case, 2015 re the University of Cape Town), all of the positive examples of culture being leveraged to effect pedagogical change come from institutions that hold positions of relative financial advantage within the sector. This may simply reflect the relative likelihood of academics from more advantaged institutions having the time and resources to publish articles on pedagogical change, but it may also indicate that those institutions with more material resources at their disposal have been able to better effect pedagogical change on their campuses, a theme picked up by Leibowitz (2016a) in her study of factors affecting the adoption of 'socially just pedagogies'. This is at least theoretically possible, given that most of the 'success stories' in the literature present examples of institutions working through individual departments to effect change in pedagogy, a process which is both time and labour intensive.

This review is clearly limited in its scope, given that it only focuses on articles published within one journal. As the editorial boards of journals always exhibit particular preferences in their choices of articles to publish, there is no escaping the fact that any one journal can only ever give a partial account of the literature on a given topic. The themes discussed within the articles included in this review do, in fact, give a partial account of the topic of institutional culture, as there is a lack of engagement with a number of important themes examined by others writing on the topic. Beverly Thaver, for instance, has focused specifically on the government's mandate that universities increase their hiring of black academics as an explicit strategy for changing institutional culture (a policy initiative which reflects a particular 
understanding of how academic 'identities' drive pedagogical change). As the intention behind the hiring policy is that 'new entrants to South African higher education will be carriers and creators of different cultural norms and practices' (Thaver, 2009, p. 28, emphasis added), the impacts of the policy (or lack thereof) are a crucial aspect of the link between institutional culture and pedagogical change. However, there is limited engagement with the topic within the SAJHE, aside from a few articles focused on the socialisation difficulties experienced by black academics hired by historically white institutions as a result of the policy. There is also very little about the role of language in perpetuating entrenched cultural norms, despite the fact that language is a powerful cultural symbol which both literally and figuratively excludes students and staff from certain racial and ethnic backgrounds (Thaver, 2009).

The range of institutions represented by work published within the SAJHE is also an important limitation of the review. In particular, the review is restricted in its ability to engage with questions of institutional culture within relatively disadvantaged historically black institutions (HBIs). Although a number of articles focus on research conducted within HBIs, most have worked with more advantaged institutions, such as the University of the Western Cape, or have included very little institutional-level analysis of how culture may differ across institutional types. For instance, there is an understandable focus on the experience of black academics within historically white or merged institutions within the literature, but the lack of engagement with questions about how culture is perceived by black academics within historically black institutions limits our ability to understand how institutional culture relates to pedagogy in such contexts. If similar tensions to those examined within historically white institutions were to be identified between the individual identities of black academics and the institutional cultures of more disadvantaged historically black institutions, then we would have a more nuanced understanding of how assumptions around knowledge, curricular content and relationships within classrooms can serve to inhibit pedagogical transformation, even in the absence of an explicit history of racial exclusion and support for the apartheid regime. However, we can only guess at such relationships if there is no examination of these questions within the published literature and that limits our ability to fully comprehend the role of institutional culture in perpetuating or challenging pedagogical norms across the sector.

\section{Implications, contributions and ways forward}

When taken as a whole, the literature reviewed for this chapter clearly confirms that institutional culture is a crucial consideration that must inform any discussion of how higher education can contribute to the public good in South Africa. Although it presents a largely pessimistic picture, which suggests that institutional cultures have proven largely resistant to change and have therefore largely served as a barrier to the uptake of more transformative approaches to pedagogy, there are individual stories of hope which can be identified, particularly within some of the more recent literature examining successful departmental-level and cross-institution 
initiatives (e.g. Bozalek, Carolissen, Leibowitz, Nicholls, Rohleder, \& Swartz, 2010) implemented by some of the better resourced institutions in the sector.

The review also makes some important theoretical contributions. First, it underscores the highly contextual (and political) nature of the concept of institutional culture. As such, it problematises the common practice of uncritically applying theoretical understandings of institutional culture, developed within particular systems of higher education, to contexts with fundamentally different experiences with - and histories of - higher education. Although often acknowledged as problematic, the practice remains widespread, due to the dominance of particular countries within the internationally accessible published literature. Although some analysis of institutional culture is broadly applicable across national borders, much is contextspecific and assumes an understanding of the conditions giving rise to the theoretical perspectives advanced. Such nuance is often missing in literature that relies on theoretical understandings developed outside of the local context in question, particularly when those understandings are part of the dominant (i.e. Western) canon.

At the same time, the review offers an important reminder of the potential wider benefit of theoretical understandings emerging from parts of the world less traditionally represented on the global stage. The literature on institutional culture presented in this chapter has much to offer to those interested in the concept outside of South Africa, including in the traditionally dominant USA and UK. The notion of institutional culture as 'whiteness', for instance, is a concept which could usefully inform many of the contemporary debates about racism on American university campuses, which - although prolific - tend not to explicitly position institutional culture in such racially specific terms. Indeed, given the fact that higher education has served to exclude populations in countries around the world, a frank engagement with the ways in which university cultures continue to model particular privileged norms and behaviours would be a welcome addition to the field in many contexts. The South African literature on mergers also offers useful insights for the field as a whole. Although mergers occur within all systems of higher education, with inevitable impacts on institutional culture, the fact that the South African mergers were effected with the explicit intention of changing cultural norms and values renders this literature particularly valuable for those interested in the possibilities of pedagogical change. The South African literature also offers a useful perspective on the ways in which institutional culture changes (or remains static) during marked periods of transition within a higher education system, a topic which is rarely acknowledged or discussed in the Western literature. Another relatively minor theme within the SAJHE literature, which nonetheless offers substantial scope for broadening international discussions on the topic, is the discussion of how institutional culture tends to be particularly entrenched (and, therefore, difficult to change) in contexts in which academics spend their entire academic life - from doctoral study through to full-time employment - within the same institution (or institutional type). Although this situation clearly arises in other contexts, it is rarely mentioned in the dominant literature, despite the fact that acknowledgement of the ways in which such norms around academic training and 
recruitment can impact on attempts to change pedagogy would significantly enhance our broader understanding of how institutional cultures can affect teaching and learning.

The pragmatic implications of this review are harder to define, aside from the obvious acknowledgement that institutional cultures play a crucial role in any attempt to change pedagogy. Given that institutional culture has long been positioned as the 'keyword' in South Africa's higher education transformation agenda, this finding alone is not new. It is, however, a useful reminder that universities must acknowledge and engage with the most problematic aspects of their histories and identities in order to effect any meaningful pedagogical change on their campuses. The 'success stories' represented in the literature reviewed for this chapter all managed to do this by working within departments to effect change at the local level. Some focused this work within the boundaries of a particular academic department (e.g. Heydenrych $\&$ Case, 2015); others chose to connect departments with similar disciplinary backgrounds at institutions of different types, as an explicit attempt to find common ground across historically entrenched boundaries (e.g. Bozalek et al., 2010). These lessons could prove useful to others attempting to transform pedagogy within their institutions. The gaps identified by the review are also important for practitioners to acknowledge, as they highlight our limited knowledge about how culture might affect academic identities, motivations and behaviours within the profiles of institutions that are less frequently researched. The fact that nearly all of the articles identified within the SAJHE focused solely on the links between institutional culture and academic behaviour, stopping short of any analysis of how institutional culture may directly or indirectly affect student learning, is another crucial gap for practitioners to acknowledge.

Ultimately, the question of whether or not institutional culture can be changed to allow for more transformative pedagogies reflects a deeper question around whether higher education merely reproduces the norms of the society in which it resides or can act to shape what that society might become in the future. In other words, is higher education simply reproductive or is it potentially transformative? On balance, the literature reviewed for this chapter suggests that Walker (2015) might be correct when she argues that it can be both and, indeed, positions institutional culture as fundamentally implicated in either possibility. Although sometimes dismissed as too vague a concept to be of any pragmatic use or theoretical value, we clearly ignore the influence of institutional cultures at our peril.

\section{References}

Ashwin, P. (2009). Analysing teaching-learning interactions in higher education: Accounting for structure and agency. London: Continuum.

Badat, S. (2009). Theorising institutional change: Post-1994 South African higher education. Studies in Higher Education, 34(4), 455-467.

Baloyi, M. C., \& Phago, K. G. (2012). Structural functional analysis of Tshwane University of Technology: Post merger implications. South African Journal of Higher Education, 26(5), 873-890.

Becher, T. (1989). Academic tribes and territories: Intellectual enquiry and the culture of disciplines. Bury St Edmunds: SRHE \& Open University Press. 
Bester, M., \& Scholtz, D. (2012). Mapping our way to coherence, alignment and responsiveness. South African Journal of Higher Education, 26(2), 282-299.

Bhorat, H., Mayet, N., \& Visser, M. (2010). Student graduation, labour market destinations and employment earnings. In: M. Letseka, M. Cosser, M. Breier, \& M. Visser (Eds.), Student retention and graduate destinations: Higher education and labour market access and success (pp. 97-124). Cape Town: HSRC Press.

Bitzer, E. M. (2010). A university department as a community of practice: A quality promotion perspective. South African Journal of Higher Education, 24(1), 15-31.

Bozalek, V., Carolissen, R., Leibowitz, B., Nicholls, L., Rohleder, P., \& Swartz, L. (2010). Engaging with difference in higher education through collaborative inter-institutional pedagogical practices. South African Journal of Higher Education, 24(6): 1023-1037.

Bozalek, V., \& Dison, A. (2013). Using the human capabilities approach as a normative framework to evaluate institutional teaching and learning interventions at UWC. South African Journal of Higher Education, 27(2), 383-400.

Clark, B. R. (1972). The organisational saga in higher education. Administrative Science Quarterly, 17, 178-184.

Council on Higher Education (Eds.). (2007). Review of higher education in South Africa: Selected themes. Pretoria: Council on Higher Education.

Cox, B. E., Mclntosh, K., Reason, R. D., \& Terenzini, P. T. (2011). A culture of teaching. Research in Higher Education, 52, 808-829.

Deacon, R., Osman, R., \& Buchler, M. (2009). Audit and interpretative analysis of education research in South Africa: What have we learnt? Pretoria: National Research Foundation.

Department of Education (1997). Education White Paper 3: A programme for the transformation of higher education. Pretoria, South Africa: Department of Education.

Duthie, S. R., \& Freeman, L. (2015). From marginal to mainstream: An argument for locating education development in the academic department. South African Journal of Higher Education, 29(5), 78-92.

Garnett, A., \& Pelser, T. (2007). Organisational barriers to creativity in South African higher education institutions. South African Journal of Higher Education, 21(1): 50-67.

Hemson, C., \& Singh, P. (2010). Shadows of transformation: Inclusion and exclusion of academic staff at a university of technology. South African Journal of Higher Education, 24(6), 935-952.

Henkel, M. (2000). Academic identities and policy change in higher education. London: Jessica Kingsley Publishers.

Heydenrych, H., \& Case, J. M. (2015). Academic development in the mainstream: A case study in an undergraduate engineering programme in South Africa. South African Journal of Higher Education, 29(5), 179-200.

Higgins, J. (2007). Institutional culture as keyword. In Council on Higher Education (Eds.), Review of higher education in South Africa: Selected themes (pp. 97-122). Pretoria: Council on Higher Education.

Kezar, A. (2001). Understanding and facilitating organizational change in the 21st century: Recent research and conceptualizations. ASHE-ERIC Higher Education Report 28(4). New York: John Wiley, \& Sons, Inc.

Kezar, A. (2014). How colleges change: Understanding, leading, and enacting change. New York, NY: Routledge.

Knight, P. T., \& Trowler, P. R. (2000). Department-level cultures and the improvement of learning and teaching. Studies in Higher Education, 25(1), 69-83.

Leibowitz, B. (2016a). In pursuit of socially just pedagogies in differently positioned South African higher education institutions. South African Journal of Higher Education, 30(3), 219-234.

Leibowitz, B. (2016b). Professional academic development - The influence of context on motivation. South African Journal of Higher Education, 30(6), 191-206.

Leibowitz, B., \& Adendorff, H. (2007). Teaching and learning strategies as mechanisms to advance change at university level: A case study. South African Journal of Higher Education, 21(1), 112-128.

Martin, J. (1992). Cultures in organisations: Three perspectives. New York: Oxford University Press.

McKinney, C. (2007). Caught between the 'old' and the 'new'? Talking about 'race' in a post-apartheid university classroom. Race Ethnicity and Education, 10(2), 215-231. 


\section{HigheR EDUCATION PATHWAYS}

McLean, M., Walker, M., Dison, A., \& Vaughan, R. (2008). Strengthening professionalism for the public good: Implications for professional education. Working Paper 3: Development Discourses: Higher Education and Poverty Reduction in South Africa. London: DFID.

Mgqwashu, E., \& Bengesai, A. (2015). Exploring an analytical framework for a discursive construction of teaching and learning: The case of academic literacy in an engineering faculty. South African Journal of Higher Education, 29(4): 211-227.

Ntshoe, I., Higgs, P., Higgs, L. G., \& Wolhuter, C. C. (2008). The changing academic profession in higher education and new managerialism and corporatism in South Africa. South African Journal of Higher Education, 22(2): 391-403.

Park, T., \& van der Merwe, A. (2009). The transformative role of ICT in higher education: A case study of the alignment of educational technology utilization with the vision of Stellenbosch University. South African Journal of Higher Education, 23(2), 356-372.

Pithouse-Morgan, K., Masinga, L., Naicker, I., Hlao, T., \& Pillay, D. (2016). 'Sink or swim?': Learning from stories of becoming academics within a transforming university terrain. South African Journal of Higher Education, $30(1), 224-244$.

Reddy, T. (2007). Staff perceptions of the merger between two South African regional technikons. South African Journal of Higher Education, 21(3): 485-502.

Rothmann, S., Barkhuizen, N., \& Tytherleigh, M. Y. (2008). Model of work-related ill health of academic staff in a South African higher education institution. South African Journal of Higher Education, 22(2), 404-422.

Roy, I. J. (2007). Staff developers' perceptions on building a culture of teaching and learning. South African Journal of Higher Education, 21(7), 907-918.

Sattar, K., \& Cooke, L. A. (2012). A conceptual framework for the quality assurance of programme design at the Durban University of Technology. South African Journal of Higher Education, 26(2), 372-390.

Schein, E. H. (1985). Organizational culture and leadership. San Francisco, CA: Jossey-Bass.

Schendel, R. (2016a). Adapting, not adopting: Barriers affecting teaching for critical thinking at two Rwandan universities. Comparative Education Review, 60(3), 549-570.

Schendel, R. (2016b). Constructing departmental culture to support pedagogical change: Evidence from a case study in Rwanda. Higher Education, 72(4), 487-504.

Small, R., Smith, J., Williams, C., \& Fataar, A. (2011). Social regulation and shifting institutional culture in higher education: A reflective account of a Faculty of Education. South African Journal of Higher Education, 25(3), 554-467.

South African Journal of Higher Education (n.d.). Focus and scope. Retrieved from http://www.journals.ac.za/ index.php/sajhe/about/editorialPolicies\#focusAndScope

Thaver, B. (2009). Transforming the culture of higher education in South Africa. Academe, 95(1), 28-30.

Tierney, W. G. (2008). The impact of culture on organisational decision making: Theory and practice in higher education. Sterling, VA: Stylus Publishing.

Trowler, P. (2005). A sociology of teaching, learning and enhancement: Improving practices in higher education. Revista de Sociologia, 76, 13-34.

Trowler, P., \& Cooper, A. (2002). Teaching and learning regimes: implicit theories and recurrent practices in the enhancement of teaching and learning through educational development programmes. Higher Education Research and Development, 21, 221-240.

Unterhalter, E. (2010). Considering equality, equity and higher education pedagogies in the context of globalisation. In E Unterhalter \& V Carpentier (Eds.), Global inequalities and higher education: Whose interests are we serving? Basingstoke, England: Palgrave Macmillan.

Vandeyar, S. (2010). Shifting selves: Constructing and negotiating academic identities. South African Journal of Higher Education, 24(6), 914-934.

Walker, M. (2015). Imagining STEM higher education futures: Advancing human well-being. Higher Education, $70,417-425$.

Walker, M., \& McLean, M. (2010). Making lives go better: University education and 'professional capabilities'. South African Journal of Higher Education, 24(5), 847-869.

Weick, K. E. (1976). Educational organisations as loosely coupled systems. Administrative Science Quarterly, 21, 1-19. 


\title{
CHAPTER 11
}

\section{THE LENSES WE USE TO RESEARCH STUDENT EXPERIENCES}

\author{
Amanda Hlengwa, Sioux McKenna and Thando Njovane
}

\section{Introduction}

The recent student protests that erupted in the South African higher education landscape in 2015 and 2016 suggest that research concerning student experiences in our institutions has become all the more crucial. In light of this, our chapter argues for theoretically rigorous and conceptually rich approaches to research on the student experience, without which we will not be in a position to address the significant concerns raised by these protests. There is, of course, already a robust body of work detailing the student experience (for example Case, 2013; Case, Marshall, McKenna, \& Mogashana, 2018; Walker \& Wilson-Strydom, 2017). However, questions are often raised about the extent to which such research is being drawn on in subsequent studies (Niven, 2012) and this suggests that limited accounts of student experience remain dominant despite this body of research (Boughey \& McKenna, 2016). It thus seemed important to make sense of the ways in which current research on student experience is being constructed.

This chapter provides a meta-analysis of research on the student experience as evidenced in South African postgraduate theses in higher education. Postgraduate research is a useful place in which to reflect on current research approaches, given that postgraduate education contributes to the 'boundaries of the field' (Higher Education Qualifications Sub-Framework, 2013). By looking at what theories postgraduate students are drawing on and how they are conceptualising students in their studies of the student experience, we should be able to establish a sense of what is happening at the boundaries of the field. Postgraduate students have agency in selecting what topics to focus on and how to do so, but they are constrained and enabled by their structural and cultural contexts. The ways in which masters and doctoral scholars undertake their research would be strongly shaped by the ideas and texts introduced to them by supervisors. The theories they bring to their studies would be selected from those in circulation in the field. By analysing masters and doctoral theses on student experiences we 
were thus not critiquing the work of these specific postgraduates, but rather we were making sense of the field. The methodological and theoretical lenses brought to any phenomenon, such as that of student experience, have implications for what we see, understand and recommend. The intention of this study was thus to illuminate the current boundaries of research into student experience and to raise concerns about blind spots that emerged through this analysis.

Our analysis of 123 masters and doctoral theses found that within the broad range of theoretical approaches are those that could be considered theoretically rigorous and those that seem to be drawing on more superficial engagement with theory, or even a misapplication of theory. And we found that the conceptualisation of the student oscillated between those accounts that focused on the individual in a decontextualised way and those that positioned the student experience within broader social structures.

\section{Methodology}

This study began when most universities had been shut down by student protests calling for the eradication of fees, alongside concerns about various aspects of the student experience ranging from the state of accommodation, and the perceived colonial nature of course content to the racially unrepresentative make-up of the professoriate (Luescher, Loader, \& Mugume, 2017). During this time, the issue of student experience was, and continues to be, paramount and occupied significant space in the media and the higher education sector. We wanted, however, to step back from the turbulence caused by this transformative moment and try to make sense of how student experience is conceptualised by those researching it.

A critical discourse analysis was used to examine which topics are being focused on in the current research on the student experience. We then analysed the discursive constructions of students and student experiences, together with the theories being drawn on to make sense of these. The perspective underpinning this approach is an understanding that research is never neutral; that the selection of topics and the approaches through which to study them are influenced by both the graduate student and supervisor's 'personal projects' (Archer, 2000, 2007); by their disciplinary histories, norms and values (Maton, 2014); by the research community in which they are studying (McKenna, 2017); and by the discourses available to them by which their experiences of reality are co-constructed (Archer, 2000; Fairclough, 2009). Discourses in this understanding are more than simply linguistic representations of meaning; they are understood to be mechanisms with the power to enable or constrain events and experiences (Archer, 2005). While discourses are not the only mechanisms at play in the construction of student experience in the 123 theses analysed here, they are understood to be significant (Fairclough, Jessop, \& Sayer, 2002). Discourses are social in nature - they emerge from the supervisors' concerns or the concerns of other researchers in the field, as much as from each postgraduate scholar's personal projects, and they function as mechanisms alongside a myriad other mechanisms such as institutional structures and cultures. 
In seeking to analyse the ways in which student experience is being researched in masters and doctoral studies, we adopted the time frame of studies completed between 2008 and 2017. Having set our time frame, we then searched the e-repositories of public universities in South Africa and looked at titles and abstracts to identify those studies related to student experience. Through online searches and email communication with institutional librarians, we were eventually able to develop a list of 123 theses that interrogated some aspect of student experience. These studies were entered into a spreadsheet with the following information: Title of study, Year of graduation, Masters or Doctorate, Institution of study (and institutional research site, if different), Language of study, Scale of study, Abstract, and then from the study abstract: Relevant findings, Theoretical frameworks and Data collection methods. Having thus prepared the data, we began by examining the topics that were covered within this broad area of 'student experience studies', together with the theoretical approaches being used by postgraduate researchers. We then analysed the ways in which the student was discursively conceptualised in the studies.

Table 1 Overview of doctoral and masters thesis data

\begin{tabular}{|c|c|c|c|c|c|c|c|}
\hline \multicolumn{3}{|l|}{ Masters } & 102 & \multicolumn{3}{|l|}{ Doctorate } & 21 \\
\hline \multicolumn{3}{|l|}{ Single site } & 105 & \multicolumn{3}{|l|}{ Multi-site } & 18 \\
\hline Traditional university & 100 & $\begin{array}{l}\text { Comprehensive } \\
\text { university }\end{array}$ & 12 & $\begin{array}{l}\text { University of } \\
\text { technology }\end{array}$ & 9 & Private institution & 2 \\
\hline $\begin{array}{l}\text { Historically white } \\
\text { institutions }\end{array}$ & 60 & $\begin{array}{l}\text { Historically black } \\
\text { institutions }\end{array}$ & 12 & Unspecified & 51 & & \\
\hline Urban universities & 92 & Rural universities & 25 & $\begin{array}{l}\text { Mix of rural \& urban } \\
\text { or unspecified }\end{array}$ & 6 & & \\
\hline
\end{tabular}

Table 1 provides an overview of the 123 studies. It should be noted that the university characteristics were taken as the one where the thesis was registered, unless there was clear evidence in the title or abstract that the site of the student experience being researched was a different university (or universities) to the one where the masters or doctoral qualification was undertaken. The table above reveals the dominance of historically white institutions as study sites. This situation is evident across many other chapters in this book and speaks to the continued dominance of historically white and traditional universities in research productivity (see Cloete, Mouton, \& Sheppard, 2016). This trend further suggests that, over and above the concerns about the theoretical frames and conceptualisations of student experiences that are raised in the rest of this chapter, there is a significant lack of studies exploring student experience in historically black universities. There is also a disparity in representation across institutional types, with $81 \%$ of the studies being undertaken in traditional universities, with little research focused on comprehensive universities and universities of technology and scant attention given to private institutions. 
Across the whole sample, $83 \%$ were masters studies, which is in line with the national average of $82 \%$ of combined masters and doctoral graduations in South Africa being at masters level (Council on Higher Education, 2017). Moreover, 112 of the 123 studies were empirical, most were qualitative and medium to large scale (over 50 participants), and $85 \%$ were based in single sites. There is reason for concern about the large number of single site studies, many of which were within a single classroom, as there was not much scope for sector-wide understandings to emerge within a specific masters or doctoral study. This speaks to the concern raised in the National Research Foundation (2009) report on education research in South Africa, where $94 \%$ of education research was found to be small-scale. Given the time constraints of a masters or doctoral study, perhaps it is not surprising that most took place in one setting. While such studies enable rich analysis of thick data, they do not necessarily allow for system-level accounts of student experience. Single site studies are not in themselves problematic, but when they comprise the bulk of the studies being undertaken, we need to examine whether our research is structured in ways that can illuminate systemic problems.

It should be noted that our analysis of the data only went as far as the thesis title and abstract, and, in a few cases, a brief look at the study's introduction and concluding chapters. A thorough analysis of the full 123 theses would no doubt allow for more nuanced findings. We would however argue that because the abstract that is uploaded onto various databases is meant to be able to 'stand alone' as the representation of the study, it is a significant piece of data from which to make sense of the study focus, the theoretical approach and the discursive constructions of the student.

The remainder of this paper looks at four issues emerging from this research. The first is about the use of theory in the studies and the implications this has for the kinds of conclusions that can be reached; the second, third and fourth issues relate to the discourses whereby students are conceptualised across the theses. Firstly, we consider examples where the student is constructed as a customer and the role of the university is to be efficient in serving the customer. Next, we look at examples where the student is decontextualised from her social context and background and understood as an individual possessing (or lacking) certain inherent attributes. Finally, we look at those studies, in the minority, that explicitly considered issues of institutional context and other larger structures in their interrogation of the student experience.

\section{Theory 'lite'}

Echoing concerns that much education research is poorly theorised (Shay, 2012; Tight, 2014), we found that a number of abstracts suggest a fairly superficial engagement with theory, a misapplication of theory, or used theory that has been characterised as 'pop psychology'. With regards to the latter, a number of abstracts drew from popular everyday theories that have been regularly debunked in available literature in the field (see, e.g. Kandlbinder, 2014; Teo, Segal, Morgan, Kandlbinder, Wang, \& Hingorani, 2012; Ylijoki, 2014). There were, for example, studies based on 'theories' from popular texts such as the 'whole brain' theory, 'left and right 
brain' theory, and 'multiple intelligences'. Such everyday theories were drawn on despite repeated cautions in the literature about the danger of using everyday accounts in educational research (Boughey \& McKenna, 2016; Richardson, 2005).

There was also evidence of the misappropriation of theory. For example, there was a study reporting on 'deep and surface learners' in ways that suggest students themselves are particular kinds of learners. This is a misunderstanding of Marton and Säljö’s theory (1976a, 1976b), despite there being literature cautioning against this very issue (see, e.g Haggis, 2009; Richardson, 2005). There were also some problematic references to academic literacies theory that did not recognise that this is a theory which understands the reading and writing practices of the academy as emerging from social practices that are inherently political in nature and contests understandings of language as comprising a set of neutral skills. Some theses that referred directly to academic literacies theory did so in ways that were the antithesis of the theory by advocating for generic add-on language skills courses.

... acquiring literacy skills needed in everyday living and the world of work. It has become necessary to find a suitable means of helping these students to cope linguistically. (M94)

The issue of language in particular was referred to in what may be described as 'commonsensical' ways. Language use in the academy was understood in some studies as if related to vocabulary, grammar and punctuation alone, and in such studies there was a striking silence regarding the extent to which disciplinary practices emerge from particular socio-economic value systems and histories, coupled with structures of target knowledge (Maton, 2000; Muller, 2000; Shay, 2015).

.. difficulties of English second language speakers: 1) more difficulties with comprehension, vocabulary, structural analysis than first language counterparts; 2) Low exposure to new English vocabulary;3) cultural specificities and metaphorical structures of English affecting writing abilities; 4) lack of introduction to assumptions underlying Western English thinking on issues of cohesion, discourse, grammar, inference, metaphorical expressions, vocabulary, and genre. (M16)

The abstracts of a few of the theses did not suggest a connection between the study and what is already established within the field or what the contribution to the field might be. It would seem that the use of inadequate theories and the misapplication of established theories can be seen on occasion to have produced banal conclusions, offering little more than commonsensical observations.

Finally, results indicate that the students' Multicultural Competence training is not sufficient in preparing them to work with culturally diverse individuals. (M5) 
In order to address binge drinking, strategies need to be implemented in the student, family, university and community context. (M70)

There were a number of studies that appeared to lack criticality due to weak theoretical framing. This was in notable contrast to those studies that drew on robust theoretical frameworks that provide explanatory power which contextualised even small-scale studies within larger system level debates. These theories also had effects on the ways in which the student was discursively conceptualised. The remainder of the chapter considers the three main conceptualisations of the student as evidenced in the 123 theses.

\section{Efficiency discourses and the student as customer}

The 123 studies were underpinned by various concerns and rationales: many were explicitly focused on issues of social justice (such as those looking at issues of inclusion, disability, transformation) and others were focused more on efficiency discourses (retention and throughput). In the latter group, there were studies where the student was positioned as a customer seeking value for money. Thus, the notion of the market economy as contributing to the student experience emerged as a strong discourse. In some of the studies this was overt:

The attraction to higher education institutions is that graduates enjoy a higher status in our society as they are seen to play a particularly important role in managing the knowledge-driven economy. The significance of this status relates to the extent of the application of knowledge to the economy, a status which provides competitiveness among nations. (D52)

... there is growing competition for customers who have a wider choice of service provider supplied by the global market. (M3)

Student tertiary graduation is therefore of great importance, not only to the student but also because it promotes positive outcomes for South African labour market, society and the HEIs. (M54)

Much has been written on the commodification of higher education and the potential impact it has on our relationships with students. Fears that 'the customer is always right' thinking will lead us to avoid teaching challenging concepts, or to the hiring and firing of academics on the basis of popularity, have already come to fruition in some institutions around the world. The notion of the student as customer also foregrounds the credentialing role of higher education at the expense of its role in developing critical citizenry and serving the public good. Furthermore, such conceptualisations of higher education strengthen the argument that if the key purpose of higher education is to provide students with the private 
goods necessary for better jobs then there is little reason for taxpayer subsidisation of higher education through the state. The 'user pays' model of funding higher education was vociferously rejected by many students during the 2015 and 2016 protests but was also deeply entwined in some of the studies on student experience, where the student was conceptualised as the customer.

\section{The 'decontextualised learner'}

Boughey and McKenna $(2015,2016)$ used the term 'decontextualised learner' to describe the ways in which students are often understood as separate from the socio-cultural world. Within this discourse, the student is stripped of heritage, norms, values and social practices. Her success and failure in higher education is understood to emerge from characteristics inherent in her as an individual. She is motivated, intelligent, good at English, etc. Or she is not. Understood as such, any potential problems experienced by the student are seen as stemming from her own innate attributes (or lack thereof). This discourse was evident in various ways in much of the data. Student failure was ascribed to factors such as age, under-preparedness, lack of language or academic skills (which were understood to be neutral), or their having poor problem-solving abilities.

... explore whether factors ... predictive of performance ... cognitive learning style, learning strategies employed, motivation ... (M19)

... fail to demonstrate resilience when it comes to being academically successful. (M8)

... lacked effective coping strategies such as time management. (M27)

... high emotional intelligent and constructive emotion-regulation strategies in order to achieve student success. (M54)

How do pre-entry academic and non-academic factors influence students' first-year experience and academic performance? (D95)

The focus was identifying and itemising the factors constraining student success. These were often understood exclusively in terms of the students' attributes and where they were more broadly conceptualised, they were still seen to be discrete issues rather than understood as complex intersectional social mechanisms, for example:

Not only are some of these students academically disadvantaged, but others are also drawn from communities with low socio-economic status. (M16) 
The responsibility of the university under such a conception would seem to be (a) to select students wisely and (b) to provide them with opportunities to acquire any (neutral) skills they may be lacking due to poor prior schooling.

The academic selection criteria and its impact on throughput rates ... will become the subject of research scrutiny. (M96)

The dominant focus on attributes assumed to be either inherent or lacking in the student can be seen to reinforce the notion that higher education is a meritocracy in which the hard working and the bright are duly rewarded (see also Armstrong \& Hamilton, 2013; Guinier, 2016; Mettler, 2014). This ignores the international literature that shows consistent correlation between university success and students' socio-economic background (e.g. Arum, Gamoran, \& Shavit, 2012; Walpole, 2003), a correlation that takes a racialised form in South Africa (Council on Higher Education, 2017).

Where problems of student throughput and retention were interrogated within the 123 theses analysed here, there was largely a silence on how the norms, values, structures and practices of the institution, society, academics etc. might play a role. For example, one thesis appears to acknowledge the ways in which social structures are implicated in the gendered differentiation of success in Accounting: 'Accounting is a male dominated profession historically. Females underperform and are thus dissuaded from taking up this profession.' The solution however does not reflect a desire to better understand and address such issues; instead it is: '... the need of the hour to understand the educational psychology of female accounting students in higher education' (M98).

It may well be the case that each of the many studies that focused on characteristics of individual students justified this stance and articulated the limitations in such an approach within the thesis itself in ways that we did not ascertain from the abstract. Furthermore, taken separately, such studies are not particularly problematic, but collectively they raise concerns about the dominant lenses being brought to bear in research on the student experience. When the overwhelming majority of studies take such an approach, there is a question to be asked about the conceptualisation of the student. Notions of the student as a social being, the university as a social construct, and higher education practices as political were greatly overshadowed by the dominance of studies in which success or failure is primarily seen to emerge from the attributes inherent in the individual.

Where other issues beyond the factors deemed to be inherent in the student were considered in the studies, such as institutional culture, these were still largely in terms of the implications for the student rather than for the institutional culture itself:

What are the major challenges educationally disadvantaged students face at a predominantly white, Afrikaans university and how do [these students] function within the university. (M24) 
It has now been recognised that students are in need of a strong foundation that will bridge the gap from school to university and will allow them to cope. (M94)

Aligned to the 'decontextualised learner' discourse, it is perhaps unsurprising that a number of these studies proffered solutions to the problem of poor student success through remedial add-on interventions. These recommendations included calls for academic support in the form of additional tutorials, supplementary instruction, online courses or enhanced orientation programmes. Such initiatives may well be beneficial to the student, and studies into their effectiveness are useful contributions to the field of student experience research, but they are arguably based on the premise that both the problem and the solution rest outside of the core university structures and cultures, the curriculum content or the teaching and assessment approaches. The university remains largely untouched while students are slotted into various initiatives to fix the lacks they have.

Evaluations of such add-on initiatives often acknowledged that there were difficulties with their implementation such as 'minimal student participation in all programmes, including those that were compulsory' (D44), 'stigmatization' (D52), and 'poor perceptions about these programmes' (M67). The use of under-qualified staff hired on contract to run these add-on initiatives was also flagged as an issue, as has also been noted in the literature (CHE, 2017; Dhunpath \& Vithal, 2014; Moyo, 2018). But the proposed solution to the particular problem of under-qualified staff offering such initiatives seemed to reiterate the a-theoretical common sense approach:

... an intensive and ongoing training of all facilitators in functional literacies, basic counselling and handling diversity ... (D44)

Most of the evaluations of add-on initiatives that identified the problems inherent in them called for improved versions of add-on initiatives. There were very few studies that called for a significant re-thinking of the entire approach, as this one did:

... although [the intervention] facilitated students' entry into the university, it simultaneously ... exacerbated their experiences of exception. ... although the university has made major structural changes to accommodate students from disadvantaged educational backgrounds, the ideas that shape the [intervention] perpetuate the view that these students have an educational 'deficit'. In conclusion, the study suggests that higher education should reconsider the idea of separate programmes... (D80)

While the dominant understanding in the 123 studies we analysed was that of the student experience as emerging primarily from the attributes of the individual, there were certainly 
also studies that offered a more nuanced interrogation of the student experience and it is to these that we now turn.

\section{Student experiences as social}

Across almost all of the studies, there was a strong axiological rationale, much of which focused on the experiences of first generation students. Where a field of study has a strong emphasis on moral, ethical and ideological concerns, it is described as axiologically charged (Maton, 2014). The kind of charge has an impact on which research topics are taken up, but it is important to note that for research to have value, it needs to have explanatory power.

As has been argued thus far, many of these studies positioned students as being in need of remedial assistance outside of the mainstream curriculum, but a few of them also provided a broader social lens which allowed for conclusions to be reached at system level.

Such studies acknowledged that the student experience emerges from the interplay between the norms, values and practices of the institution and those of the students, and thus there was a need to consider the complexities of such interplay.

... students' understanding of the behaviours they should display in higher education and how this clashes with the expectations of academics. (M93)

In general, higher education institutions do not have control over student attributes that significantly influence persistence, but this study demonstrates that institutional factors play equally important or even more significant roles and are under the control of institutions to change. (D108)

Such studies revealed concerns with institutional culture and other structural matters pertaining to social and academic inclusion and exclusion.

In debates around transformation, black students are frequently represented in stigmatising ways. These negative representations are part of a discourse that holds the increasing numbers of black students responsible for lowering university standards. When black students encounter these discourses, it can affect their selfesteem and academic performance. (M26)

Racist, homophobic, xenophobic and sexist biases from both peers and faculty were identified as key issues in the student experience. There were studies focused on the ways in which racism was experienced in particular ways by black African international students because of: 
... narrowness of ... transformation focus, the prevalence of racial stereotypes ... and the racialisation of space on campus. (M26)

Universities were thus seen to reflect the prejudices of society, including homophobia: ... predominantly heteronormative institutional spaces homosexual students ... experience social isolation, rejection, prejudice, harassment... [to the point where they] end up having multiple identities. (M34)

Findings reveal a persistent culture of sustained tolerance for homophobia among the general students in the residences, determined fundamentally by the systemic circumstances present in higher education residential spaces. These conditions normalise homophobia... (M20)

Most of the studies were conducted in historically advantaged universities, and it was interesting that most of those few studies conducted within historically black universities did indeed focus on issues of the institution and not just the attributes of the student. However, such focus was on fundamental issues such as the shortage of resources and students struggling to use IT facilities, rather than issues of institutional culture.

Barriers when accessing computer and ICTs: 1) lack of access to actual computer hardware and internet; 2) digital eg. Lack of online content in understandable format, language and cultural relevance; 3) shortage of experiences and trained facilitators; 4) students in low socio-economic groups experience lack of resources including maintenance, use, effectiveness; 5) lack of IT literacy; 6) shortage of peer support with IT. (M6)

There were a large number of studies which focused on disabilities and most of these included a concern with institutional structures and cultures, and the extent to which universities are welcoming places for a full range of people or whether they are 'created for able-bodied student' (M21).

People with impairments have been treated differently from that of their ablebodied counterparts and, as a group of people have generally been excluded from social activities. (M21)

Such exclusion manifests as marginalization and oppression which does limit the students with impairments to realise their potential as citizens. (M21)

Alongside the focus on physical disability were studies related to psychological well-being, though again the intersections between issues of gender, race, physical well-being, financial stability, 
psychological well-being and so on do not seem to be particularly well understood and simple relationships tended to be sought between student characteristics and student experiences.

\section{Conclusion}

The theories used and conceptualisations of students evidenced across the 123 masters and doctoral studies emerged from multiple influences. As indicated, the postgraduate scholar's personal projects and concerns would intersect with the influence of the supervisor's history and research interests, and the availability of particular ideas and theories in the literature. The concerns raised in this study about some of the conceptualisations of students are thus not a critique of any of the individual masters and doctoral graduates but rather, we are suggesting to the field of researchers concerned with student experiences that there are some issues that we collectively need to confront.

In this chapter we argue that if we do not have theoretically rigorous and conceptually rich approaches to researching the student experience, we will not be in a position to address the significant concerns raised by the student protests mentioned earlier. Our meta-analysis of 123 masters and $\mathrm{PhD}$ studies that look at issues of student experience in higher education revealed some of the conceptual gaps within existing research on the student experience, which impedes a nuanced understanding. While some of the research was indeed critical, we found that a significant proportion of current research suffers from a lack of criticality with regards to discursive constructions of the student, together with somewhat problematic recommendations for responding to issues of student dissatisfaction and poor student retention and throughput. The study calls for stronger theorisation of such studies and better dissemination of existing critical approaches to teaching and learning in research.

\section{References}

Archer, M. (2000). Being human: The problem of agency. Cambridge: Cambridge University Press.

Archer, M. (2005). Structure, culture and agency. In M. D. Jacobs \& N. W. Hanrahan (Eds.), The Blackwell companion to the sociology of culture. Sussex: Blackwell Publishing Ltd.

Archer, M. (2007). Making our way through the world: Human reflexivity and social mobility. Cambridge: Cambridge University Press.

Armstrong, E. A., \& Hamilton, L. T. (2013). Paying for the party: How college maintains inequality. Cambridge, MS: Harvard University Press.

Arum, R., Gamoran, A., \& Shavit, Y. (2012). Expanded opportunities for all in global higher education systems. In L. Weiss \& N. Dolby (Eds.), Social class and education. New York: Routledge.

Boughey, C., \& McKenna, S. (2015). Analysing an audit cycle: A critical realist account. Studies in Higher Education, 42(6), 963-975.

Boughey, C., \& McKenna, S. (2016). Academic literacy and the decontextualized learner. Critical Studies in Teaching and Learning, 4(2), 1-9.

Case, J. M. (2013). Researching student learning in higher education: A social realist approach. London: Routledge.

Case, J. M., Marshall, D., McKenna, S., \& Mogashana, D. (2018). Going to university: The influence of higher education on the lives of young South Africans. Cape Town: African Minds. 
Cloete, N., Mouton, J., \& Sheppard, C. (2016). Doctoral education in South Africa. Cape Town: African Minds.

Council on Higher Education (2017). VitalStats: Public higher education data of 2015. Pretoria: Council on Higher Education.

Dhunpath, R., \& Vithal, R. (2014). Alternative access to higher education: Underprepared students or underprepared institutions? Cape Town: Pearson.

Fairclough, N. (2009). A dialectical-relational approach to Critical Discourse Analysis in social research. In R. Wodak \& M. Meyer (Eds.), Methods of Critical Discourse Analysis. 2nd ed. Los Angeles: Sage.

Fairclough, N., Jessop, B., \& Sayer, A. (2002). Critical realism and semiosis. Alethia, 5(1), 1-10.

Guinier, L. (2016). The tyranny of the meritocracy: Democratizing higher education in America. Boston MA: Beacon Press.

Haggis, T. (2009). What have we been thinking of? A critical overview of 40 years of student learning research in higher education. Studies in Higher Education, 34(4), 377-390.

Higher Education Qualifications Sub-Framework (HEQSF) (2013). Notice No 549, South African Government Gazette No. 36721, 2 August 2013.

Kandlbinder, P. (2014). Theorising teaching and learning in higher education research. In J. Huisman \& M. Tight (Eds.), Theory and method in higher education research II (International Perspectives on Higher Education Research, 10: 1-22). Emerald Group Publishing Limited.

Luescher, T. M., Loader, L., \& Mugume, T. (2017). \#FeesMustFall: An internet-age student movement in South Africa and the case of the University of the Free State. Politikon: South African Journal of Political Studies, 44(2), 231-245.

Maton, K. (2000). Languages of legitimation: The structuring significance for intellectual fields of strategic knowledge claims. British Journal of Sociology of Education, 21(2), 147-167.

Maton, K. (2014). Knowledge and knowers: Towards a realist sociology of education. London: Routledge.

Marton, F., \& Säljö, R. (1976a). On the qualitative difference in learning I-Outcome and Process. British Journal of Educational Psychology, 46, 4-11.

Marton, F., \& Säljö, R. (1976b). On the qualitative difference in learning II-Outcome as a function of the learner's conception of the task. British Journal of Educational Psychology, 46, 115-127.

McKenna, S. (2017). Crossing conceptual thresholds in doctoral communities. Innovations in Education and Teaching International, 54(5), 458-466.

Mettler, S. (2014). Degrees of inequality: How the politics of higher education sabotaged the American dream. New York: Basic Books.

Moyo, M. (2018). An analysis on the use of the Teaching Development Grant in South African universities (unpublished doctoral dissertation). Rhodes University.

Muller, J. (2000). Reclaiming knowledge: Social theory, curriculum and education policy. Routledge: London.

National Research Foundation (2009). Audit and interpretative analysis of education research in South Africa: What have we learnt? Pretoria: National Research Foundation.

Niven, P. (2012). Narrating emergence in the curious terrain of academic development (unpublished doctoral dissertation). Centre for Higher Education Research, Teaching and Learning, Rhodes University.

Richardson, T. E. (2005). Students' approaches to learning and teachers' approaches to teaching in higher education. Educational Psychology, 25(6), 673-680.

Shay, S. (2012). Educational development as a field: Are we there yet? Higher Education Research and Development, 31(3), 311-323.

Shay, S. (2015). Curriculum reform in higher education: A contested space. Teaching in Higher Education, 20(4), $431-441$.

Teo, S. T. T., Segal, N., Morgan, A. C., Kandlbinder, P., Wang, K. Y., \& Hingorani, A. (2012). Generic skills development and satisfaction with groupwork among business students: Effect of country of permanent residency. Education \& Training, 54(6), 472-487.

Tight, M. (2014). Discipline and theory in higher education research. Research Papers in Education, 29(1), 93-110.

Walker, M., \& Wilson-Strydom, M. (Eds.). (2017). Socially just pedagogies, capabilities and quality in higher education. New York: Palgrave. Retrieved from link.springer.com/book/10.1057/978-1-137-55786-5 
Walpole, M. (2003). Socioeconomic status and college: How SES affects college experiences and outcomes. The Review of Higher Education, 27(1), 45-73.

Ylijoki, O. (2014). A temporal approach to higher education research. In J. Huisman \& M. Tight (Eds.). Theory and method in higher education research II. (International Perspectives on Higher Education Research, 10: 141-160). Emerald Group Publishing Limited. 
PART C

\section{SITUATING: WHAT WE KNOW ABOUT SOUTH AFRICAN HIGHER EDUCATION}





\section{CHAPTER 12}

\section{THE RISING CHALLENGE OF UNIVERSITY ACCESS FOR STUDENTS FROM LOW-INCOME FAMILIES}

Langutani Masehela

\section{Introduction}

Fee-free higher education for students is not an affordable or sustainable option for South Africa. The knowledge and skills acquired in the course of achieving higher education qualifications generate significant lifetime private benefits for successful students as well as long-range social benefits for the public at large. Although higher education institutions admit an increasingly large proportion of students from poor families, students from middle class and wealthy families still tend to be disproportionately well-represented. For all these reasons, the costs of higher education should be shared equitably between public and private beneficiaries. (Department of Education, 1997, p. v)

The opening quote from the South African Department of Education presented two decades ago remains relevant today. It indirectly suggests that institutions of higher learning should seriously reconsider, among other challenges, admission opportunities in order to avoid disproportionate representation of incoming students. Marginson (2011, p. 424) argues that: 'The price of social peace is that unequal access to both public and private goods in higher education is made acceptable and is allowed to happen on a vast scale with only muted criticism.' The current unequal access to higher education creates a blind spot that prevents policy-makers and decision-makers from seeing beyond the walls of universities. This impacts negatively on students from poor backgrounds. This neglect may have been the cause of \#FeesMustFall movement in South African public universities in the recent past, which is the focus of Chapter 13. The movement led to the abrupt and unexpected 
announcement of free education in South Africa on 16 December 2017 by the former president of the country Jacob Zuma, which was generally well received by the public, especially by students and prospective students. However, given that South African public universities are mostly reliant on government funding and student fees, this left many university leaders uncertain about how they would source funding for their institutions. This was confirmed by the response of Bawa, the chief executive officer of Universities South Africa, to the question of where institutions would source funds for free education. He indicated that universities were awaiting the finance minister's budget speech of February 2018 (Child, 2018). Thus, there is a tension between the public good for producing a greater number of highly educated people and the need to find the money to pay for this.

In addressing issues of social justice as advocated by Sen (2009), there arise issues of fairness and inclusion in accessing higher education. While this is critical, it is also important to understand the past in order to respond appropriately to the present situation with regard to student admissions and related issues in higher education. The ban on racial segregation and related practices in South Africa in the 1990s positively led to increased access to higher education. However, what emerged thereafter confirmed that increased access to higher education does not necessarily translate into social justice because not every entrant to the higher education space is able to get financial assistance. This thinking is in line with what Magwedze (2017) reported about the University of South Africa's (Unisa) stance on President Zuma's decision to provide fee-free higher education. Unisa argued that the decision would put pressure on universities. This means that financial demands create challenges for incoming and existing students to navigate this space. World Bank Africa (2009) identifies monetary and non-monetary barriers to access higher education. Included in the non-monetary barriers are the admission process of an institution and family environment.

In particular, students from low-income families continue to experience obstacles to entering higher education institutions due to financial constraints. A good matric pass is no guarantee for a bursary or any other financial assistance for school leavers due to the high level of competition for these bursaries, which are given on merit, but without taking account of any disadvantage an applicant may have faced. Therefore, students from poor backgrounds find themselves more often than not at a disadvantage. Such students are left in a limbo; they have passed matric well, but they do not have funds to continue with their studies in tertiary institutions due to lack of financial support. They have to make drastic decisions as to whether or not they continue with their aspirations of becoming university students. This study provides evidence that these students are resilient; they continue to push their way through into further or higher education systems because they believe that education will change their lives for the better.

The recent \#FeesMustFall movement (see Chapter 13) is testimony to the frustrations that students face in their attempt to access higher education. \#FeesMustFall cannot be understood by only analysing the violent protests, police presence on campuses or the protracted impasse 
between university management and students in their fight for free, quality, and decolonised higher education. There is also a need to take account of the frustrations caused by the hidden bottlenecks that exist at social level before students even gain access to higher education.

In an attempt to unearth the challenges that students from low-income families encounter in their attempts to access higher education, this chapter first provides an outline of the context of study. This is critical because the geographical location of the institution, family backgrounds of students it mostly attracts and its status of being a historically disadvantaged institution were central to the rationale for conducting this study. Given the overall purpose of this book in answering the broad question of how higher education contributes to the public good in the South African context, this chapter provides empirical data on the social lives of students who are admitted to historically black universities, which are based in rural communities and which attract mainly students from low-income families. The data provide insights into how students finance their course registration and other necessities at the beginning of the year. The study draws on the philosophy of Amartya Sen's (2009) capability approach which he expanded to develop a theory of justice. In analysing the data, I used Margaret Archer's (1995) framework of structure, culture and agency to unpack the kind of life that students experience as they attempt to make their way through the higher education context. In closing, the chapter suggests an alternative way of addressing the shared challenges by proposing how rural and historically black universities in South Africa can contribute to the public good, despite being viewed as institutions that do not offer their graduates the highest economic and social returns. The institution under study was a historically disadvantaged institution and is still not viewed as a prestigious university.

\section{Context of the study}

The history of South African higher education institutions is more of a symbol of segregation, which is portrayed in the physical structures, the graduates and geographical positioning of the institutions. This chapter highlights the experiences of students as they sought to fund their registration fees and other necessities at the beginning of the year. The students were enrolled in a historically black institution, which is located in the rural outskirts of Limpopo province, and attracts mostly students from low-income families.

The institution was granted a zero-fee-increase in 2016 during the negotiations with student activists on the \#FeesMustFall campaign in South Africa. The rationale for declaring this institution as a zero-fee-increase institution was that more than $90 \%$ of its students were studying through the National Student Financial Aid Scheme (NSFAS). Students who qualify for this scheme are those whose parents or guardians are not working or are in informal or low paying employment. While there was a high percentage of NSFAS recipients in this institution, there were still a substantial number of students who were without any form of financial support. It is important to be clear that the challenges that students experienced in this institution were not of their own making. There was insufficient 
infrastructure to adequately support students. Accommodation was a challenge and, although institutional structural challenges are not the focus of this chapter, they impacted negatively on the experiences of students because they meant that students had to find ways of managing during their first few days or even weeks at university. The inconvenience caused by the lack of infrastructure in the institution led to financial inconvenience to students at the beginning of the year because as well as finding the money for registration fees, students also had to find and pay for temporary accommodation, food and other basic human needs.

\section{Aim of study}

The aim of this study was to explore how students from low-income families without bursaries or any other sources of financial assistance acquired registration fees and other necessities at the beginning of the academic year. The study sought to explore alternative strategies that students employed to enter higher education, the risks that they took, and the trade-offs that resulted from this precarious situation. Prodan, Maxim, Manolescu, Arustei, and Guta (2015) identify three major barriers to accessing higher education: poor academic preparation, lack of financial resources and lack of knowledge about application and enrolment procedures in higher education. For the purposes of this chapter, the focus is only on the lack of financial resources and only focuses on the period when students attempted to access admission to study at university. It seeks to explore how students accessed basic resources including registration fees; personal needs such as groceries, bed linen, and accommodation on or off campus; transport; and other related needs that are necessary during the registration period.

Singh (2001, p.10) argues that: 'In a country like South Africa, where higher education transformation is part of a larger process of democratic reconstruction, we do not entirely subsume social responsiveness to economic responsiveness.' One can argue that as an attempt to correct the inequalities of the past, a national quality assurance system for higher education was established in the early 2000s. The system aimed not only to enhance higher education access, but also to enhance high standards of provision and their concomitant intellectual and economic benefits (Council on Higher Education, 2001). However, there was an understatement of the economic challenges to widening access to higher education. Even though NSFAS was established, it was and still is unable to address fully the needs of all students who require such assistance.

The major motivator for this study is poverty. The observable problem that society faces today in South Africa is the existence of a very unequal society. Poverty is considered as multidimensional. Lötter (2011) defines poverty as a lack of economic capacities. Lötter identifies two forms of poverty: intermediate and extreme poverty. Intermediate poverty is not having sufficient economic capacities to participate in characteristic social activities judged to be constitutive of being human in a given context. Extreme poverty is a situation where there is lack of economic capacity to meet basic needs such as shelter, nutrition, clothing and medical 
care. Statistics South Africa and the National Treasury have proposed a poverty line based on 'the money income needed to purchase a nutritionally adequate food supply and other essential requirements' (Department of Higher Education and Training, 2013, p.viii). The government's lack of a definition of the poor might have contributed to its failure to provide the financial resources needed to allow poor students to access higher education institutions. Prodan et al. (2013) and World Bank Africa (2009) show the barriers created by the lack of financial resources.

\section{Theoretical framework}

This study is framed around the capability approach initiated by Amartya Sen (1999) and which is discussed in detail in Chapter 8. Sen focuses on what people are capable of doing and becoming, instead of what they already have. Therefore, this study investigates what students and their families are capable of doing in order to access finances for their registration fees and other necessities at the beginning of an academic year to eventually realise their development as human beings. Sen (1999, p. 3) defines development 'as a process of expanding real freedoms that people enjoy'. The experiences of students, together with their families, are linked to finding freedom. Sen (1999, p. 5) further contends that:

\section{What people can positively achieve is influenced by economic opportunities, political liberties, social powers, and the enabling conditions of good health, basic education, and the encouragement and cultivation of initiatives.}

Sen's argument helps us to understand the challenges that students from low-income families are confronted with as they seek economic resources to access higher education. Sen (1999, p. 11) contends that 'poverty is not just a lack of money; it is not having the capability to realise one's full potential as a human being'.

\section{Analytical framework}

\section{Social realism}

In conjunction with Margaret Archer's (1995) social realist framework of structure, culture and agency, the capability approach has enabled the study to respond to the research question in a non-conflationary manner. Non-conflation implies that the researcher was able to analyse structure, culture and agency independently of each other because of the temporary separation of these domains for analytical purposes. Therefore, as access to higher education in South Africa has increased to all citizens, there seems to have been a conflation of the social and the economic by policy-makers. Therefore, the capability approach emphasises that increasing access is not enough; it actually needs to be accompanied by an enabling economic environment as well. 
Archer's framework highlights the clash between social structures, that is between family structures and higher education structures. The clash is in relation to the economics of these institutions. Higher education institutions sustain themselves through fees of students from both low-income families and well-to-do families. This system perpetuates pressure on students from low-income backgrounds, which acts as a barrier to successfully accessing higher education. Students' inability to honour their financial obligations in the attainment of higher education can, in Sen's (1999) terms, be understood as an 'unfreedom'.

The framework also enables the researcher to analyse both the culture of the institution in dealing with students who intend to register with that institution, as well as students' family cultures, in terms of the manner in which the students value education. Furthermore, with regard to culture, the framework enables the researcher to understand the socioeconomic background of families from which the students come. Finally, the framework allows the researcher to analyse the level of agency that students and their families exercise during their quest to access higher education at the beginning of the academic year. Agency includes the risks and trade-offs that students and their families are willing to take for the sake of accessing higher education.

\section{Methodology}

\section{Participants}

Participants of the study were senior students, that is third-year students and beyond, who were academic peer mentors and tutors in the university. The rationale behind using mentors and tutors was, firstly, that they were easily accessible to the researcher of this study because of her role as the institutional coordinator of the mentoring and tutoring programme. Secondly, most students who join the mentoring and tutoring programme do so because of the financial gains attached to it. Thirdly, the study also targeted mentors and tutors who did not receive any form of financial aid such as NSFAS, bursary or scholarship. These are students who were fully reliant on themselves or their families for financial assistance. Therefore, each mentor or tutor who was mainly dependent on family or self-funding for their studies qualified to participate in this study.

\section{Method of data collection}

Data were collected through an open response questionnaire which was emailed to the peer mentors and tutors. A total of 100 questionnaires was distributed to tutors and mentors of which 37 responses were returned. The rationale for email communication was mainly to encourage freedom of expression. Since the study carries with it very sensitive and, to a certain extent, humiliating experiences, the researcher felt it would be better not to have face to face contact with the respondents. The questionnaire comprised four questions: 
1. Have you faced situations where lack of resources led to failure to register?

2. If you are not directly responsible for raising funds to pay for your registration fee, how do you source such funds?

3. Have you faced precarious situations and had no control to change the situation because of financial issues?

4. Where have you turned to for support? What alternatives did you access when you could not find the support you needed?

The answers to these questions enabled the researcher to have an understanding of the cultural practices that are common in low-income households. In the next section, I provide a critical analysis of this in relation to Sen's theory of social justice. The answers to these questions further provided insight into the role that universities are capable of playing in assisting students in need of financial support.

\section{Results}

The results are presented in line with the four questions that respondents answered in the questionnaire: the impact on the students of a lack of financial resources; how they had sourced funds for registration; whether they had felt that financial issues had limited their control of situations; and where they turned to for support. These questions assisted in answering the research question that aimed at understanding how students from a historically disadvantaged institution navigated their way, as they attempted to gain access to higher education.

\section{The impact of a lack of financial resources on students}

In agreement with Mbembe's (2016) argument that university education is impossible without an extensive material infrastructure, one could add that university education also becomes impossible without extensive socio-economic support for the students who are engaged in that education. This is especially the case for students from low-income backgrounds. Data collected from the participants in the study confirmed that lack of basic social and economic needs made it almost impossible for the students to learn. This study focused on challenges experienced during the registration process. However, this kind of life persists beyond registration.

It was very difficult to study without funds to satisfy the daily basic needs like food, transport and for buying books. It was very hard, I sometime had to bring my porridge and green vegetables from home. It was very hard, but I had to carry on in a difficult situation. (Respondent 9)

Last year I did not have money for registration. I ended up registering on the last day of the extended registration day. I was blocked entry in the library and computer lab. I 
wrote my first test while I was unregistered and without textbooks. I relied on lecturer's slides since I was blocked entry in the library and lab. Bursaries that required registered students passed me since their criteria was confined to only registered. Most of the time I relied on friends in order to sleep with a stomach that contained food. I survived morning classes with an empty stomach. I sometimes missed/skipped afternoon classes because it really was/is difficult to cope with an empty stomach. (Respondent 37)

Although Respondent 37 does not share where s/he eventually sourced funds for registration, there is evidence that it was very difficult to find registration fees. Similarly with Respondent 9, it was a challenge to have food and to pay for transport.

\section{How did students source funds for registration?}

While there is evidence that, in some cases, parents and/or other relatives provide funds for enrolment and other necessities, the study further revealed that in low-income households there is a culture of self-reliance. This implies that individuals who are enrolled at university take responsibility for their own studies because parents or significant others are unable to support them.

I was the one as I am the bread winner at home. After school, I had to do some work, like plant vegetables and sell to local communities. (Respondent 9)

Yes, I am a hairdresser. I used my strength to [plait] people's hair so that I can raise some fund for food, clothes and accommodation. (Respondent 4)

Yes, there was a time where I didn't have money to pay for the landlord [residence owner]. Therefore I didn't know what to do because at home they said they don't have money. What I did I sold my SBUX in order to get money to pay for my room off campus. (Respondent 15)

I borrowed money from my lecturer and she was kind to lend me, that how I registered. (Respondent 14)

It is evident that students continued to try to access higher education under very difficult circumstances. They exercised agency in a manner that enabled them to stay connected to the institution. The three quotations above show how the students responded to the situation by realising their hidden entrepreneurial abilities; one plaited other people's hair, another planted vegetables and sold them to the local community and the other one sold her NSFAS allowance (SBUX) in order to pay her rent. 


\section{Students' lack of power to change bad situations}

It is important to note that it is not only families that can play a role in helping to resolve students' financial constraints during the registration period. Institutional structures, in the form of registration fees, constrain students from entering institutions of higher learning. This highlights the importance of the effective interaction between social and institutional structures in supporting students' successful engagement with higher education. The lack of such interaction between society and university structures can perpetuate current practices that are impeding social justice.

Student Representative Council [SRC] came to my rescue. A provision was made for disadvantaged students to submit their documents so that they can be able to register. I submitted my documents and was able to register. (Respondent 37)

They [NSFAS] take too long to respond to our application and as a result we have to find other means. (Respondent 11)

Students' responses indicated a lack of institutional structures to support students. The SRC and NSFAS appear to be the only structures that offer students financial support. This is a matter of concern because it suggests that the institution did not provide sufficient resources to support disadvantaged students. Case (2016, p. 3) asked the question: 'To what degree can institutions formulated to produce an elite be reformed to meet the needs of a different world?' Whilst Case directed this question to curriculum structures, the same question can be directed to access-related concerns.

\section{Where did students turn for support?}

Nonetheless, there are students whose family members, such as parents and others who are employed, are in a position to assist in meeting registration fees. Relatives who take responsibility of providing financial assistance to the needy student are practising what is called 'black tax' in South Africa. According to Vuyelwa Mtolo (2018) 'black tax' is a colloquial term for sharing one's salary with family and making sure that they are well taken care of, before considering taking care of one's self.

My dad sacrificed to get me money to register. (Respondent 8)

My parents pay my registration fee. (Respondent 16)

Grandmother uses her savings. (Respondent 32) 
The study found that some students faced insurmountable obstacles in their attempt to source registration fees and other necessities to begin life on or around campus at the beginning of an academic year. Results revealed that among the risks that female students in particular faced was engaging in multiple sexual relationships with men who could afford to give them money. One respondent had this to say:

\section{I had no money for rent and food and had to sleep with three different men to raise money. (Respondent 32)}

This is referred to as a 'blesser-blessee' relationship, which is normally understood in terms of a wealthy man (blesser) offering financial or material support to a younger female companion (blessee) in exchange for sex, friendship, etc. However, there was also evidence in the study of male students taking on the role of 'blessee'.

Some students were unable to register because they did not have the funds to do so:

Father dies in 2009 and dropped out in 2010 because of debt. (Respondent 1)

I have faced situation of risk where I did not have courage to change the situation because of financial issues. I wanted to drop out and leave my research unfinished. (Respondent 14)

The students' responses suggested that the Student Representative Council (SRC) had offered some financial assistance to students. Students reported mixed experiences on accessing this help:

Engaged the SRC but could not get help then had to ask my parents. (Respondent 33)

I tried the SRC and they were of help. (Respondent 11)

SRC actually helped me. (Respondent 17)

\section{Summary of key findings}

In summary, the study confirms that students face difficulties in their quest for higher education which is likely to lead to drop out, discouragement, or potentially risky behaviours. Although there were no formal structures in the institution to support students who lacked financial and material resources, other structures such as the SRC offered some support. Whilst this helps some students to succeed, such provision needs to be formalised and extended if students are to be supported on a fair and consistent basis. 


\section{Conclusions and recommendations}

In considering potential responses to the situation identified by this study, a number of potential strategies are identified. First, there could be specialised funding to assist students at the beginning of the year while they await allocation of funds by government. The institution could explore the possibility of taking on and extending the current SRC initiative and build it into a solid formal support structure.

Second, this study shows the manner in which the higher education system perpetuates the challenges faced by these students and therefore widens levels of inequality and injustice. This suggests that there is a need for greater financial support from the government and charity organisations, such as the Thusanani Foundation. While recognising that institutions and government cannot afford to carry the financial burden of all students who struggle financially, there needs to be greater provision to support students who are in need. This could be done through partnerships with the private sector, whereby students are placed in organisations to do specific jobs that will earn them money for fees and related needs.

Finally, and most importantly, institutions should reconsider how to support needy students. In line with Sen's capability approach, an institution could consider setting up a capabilities centre. This centre could serve as a one-stop-shop for students who need assistance, especially financial assistance. The centre could take the initiative of searching and harnessing talent from students across the board, not only needy students.

\section{References}

Archer, M. S. (1995). Social realist theory: The morphogenetic approach. Cambridge: Cambridge University Press.

Case, J. M. (2016). Higher education and social justice: Asking the education questions. Think piece for the keynote address. Higher Education Close Up. University of Lancaster, Lancaster, UK.

Child, C. (2018). CEO of Universities SA answers questions about free university. Times Live. Retrieved from https://www.timeslive.co.za/news/south-africa/2018-01-02-ceo-of-universities-sa-answers-questionsabout-free-university/

Council on Higher Education (2001). HEQC founding document. Pretoria: Council on Higher Education.

Department of Education (1997). White Paper 3: A programme for the transformation of higher education. Pretoria: Department of Education.

Department of Higher Education and Training (2013). Report on Working Group on free university education. Pretoria: Department of Higher Education and Training.

Lötter, H. (2011). Poverty, ethics and justice. Cardiff: University of Wales Press.

Magwedze, H. (2017). Unisa says decision on free higher education puts pressure on universities. Eye Witness News. Retrieved from http://ewn.co.za/2017/12/17/unisa-says-decision-on-free-higher-education-putspressure-on-universities

Marginson, S. (2011). Higher education and public good. Higher Education Quarterly, 65(4), 411-433.

Mbembe, A. J. Decolonizing the university: New directions. Arts \& Humanities in Higher Education, 15(1), 29-45.

Mtolo, V. (2018). Living with 'black tax'. The Witness. Retrieved from https://www.news24.com/SouthAfrica/ News/living-with-black-tax-20180316 
Prodan, A., Maxim, E., Manolescu, I., Arustei, C. C., \& Guta, A. L. (2015). Access to higher education: Influences and possible implications. Procedia Economics and Finance, 20, 535-543.

Sen, A. (1999). Development as freedom. Oxford: Oxford University Press.

Sen, A. (2009). The idea of justice. London: Allen Lane.

Singh, M. (2001). Re-inserting the 'public good' into higher education transformation. KAG/SANO Higher Education Discussion Series, 1, 8-18.

World Bank Africa (2009). Literature review on equity and access to tertiary education in the Africa region. New York: World Bank. 


\title{
\#FEESMUSTFALL: A MEDIA ANALYSIS OF STUDENTS' VOICES ON ACCESS TO UNIVERSITIES IN SOUTH AFRICA
}

\author{
Mikateko Mathebula and Talita Calitz
}

\section{Background}

\#FeesMustFall is a student-led protest movement that began in mid-October 2015 in response to increases in fees at South African universities and out of the sheer frustration brought on by the inability to pay registration and tuition fees in full, and on time, at the beginning of each academic year. The wave of protests that became known as \#FeesMustFall started at the University of the Witwatersrand (WITS) and spread to the University of Cape Town (UCT) and Rhodes University (RU) before rapidly spreading to other universities across the country. At the core of the movement was the call for free education, with some students insisting that higher education should be free for all, while others argued that it should only be free for the poor.

The movement received widespread media attention both locally and internationally. Much of the response from critics and academics in the media focused on the viability of free education, with various models being proposed for fee-free higher education. However, while some argued that free education is both feasible and necessary (see Vally, Motala, Naidoo, Hlatshwayo, Maharajh, \& Marawu, 2016); others argued that it would be unsustainable (see Burger, 2016).

Responses have also focused on the worrying trend of police brutality and the presence of the military, and private security guards on campuses (de Vos, 2015; Gillespie, 2017). A recent policy response on this issue has been the release of the Centre for Research on Violence and Reconciliation's (2016) '\#Hashtag report', which describes the experiences of students at nine universities, reflects on \#FeesMustFall violence (for which police carried much of the blame), and provides recommendations for reconciliation between universities and students. In academia, researchers have responded by taking up the question of curriculum transformation 
and decolonisation (see for example Heleta, 2016; LeGrange, 2016; Luckett, 2016; Luckett \& Naicker, 2016; Mbembe, 2016).

Debates around student protests, and the role of student activism in bringing about social change were also sparked, especially after President Jacob Zuma declared that there would be a no-fee increase in 2016 (Arend, 2016; also see Moolman \& Jacobs, 2018).

Although media coverage and analysis of the movement has rightfully centred on fees, this chapter shows that \#FeesMustFall was also concerned with the class struggle that is implicit in the demand for free higher education, as well as complaints about the unaffordability of tuition fees, and living costs associated with being at university. Broadly, this activist stream is concerned with access, that is: who has what kind of access (secure or provisional); for how long (weeks, a term, a semester or the whole year); under what conditions (upfront payments, high matric grades); to what kinds of institutions of higher learning (well- or under-resourced) - and how these factors intersect to compromise access in the same way that annual increases in funds payable for registration, tuition fees and living expenses do.

It is important to note that what came to be known as the 'Fallist' movement did not necessarily begin in 2015. At poorer or historically disadvantaged institutions (HDIs) such as the Cape Peninsula University of Technology (CPUT), ${ }^{18}$ Fort Hare University (FHU) and the Tshwane University of Technology (TUT), students had been protesting regularly against exorbitant university fees, annual fee increases and the cost of higher education in general since 1994 (Davids \& Waghid, 2016). Unlike previous protests at HDIs, which were restricted to individual institutions, \#FeesMustFall received major media attention and sparked solidarity protests as far as London and New York (Davids \& Waghid, 2016). This is possibly because it began at a historically advantaged institution (HAI), but also because it was all encompassing in that students from HDIs such as the University of the Western Cape (UWC), CPUT, TUT, etc. were very active in the protests alongside students at HAIs such as WITS. Widespread media coverage of similar student protests in other parts of the world was observable prior to 2015, for example in Chile during 2011-2013, and Canada in 2012.

\section{Introduction}

South Africa currently has 30.81 million internet users, meaning about $54 \%$ of the total population has access to the internet (Kemp, 2018). The most common use of it amongst South African adults is communication, followed by social networking and information (McLeod, 2017). The move to mobile media has been accompanied by the rise of social media, most importantly Facebook but also microblogging tools, for example Twitter (Nielson, Cornia, \& Kalogeropoulos, 2016). Social media is not only widely used to share experiences and stay in touch with friends and family, it also plays an increasingly important role as a source of news

18 CPUT and TUT are not 'typical' HDIs, having resulted from mergers between historically advantaged (HAIs) and historically disadvantaged institutions. For example, CPUT is the result of a merger between Cape Technikon (HAI) and Peninsula Technikon (HDI). 
(Nielson et al., 2016). In the case of \#FeesMustFall, university students used social media to inspire solidarity and mobilise activism, propelling the question of free higher education as a topical issue which then set a news agenda for the media and the public at large. Despite widespread coverage of \#FeesMustFall in the media, little has been done to consolidate this information to allow comprehensive reading and nuanced understanding of the movement as presented to the general public. In an attempt to offer this, our analytical account of student activism is contextualised within developments in the wider space of higher education, mainly in the period from October 2015 to November 2017, and is based on four groups of online news and information sources. Firstly, we used selected accounts published in The Conversation, The Daily Vox and The Maverick, for informed commentary and debates put forward by various higher education stakeholders (both academic and non-academic). Secondly, we looked at news reports published in popular online news sites such as News24, but also the online versions of The Mail \& Guardian, Times and City Press for accounts that are written from a more journalistic point of view. Thirdly, we crosschecked the descriptive record of events and key issues presented in the two former platforms, with academic literature (mainly journal articles published in the South African Journal of Higher Education) and lastly we used policy documents from the Council on Higher Education (CHE) and Department of Higher Education and Training (DHET) to bring these data into conversation. Although we focused on online news platforms (thereby excluding traditional print media), our interpretations are also informed by observations made on broadcasting media, social media, and personal reflections in relation to the broad topic of university access and human development (see Boni \& Walker, 2013; Wilson-Strydom, 2011). Based on this process, we constructed a media-based narrative of the \#FeesMustFall movement, which is presented thematically, based on our analysis and understanding of the key conceptual and pragmatic issues that appear to underlie this branch of student activism.

We begin with a discussion on access, and the pivotal role the possession of adequate finances play in reserving a place at university in the first instance. This is followed by a discussion on the exclusionary role played by institutional culture, especially race- and classbased discrimination which diminishes access for low-income, black and rural youth. Thereafter we unpack the different ways in which students resist the spatial, academic, financial and socio-cultural barriers they face in their attempts to gain and to secure access to universities. Finally, we consolidate these different sections in the summative discussion on an intersectional understanding of access, before concluding with reflections on the use of online news platforms as a source of secondary data.

\section{An interplay between university access and financial resources}

According to the report on the second National Stakeholder Summit on Transformation in Higher Education (DHET, 2016) widened access to higher education has resulted in an increased number of low-income students gaining access to institutions of higher learning. Since 1994, the number of university entrants has gone up, with headcount enrolments doubled from 495356 
in 1994 to 1.1 million in 2016; with 975837 enrolments in public higher education institutions (HEIs) and 167408 in private HEIs (DHET, 2018). The majority of students enrolled in public HEIs in 2016 were black (71.9\% or 701482 ), followed by white (15.6\% or 152489$)$, coloured (6.3\% or 61963$)$ and Indian/Asian (5.2\% or 50 450) students. In relation to gender, 114942 more female students were enrolled compared to male African students. Lower gender differences are recorded for Indian/Asian, coloured and white students (DHET, 2018).

Access has also been increased through the establishment of new universities in Mpumalanga and the Northern Cape, and the DHET is expanding the number of places available in Further Education and Training (FET) and TVET colleges. The White Paper on Post-School School Education and Training (PSET) has also proposed that contact institutions with capacity increase enrolments through distance education (DHET, 2013). Moreover, the announcement of free higher education for first-time entry students who come from households that earn less than ZAR 350000 annually, will also increase access for many.

However, black students continue to be under-represented in relation to the overall South African population, that is, black students make up $71.9 \%$ of the student population in public HEIs, even though black South Africans comprise $80.8 \%$ of the population, while white South Africans comprise $8 \%$ of the population, and $15.6 \%$ of the student population. Also, access for black students at formerly white universities can be uneven, for example Stellenbosch University (SU) has a higher number of white students than black students. Access to universities also remains out of reach for many academically qualifying black youth, partly because affordability problems remain rife (DHET, 2015a, 2015b). These factors can result in university-ready youth contributing to the 3.2 million young people aged 15-24 years who are not in employment, education or training (NEET) (DHET, 2017). Those who do manage to put together funds for registration and tuition fees, often cannot keep up with the costs for every semester, and can be forced out of universities as a result. So, even if access may initially be attained, it remains slippery for low-income students; their financial circumstances are not conducive to acquiring secure access. Consider the grim circumstances reported in the Mail and Guardian by Abdulla and Wazar (2017), told by students who are aware of the evasive nature of the access they have/had:

I am currently facing several problems. First is that I can't get my National Student Financial Aid Scheme [NSFAS] application results because I wrote supplementary exams this January and February and my examination results are not out. Without NSFAS confirmation, I can't register and my residence space will be given to someone else. My registration costs are ZAR 9633, my tuition for 2017 is ZAR 38700 and ZAR 50500 is for residence. I came back to Grahamstown to prepare for my exams and to sort out my fees. I have been sleeping in different places, sometimes with friends and most of the time in the computer lab and showering at the gym. (Makungu Mabunda, third year BSc student at Rhodes University) 
Makungu's situation is not unique, and it illustrates how points of financial access (outstanding tuition fees) work alongside points of academic access (not being allowed to register in the new academic year) as a structural arrangement that limits and complicates inclusion. Here, inclusion is complicated because Makungu's tuition fees from the previous academic year have not been settled in full, which results in the university withholding his examination results, which then gets in the way of his application for the National Student Financial Aid Scheme (NSFAS), as he needs proof that he has successfully completed the previous year in order to be considered for funding in his second year. Even if both academic and financial points of access were overcome, Makungu, like many Fallist supporters, argues that black $\operatorname{tax}^{19}$ hinders social mobility for black graduates and their families, limiting the transformative potential of securing access to university:

\section{A poor person has black tax that they need to pay once they start working. A poor person must fix the situation of the place they are from once they start working. If you are poor and on NSFAS it means that you are probably going to start your life nicely ten years after university. The poor should get free education not a loan, that's if we are trying to balance the unjust [injustice] of the past.}

Higher education policy in South Africa has long recognised the importance of student financial aid in helping low-income students to access university studies and to increase equity. Since its inception, the NSFAS provision of financial aid to the poorest students (with a household income below ZAR 120000 per annum) has been instrumental in providing access to education for students from low-income and working-class backgrounds who would otherwise not have been able to access universities. Through NSFAS, the government has supported 1,5 million students, many of whom were first-generation university entrants (DHET, 2016). However, the 2010 Ministerial Review of NSFAS found that NSFAS resources have not been well governed and optimally managed since its inception, and that some $72 \%$ of NSFAS-funded students drop out, indicating that access is not being translated into (academic) success. This points to the fact that funding on its own is not the main driver of poor participation levels by especially low-income students. The intersection of funding and other factors such as accumulated disadvantage, poor schooling, access to HEIs and the persistence of these challenges is a crucial factor. It is also problematic that there are high internal inefficiencies (low throughputs/high drop-out rates) within the South African university system. In the quote below, taken from Abdulla and Wazar's (2017) report, Babalwa's situation raises questions about the administration of and requirements for the allocation of NSFAS funding. Babalwa clearly qualified for study at the Durban University of Technology, and comes from a very low-income household, but her application for funding was rejected multiple times, with unclear reasons for this rejection:

19 In South Africa, 'black tax' refers to the financial burden carried by black youth who feel and/or are obligated to help support their low-income family members, particularly upon graduation and gaining employment, or during their higher education studies. 
My siblings and I have been living with my grandmother since I was seven years old, when my parents passed on. She has been taking care of me and my four cousins, who also lost both their parents. We survive solely on her pension of ZAR 1500 a month. I matriculated in 2013 but had to take a gap year because of financial difficulties. I have been a public relations student at DUT since 2015. After waiting months for a response from NSFAS, my grandmother called on my behalf only to find out that my application had been unsuccessful. I applied again for my second year, only to receive the same response. I applied again last year in September. My application is yet to be evaluated. I am currently doing an internship at DUT as part of the curriculum. However, I still owe my second-year fees and accommodation costs, and I do not have my results. (Babalwa Dingindlela, second-year Public Relations student at DUT)

Another concern covered widely in the media is related to NSFAS funding allocation requirements, which previously excluded students whose family incomes rose above the NSFAS threshold (at the time, ZAR 120000 per annum) for support, but below the necessary threshold to obtain reasonable commercial loans. Below, Thando's description of her financial circumstances captures the plight of the 'missing middle':

My mother works as a teacher and is the sole breadwinner at home. I live with my two siblings and a cousin, whom my mother supports on her annual income of ZAR 240000. I know that my family is better off than many others but we're still in a difficult position and can't afford the fees. I have the registration amount but can't register because I still owe last year's fees. (Thando Ndlovu, second-year BSc student, WITS)

It is clear that in South Africa, factors affecting access to universities cannot be discussed without addressing access to financial resources. We have to consider if and how all students get a hold of the necessary funds to afford their registration, tuition, accommodation and text book fees etc., as well as think about how our university funding models affect the extent to which universities include or exclude low-income students in their quest to access and participate in higher education (see Sader \& Gabela, 2017). However, as the following sections show, financial resources are the key, although not the only, determinant of access to university.

\section{Exclusion}

The transformation of institutional cultures in higher education has been identified as a crucial factor in enabling student access (see Chapter 10 and Higgins, 2007; Rhodes University, 2014; Matthews \& Tabensky, 2015). Students' resistance to discriminatory structures is aligned with policy and academic research aimed at transformation of South African universities 
(see Badat, 2007; Department of Education, 2008). Students conceptualised being excluded from higher education both in terms of financial exclusion and institutional cultures that inhibit equitable access to and participation at university (see Calitz, 2018; Wilson-Strydom, 2015). Student voices have thus highlighted the connection between access, fees and exclusion from the university, while bringing questions about institutional culture to public spaces (see also Centre for Research on Violence and Reconciliation, 2016).

\#FeesMustFall has played a role in organising a national focus on institution-specific forms of resistance such as \#RhodesMustFall at UCT (see Murris, 2016), \#Luister at SU (see Nicolson, 2015, 2016) and \#SteynMustFall, at the University of the Free State (see Luescher, Loader, \& Magume, 2017). As part of these divergent movements, student voices identified institutional transformation as a condition for increasing access, with race and class playing an important role in exacerbating fee-based exclusion (see also Chetty \& Knaus, 2016; Poplak, 2016). According to Ismail (2016), Tshepiso, an undergraduate at WITS, explained that:

Fees are the starting point. When I first got here I thought that Wits was bliss because I saw a bunch of white people sit with a bunch of black people, having lunch and hugging. And I didn't realise that this is one of the most segregated places ever.

The protest movement suggests that university cultures are more likely to exclude and marginalise low-income, black and rural students at historically white and/or well-resourced universities. While some media reports have focused explicitly on the link between fees and exclusion, student activists also foregrounded the role of institutionalised racism and socioeconomic stigma in exacerbating financial exclusion.

As Cele (2015) reports, student leaders positioned themselves in resistance to institutionalised racism and socio-economic exclusion at universities. The WITS SRC issued a statement in January 2016 that situated financial and academic exclusion alongside structural injustices (Singh, 2016):

One academic and financial exclusion is one too many, and we know that academic exclusions are often linked to financial issues because there is a campus for the rich and a campus for the poor.

By bringing these points of financial and institutional exclusion together, student protests have articulated how unequal access to resources is more likely to intensify structural forms of exclusion.

At the University of Cape Town (UCT), some undergraduate students reported being excluded due to poverty and institutionalised racism. Onishi (2015) writes about a student who grew up in an under-resourced environment, and still graduated at the top of his high school class. At UCT, the student recognised the socio-economic gap between black and white students, based on ownership of material goods such as cars. The student also pointed out how, 
in his experience, black students ranked at the bottom of academic achievement outcomes. Onishi (2015) writes about another black, working-class student at UCT who reported his experience of structural exclusion based on his socio-economic status and race:

For someone from the townships, coming from there to here [UCT] is a huge change ... No one goes into your face and says, 'You're not welcome here.' No one says that you don't belong here. But it's just that the structure, and the environment itself, says that I'm not welcome here.

In a different narrative, Onishi (2015) describes a student's perspective on how socio-economic status created tension and divisions within the protest movement, which had to be negotiated as part of activists' stance on institutional transformation:

The elephant in the room was class, ... Class was never discussed. It was neatly swept underneath the rug. ... I knew that if you bring up class too early in this organisation, all you would do is to split the black students ... Then it would be blacks-who-have and blacks-who-don't-have. And at UCT, you can see that quite blatantly.

As Ismail (2016) points out, a related aspect of exclusion is being unable to access the physical space of the university, including residences, due to a lack of finances:

We were staying there [sleeping in Senate House] because we don't have money to stay [in university residences] ... personally have no funding at all ... In December, we ended up living in classrooms and lecture rooms and things like that. If you want to take a bath, there is nowhere to bathe, so you borrow a student card and go to the swimming pool, and you swim.

From the above excerpts, student's experiences point to exclusion that could be framed in terms of accumulative disadvantage (Wolff $\&$ de-Shalit, 2007), where a lack of financial aid or inadequate funding to cover academic and living costs intersects with less visible forms of structural exclusion (see also Leibowitz \& Bozalek, 2014). Mbembe (2016, p. 30) brings together the question of access and institutional culture in the following way: 'When we say access, we are also saying the possibility to inhabit a space to the extent that one can say, "This is my home. I am not a foreigner. I belong here.'” Some analyses of \#FeesMustFall suggest that race- and class-based oppression have been sidelined in the interpretation of the protest movement, because of the assumption that student loans and scholarships have been an adequate response to economic inequality (see Chetty $\&$ Knaus, 2016). However, the Fallist movement has directed attention to the structures at universities that perpetuate unequal access, participation and success for many black, working-class and 'missing-middle' students. 


\title{
Resistance
}

While some academic and media responses to \#FeesMustFall have recognised the role of student protest in resisting socio-economic inequality, others have dismissed the movement as disruptive, violent, ignorant of the financial pressures facing universities, and insensitive to students who want to continue with their studies (Chetty \& Knaus, 2016). In our analysis, the \#FeesMustFall movement is part of the post-apartheid class struggle in which black youth across the socio-economic spectrum are resisting institutions and policies that fail to adequately address the widening gap between socio-economic elites, the middle class and the poor. This has been achieved by aligning demands with the transformation agenda that has characterised higher education policy and academic research since the 1990s, and which has shaped subsequent policy objectives (see CHE, 2013; DHET, 2013). Adam Habib, the Vice-Chancellor of WITS, acknowledged that the movement 'achieved in seven days what we vice chancellors had been talking about for a decade' (Ismail, 2016) while a university lecturer from WITS states that the movement has initiated 'a conversation [that] the university should have had the integrity to have before students had to be the ones to push it' (Ismail, 2016; see also Poplak, 2016).

Abdulla and Wazar (2017) quote an undergraduate student at Rhodes University, who affirmed the movement's positive impact on fees and funding:

Before Fees Must Fall, Rhodes University registration was 50\% of your fees, this means one was required to pay $+/-Z A R 45000.00$ in January. That's a lot! It was an institution excluding the poor. And by the end of the second term/block you were required to pay all your fees. Now it's $10 \%$ for registration, which is reasonable.

However, not all students support the movement and its chosen tactics of protest, which have included disrupting classes, tests and exams, and vandalising university property. In response, some academics have resisted the misrepresentation of students as disruptive:

\begin{abstract}
Modern forms of class prejudice are invisible even to the perpetrators, who remain unconvinced of the class struggle of black youth. They dismiss it as unruly behaviour and a lack of respect for the new 'progressive' order governing universities. Protesters are berated for not understanding universities' financial pressures; they are viewed as being insensitive to their peers who just want to get on with their education without disruptions. (Chetty \& Knaus, 2016)
\end{abstract}

In light of our argument above, the aim of this section is to understand how student protesters conceptualised their resistance to inequality during \#FeesMustFall. We identify students' call for decolonised education as a tool to bring attention to and address issues that underlie the nexus between access to universities, structural inequalities in higher education and in wider society. 


\section{The decolonial turn}

In addition to calls for free higher education, students involved in the Fallist movement articulated their resistance against the colonised nature of university cultures. In this way, the student movement has brought the question of fees and access to their critique of untransformed knowledge systems and curricula, universities buildings/symbols, and institutional practices, especially in the role they play creating conditions that enable access to knowledge. With some students' demand for 'free, quality, decolonised education', \#FeesMustFall has played a role in bringing the notion of 'decolonising higher education' into public debate in South Africa. While there is an ongoing academic debate about how a decolonised university would function, and despite theoretical disagreements across disciplines and institutions, the \#FeesMustFall movement has amplified the decolonisation debate in the South African higher education agenda. As the movement intensified, \#FeesMustFall was used to position class struggle in the lived experiences of students. Another motivation for decolonising education has been students' resistance to the slow pace of socio-economic transformation in South Africa and the urgent need to decolonise the public space of the university (see also Poplak, 2016). In the DHET discussion about the protests in 2015, the question of access is discussed, together with institutional transformation:

While access has increased significantly, equity of opportunity and outcomes are dependent on transformed environments within institutions, and mentoring and support, and should be viewed as a wider movement towards democratising education and facilitating students' possibilities to succeed. (CHE, 2015, p. 5)

The Fallist movement framed its objectives as a response to existing policy about transforming higher education teaching and learning, as stipulated in the CHE's proposal for curriculum flexibility:

The onus on higher education institutions is to assume greater responsibility for achieving the qualitative transformation reflected in the missions of many, but now requiring their urgent realisation. (CHE, 2013, p. 9)

\section{An intersectional understanding of the protest movement}

An intersectional understanding of \#FeesMustFall encourages conceptualising access to higher education, and universities in particular, as a multi-dimensional concept that encompasses not only funding. Thinking of access in this way can tell us a lot about different forms of exclusion that are being experienced by black youth, and how fighting for it represents resistance to social injustice. As Disemelo (2015) explains: 
Our protest is not just about 'one thing', even if that ubiquitous hashtag suggests otherwise. It is inherently intersectional, spanning various yet interrelated sociopolitical and economic issues. It is, firstly, about access to equal and quality education. It is about teasing out the ever-so-confusing intricacies of class relations in post-apartheid South Africa. It is about eradicating the painful exclusions and daily micro aggressions which go hand-in-hand with institutional racism within these spaces. And it is also about laying bare the failures of the heterosexual, patriarchal, neoliberal capitalist values which have become so characteristic of the country's universities.

\section{Reflections on the use of online news as a source of secondary data}

Digital media offers us opportunities to engage with the news in unprecedented ways, by commenting on stories, sharing them, discussing them with others, or even publishing our own material via user-friendly tools such as blogs or social media (Nielson et al., 2016) or opinion pieces in platforms such as The Conversation.

By using online news sources, we were able to get an impression of what most South Africans are likely to read about the student protests, not least because these platforms encompass issues discussed widely on social media too. At the same time, we were able to get timely data containing students' voices on the issue of access to university in South Africa.

On the one hand, one could argue that online news sources are 'mere substitutes for "better", but more expensive, primary data' (Cowton, 1998, p. 430), or that their content is less worthy than academic journals for any serious education or research purpose because of their sensationalist character. So the drawbacks are clear: online news platforms do not offer scholarly accounts and there is often a lack of bibliographic data; also, as researchers, we were not able to exercise any control over how the information and data we used was collected.

On the other hand, news reflects social and cultural values of a certain place and time, and can contain unique information that may not be found elsewhere. Moreover, they often contain pertinent vignettes of contemporary life and offer a lot of material for sociological research (reader comments, etc.). In our case, we observed the following benefits of using online news media as a secondary data source: relevant and timely information was readily available (provided one had access to the internet); we had access to diverse sources of information that could easily be cross-checked for validity; news reports and articles were relatively short which made information gathering efficient; some sources contained excerpts from interviews between journalists/reporters and students or other higher education stakeholders (which we would not have been able to gather ourselves); and photographs often accompanied the articles we read which gave us a glimpse of what it might have been like to be at various campuses during the protests (helpful when the researcher cannot be on site). The process of selecting, reading and analysing various news reports and articles over a 
relatively short period of time encouraged us to think more closely about the theoretical ambitions and substantive issues brought forward in the student protests. We did face challenges in selecting which sources to use, and which not, so some intuitive reasoning was used to make these decisions when the criteria we applied reached their limits. It helped that we worked as a team, and we would recommend that researchers looking to undertake similar work do the same.

\section{Conclusion}

We have analysed different voices on \#FeesMustFall, as represented in selected online news platforms, and presented access into university as a trajectory with various layers and contentious points of entry and exit that minimally requires a threshold of adequate financial resources. From our analysis, we have extrapolated some key functions of the movement:

- \#FeesMustFall has fulfilled crucial functions in aligning students' demands with existing higher education policy, bringing policy objectives into public debate, and also inspiring new directions in research due to the emphasis on decolonising higher education.

- By positioning their resistance to injustice as aspirations for the public good, student activists have managed to mobilise fellow activists, and draw sympathy from and engage researchers in and outside of academia, as well as inform policy debates.

- The \#FeesMustFall movement has also coupled fees and access to the broader project of decolonising and transforming South African public universities (see also the Centre for Research on Violence and Reconciliation's \#Hashtag Report, 2016) and it has reminded us that students who face socio-economic exclusion are more likely to be marginalised by untransformed university environments.

To conclude, the protests can be understood as acts of resistance against rising tuition fees. Our analysis also suggests that protest action reflects the persistent inequalities that affect youth attempting to gain access to university in the hopes of improving their lives, and their families' lives.

\section{References}

Abdulla, M. J., \& Wazar, M. (2017). Big dreams, high fees. Mail and Guardian. Retrieved from https://mg.co.za/ article/2017-02-24-00-big-dreams-high-fees

Arend, A. (2016). Zero increase in fees - Zuma. News 24. Retrieved from https://www.news24.com/ SouthAfrica/News/Zero-increase-in-fees-Zuma-20151023

Badat, S. (2007). Higher education transformation in South Africa post 1994: Towards a critical assessment. Pretoria: Centre for Education Policy Development. Retrieved from http://www.cepd.org.za/files/pictures/ CEPD_SolomonMahlanguLecture1_Badat_2007.pdf

Boni, A., \& Walker, M. (2013). Human development and capabilities: Re-imagining the university of the twentyfirst century. London: Routledge. 
Burger, P. (2016). Between the devil and the deep blue sea? The financing of higher education. Econ3X3. Retrieved from http://www.econ3×3.org/sites/default/files/articles/Burger\%20P\%202016\%20 Government\%20subsidies\%20to\%20higher\%20education\%20-\%20FINAL2.pdf

Calitz, T. (2018). Enhancing the freedom to flourish in higher education: Participation, equality and capabilities. London: Routledge.

Cele, S. (2015). The women who led the \#FeesMustFall protest. City Press. Retrieved from https://city-press. news24.com/News/New-activist-generation-Profiles-20151025

Centre for Research on Violence and Reconciliation (2016). \#Hashtag: An analysis of the \#FeesMustFall movement at South African universities. African Portal. Retrieved from https://www.africaportal.org/ publications/hashtag-an-analysis-of-the-feesmustfall-movement-at-south-african-universities/

Chetty, R., \& Knaus, C. B. (2016). Why South Africa's universities are in the grip of a class struggle. The Conversation. Retrieved from http://theconversation.com/why-south-africas-universities-are-in-the-grip-ofa-class-struggle-50915

Council on Higher Education (2013). A proposal for undergraduate curriculum reform in South Africa: The case for a flexible curriculum structure. Pretoria: Council on Higher Education. Retrieved from http://www.che. ac.za/sites/default/files/publications/Full_Report.pdf

Council on Higher Education (2015). Transformation in higher education. Discussion paper prepared for the second national Higher Education Transformation Summit, 2015. Pretoria: Council on Higher Education. Retrieved from http://www.justice.gov.za/commissions/FeesHET/docs/2015-HESummit-Annexure06.pdf

Cowton, C. J. (1998). Using secondary data in business ethics research. Journal of Business Ethics, 17(4), 423-434.

Davids, N., \& Waghid, Y. (2016). \#FeesMustFall: History of South African student protests reflects inequality's grip. Mail \& Guardian. Retrieved from https://mg.co.za/article/2016-10-10-feesmustfall-history-of-southafrican-student-protests-reflects-inequalitys-grip

de Vos, P. (2015). \#FeesMustFall: On the right to mass protest and the use of force by police. Constitutionally Speaking. Retrieved from https://constitutionallyspeaking.co.za/feesmustfall-on-the-right-to-mass-protestand-the-use-of-force-by-police/

Department of Education (2008). Report of the ministerial committee on transformation and social cohesion and the elimination of discrimination in public higher education institutions. Commonly referred to as the 'Soudien Report'. Retrieved from https://www.ukzn.ac.za/wp-content/miscFiles/publications/ ReportonHEandTransformation.pdf

Department of Higher Education and Training (2013). White paper for post-school education and training: Building an expanded, effective and integrated post-school system. Pretoria: Department of Higher Education and Training. Retrieved from http://www.dhet.gov.za/SiteAssets/Latest\%20News/White\%20 paper\%20for\%20post-school\%20education\%20and\%20training.pdf

Department of Higher Education and Training (2015a). Are we making progress with systemic structural transformation of resourcing, access, success, staffing and researching in higher education: What do the data say? Annexure 3 - Paper prepared for the second national Higher Education Transformation Summit 2015. Pretoria: Department of Higher Education and Training. Retrieved from http://www.justice.gov.za/ commissions/FeesHET/docs/2015-HESummit-Annexure03.pdf

Department of Higher Education and Training (2015b). Annual report 2014/15. Pretoria: Department of Higher Education and Training. Retrieved from http://www.dhet.gov.za/Commissions\%20Reports/DHET\%20 Annual\%20Report\%202014-2015.pdf

Department of Higher Education and Training (2016). Report on the second national higher education transformation summit. Pretoria: Department of Higher Education and Training. Retrieved from http://www.dhet.gov.za/summit/Docs2015.html

Department of Higher Education and Training (2017). Fact sheet on 'NEETS'. Pretoria: Department of Higher Education and Training. Retrieved from http://www.dhet.gov.za/Planning\%20Monitoring\%20and\%20 Evaluation\%20Coordination/Fact-sheet-on-NEETs-Final-Version-27-Jan-2017.pdf

Department of Higher Education and Training (2018). Statistics on post-school education and training in South Africa 2016. Pretoria: Department of Higher Education and Training. Retrieved from http://www. dhet. gov.za/DHET\%20Statistics\%20Publication/Statistics\%20on\%20Post-School\%20Education\%20and\%20 Training\%20in\%20South\%20Africa\%202016.pdf 


\section{Higher EDUCATION PATHWAYS}

Disemelo, K. (2015). South African student protests are about much more than just \#FeesMustFall. The Conversation. Retrieved from https://theconversation.com/south-african-student-protests-are-about-muchmore-than-just-feesmustfall-49776

Gillespie, K. (2017). Favour rigorous debate, not security. Mail \& Guardian. Retrieved from https://mg.co.za/ article/2017-03-03-00-favour-rigorous-debate-not-security

Heleta, S. (2016). Decolonisation of higher education: Dismantling epistemic violence and Eurocentrism in South Africa. Transformation in Higher Education, 1(1), 1-8.

Higgins, J. (2007). Institutional culture as keyword. In Council on Higher Education (Ed.), Review of higher education in South Africa: Selected themes. Pretoria: Council on Higher Education.

Ismail, S. (2016). What now for South Africa's \#FeesMustFall movement? At the University of the Witwatersrand, where protests began, students navigate the future of a fractured movement. Al Jazeera.

Retrieved from https://www.aljazeera.com/indepth/features/2016/02/south-africa-feesmustfallmovement-160205083002040.html

Kemp, S. (2018). Digital in 2018: World's internet users pass the 4 billion mark. We are Social. Retrieved from https://wearesocial.com/blog/2018/01/global-digital-report-2018

Le Grange, L. (2016). Decolonising the university curriculum. South African Journal of Higher Education, 30(2), $1-12$.

Leibowitz, B., \& Bozalek, V. (2014). Access to higher education in South Africa: A social realist account. Widening Participation and Lifelong Learning, 16(1), 91-109.

Luescher, T., Loader, L., \& Mugume, T. (2017). \#FeesMustFall: An internet-age student movement in South Africa and the case of the University of the Free State. Politikon, 44(2), 231-245.

Luckett, K. (2016). Curriculum contestation in a post-colonial context: A view from the South. Teaching in Higher Education, 21(4), 415-428.

Luckett, K., \& Naicker, V. (2016). Responding to misrecognition from a (post)/colonial university. Critical Studies in Education, 1-18.

Matthews, S., \& Tabensky, P. (2015). Being at home: Race, institutional culture and transformation at South African higher education institutions. Pietermaritzburg: UKZN Press.

Mbembe, A. J. (2016). Decolonizing the university: New directions. Arts \& Humanities in Higher Education, 15(1), 29-45.

McLeod, D. (2017). Internet access in SA: Rural areas falling far behind. NewsCentralMedia. Retrieved from https://techcentral.co.za/internet-access-sa-rural-areas-falling-far-behind/75789/

Moolman, A., \& Jacobs, L. (2018). Responses to the short-term effect of the zero per cent fee increase on South African universities. South African Journal of Higher Education, 32(1), 178-191.

Murris, K. (2016). \#Rhodes Must Fall: A posthumanist orientation to decolonising higher education institutions. South African Journal of Higher Education, 30(3), 274-294.

Nicolson, G. (2015). Stellenbosch: 'Luister' could lead to change. Daily Maverick. Retrieved from https://www. dailymaverick.co.za/article/2015-09-01-stellenbosch-luister-could-lead-to-change/\#.WsTF7GhL_IU

Nicolson, G. (2016). Fees Must Fall: Reloaded. Daily Maverick. Retrieved from https://www.dailymaverick.co.za/ article/2016-01-12-fees-must-fall-reloaded/\#.WsObhWhL_IU

Nielsen, R. K., Cornia, A., \& Kalogeropoulos, A. (2016). Challenges and opportunities for news media and journalism in an increasingly digital, mobile, and social media environment. Council of Europe report DGI(2016)18. Reuters Institute for the Study of Journalism, University of Oxford. Retrieved from http:// reutersinstitute.politics.ox.ac.uk/sites/default/files/research/files/Challenges\%2520and\%2520opportunities \%2520for\%2520news\%2520media\%2520and\%2520journalism\%2520in\%2520an\%2520increasingly \%2520digital\%252C\%2520mobile\%2520and\%2520social\%2520media\%2520environment.pdf

Onishi, N. (2015). Students in South Africa protest slow pace of change. The New York Times. Retrieved from https://www.nytimes.com/2015/09/09/world/africa/student-protests-in-south-africa-highlightdissatisfaction-with-pace-of-change.html

Poplak, R. (2016). The rock, the hard place, and the cruel beauty of an uncaring universe. eNCA. Retrieved from http://www.enca.com/opinion/adam-habib-\%E2\%80\%93-the-rock-the-hard-place-and-the-cruel-beautyof-an-uncaring-universe 
Rhodes University (2014). Full report on the Rhodes University institutional culture survey 2014, prepared by the Office of Equity and Institutional Culture. Retrieved from http://www.ru.ac.za/media/rhodesuniversity/ content/equityinstitutionalculture/documents/Full\%20Report\%2030\%20March.pdf

Sader, S. B., \&. Gabela, N. P. (2017). Spatialities of widening participation: Narratives of first year students receiving financial aid. South African Journal of Higher Education, 31(1), 227-242.

Singh, K. (2016). \#FeesMustFall campaign back. News24. Retrieved from https://www.news24.com/ SouthAfrica/News/feesmustfall-campaign-back-20160110

The Daily Vox. Retrieved from https://www.thedailyvox.co.za/released-fallist-bonginkosi-khanyile-prison-protestrevolution-rumana-akoob/

Vally, S., Motala, E., Naidoo, L., Hlatshwayo, M., Maharajh, R., \& Marawu, Z. (2016). Free education is possible if South Africa moves beyond smoke and mirrors. The Conversation. Retrieved from https:// theconversation.com/free-education-is-possible-if-south-africa-moves-beyond-smoke-and-mirrors-65805

Wilson-Strydom, M. (2011). University access for social justice: A capabilities perspective. South African Journal of Education, 31, 407-418.

Wilson-Strydom, M. (2015). University access and success: Capabilities, diversity and social justice. London: Routledge.

Wolff, J., \& de-Shalit, A. (2007). Disadvantage. Oxford: Oxford University Press. 


\title{
CURRICULUM \\ TRANSFORMATION: \\ LOOKING BACK AND \\ PLANNING FORWARD
}

\author{
Suellen Shay and Thandeka Mkhize
}

\section{Introduction}

This volume provides an opportunity for critical engagement and debate from a variety of perspectives on the question; to what extent does undergraduate education in South Africa support the public good? The focus of this chapter is on curriculum - what have we learned in South Africa about attempts to reform curricula in order to address what we know to be an unjust and unequal differentiation of the student experience? This question is posed at a critical time - what the introductory chapter refers to as a 'knife edge' - with respect to the future of South African higher education. The undergraduate curriculum is one of the most critical items on this reform programme.

We begin by interrogating the broader purposes of higher education and the notion of the 'public good'. As Marginson (2011) argues, higher education for the public good raises the questions of 'whose public good'? and 'in whose interests'? It could be argued that higher education in South Africa has always served the 'public good'. As Lange (2012) argues, South African universities were part of the settler society, performing a variety of social, economic and ideological functions in the colonial context. Under apartheid, the system served the narrow exclusive interests of the white minority public. The legislatively differentiated apartheid system was set up to 'serve' a variety of different publics - in the first instance, the differentiation between the traditional universities and the technikons, and then within each of these sectors, a different racial, language and de facto socio-economic sectors of the public. Overnight, this differentiated system had to construct a radically different, democratic vision of the 'public', in short, a radical shift from the white minority to the black majority. The White Paper 3 (Department of Education $[\mathrm{DOE}], 1997)$ articulated this new vision and purpose for higher education. As Lange 
(2012, p. x) puts it, 'The task of the new democratic government was to broaden the notions of public and citizenship in all spheres of life in the country'.

The notion of broadening the public echoes strongly Fraser's (2005, p. 73) definition of social justice. She writes, 'Justice requires social arrangements that permit all to participate as peers in social life'. A higher education system that seeks to be socially just is one that is seeking to ensure, to use Fraser's term, 'parity of participation'. 'Parity of participation' is a higher education system that enables equity of access and equity of outcomes. To achieve this, Fraser argues, means overcoming economic, cultural and political obstacles.

Social justice in higher education requires that fair opportunities are made available to all students to enter higher education and to be given the opportunity to succeed. Failure by higher education institutions to provide these opportunities has resulted in racially skewed participation rates and academic performance, high dropout and high failure rates of, particularly, black students. There are thus many obstacles that remain before 'parity of participation' can be achieved. Social justice in higher education remains a goal that South Africa has not yet achieved.

This review of what we know covers the following themes:

- The policies that have had a direct or indirect impact on attempts at curriculum reform in South Africa;

- The specific curriculum reform initiatives of the extended degree and the proposed flexible degree;

- The calls for a 'decolonised curriculum' and the implications for knowledge

- Small scale qualitative and large scale quantitative studies on the student experience in extended degrees; and

- The scholarship on knowledge and curriculum, informing or in critique of these policies and practices.

The purpose of this review is to explore the history of attempts at undergraduate curriculum initiatives and reforms in order to map a way forward.

In this chapter, we explore the competing narratives of transformation from the mid-1980s to the recent student protests. We select one strand of this history of curriculum policies and interventions that has had equity of access and outcomes as its aim. We trace the evolution of the extended degree programmes (EDPs) from the mid-1980s to the proposed flexible degree in 2013. We agree, as Lange argues (2017), that the relationship between curriculum, knowledge and identity is critical to curriculum transformation. This is however not sufficient. We argue that structural change is necessary if we are to achieve systemic change.

\section{Curriculum reform: Competing discourses of transformation}

Since 1994 there have been a number of higher education policies that have directly or indirectly impacted on attempts at curriculum reform in South Africa (DOE, 1997; 
Department of Higher Education and Training [DHET], 2013; National Planning Commission [NPC], 2011). The challenges set out by these policies, as well as the tensions between the challenges, are mirrored in the range of attempts to reform university curricula, as well as various curriculum initiatives. The White Paper 3 (DOE, 1997) refers to a threefold national agenda of transformation, reconstruction and development. The policy is explicit about the tensions between the challenges of transformation on the one hand and economic growth on the other. The White Paper's definition of transformation is unambiguously about 'parity of participation': the 'promotion of equity of access and fair chance of success to all who are seeking to realise their potential through higher education, while eradicating all forms of unfair discrimination and advancing redress for past inequalities' (1.14). At the same time it notes the 'formidable' challenges for the South African economy in 'integrating itself into the competitive (international) arena ... which places a premium on knowledge and skills, leading to the notion of the "knowledge society" (DOE, 1997, 1.9). Thus, we can see in the White Paper the tensions between retrospective and prospective orientations (Shay, 2015). The former are oriented towards the legacy of the past and the need for redress and the latter are oriented towards the challenges of the future and the imperatives of a global economy. In the two decades since the White Paper 3 (DOE, 1997), these policy discourses of equity and redress vs. growth and economic development continue to compete for dominance in the policies which have followed: the National Development Plan (NPC, 2011), the White Paper for Post-School education and Training (DHET, 2013), and most recently the draft National Plan for Post-Secondary Education and Training (DHET, 2017).

Not surprisingly, the attempts at curriculum reform have mirrored these competing discourses for what constitutes transformation. For example, the National Qualifications Framework (NQF) (South African Qualifications Authority [SAQA], 2008) attempted to deal with parity of participation, as well as economic growth. Since the mid-1980s the extended degree programmes (EDPs) and the Foundation Grant have attempted to redress the consequences of inequality in access and success. In the mid-1990s there was an attempt to address the needs of the knowledge economy by shifting curriculum coherence from the disciplinary majors to outcomes-focused programmes (Ensor, 2004). Although the institutional mergers were not directly about curriculum reform, the implementation of the merger policy (DOE, 2002) had massive implications for university curricula, especially in the newly created comprehensive universities as curricula across different vocational, professional and academic pathways of the HEQSF were to be merged into one (Oosthuizen, 2014). More recently, the proposal for the flexible degree (Council on Higher Education [CHE], 2013) attempted to build on the strengths and limitations of the extended degree programme by addressing both issues of equity and development, but as a system-wide reform rather than only for a minority of students. And finally, the calls for decolonising the curriculum which arose during the student protests have spurned all previous attempts at reform: the choice of the term 'decolonisation' itself signals a rejection of transformation as a 'failed project' (Mpofu-Walsh n.d.). 
In Lange's (2017) review of 20 years of curriculum reform 'against the grain of student protests', she argues that all the policy attempts of the past two decades have failed to bring about the transformation of university curricula. Her critique is that the policy choices of the past two decades did not create the space for an examination of curriculum from the point of view of epistemology and identity. Instead, much of the attempts at reform focused on structure, leaving issues of epistemology and identity unquestioned.

We argue that at this point in time the review of the undergraduate curriculum is essential. We argue that the transformation agenda must be sufficiently broad to address the concerns of the White Paper 3 (DOE, 1997), but must now also include the critiques arising from decolonisation. A transformation agenda must now include the imperatives for equity, appropriately prepared graduates, and a decolonised curriculum. In order to address these transformational goals, in order to achieve systemic curriculum review, structural change is essential.

\section{Curriculum-based attempts for 'parity of participation' - from extended to flexible structures}

In order to look at the relationship between curriculum, knowledge and identity, as well as issues of curriculum structure in more depth, we focus on one strand of policy and intervention. We examine attempts by the higher education sector to address 'parity of participation' through curriculum: the establishment of academic development programmes (ADPs), which later became extended degree programmes (EDPs). These were followed in 2013 by the proposal for a restructuring of the undergraduate degree, referred to as the 'flexible degree' (CHE, 2013).

The courses, and eventually the accredited state-subsidised programmes that were established by academic development practitioners in the mid-1980s were not set up to reform South Africa's higher education undergraduate curriculum. They were set up to address the challenges faced by initially white English-speaking universities, as increasing numbers of black students were being admitted. (While sharing many common features with 'academic development' in the UK, South African 'academic development' historically had students as its primary focus; see Chapter 15 for further discussion.) It was clear that, although these students were some of the most talented students in the country, unless some kind of curriculum support was put in place, these students were unlikely to succeed - this was referred to as a 'revolving door' syndrome. The model of curriculum provision that developed over the next decades, and exists to this day in nearly all South African higher education institutions, is an extended degree. The programme specifics vary across institutions and faculties, but essentially the first academic year is extended over a period of 18 months or two years, giving students more time and a more supportive pedagogy (e.g. smaller classrooms, specialist teachers etc.). By 2004 these programmes had been formalised into state-approved extended degrees that attracted additional state subsidy. This is referred to as the Foundation Grant and consists of ring-fenced funding for students on approved EDPs. 
These programmes from their onset understood their mission to be about access for students who would not otherwise have been admitted. Access was understood to be both about formal entry into the university and epistemic access to the disciplines and their respective modes of inquiry. It was premised on the need to address and redress the injustices of apartheid education and the consequential 'gap' in students' preparedness for university studies. Most of these programmes understood their role to make explicit the underlying epistemological foundations of the disciplines - the 'literacies' - that caused many students to stumble. The premise was also, though this was less explicit, that universities were 'under-prepared' for these students who represented the best that the schooling system had to offer. Thus, this reform was never simply about a different structure, that is, an additional year added to a degree. It was about a curriculum structure that enabled formal and epistemological access to the disciplines as a form of redress for the ongoing injustice of unequal education.

These programmes over their three decades of history are an interesting case study for the relationship between curriculum, knowledge and identity. Even those programmes which have successfully offered students sound epistemological foundations for further study have had little or no impact on the knowledge (both the 'what' and the 'how') further along the degree - the so-called 'mainstream' curriculum has been largely unaffected. Thus, with a few exceptions, these programmes have been an extended first year over two, rather than an extended three years over four. The sound curriculum and pedagogic principles that inform the foundational years of the degree have not extended across the full degree or diploma (CHE, 2013; Shay, Wolff, \& Clarence-Fincham, 2016; Smith, 2012); the epistemic transitions further along the degree remain significant obstacles for many students. This has resulted in generally poor completion rates for many of these programmes (Shay et al., 2016).

From a more critical standpoint it could be argued that the existence of the EDPs has deferred the need for curriculum review of the so-called 'mainstream' undergraduate curriculum. Lange's (2017) argument about the relationship between curriculum and identity is apt here - the higher up the degree, the more academics are invested in the knowledge transmitted through curriculum. Transformation of the curriculum beyond first year would require in some cases changes to how academics view their knowledge, their discipline and ultimately themselves. These shifts in academic identity are a necessary condition if students are to gain epistemological access to their disciplines, since providing epistemological access includes the narrowing of the gap between the worldview of students, lecturers and the target knowledges (Boughey, 2005). Currently, this gap is wide.

Over the years, issues of academic development identity, both those of students and staff, have become increasingly troubled, as Clegg (2009) notes across many national contexts, not only South Africa. The burden of stigma has hung over the programmes from their inception. Students feel misrecognised by a deficit discourse of 'underpreparedness' and 'disadvantage' (Kotta, 2011; Luckett \& Naicker, 2016; Mogashana, 2015). This is not to deny that a significant number of students have benefited from these programmes. While these programmes 
have played a critical role in equity of access, they have not been as successful in achieving equity of outcomes (CHE, 2013; Lange, 2012; Luckett \& Shay, 2018). These programmes cannot be the model for transforming curriculum - they cannot be the solution to the crisis of throughput currently in evidence. As the CHE (2013, p. 70) concludes in its review of the extended degree programmes, 'notwithstanding evidence of progress and success, the benefits of curriculum extension will not be fully realised until it is taken to scale and become an integral element of mainstream provision'. Luckett and Shay (2018) are more critical, arguing that these programmes are more affirmative than transformative, using a distinction made by Fraser (2009). This distinction points to approaches that enable the status quo to prevail, as opposed to approaches that genuinely bring about change of the whole system.

Responding to the limitations of the extended degree, in 2012 the Council of Higher Education (CHE) commissioned a proposal for the restructuring of the undergraduate degree; this has come to be called the flexible degree, that is, the restructuring of the length of the undergraduate degree from three to four years. This proposal is an attempt to deal with some of the shortcomings of the de facto two-track curriculum system currently in place: the extended degree curriculum and the 'mainstream' curriculum. It addresses in structural terms the assumptions about entry level, for example who is the curriculum for, how to ensure that there is epistemic access at all major transitions in the degree, and more elective space to allow for some breadth of knowledge to ensure better prepared graduates. It challenges 'colonial' assumptions about the three-year minimum time as 'normal' minimum time to graduation.

More specifically, the flexible degree proposal seeks to address key existing structural problems through a set of curriculum reform principles. Once again, the flexible degree was never simply about an additional year. The restructuring would enable the implementation of four principles. Firstly, the principle of foundation provision: a recognition that serious knowledge gaps need to be filled, given problematic curricular assumptions about students' prior knowledge. Secondly, the principle of epistemic transitions is an acknowledgement that addressing the entry-level gaps will not suffice; there is a need to scaffold students' epistemic development beyond foundation provision. Thirdly, the principle of enhancement notes that there is a need for a structure that enables greater 'breadth' of exposure in order to produce graduates for the contemporary world. Fourthly, the principle of enrichment acknowledges that there is the necessity for 'curriculum enrichment through key literacies', for example digital, quantitative, academic, multilingualism (CHE, 2013; Shay et al., 2016).

The proposal was presented to the sector and the ministry for higher education and training in 2013. While most of the sector was cautiously supportive of the proposal, the minister of higher education at the time was not. The reasons given for rejecting the proposal were that the performance data supporting the proposal were dated ('things had improved') and the state had devised other less radical mechanisms for addressing the systemic problems. These included the ring-fenced funding for the improvement of teaching and learning and doubling the numbers of students on the extended degree from $15 \%$ of the enrolments to $30 \%$. 
In retrospect there are lessons to be learned. One of the failings of the proposed policy is that it did not make sufficiently explicit what the restructuring would enable. The goal for reform is not a restructured curriculum - the goal is what the new structure enables. Secondly, the proposed policy underestimated the relationship between curriculum reform and academic identity. Any significant curriculum reform will be a profound challenge to academic identities. If academics do not subscribe to the fundamental principles underpinning the reform, it is likely to be met with resistance. Thus, going forward, any proposed structural reform needs to make more explicit what the new structure enables that the existing structure cannot accommodate. In addition, the impact of the restructuring on academic identity should not be underestimated. Many academics see their primary purpose to transmit the knowledge of their discipline and ideally, to encourage postgraduate students to enter their area of specialisation. They do not see their primary purpose as enabling epistemological access, nor do they necessarily have any commitment to the breadth of a student's academic experience. The key principles of the flexible degree were and remain a 'hard-sell' to the academy.

Barely had the dust of the flexible degree consultation process settled, when the \#RhodesMustFall (RMF) movement put a different set of education issues on the table. Apartheid had created a legacy where, to this day, the quality of education is to a large extent based on race. Issues of income level, schooling, race, home language and cultural background all intersect to complicate the issue of access to higher education in South Africa (Ferreira \& Mendelowitz, 2009).

One of the main grievances of protesting students during the \#RMF movement was the need for a decolonised curriculum. Their argument was that the university curriculum needed to be 'transformed to reflect the lived experiences of African people, including recognition of their scholarly work which is often on the periphery' (Lange, 2017, p. 10). Thus one of the meanings of 'decolonising the curriculum' was putting African scholarly work at the centre of the curriculum. There has been much debate, however, about what a decolonised curriculum might look like. Mbembe (2016) cautions against taking the curriculum decolonisation project at face value and argues that a curriculum that has Africa at the centre need not shut out the West and other parts of the world, but consider them from an African perspective. Jansen (2017) teases out a number of strands of potential meanings: decolonisation as the decentring of European knowledge, as the Africanization of knowledge, as an additive-inclusive approach, as critical engagement with settled knowledge, as encounters with entangled knowledge, and as the repatriation of occupied knowledge. Each of these he discusses in terms of their different political understandings of what needs to be changed.

We turn back on this brief history of attempts to enhance 'parity of participation' through curriculum change to explore what we can learn that will shape the interventions we put in place going forward, at institutional and national level. Following from Lange (2017), the relationship between curriculum, knowledge and identity needs further exploration. 


\section{Conceptualising curriculum and knowledge: The how, what and who of knowledge}

From some theoretical perspectives, curriculum, knowledge and identity cannot be separated. Bernstein (1975, p. 85) defines curriculum as 'what counts as valid knowledge'. Bernstein's interest is in the underlying rules, what he calls 'codes' that shape what is considered valid, or, put another way, the principles which regulate why in any given curriculum certain kinds of knowledge, skills and dispositions become privileged over others. These rules shape not only selection (of knowledge), but sequence, pacing and evaluation. So, while the focus of curriculum review is often on what is taught (e.g. the content) and how it is taught (e.g. pedagogy), a Bernsteinian focus is on the codes where 'codes' refer to underlying principles which shape the what, how and why of curriculum choices. These choices are not neutral. All curricula involve a set of assumptions about, for example, who the curriculum is for, what kind of graduates will emerge, and what kind of graduates does society need. These assumptions are invisibly embedded in admission points and subject requirements, in expected curriculum load, in progression rules, in expectations of minimum time, and in rules for academic exclusion.

The term 'curriculum structure' refers broadly to the parameters of starting level (and related assumptions about students' prior knowledge), duration, the pace and flexibility of progression pathways, and the exit level (CHE, 2013). Structural decisions are based on assumptions about knowledge (how much, what kind, whose) and identity (who is this curriculum for, who is best suited to teach). All of these constitute the exoskeleton or structure of the curriculum. Long before a student writes their first essay or test, these structures shape students' experience of the curriculum as either enabling or obstructive. Like the colonial lines drawn on the map of the African continent, these structures represent a whole range of political interests that may have little to do with students' best interests. In this sense, to open up curriculum structures for interrogation is an important part of the decolonial project. To interrogate the structure is to disrupt assumptions about what constitutes valid knowledge and identities. The review of structures is also a strategic catalyst for change. National or institutional policy cannot mandate changes to knowledge and identity, but it can mandate changes to structure. Thus curriculum restructuring can be a powerful lever for curriculum reform.

Alongside the trajectory of both policy and curriculum interventions detailed above, there has been a rich and sustained body of scholarship on the relationship between curriculum and knowledge, sometimes arising out of the policy and practices and sometimes in critique of them. As noted above, there has been a significant body of scholarship arising out of the field of academic development that has explored the 'literacies' as a means of enabling epistemic access, that is, the academic discourses that students require to succeed in the disciplines (Bangeni \& Kapp, 2017; Boughey, 2005; Thesen \& van Pletzen, 2006). The focus of this scholarship has been less on the 'what' of knowledge and more on the 'how'. How do students become fluent in the discourses of the academy and their respective disciplines? The challenge 
of navigating the 'epistemic transitions' of the undergraduate degree remains critical if we are to address issues of academic dropout and poor completion rates due to repeated failure.

Another more recent body of scholarship since 2000 in South Africa has looked at epistemological access from a social realist point of view, that is, reasserting the 'what' of knowledge, that knowledge matters, that there are different forms of knowledge and that giving students access to 'powerful knowledge' is a matter of social justice (Muller, 2000, 2009, 2014; Young, 2013). This scholarship has spawned a number of studies exploring knowledge and curriculum differentiation in the disciplines (Luckett, 2012; Shay, 2013; Wolff \& Luckett, 2013).

The third growing body of scholarship is around issues of 'whose' knowledge. These debates have been around for years but rose to the fore during the 2015 call to decolonise the curriculum. \#RhodesMustFall exposed the epistemic dislocation that students feel within the so-called Western or colonial traditions of knowledge (Motsa, 2017). The protests called for a re-examination of the notion of 'epistemic access'. Epistemic access can only be understood within a framework of epistemic diversity, that is, epistemology that is open to dialogue among different epistemic traditions (Mbembe, 2016). This call questioned the Western academic model of knowledge production still in use in most South African universities - a model that creates the perception that legitimate knowledge can only be produced by the West, that Africans are incapable of knowledge production. The aim of higher education is to develop students' intellectual lives through redistributing equally 'the capacity to make disciplined inquiries into those things we need to know, but do not know yet' (Mbembe, 2016, p. 30).

The problem with respect to a systemic plan of action for curriculum reform is that these bodies of scholarship are sceptical of each other. Even before the protests, it was difficult for those in the social-constructivist literacy camp to engage in dialogue with those in the social realist 'powerful knowledge' camp. Each has different ontological points of departure. The basis of legitimacy lies in different underlying codes, what Maton (2014) would refer to as a stronger knowledge codes in social realist views of knowledge and stronger knower codes in social-constructivism and postcolonial theories of knowledge. Since 2015 it has been even more difficult to find a common platform to talk about curriculum reform. The 'decolonial' framing has become the dominant frame for any review discussion. This is understandable given the high levels of frustration at previous failed attempts at transformation. It has however had the consequence of narrowing the reform agenda, as well as polarising the debates. The knowledge debates have shifted away from how to promote epistemological access to powerful knowledge to 'whose' knowledge, where legitimacy is strongly located in the knower or the producer of the knowledge. Maton's (2014) argument is apt: knowledge claims always have both an epistemic and social relation, that is they are always about something and about someone. The issue is which is dominant and whose interests are served by this.

What we can see over this period from the 1980 s to 2016 is that, although the same call is made for social justice and for parity of participation, the understanding of the problem has 
evolved. To some extent these different understandings sit uncomfortably beside each other as we face questions of 'where to next'? One body of scholarship is trying to re-centre knowledge and the other is questioning: whose knowledge? What legitimates this as powerful knowledge? Any attempt at systemic curriculum reform has to contend with policy discourses reflecting different priorities, different theories underpinning the relationship between curriculum and knowledge, and even different understandings of 'decolonisation' that appear incommensurable.

For the possibility of any systemic curriculum reform agenda going forward, the starting point is respectful, productive dialogue where a sufficiently common base of values and goals can be found. We believe that curriculum that enable 'parity of participation' can be one of the goals, although assumptions underlying this have to be thoroughly interrogated from the start.

For the possibility of any systemic curriculum reform agenda going forward, we need to keep our goal of 'parity of participation' in view. Despite what might appear to be incommensurable positions, it is imperative that we commit ourselves to respectful dialogue that can find a sufficiently common base of values that can inform reform practice.

\section{Conclusion: What now?}

Moving forward, the state has the opportunity to return with renewed commitment to 'parity of participation', to equity of access and equity of outcomes through a bold policy of curriculum transformation. There is currently no policy or intervention in place that will address the scale of the change needed. The existing state commitments - ring-fenced funding for teaching and learning and increasing the percentage of students on extended curricula - will not bring about the necessary change. Leaving institutions to address the challenges will not 'move the needle' of systemic change. What is now required from the state is a bold policy on curriculum restructuring. This restructuring would enable at institutional level a different undergraduate degree that adheres to the principles outlined in the CHE's (2013) flexible degree proposal and at the same time is responsive to some of the key issues arising from the calls for decolonising the curriculum.

This policy must not fall into the trap of previous attempts where structural changes are prioritised, bypassing changes to knowledge and identity. The challenge is that policy cannot, we would argue, prescribe or mandate on issues of epistemology (what, how and by whom knowledge is produced). Nor can it mandate on issues of identity - student or staff (who the teachers and who the taught should be). Policy can however address structure. A restructuring can thus be a lever for change, to bring about an interrogation of the status quo; a policy on curriculum restructuring can provide the enabling framework for knowledge and identities to be reimagined, decentered, recentered.

In closing, we return to the proposition that curriculum is central to a transformed student experience. Curriculum can play a significant role in addressing the unjust and unequal differentiation that our students experience. A reform agenda which ultimately addresses issues of knowledge and identity needs to start with a bold re-framing, an interrogation of key 
assumptions which underpin our current curriculum structure. We close by suggesting four guiding questions for such a curriculum transformation process:

- In what ways does the curriculum structure (issues of entry, placement and progression) enable a successful student experience?

- In what ways does the curriculum content recognise and speak to diverse students' experiences - prior to and upon arrival at university?

- In what ways does curriculum content and epistemology centre the rich sources of knowledge production in and about Africa, in and through its languages?

- In what ways does our curriculum prepare our students for the challenges of a rapidly changing workplace?

\section{References}

Bernstein, B. (1975). Class, codes and control: Towards a theory of educational transmission (vol. 3). London: Routledge.

Bangeni, B., \& Kapp, R. (Eds.). (2017). Negotiating meaning and identity in higher education: Access persistence and retention. London: Bloomsbury.

Boughey, C. (2005). Epistemological access to the university: An alternative perspective. South African Journal of Higher Education, 19, 638-650.

Clegg, S. (2009). Histories and institutional change: Understanding academic development practices in the global 'north' and 'south'. International Studies in Sociology of Education, 19(1), 53-65.

Council on Higher Education (2013). A proposal for undergraduate curriculum reform in South Africa: The case for a flexible curriculum structure. Pretoria: Council on Higher Education.

Department of Education (1997). Education White Paper 3: A programme for the transformation of higher education. Pretoria: Department of Education.

Department of Education (2002). Transformation and restructuring: A new institutional landscape for higher education. Pretoria: Department of Education.

Department of Higher Education and Training (DHET) (2013). White paper for post-school education and training: Building an expanded, effective and integrated post-school system. Pretoria: Department of Higher Education and Training.

Department of Higher Education and Training (DHET) (2017). National plan for higher education and training. Retrieved from http://utlo.ukzn.ac.za/Libraries/Documents/NPPSET_consultation_draft_16_ November_2017.sflb.ashx

Ensor, P. (2004). Contesting discourses in higher education curriculum restructuring in South Africa. Higher Education, 48, 339-359.

Ferreira, A., \& Mendelowitz, B. (2009). Diversity, double-talk and (mis)alignment: Pedagogic moves for epistemological access. Southern African Linguistics and Applied Language Studies, 27(1), 77-92.

Fraser, N. (2005). Reframing justice in a globalizing world. New Left Review, 36, 69-88.

Fraser, N. (2009). Scales of justice: Reimagining political space in a globalizing world. New York: Columbia University Press.

Jansen, J. (2017). As by fire: The end of the South African university. Cape Town: Tafelberg.

Kotta, L. (2011). Structural conditioning and mediation by student agency: A case study of success in chemical engineering design (unpublished doctoral dissertation). University of Cape Town, Cape Town.

Lange, L. (2012). Knowledge, curriculum and transformation. In R. Venter \& F. Tolmie (Eds.), Transforming theological knowledge: Essays on theology and the university after apartheid (pp. 31-44). Stellenbosch: SunMedia. 
Lange, L. (2017). Twenty years of higher education curriculum policy in South Africa. Journal of Education, (68), $31-57$.

Luckett, K. (2012). Disciplinarity in question: Comparing knowledge and knower codes. Sociology Research Papers in Education, 27(1), 19-40.

Luckett, K., \& Naicker, V. (2016). Responding to misrecognition from a (post)/colonial university. Critical Studies in Education, On-line First 1-18.

Luckett, K., \& Shay, S. (2017). Reframing the curriculum: A transformative approach. Critical Studies in Education, 1-16.

Marginson, S. (2011). Higher education and public good. Higher Education Quarterly, 65(4), 411-433.

Maton, K. (2014). Knowledge and knowers: Towards a realist sociology of education. London: Routledge.

Mbembe, A. J. (2016). Decolonizing the university: New directions. Arts and Humanities in Higher Education, 15(1), 29-45.

Mogashana, D. (2015). The interplay between structure and agency: How academic development programmes students 'make their way' through their undergraduate studies in Engineering (unpublished doctoral dissertation). University of Cape Town, Cape Town.

Motsa, Z. (2017). When the lion tells the story: A response from South Africa. Higher Education Research and Development, 15(1), 29-45.

Mpofu-Walsh, S. (n.d.). The game's the same: 'MustFall' moves to Euro-America. In G. Godsell, R. Chikane, S. Mpofu-Walsh, O. Ntshingila, R. Lepere, S. Mofoko, et al. (Authors) \& S. Booysen (Ed.), Fees Must Fall: Student revolt, decolonisation and governance in South Africa (pp. 74-86). Johannesburg: Wits University Press.

Muller, J. (2000). Reclaiming knowledge: Social theory, curriculum and education policy. London: Routledge.

Muller, J. (2009). Forms of knowledge and curriculum coherence. Journal of Education and Work, 22(3), 205-226.

Muller, J. (2014). Every picture tells a story: Epistemological access and knowledge. Education as Change, 1-15.

National Planning Commission (2011). National Development Plan: Vision for 2030. Pretoria: Ministry of the Presidency.

Oosthuizen, M. (2014). Challenges relating to the establishment of comprehensive universities in the South African higher education sector. In T. Gibbon (Ed.), Driving change: The story of the South Africa Norway Tertiary Education Development Programme (pp. 103-126). Cape Town: African Minds.

Shay, S. (2013). Conceptualizing curriculum differentiation in higher education: A sociology of knowledge point of view. British Journal of Sociology of Education, 34(4), 563-582.

Shay, S. (2015). Curriculum reform in higher education: A contested space. Teaching in Higher Education, 20(4), $431-441$.

Shay, S., Wolff, K., \& Clarence-Fincham, J. (2016). New generation extended curriculum programmes: Report to DHET. Cape Town: University of Cape Town.

Smith, L. (2012). Measuring the impact of educational interventions on the academic performance of black academic development students. Southern African Review of Education, 18(1), 85-113.

South African Qualifications Authority (2008). The higher education qualifications framework: (Act No. 67 of 2008). Pretoria: South African Qualifications Authority.

Thesen, L., \& van Pletzen, E. (Eds.). (2006). Academic literacy and the languages of change. London: Continuum.

Wolff, K., \& Luckett, K. (2013). Integrating multidisciplinary engineering knowledge. Teaching in Higher Education, 18(1), 78-92.

Young, M. (2013). Overcoming the crisis in curriculum theory: A knowledge-based approach. Journal of Curriculum Studies, 45(2), 101-118. 


\section{UNDERSTANDING STUDENT EXPERIENCES THROUGH THE LENS OF ACADEMIC STAFF DEVELOPMENT PRACTICE AND RESEARCH}

Sherran Clarence

\section{Introduction}

The term academic development is used in a few ways in South Africa and usually encompasses both staff and student development. When focused on lecturers, it is usually termed academic staff development. Most universities have centres for teaching and learning, such as the Fundani Centre for Teaching and Learning at the Cape Peninsula University of Technology, and CHERTL (Centre for Higher Education, Research, Teaching and Learning) at Rhodes University. These are staffed by researchers and practitioners who work with both staff and students to improve teaching and learning, such that formal access to higher education translates into success for greater numbers of students (see Scott, 2009). The Higher Education Quality Council (HEQC) defines academic development thus:

\section{A field of research and practice that aims to enhance quality and effectiveness of teaching and learning in higher education, and to enable institutions and the higher education sector to meet key educational goals, particularly in relation to equity of access and outcomes. (HEQC, 2007, p. 74, cited in Scott, 2009, p. 22)}

The emphasis on 'equity of ... outcomes' is particularly important in considering how academic staff development in particular understands its role in relation to students. Success - a positive outcome - in higher education, read most commonly in the attainment of a qualification that enables the graduate to work, and develop a career, is a key aspect of a path 
to the personal goods of education: work, income, ability to support one's family, and a desirable lifestyle. But, success for greater numbers of especially black students in South Africa (Council on Higher Education [CHE], 2013; Scott, 2009) is also central to advancing higher education as a public good.

Formal access to higher education is largely, although not completely, assured for many more black students now than it ever has been in the past. In practice, this is difficult to achieve for many students, for reasons of finance, preparedness linked to prior education and home literacy background, and family support (CHE, 2013). But, in principle, anyone who meets the entrance requirements and can pay the fees can come to university, regardless of race, class or gender. In terms, though, of what Wally Morrow called 'epistemological access' (2009) - access to the means of acquiring, critiquing and creating knowledge - both access and success are still notably skewed in favour of white students, and students with a more 'congruent' home and school literacy background (CHE, 2013; McKenna, 2004). This means, in practice, that participation and graduation rates of especially poorer black students remain worryingly low, almost 30 years into democracy (CHE, 2013; Dietrich, Moja, \& Pazich, 2014). A significant implication, in terms of seeing higher education as a public good, is that fewer qualified black graduates are entering the professions than should be, and that fewer black graduates are contributing in meaningful, formal ways to innovation, practice and development within their chosen fields. The overall effect of skewed success rates means that higher education, as both a public and a personal good, continues to be constrained.

What can academic development do about this? Focusing specifically on academic staff development, this chapter will draw on the literature published in and about South African academic development between 2007 and 2017. Through a critical review of the available literature, the chapter will argue that significant strides have been made in the field towards developing a more robust, latterly theorised approach to improving teaching and learning. Yet, in spite of these developments, persistent deficit conceptions of the sector, and of both lecturers and students, continue to constrain the transformative and emancipatory potential of the field, particularly in relation to constructing higher education as a pathway to both public and personal goods.

The chapter begins with an overview of the history of academic development in South Africa, before moving on to consider current foci and trends in the literature.

\section{A brief history of academic development work in South Africa}

Academic development work in South Africa has its origins in the 1980s, when relatively low numbers of black students began enrolling in historically white universities. These students, coming from poorer socio-economic and poorly resourced school backgrounds, struggled to meet the academic demands of these universities, created for a traditionally homogenous, middle class, white student body (Scott, 2009). These students were thus labeled as 'unprepared' 
for higher education. As was discussed in Chapter 14, academic support programmes were created, ostensibly to give them more of what white students had had access to in their prior schooling, so that they could progress in their studies. However, academic development practitioners in these universities began to realise that these 'add on' programmes were patronising, and limited in their reach and outcomes. What was needed, rather, was wider or broader teaching and learning development, focused on staff development as well as on student development (Boughey, 2014; Scott, 2009).

From these beginnings, academic development, or $\mathrm{AD}$, work in higher education has focused on four different areas of influence: student development (particularly in foundational and extended curriculum programmes); staff development; curriculum development; and institutional development (HEQC, 2007, cited in Scott, 2009). This chapter focuses on research that is concerned primarily with staff and curriculum development work, but it should not be seen as completely separate from student and institutional development work, as these areas of focus are necessarily intertwined.

The student experience of higher education is primarily one of learning: attending lectures and tutorials, writing assignments, working with peers, reading, and so on. These experiences are varied, of course, but it is worth noting the amount of literature devoted, in South Africa and globally, to improving teaching and learning such that students have less alienating, difficult, and trying experiences of higher education (see Quinn, 2012b; Jacobs, 2007; McKenna, 2004, 2012). This, in my view, is the primary value of academic staff development: to contribute to the student experience by working in constructive, theoretically sound ways with lecturers, such that teaching and learning is significantly improved. Improvement, influenced by the literature explored in the following sections, can be understood here as enabling teaching and learning to be more inclusive, thoughtful, socially and environmentally aware, and cognisant of diversity and difference. It also encompasses creating curricula and assessment structures that are fit for purpose, and can enable the greatest number of students to achieve meaningful success.

This chapter now moves to explore what we know about academic development in South Africa, from the perspective of published research primarily focused on staff and curriculum development. It seeks to connect to this research the question of how students experience teaching, learning and assessment in South African universities. While staff development is directly focused on building the relevant educational knowledge, skills and confidence of lecturers and tutors, it is always concerned with doing all of this to enhance 'equity of access and outcomes' (Scott, 2009, p. 22). However, there are different understandings in the field of academic development, and higher education more broadly, about what constitutes 'equity' in terms of access and outcomes, what paths would lead us to greater equity, and how to enable students to achieve the best possible educational outcomes. Thus, this chapter also adds a layer of critique to the literature on staff development, to explore to what extent the ideological or theoretical underpinnings could influence outcomes or experiences of learning for students. 


\section{Reframing the student experience through the lens of $\mathrm{AD}$}

Students are the core 'stakeholders' in any higher education system. Without students we would not be working in universities; we would be working in research institutes. Thus, teaching, learning and assessment aimed at enhancing or enabling success for the greatest number of students is - or should be - higher education's core goal. Research, innovation, policy development and so on should all contribute towards achieving this goal. Yet, as several researchers have pointed out over the years, in South Africa and elsewhere, teaching and its allied practice-oriented activities are often under-valued and under-rewarded, compared to research (Ndebele \& Maphosa, 2014; Scott, 2009). In many university contexts, academic development work struggles consistently with an ongoing tension between focusing on practical, teaching-and-learning-oriented development work, or research and scholarly work. Following this logic to one possible conclusion, should teaching remain systemically undervalued, students who come to university to learn, grow and graduate with the capacity to advance the public good, as well as their own personal good, are short-changed. Their experience of learning will be compromised. Students, in particular, have highlighted this in recent protests across universities in South Africa. Among many demands made, a relevant one here is demands for more equitable, open, and socially just teaching and learning environments.

Currently, then, higher education in South Africa is on the verge of change, although the forms this will take are as yet unclear. Calls for curriculum renewal and changes to staffing and teaching approaches, primarily from students under the broad coalition of the \#FeesMustFall movement (see Chapters 13 and 14 for further discussion), implicate issues of race, class, gender, systemic (under)privilege and systemic (in)equity of both access and success. Parts of the academic development field have been grappling for some time with these questions, and these protests have reinvigorated this space and opened it up to new debates, and consideration (see Luckett, 2016; Quinn, 2012a, 2012b; Shay, 2016; Vorster \& Quinn, 2017). Since the 1980s, and especially since the end of apartheid in 1994, South African universities have been widening formal access, especially to previously excluded students, primarily black students. Yet, success is still skewed in favour of those students who are better prepared academically and financially for study at tertiary level (CHE, 2013; Scott, 2009; Scott, Yeld, \& Hendry, 2007). Many students who are less able to achieve this seemingly elusive academic success can see that systemic inequalities, privileges and structures, such as the curriculum, need to be addressed for that success to be realistically in reach of academically and financially underprepared students (Cooper, 2015).

There are aspects of university structure, culture and practices that influence how students and lecturers are positioned relative to one another. These structures and cultural elements also influence how academic development work is understood, practised, resourced and supported. The sector is currently comprised of a mix of 26 traditional, comprehensive and technologyoriented universities, located in both rural and urban areas, and with markedly diverse staff and student bodies. It stands to reason, then, that there is a wide range of structural, cultural 
and practice-oriented contexts. Academic development work, thus, needs to be understood as a differentiated body of practices; there is one definition of academic development, according to the HEQC, but there are many different ways of realising the espoused goals mentioned in the introduction of this chapter.

The following sections unpack the key discourses and issues affecting academic development work, and attempt to tease out some of the more important differences and divergences in $\mathrm{AD}$ praxis and research.

The primary systemic discourse that appears to be implicated in much of the literature is termed the 'deficit discourse' (Quinn, 2012b; Smit, 2012). One could argue that all students and academics have some kind of 'deficit' in relation to the expectations set for achievement and success; otherwise there would be no real need for staff and student learning and development workshops. However, the deficit discourse as it is operationalised in academic development is politicised, and underpinned by certain ideological assumptions about learning and success. These assumptions tend to construct education as a journey undertaken by an autonomous student, who is primarily responsible for her own success, which must be achieved through motivation, commitments and hard work (Boughey \& McKenna, 2016; McKenna, 2012; Pym \& Kapp, 2013). This instantiation of the deficit discourse largely neglects, or obstructs, a view of the deeper structures and systems at play in higher education that can enable, and constrain, equitable access and outcomes for students (Boughey, 2014; Boughey \& McKenna, 2017; Smit, 2012). These can also further enable and constrain staff engagement, agency and learning (Vorster \& Quinn, 2012), primarily through locating 'problems' with teaching and student success in individual lecturers or departments, rather than seeing these issues from a whole-system perspective. This deficit approach to teaching and learning development, pinpointing problematic lecturers and departments that need to improve, or update their practices, can be isolating for lecturers and departments. This is counter-productive to improving student learning experiences, as well as lecturers' own teaching and learning experiences.

The deficit perceptions of academic lecturers, students, and the university itself need to be critically and carefully deconstructed. They are not new; Akoojee and Nkomo (2007) show, for example, through a critical review of research into student success, that the problem of students' underpreparedness and poor success rates has been researched and debated since the 1930s in South Africa. A striking difference, though, between the pre- and during-apartheid higher education sector and that of the present, is that the student body now is increasingly diverse, linguistically, culturally, socio-economically and in terms of their prior education (CHE, 2013; Scott, 2009). Politically, the problems are different now - specifically, apartheid is over and we are no longer fighting for everyone to have the same rights and opportunities. We all have the same rights and opportunities in principle, but in practice the vast gap between rich and poor, and systemic poverty and inequality significantly constrains the realisation of these for many South Africans. There is perhaps, then, a more urgent sense that the notion of deficit from a systemic perspective needs to be addressed if we really are to construct and enact 
higher education as a public or social, as well as private, good, that makes a meaningful contribution on micro and macro levels (Boughey, 2007; Singh, 2001).

Neoliberal ideologies that cast the system and its standards as unproblematic, and the students and staff that cannot fit in as needing support, coaching and a stronger work ethic, arguably underpin deficit discourses that currently hold sway in higher education (Boughey \& McKenna, 2016; Smit, 2012). Internationally, there is a dominance of the meritocracy discourse writ large, connected with more conservative political stances that tend to obscure systemic inequalities and privilege by focusing on a discourse of success being a result of hard work, grit and determination. These are connected with neoliberal constructions of the university understood in narrower terms as producing workers for the knowledge economy, obsessed thus with measuring skills and knowledge in transparent, standardised ways (see Hargreaves, 2002; Sellar \& Gale, 2011; Shore, 2010). Hargreaves (2002) argues that the knowledge economy serves the private good; thus, if universities pursue the current neoliberal path, it may become increasingly challenging to centre the public good, and legitimate pathways to this within higher education. This has implications for how students are positioned, supported and educated, too.

Boughey and McKenna (2017) point to the powerful ways in which students are constructed in institutional audit documents as 'decontextualised learners' that can be helped to fit in better through teaching and learning interventions outside of mainstream programmes and courses (such as English for Academic Purposes-type courses). Pym and Kapp (2013) and Pym (2006) challenge these instantiations of the deficit discourse through their account of an academic development programme for commerce students at a historically white university. The programme they look at in these papers challenges, as they put it, 'assimilationist, deficit notions of the teaching and learning process' (Pym \& Kapp, 2013, p. 272). It does this through asking key questions about:

- What counts as 'success' and why;

- What knowledge counts as legitimate and who determines this; and

- Whether and why we are unreflexively expecting black students to shoehorn themselves into a vision of education and success that cannot or will not account for their embodied selves, including their learning needs and approaches (see also Case, 2013; Case, Marshall \& Linder, 2010; Marshall \& Case, 2010).

Teaching and learning, assisted with academic development work that is aligned with transformation imperatives, then, needs to act on these questions by opening up spaces for reimagination and rethinking of the value orientations of curricula and other structures within the university that work to construct success and failure in particular ways.

One way to open up space, in academic development as a field in particular, is to engage with theorised ways of thinking about learning, teaching, student development and higher education. 


\section{Ways of theorising practice, and practising theory}

An important starting point in choosing any theoretical approach to teaching and learning development is to consider the context in which one is working. Theory acts as a critical 'lens' through which we can 'see' our work, our context, our teaching and so on with perhaps fresh eyes, connecting what we may experience to other contexts that share similarities. In this way, using theory judiciously can lift us out of our own, relatively narrow, contexts and connect us with the work and research done in other contexts, from which we can learn. The South African context is a highly unequal one. University spaces are shared by students particularly, with markedly different levels of prior learning, literacy development, family support, financial independence and preparation for the myriad demands of higher education (Badat, 2012; CHE, 2013; Scott, Yeld, \& Hendry, 2007). Thus, theory can help those working in academic development to 'see' and critique their local instantiations of this broader context, and deficit discourses.

Currently, there is a move in South African academic development research and practice towards using critical theories that can shine new light on issues of diversity, inequality, and the skewed outcomes of higher education (see CHE, 2013; Scott, Yeld, \& Hendry, 2007). Yet, this move is limited, and tends to be happening in universities that have a less overt divide between research and practice in academic development. The authors included in this section also tend to represent primarily well-resourced teaching and learning centres, and universities with wellfunded and supportive research offices. Thus, the field itself is significantly skewed in terms of where the knowledge about current academic development work is produced, and notably, the source of critiques of a-theoretical, outdated and ideologically problematic academic development work.

Particularly, this work draws on the work of Nancy Fraser on participatory parity (Bozalek \& Boughey, 2012; Leibowitz \& Bozalek, 2016), Basil Bernstein's work on the pedagogic device and the discourses that underpin it, and on education more generally (Shay, 2016; Vorster, \& Quinn, 2012), Margaret Archer's social realist account of structure, culture and agency (Case, 2013; Leibowitz, Bozalek, van Schalkwyk, \& Winberg, 2015; Luckett \& Luckett, 2009; Quinn, 2012b); Legitimation Code Theory (Blackie, 2014; Clarence, 2016; Shay, 2016; Vorster \& Quinn, 2015), and Academic Literacies (Clarence, 2012; Clarence \& McKenna, 2017; Jacobs, 2007, 2013). Notable too is the work being done using Amartya Sen and Martha Nussbaum's Capabilities Approach (Walker, 2003; Walker \& McLean, 2015; Walker \& Wilson-Strydom, 2016). Responding to Scott's (2009, p. 22) exhortation for academic development work to focus on improving 'equity of access and outcomes' for students, all of this work has in common is a firm grounding in theorised accounts of learning, teaching and academic development.

Rather than proceeding from an account of students (and lecturers) as autonomous individuals on whom success or failure solely depends, the more recent research that draws on sociological and political theories of society, justice and equity implicates the systems that we 
are all part of. Autonomous approaches to the study of student learning, and by extension also the lecturers' and tutors' learning, tend to imply that if individuals try hard, don't give up, and apply themselves conscientiously, they will succeed (Boughey \& McKenna, 2016, 2017). These approaches have been roundly criticised in South African higher education, at the very least by the authors cited in the above paragraph. Primarily, in such an unequal context shaped by the legacy of apartheid, focusing on individuals over the systemic structuring of inequality is unjust. The social, political and economic systems that we are all a part of shape the 'space of possibles' to paraphrase Maton (2014). Those born into middle class homes, with access to well-resourced schools, libraries, financial networks of support and so on will have an easier time navigating their way through higher education than those born into working class homes, and having access only to poorly resourced schools, and little to no financial back-up (Letseka $\&$ Maile, 2008; van Zyl, 2016). Lecturers who have been these different students will be shaped by those experiences, and also by the opportunities that exist in their universities for further learning and teaching development. Academic development opportunities are also unevenly provided, with better resourced universities having more visible, funded and structured units for academic development that run courses, one-on-one engagements and so on (Moyo, 2018; Scott, 2009). Hence, any academic development work that focuses on changing the individual over addressing systemic inequalities and challenges will inevitably create a 'band-aid' solution rather than deeper, more meaningful change or improvement.

Academic staff development work is thus moving firmly, albeit unevenly, toward theorised, scholarly 'praxis' (theorised practice). To be relevant to disciplinary academic lecturers, and to claim status and significance within universities, academic staff development work needs to have its own theorised and scholarly positions from which it works, and needs to be able to bring relevant theoretical tools to bear on work within the disciplines (Clarence, 2016; Quinn, 2012a). This is necessary to enable academics to reflect anew on aspects of curriculum and teaching with these tools and in collaboration with respected academic developers working as critical peers. Following Quinn (2012a), academic development should be seen as a 'metaprofession', and thus needs to have firm scholarly foundations of its own. All of the authors writing from this understanding of academic development work are sceptical or dismissive of academic staff (or student) development framed as 'skills development' or individualised, ad hoc work. Rather, this work has become increasingly focused on understanding deeper mechanisms and structures that constrain or enable change.

Academic literacies, with its underlying ideological focus on transformation, and equitable access to ways of making meaning and learning the 'rules' of the academic game, has long been a guiding theoretical approach in South African academic development work. Scott (2009) and Boughey (2014) trace the growth and shifts in the academic development movement in South Africa since the mid-1980s. Their work shows, in particular, how AD units that were created in the 1980s, and that have been framed by an 'activist' stance have focused on moving away from a notion of 'fixing' black students' literacy deficits, to changing the nature of teaching and learning to account for a changing student body and wider social context. This move, as noted earlier in 
this section, has not yet happened across the sector. The dominance of deficit discourses, and their 'common sense' nature, given apartheid's educational legacy that continues to constrain especially black students' educational development, means that not all academic development work is focused in the same direction. There are still instances of 'bolt-on' student writing and 'literacy' courses, skills development programmes, and one-off workshops for staff focused on practical tips for teaching without deeper underpinning. It is clear that far more work needs to be done in changing understandings of social justice, equity, and criticality in the field of academic development, for both staff and students. There is thus a need for expanding the theory the field draws on in directions offered by social realism, Legitimation Code Theory, the Capabilities Approach, and participatory parity. The field will thus benefit from theorising its work, and sharing these theorised understandings and approaches more widely.

Such deeply theorised, scholarly approaches to academic development work are changing both the nature and the status of academic development. Although the field as a whole struggles against marginalisation and precarious funding and tenure (Scott, 2009), there are more universities in 2018 with centralised, funded units or centres for teaching and learning than there were ten or twenty years ago. There is also greater recognition of the valuable role that academic development as a scholarly field of practicse and research can and should play in professionalising teaching in higher education. Although the field in South Africa is unevenly resourced, and does not work consistently from within theorised, critical understandings of the sector itself, or student access and success, there is evidence to suggest that the field understands its role as one that should create greater equity of outcomes in the future.

\section{Conclusion}

The most significant changes in academic development as a field have been enacted by 'activist' academics (Scott, 2009), and those who identify themselves as such, including many of the authors cited in this chapter. These academics have long been concerned with the political and social environments surrounding, influencing, and being shaped by higher education. These concerns have in turn influenced the work done in the academic development field, initially with students and then with academic lecturers as well. Thus, we know that academic development does not hold itself up as a neutral space where lecturers can learn value-free 'tips and tricks' to improve their local teaching, or solve individual problems. Rather, through its particular concern with theoretical approaches that are ultimately deeply concerned with questions of equity, access and justice, academic development locates itself within its local, and wider political, social and institutional contexts, and works to surface underlying tensions, goals and knowledges. Through this situated, critical positioning, academic developer activists work to change higher education, to create a more open, critical, socially just culture of teaching and learning.

Yet, this description of academic development as a field does not reflect the South African higher education sector as a whole. The deficit discourses that obscure systemic inequality and 
privilege are tacitly dominant, and have become so inured that they are both hard to see, and to challenge. Thus, while there is a growing body of theorised research and practice in AD, there is still a notable lack of theorisation of academic development work (Boughey \& Niven 2012; Shay, 2016). In many universities, especially those with significant numbers of students from poorer socio-economic and educational backgrounds, there is a perhaps understandable preoccupation with policy standardisation and measurable skills development. This constrains a more critical, theorised, and open approach to academic development, which would challenge dominant, individualised conceptions of students and lecturers as needing to work harder and care more.

There is much to be done to change students' and lecturers' experiences of higher education to make them more inclusive, enabling and resonant with personal goals and ambitions. Currently, there is fierce debate around decolonising the university through critiquing and changing curricula, assessment modes and teaching methodologies that continue to exclude and silence students and lecturers, whose experiences and prior knowledges are outside of what the university represents as the legitimate ways of thinking, reading, writing and knowing. These debates are in their infancy, and the time is now for academic development as a field to reclaim a firmer 'activist' identity, akin to that held in the 1980s and 1990s, and be a crucial and central part of conversations that focus on reimagining teaching and learning, thereby creating more inclusive and equitable student learning, personal and professional growth, and emancipation.

\section{References}

Akoojee, S., \& Nkomo, M. (2007). Access and quality in South African higher education: The twin challenges of transformation. South African Journal of Higher Education, 21(3), 385-399.

Badat, S. (2012). Redressing the colonial/apartheid legacy: Social equity, redress, and higher education admissions in democratic South Africa. In Z. Hasan \& Nussbaum, M. (Eds.), Equalizing access: Affirmative action in higher education in India, United States, and South Africa (pp. 121-150). New Delhi: Oxford University Press.

Blackie, M. A. (2014). Creating semantic waves: Using Legitimation Code Theory as a tool to aid the teaching of chemistry. Chemistry Education Research and Practice, 15(4), 462-469.

Boughey, C. (2007). Educational development in South Africa: From social reproduction to capitalist expansion? Higher Education Policy, 20(1), 5-18.

Boughey, C. (2014). The significance of structure, culture and agency in supporting and developing student learning at South African universities. In R. Dhunpath \& R. Vithal (Eds.), Alternative access to higher education: Underprepared students or underprepared institutions? (pp. 61-88). Cape Town: Pearson Publishers.

Boughey, C., \& McKenna, S. (2016). Academic literacy and the decontextualised learner. Critical Studies in Teaching and Learning, 4(2), 1-9.

Boughey, C., \& McKenna, S. (2017). Analysing an audit cycle: A critical realist account. Studies in Higher Education, 42(6), 963-975.

Boughey, C., \& Niven, P. (2012). The emergence of research in the South African academic development movement. Higher Education Research \& Development, 31(5), 641-653.

Bozalek, V., \& Boughey, C. (2012). (Mis) framing higher education in South Africa. Social Policy \& Administration, 46(6), 688-703. 


\section{HigheR EDUCATION PATHWAYS}

Case, J. M. (2013). Researching student learning in higher education: A social realist approach. London: Routledge.

Case, J. M., Marshall, D., \& Linder, C. J. (2010). Being a student again: A narrative study of a teacher's experience. Teaching in Higher Education, 15(4), 423-433.

Clarence, S. (2012). Making inter-disciplinary spaces for talk about and change in writing and literacy development. Teaching in Higher Education, 17(2), 127-137.

Clarence, S. (2016). Exploring the nature of disciplinary teaching and learning using Legitimation Code Theory Semantics. Teaching in Higher Education, 21(2), 123-137.

Clarence, S., \& McKenna, S. (2017). Developing academic literacies through understanding the nature of disciplinary knowledge. London Review of Education, Special Issue on Academic Literacies, 15(1), 38-49.

Cooper, D. (2015). Social justice and South African university student enrolment data by 'race', 1998-2012: From 'skewed revolution' to 'stalled revolution'. Higher Education Quarterly, 69(3), 237-262.

Council on Higher Education (2013). A proposal for undergraduate curriculum reform in South Africa: The case for a flexible curriculum structure. Pretoria: Council on Higher Education.

Dietrich, E., Moja, T., \& Pazich, L. B. (2014). Editorial. Struggling with equity: Access to higher education in the BRICS countries. Widening Participation and Lifelong Learning, 16(1), 1-4.

Hargreaves, A. (2002). Teaching in the knowledge society. Technology Colleges Trust Vision 2020 - Second International Online Conference. 13-26 October and 24 November-7 December 2002.

Jacobs, C. (2007). Mainstreaming academic literacy teaching: Implications for how academic development understands its work in higher education. South African Journal of Higher Education, 21 (7), 870-881.

Jacobs, C. (2013). Academic literacies and the question of knowledge. Journal for Language Teaching=ljenali Yekufundzisa Lulwimi= Tydskrif vir Taalonderrig, 47(2), 127-139.

Leibowitz, B., \& Bozalek, V. (2016). The scholarship of teaching and learning from a social justice perspective. Teaching in Higher Education, 21(2), 109-122.

Leibowitz, B., Bozalek, V., van Schalkwyk, S., \& Winberg, C. (2015). Institutional context matters: The professional development of academics as teachers in South African higher education. Higher Education, 69(2), 315-330.

Letseka, M., \& Maile, S. (2008). High university drop-out rates: A threat to South Africa's future. Pretoria: Human Sciences Research Council.

Luckett, K. (2016). Curriculum contestation in a post-colonial context: A view from the South. Teaching in Higher Education, 21(4), 415-428.

Luckett, K., \& Luckett, T. (2009). The development of agency in first generation learners in higher education: A social realist analysis. Teaching in Higher Education, 14(5), 469-481.

Marshall, D., \& Case, J. M. (2010). Rethinking 'disadvantage' in higher education: A paradigmatic case study using narrative analysis. Studies in Higher Education, 35(5), 491-504.

Maton, K. (2014). Knowledge and knowers: Towards a realist sociology of education. London: Routledge.

McKenna, S. (2004). The intersection between academic literacies and student identities: Research in higher education. South African Journal of Higher Education, 18(3), 269-280.

McKenna, S. (2012). Interrogating the academic project. In L. Quinn (Ed.), Re-imagining academic staff development: Spaces for disruption (pp. 15-26). Stellenbosch: SunPress.

Morrow, W. (2009). Bounds of democracy: Epistemological access in higher education. Cape Town: HSRC Press.

Moyo, M. T. (2018). An analysis of the implementation of the teaching development grant in the South African higher education sector (unpublished doctoral dissertation). Rhodes University.

Ndebele, C., \& Maphosa, C. (2014). Voices of educational developers on the enabling and constraining conditions in the uptake of professional development opportunities by academics at a South African University. International Journal of Educational Sciences, 7(1), 169-182.

Pym, J. (2006). The lost, the least and the last: A South African higher education case study exploring the possibility of defying the barriers to learning. In A. Bunker \& I. Vardi (Eds.), Research and development in higher education: Critical visions thinking, learning and researching in higher education, (vol. 29). http://www.herdsa.org.au/research-and-development-higher-education--vol-29

Pym, J., \& Kapp, R. (2013). Harnessing agency: Towards a learning model for undergraduate students. Studies in Higher Education, 38(2), 272-284. 
Quinn, L. (2012a). Introduction. In L. Quinn (Ed.), Re-imagining academic staff development: Spaces for disruption (pp. 1-14). Stellenbosch: SunPress.

Quinn, L. (2012b). Enabling and constraining conditions for academic staff development. In L. Quinn (Ed.), Re-imagining academic staff development: Spaces for disruption (pp. 27-50). Stellenbosch: SunPress.

Scott, I. (2009). Academic development in South African higher education. In E. Bitzer (Ed.), Higher education in South Africa: A scholarly look behind the scenes. (pp. 21-49). Stellenbosch: SUNPress.

Scott, I., Yeld, N., \& Hendry, J. (2007). Higher education monitor: A case for improving teaching and learning in South African higher education. Pretoria: Council on Higher Education.

Sellar, S., \& Gale, T. (2011). Globalisation and student equity in higher education. Cambridge Journal of Education, 41(1), 1-4.

Shay, S. (2016). Curricula at the boundaries. Higher Education, 71(6), 767-779.

Shore, C. (2010). Beyond the multiversity: Neoliberalism and the rise of the schizophrenic university. Social Anthropology, 18(1), 15-29.

Singh, M. (2001). Re-inserting the 'public good' into higher education transformation. Kagisano Higher Education Discussion Series, Issue 1. http://citeseerx.ist.psu.edu/viewdoc/download?doi=10.1.1.470.8247 \&rep=rep1\&type $=$ pdf $\#$ page $=8$

Smit, R. (2012). Towards a clearer understanding of student disadvantage in higher education: Problematising deficit thinking. Higher Education Research \& Development, 31(3), 369-380.

van Zyl, A. (2016). The contours of inequality: The links between socio-economic status of students and other variables at the University of Johannesburg. Journal of Student Affairs in Africa, 4(1), 1-16.

Vorster, J. A., \& Quinn, L. (2012). Theorising the pedagogy of a formal programme for university lecturers. In L. Quinn (Ed.), Re-imagining academic staff development: Spaces for disruption (pp. 51-70). Stellenbosch: SunPress.

Vorster, J. A., \& Quinn, L. (2015). Towards shaping the field: Theorising the knowledge in a formal course for academic developers. Higher Education Research \& Development, 34(5), 1031-1044.

Vorster, J. A., \& Quinn, L. (2017). The 'decolonial turn': What does it mean for academic staff development? Education as Change, 21(1), 31-49.

Walker, M. (2003). Framing social justice in education: What does the 'capabilities' approach offer? British Journal of Educational Studies, 51(2), 168-187.

Walker, M., \& McLean, M. (2015). Professionals and public-good capabilities. Critical Studies in Teaching and Learning, 3(2), 60-82.

Walker, M., \& Wilson-Strydom, M. (Eds.). (2016). Socially just pedagogies, capabilities and quality in higher education: Global perspectives. The Netherlands: Springer. 


\section{STUDENTS' EXPERIENCES OF UNIVERSITY LIFE BEYOND THE CURRICULUM}

Philippa Kerr and Thierry Luescher

\section{Introduction}

What do we know about undergraduate students' experiences of university and campus life beyond the curriculum, and the role of such experiences in students' personal development and transformation? Can any aspects of that student experience be seen as contributing to the 'public good'? This chapter offers a review of eleven years (2007-2017) of scholarly literature on students' experiences of South African higher education 'beyond the curriculum'. This includes all those aspects of university life which are not related to learning, teaching and academic development; they include the social, economic, political and health-related aspects of the student experience and student life on campus. In this chapter, we aim to give a sense of what has been written about these elements of students' experiences, what this work says, and also what it does not say.

To begin, we make two observations about what we have learnt in the process of doing this review. Firstly, what struck us early on in our reading is how many of the issues that were raised in the student protests of 2015/2016 are prefigured in numerous research papers on students' experiences from the earliest years of our review period right up to the most recent. Evidently, numerous warning bells were sounded about institutional racism and other forms of discrimination, students' sense of institutional alienation, difficulty in adjusting to the university environment, students' financial hardships and poverty on campus, and student leaders' alienation from university management structures. Indeed, apart from a few positive exceptions, and acknowledging the limitations of small-sample studies which make up the bulk of this research, the scholarly literature building up to the 2015/16 student movement paints quite a bleak picture of university life as a source of anxiety and struggle for students - and a highly racialised one at that. The literature thus suggests that protesting students were not (simply) creating, but were also articulating and responding to a crisis or crises in 
South African higher education that had been felt at the level of students' experiences for quite some time.

A second observation is that the large majority of the literature we read does not itself directly pose or attempt to answer questions about the transformative potential of higher education, or to make connections between students' experiences at university and their broader or later societal engagement towards the public good. The studies we read are mainly small-sample qualitative studies which report the experiences of a single group of purposively selected students, though there are some comparative accounts from more than one group or campus; however, they are not designed to answer questions about the impact of such experiences on students beyond their time at university. Nevertheless, in the concluding section we consider some implications that this literature may have for thinking about the relationship between students' extra-curricular experiences and the public good.

Our systematic review method was to read the contents pages of every issue of three main South African journals publishing on higher education between 2007 and 2017: Perspectives in Education (PiE), the South African Journal of Higher Education (SAJHE), and the Journal of Student Affairs in Africa (JSAA). We did not have particular keywords in mind, but those articles whose titles suggested they were about undergraduate students' experiences of university life outside of teaching and learning, curricular or access issues, were read, summarised and entered into a database. Initially we included a number of papers on student agency, access and transitions, but these were later excluded for reasons of both length limit and focus. We supplemented this systematic review with publications from outside this timeframe and set of journals, which we identified by snowballing from citations, further searches, and our own knowledge of the student experience literature. We also excluded some papers which were methodologically weak and therefore difficult to draw firm conclusions from. To provide a useful overview of this literature, we have grouped the papers into three main themes. After presenting the main substantive issues, we then offer our reflections on the meaning and implications of this literature for understanding the transformative potential of students' experiences of higher education beyond the curriculum.

\section{Theme 1: Institutional discrimination and alienation}

Students' experiences of race, racialisation and institutional racism, as well as classism, sexism, homophobia and xenophobia, make up one of the key themes we identify in studies of students' experiences of university life beyond the curriculum. Much of this work echoes themes which emerged in the landmark Soudien Report (2008), commissioned by the minister of education to research the state of social cohesion in South African universities in the wake of a racist incident at the University of the Free State (UFS) in 2007/2008. ${ }^{20}$ We have grouped research

20 This high-profile racist incident came to be known as the 'Reitz incident' and is documented in detail by van der Merwe and van Reenen (2016). 
on racism and discrimination into two subthemes: (a) institutional racism, racialisation and racial segregation on campus; and (b) forms of discrimination other than racism. Overall, these papers suggest that universities are highly racialised spaces, but where comparative perspectives are given, they suggest that this racialisation is experienced asymmetrically and accounted for differently by students of different races (and classes). Indeed, this work suggests that many students become more acutely aware of racism and racial inequality when they arrive at university than they ever were before.

\section{Institutional racism, racialisation and segregation on campus}

Research on racialisation and institutional racism comes mainly from historically white universities (or merged components thereof), especially the universities of KwaZulu-Natal, Cape Town and the Free State. Overall, this work gives a view of universities as enduringly racialised and segregated spaces in which black students repeatedly come up against the normative power of whiteness. Spanning our review period are a group of papers on race and racism at the former University of Natal, now UKZN (Bhana, 2014; Durrheim \& Mtose, 2006; Durrheim, Trotter, Piper, \& Manicom, 2004; Pattman, 2010). Durrheim et al. ((2004, pp. 143-144)) argue that even though 'the people at the University look more like the broader South African population every year, a fact that the university often cites as evidence of racial transformation', students of all races whom they interviewed nevertheless 'articulated a detailed and intricate knowledge of racial segregation in all aspects of campus life' (p. 156; see also Cross \& Johnson, 2008; Pattman, 2010; cf. Bhana, 2014; see Schrieff, Tredoux, Dixon, \& Finchilescu, 2005 for patterns of racial segregation in UCT dining halls). Durrheim et al. (p. 144) argue that transformation by numbers at UKZN had 'not meant the demise of many of the aspects of racism that motivated transformation in the first place'. But, while black, white and Indian students were all in agreement about the extent of racial segregation on campus, they had different understandings of the role of the institution in encouraging this. White students accounted for racial segregation as a natural outcome of students' differing personal and cultural preferences, whereas black students understood the university to be 'orchestrating' segregation and sponsoring racism (Durrheim et al., 2004, p. 159; cf. Bhana, 2014), for instance by giving white students preference in their choice of residence, even as whites were becoming a vanishing minority at UKZN. White students also displayed casual racism in differentiating between 'black blacks' and 'white blacks' - saying the latter were 'more developed', and thus easier to get on with, than the former (Durrheim \& Mtose, 2006). Black students thus had to grapple with the burden of 'defining aspirations for blackness which are not made in the image of white supremacy' (p. 167; see also Erasmus \& de Wet, 2003 on black students' burden of doing 'race work'; and Pattman, 2010, for dilemmas experienced by black students who had been to white schools and were in danger of being accused of 'thinking themselves white' and being called 'coconuts' by other black students). 
In a more recent small study of cross-race interactions at an unnamed historically Afrikaans university (Wertheim, 2014), students of all races also reported that their interactions with other-race peers were limited, despite sharing residences and classrooms: 'we do projects with them, but we aren't friends with them' (p. 46). Institutionalised racism was also reported, as an Indian student explained that there were residence social events on her campus at which only white students were welcome (cf. van der Merwe \& van Reenen, 2016). White students claimed that they 'did not see race' but then proceeded to tell anecdotes which not only involved racially identifying their peers but also contained racist assumptions about black students' intellectual abilities (Wertheim, 2014). Moreover, Wertheim notes that white and coloured students claimed that making friends across races was easy, whereas black students said that they had expected to make cross-racial friendships when they came to university but that this had never materialised (see also Cross \& Johnson, 2008; Essack \& Quayle, 2007; Wilson-Strydom, 2014 for students' accounts of surprise at the degree of informal segregation). At the University of the Free State, Pillay and McLellan (2010) show how superficial 'diversity language' was being used by a black and a white student leader as well as, to a lesser extent, the university management, to justify the continued separation of black and white students in residence and in other social organisations such as church and sports groups. Relevant here is Pattman (2010), one of the few authors we read who points out differences in the way race and racism work on different campuses. At UFS, for example, parts of the white university community continue to offer active and sometimes violent resistance to racial integration of residences (e.g. van der Merwe \& van Reenen, 2016); whereas at UKZN, white flight occurred, and residences quickly became almost all black as white students moved out.

Researchers at UCT have also addressed the enduring power of 'whiteness' as a construct against which black students find themselves being continually measured (Cornell, Ratele, \& Kessi, 2016; Kessi \& Cornell, 2015). Students in Kessi and colleagues' research said that coming to UCT was the first time they had ever felt so black (also see Cross \& Johnson, 2008; Essack \& Quayle, 2007), and also the first time that they became aware of the benefits and social capital that come with being white or familiar with the white world. Students of colour spoke of worries that they were only 'allowed in' to UCT in order to fill racial transformation quotas. Kessi and Cornell (2015, p. 2) argue that discourses of transformation at UCT continue to 'present black students as the problem rather than as rightful cobeneficiaries of transformation'. They argue that it is black students who must take responsibility for addressing stereotypes about black students and defending their right to be at UCT: black students 'are excluded by transformation discourses and simultaneously take on the burden of transformation' (p. 12). It is striking that a similar argument was made as early as 2003 in Erasmus and de Wet's study of institutional culture at the UCT Health Sciences Faculty. Further feelings of race-based alienation from the university were expressed by Kessi and colleagues' participants in photos that UCT students took of statue and artworks around campus which they argued glorified white people (including the infamous statue of Cecil John Rhodes, now removed) and denigrate black people, including a 
lampshade which consisted of a number of black figures hanging by their necks around the light bulb (see also Qambela, 2016, who discusses the \#RhodesSoWhite movement and the intersection of racism, xenophobia, homophobia and sexism in the university, the student movements and the Grahamstown community more widely).

Collectively, these papers give an account of how black students often feel like the racialised, derogated 'other' in historically white universities. By contrast, positive accounts of racial interactions are the minority in this literature. First-year UFS students interviewed by Wilson-Strydom (2014) about their experiences of racial and language diversity on campus gave mixed accounts. Some noted that informal segregation had not been as pronounced at their high schools as it was at UFS; others reported that they felt excluded and/or distant when trying to live with others who were different from them; others again reported that mixing with people of different languages and races was an amazingly positive experience and that everyone should learn to speak a variety of languages (English, Afrikaans and Sotho) in order to be able to connect with more people. Ambivalence about racial interactions was also captured by a black first-year student at Stellenbosch University, whose account suggests that encountering white students at close quarters for the first time can be both intimidating and liberating for black students:

For me it was just scary to interact with the white children all the time, you know, except that they are also normal, you think that they're from this Model C [historically white] schools, that they are so intelligent and so cool, and stuff, and you see 'oh my gosh, I can beat them', and then you like, 'o, okay, we're normal'... Afterwards you see that, but first, initially you think, there's no way I'm gonna be all these things... I don't know what it is, I'm sorry to say, but white children just look clever. (cited in Nel, Troskie-de Bruin, \& Bitzer, 2009, p. 981)

We found one study focusing on white students' experiences of living alongside black students in historically white Afrikaans university residences. Jackson, van der Vijver, and Biela (2013) measured the psychological well-being of white students in a context of growing 'diversity'. They claim that 'on average, white male and female students ... are in a good psychological state; this sample did not suffer from the existential trouble' (p. 304) that has elsewhere been claimed to exist among white South Africans after apartheid.

Finally, a critical counterpoint to the race work comes from Bhana (2014), the only author we read who addresses the importance of analysing race by class. She argues that, although important, the focus on race in universities obscures ongoing class inequality, and the fact that the middle and upper-middle classes have been largely deracialised, while the working classes have not. Working class black students that she interviewed at UKZN had a heightened awareness of what they were excluded from - for example having less access to technology and safe accommodation, never being able to patronise a campus coffee shop, and so on; but the appearance of a racially mixed campus obscures such underlying class divisions. 


\section{Experiences of institutional discrimination other than racism}

Studies on students' experiences of forms of discrimination other than racism are relatively sparse. The exception is a 2017 special issue of SAJHE which addresses the experiences of LGBTI students at different types of universities in southern Africa. Overall, the studies suggest that campus communities (including student residences) are not places where LGBTI students feel fully safe or comfortable: 'Most of the research findings ... [in this issue] indicate that the institutions of higher education in SADC are still heteronormative and LGBTI staff and students are marginalized, prejudiced and discriminated against' (Nduna, Mthombeni, Mavhandu-Mudzusi, \& Mogotsi, 2017, p. 1; see also Munyuki \& Vincent, 2017). LGBTI students at an unnamed rural university reported regular threats of violence and theft (Mavhandu-Mudzusi \& Sandy, 2017); black gay men living in all-male residences at Wits reported institutionalised homophobia in student residence house committees (Kiguwa \& Langa, 2017). Lesch, Brits, and Naidu (2017) show how same-sex couples have to monitor their behaviour on campus, knowing precisely which parts of campus are gay-friendly and which are not, and are nervous to publicly display affection for fear of backlash or of causing offence.

Apart from this landmark special issue, papers on LGBTI students' experiences were relatively few. Msibi (2013) describes his own experiences of homophobia as an undergraduate student from university staff, both black and white. He expresses surprise and disappointment that homophobia came from black staff whom he respected and from whom he had expected support as a black gay student. Homophobic and transphobic student experiences are also described by Cornell et al. (2016) and Qambela (2016), including protests by transgendered students over having to identify with binary gender categories in residences and bathrooms. Studies also point to the extreme pseudo-religious language that often accompanies homophobia, such as claims that gay students are 'demon-possessed' (Msibi, 2013; Nkosi \& Masson, 2017).

We found very few papers addressing sexism or heterosexual harassment. Mudaly and van Wyk (2015) discuss institutional sexism in the medical profession and how this trickles down to universities, differently shaping female and male medical students' experiences of their medical training and community service, as well as their aspirations to practise and specialise. Adams, Mabusela, and Dlamini (2013) attempted to research the prevalence of sexual harassment of female students by male staff members at one anonymous, historically black university. Van der Merwe and van Reenen (2016) show how extreme sexism and rape culture are institutionalised in some male residences at UFS; and Meth recalls how students tried to address rape culture at Rhodes University with \#RUReferencelist (Meth, 2017, cited in Langa, 2017; see also Qambela, 2016; Shefer, Clowes, \& Vergnani, 2012, below).

We also found only two papers addressing xenophobia (Pithouse-Morgan, Morojele, Pillay, Naicker, Chikoko, Ramkelawan, \& Rajpal, 2012; Singh \& Francis, 2010), which has become a disturbing public bad in the post-apartheid era. Pithouse-Morgan et al. offer a case study of 
a single international student who recounts his fears and experiences of xenophobic harassment on campus, and his consequent choice to isolate himself socially. Singh and Francis's paper is actually about using a drama exercise to address xenophobia with South African students, but it seems important to note in this discussion of students' experiences of institutional discrimination that many of the South African students who participated in the drama exercise spoke freely about their own dislike of 'foreigners'.

To conclude, this section suggests that racism and racialisation on campuses have been quite extensively researched, but, with the partial exception of literature on gay students' experiences and homophobic persecution, other forms of discrimination have not been nearly as extensively researched. Of course, the literature itself cannot tell us whether this is because these are in fact not serious problems on university campuses; or because South African researchers have blind spots about sexism and xenophobia; or because our search methods did not capture papers that do exist; or for some other reason. However, we can reiterate that concerns about the racialisation of historically white universities evidently have a long history. Almost all the work reviewed here dates from before the student protests of 2015/2016, in some cases long before. Reading about these issues in the immediate post-protest period thus felt, at times, eerily familiar.

\section{Theme 2: Student health, well-being and poverty}

A second and smaller theme in the literature we termed student health, well-being and poverty is discussed in this section. This includes papers on student poverty, food insecurity, experiences of students with disabilities, student physical and mental health, drinking, and transactional sex. Overall, this literature is probably too patchy to give a comprehensive view of the overall state of student health; however, a number of red flags are raised, especially about poverty and its knock-on effects. Two studies researched food insecurity, both at UKZN and published in 2013. Munro, Quayle, Simpson, and Barnsely's (2013) survey of over 1000 students found that more than a third of students reported food insecurity to a degree which affected their academic performance. Almost half of them experienced serious or severe food insecurity. Students on financial aid and those in access programs reported greater food insecurity than those who were not. The authors argue that food insecurity may be undermining the academic aims of the UKZN access programmes, and affecting throughput and graduation rates (see also Kassier \& Veldman, 2013). Furthermore, there is some evidence from a study of student eating and exercise habits at Nelson Mandela University (NMU) to suggest that students living in residence are relatively less healthy than others; but that students do not always make wise choices about what to spend their limited grocery money on (Gresse, Steenkamp, \& Pietersen, 2015). Concerns are also raised about the dangers of, and reasons for, student drinking and binge-drinking (Du Preez, Pentz, \& Lategan, 2016; Lategan, Du Preez, \& Pentz, 2017).

Two qualitative studies provide students' own accounts of living in poverty (Firfirey $\&$ Carolissen, 2010; Machika \& Johnson, 2015). Poor students benefiting from a university 
food programme discussed effects of poverty that ranged from food insecurity and lack of personal hygiene (e.g. showering without soap), to academic effects such as difficulty in keeping up with academic work due to unaffordability of textbooks, and psychological effects including chronic anxiety and depression over finances, feelings of shame for being poor and wanting to hide or disguise one's poverty from friends and housemates. Poor students who could not afford to live in close proximity to their university reported a long daily commute, which, compounded by care responsibilities for younger siblings and children at home, left little time for university work, thus adding 'time-poverty' to their multiple challenges (Machika \& Johnson, 2015; see also Wilson-Strydom, Strydom, \& Hen-Boisen, 2016). Despite receiving accommodation, food, book and fee allowances, students on the National Student Financial Aid Scheme (NSFAS) cannot totally escape the effects of financial insecurity: NSFAS fee payments to the universities are often late, so that some students are not allowed to re-register for subsequent years of study despite passing their modules; and the NSFAS food allowance is also limited (Machika \& Johnson, 2015). Indeed, van $\mathrm{Zyl}$ (2014, p. 1663) argues that rather than thinking of 'disadvantaged' students as 'non-traditional', they should be seen as the new normal: 'desperation defines the neomainstream' in South African higher education. Conversely, however, Langa (2017, p. 10) finds that students' experiences of poverty may be differentiated by university type and location: 'It appears that students at the universities of Limpopo and Zululand, both historically black universities, are satisfied with NSFAS while students at historically white universities feel that NSFAS is insufficient in meeting their exorbitant fees'.

At the intersection of gender and poverty is Shefer, Clowes, and Vergnani's (2012) paper on transactional sex among students at the University of the Western Cape. Student participants suggest that transactional sex is widespread on campus, and typically takes place between younger women students and older male students or working men from outside of the university. As transactional relationships take place 'across the urban-rural and local-foreigner' divides, and across differences of wealth, age and status which intersect with gender in multiple, complex ways', the authors are concerned that these unequal power dynamics may be 'exacerbating unsafe and coercive sexual practices' (p. 435) among students.

We found two papers on disabled students' experiences of campus life (Matshediso, 2010; Mutanga, 2017). Students with disabilities emphasised the importance of support from the campus disability office, from friends, and from lecturers who are sensitive to their specific needs. Some students said they had difficulty accessing buildings and facilities and blind students said that they were often uninformed about campus events because they cannot read most notices (see Mutanga, 2017, for a review).

Finally, with the exception of an early study by Schreiber (2007), who examined the presenting concerns of students using the UCT student counselling centre in the early $2000 \mathrm{~s}$ and noted that the incidence of self-reported depression was high, student mental health barely made an appearance in this literature corpus. 


\section{Theme 3: The emancipatory potential of student politics}

The last theme we identify is student politics, which is one of the longest-studied topics related to the student experience beyond the curriculum. The early studies tended to focus on key student organisations' and students' roles in the anti-apartheid struggle (Badat, 1999; Bundy, 1989; Maseko, 1994; Muller, 1991; Nkomo, 1984). In the post-apartheid period, only a few studies continued to address this topic (Koen, Cele, \& Libhaber, 2006; Luescher, 2009; Luescher-Mamashela, 2010) until the 2015/2016 student movement sparked a great number of new studies on student politics.

Interestingly, student leaders interviewed a few years before the 2015/2016 protests by Keet and Nel (2016) described feeling suffocated and misrecognised by their university management, as if they were being used to simply 'act out a script' that had already been decided on by others, rather than being taken seriously as agents of change in their own right. Otherwise, neither the older nor the newer studies focus much on students' experiences of student politics itself. They mostly take for granted that the student experience of higher education and beyond is a source of student discontent and anger that leads to student protests. In the case of the recent literature, this includes students' personal experiences of alienation, discrimination and exclusion; students' interpretation thereof in terms of the prevailing social injustices in South African society and the effects of certain higher education policies and practices; and student discontent and pessimism about broader political and socio-economic developments in the country (e.g. Badat, 2017; Booysen, 2016; Jansen, 2017; Karodia, Soni, \& Soni, 2016; Lukhele, 2015; Molefe, 2016; Nel, 2016; Nyamnjoh, 2015). We find that students' experiences of participating in student politics feature mainly in studies that look at the practices, strategies and tactics of the student movement, its internal organisation and internal divisions (Baragwanath, 2016; Langa, 2017; Luescher \& Klemenčič, 2017; Naidoo, 2015; O’Halloran, 2016; Qambela, 2016). Some studies look at specifics, for example social media activism (Bosch, 2017; de Jager, 2016; Luescher, Loader, \& Mugume, 2017); and others at the violence that accompanied the protests, particularly traumatising and racialised police violence and the securitisation of campuses, as well as violence from protestors (Langa, 2017 and contributors; Hodes, 2016; see also Metz, 2016).

While student activism is a collective and public expression of student interest in addressing educational and/or social issues, participation therein is very much a personal experience and entails a personal process of transformation. In this respect, both the older and newer literature show how black students in particular, emerging from experiences of racism and exclusion, learn in the process of student activism to centre and assert a positive black identity, and conceptualise and theorise the black experience on and off campus, along with a critique of the education system and rejection of the racialised structure of society and white supremacy (Luescher, 2009; Naidoo, 2015; also see Badat, 1999, 2015; Gibson, 2017; Mbembe, 2015). The recent studies have added an intersectional perspective to the 
race-based critique, involving gendered and working class perspectives, LGBTI students' experiences, critiques of xenophobia, and so forth (Langa, 2017; Qambela, 2016).

As for the biographical impact of the experience of student activism in South Africa - and thus the realisation of its transformative potential in terms of a pathway to the public good we have not been able to uncover any relevant studies. We also did not find studies addressing the experiences of those students not directly involved in protest action themselves. To date, the emancipatory potential of student activism is perhaps most evident in studies that are conceptualising \#RhodesMustFall and other 'decolonisation campaigns' as part of a critical pedagogical process whereby students take charge of their own learning, construct their own 'counter-curriculum', and engage in a new praxis of addressing the unfinished project of decolonisation (cf. Mangcu, 2015; Naidoo, 2015; Nyamnjoh, 2015).

\section{Discussion and implications}

This review of literature spans the period leading up to and immediately after the largest student activist movement in democratic South Africa to date, which was a defining part of students' experiences beyond the curriculum on most South African university campuses in 2015 and 2016. Starting with \#RhodesMustFall at UCT and rapidly spreading across universities, South African higher education experienced the onset of a 'decolonial moment' which brought into mainstream political discourse issues of institutional (and intersectional) alienation (see also Chapter 10) and - with \#FeesMustFall - the unaffordability of university education, issues which researchers and the students they interviewed had evidently already been pointing out for many years. Although the literature we read gives only a partial view of the whole picture of students' experiences of campus life - and it may be that important counter-perspectives were not caught in the net of our search methods - this review has been a process of 'connecting the dots' and finding that numerous red flags were raised as far back as our review period goes. Evidently, historically white universities have long been experienced as indifferent, if not actively hostile, to many 'new mainstream' students. In this sense, the protests and the issues they raised appear as a crisis that was waiting to happen, rather than as something that blew up without warning.

A second implication derives from the size and skewness of the literature reviewed here. Our research assembled a considerable dataset of over 120 articles, chapters and reports; yet, this literature almost exclusively tells the story of students at urban and historically white universities. We know very little about students at rural and historically black universities. This bias reflects the predominance of authors from a familiar subset of universities: UCT, UKZN, UWC, Wits, UFS, Stellenbosch, Pretoria, Rhodes and UNISA (in that order). This skewness is further exacerbated by the prevalence of single-institution, small-sample studies, some of which do not provide comparative perspectives from more than one group of purposively selected students. There is also typically a lack of thorough theoretical engagement in the papers; they tend to be largely problem-driven and empirical, and at best consider relevant 
conceptual lenses. Moreover, a number of papers are quite weak methodologically, with results sections consisting of a few quotes from students, with little attempt to justify this selection or the overall plausibility of the author's knowledge claims. Finally, we note that with the exception of the student politics literature, there is in fact very little research on organised campus activities, such as student associations, student participation in residence structures, sport, or student media - even though such activities are arguably crucial in the formation of student networks and skills that may live on beyond graduation and in fostering certain graduate attributes. Absence of evidence cannot be treated as evidence of absence, however, and there are likely many student experiences - both good and bad -beyond the curriculum that have not been captured here. The shape and size of the literature is therefore itself a call to action for researchers to conduct larger, comparative and perhaps historical studies on students' experiences at different campuses, in a variety of domains of student life, and over time.

Thirdly, while the studies about black students' experiences of racialisation and institutional alienation may not give us a direct answer about how higher education contributes to the public good - as this is not a question they were attempting to address - the studies do show that many of the problems of South African society at large are rehearsed and replicated - if not amplified - in universities. South African universities are not neutral enclaves or ivory towers where social cleavages are bridged or suspended. Indeed, some literature suggests that students experience inequality and racial and ethnic divides in a more powerful way when they attend universities than they did in high school. If the public good is conceptualised as sustainable social cohesion and social justice, what is the long-term effect of these experiences of what we may call these 'public bads'? Are they contributing to the public good insofar as the process of becoming aware of inequality is the first step towards opposing and addressing it? Or are they producing hurt and cynical students?

Direct evidence from the literature itself is only partially helpful. A small subset of studies in our dataset considered the contribution of higher education to democratisation in Africa. Starting with a wholesale view of students' experience of higher education, two studies show that higher education's distinct contribution to democracy is predominantly evident in graduates' critical thinking (Mattes \& Mughogho, 2010) and their greater ability to navigate the highly complex institutions of modern democracy (Mattes \& Mozaffar, 2011). Later, related studies disaggregate the student experience and its impact on different kinds of citizenship competences to show the importance of political engagement during campus life, participation in specific skills trainings (e.g. leadership training, diversity workshops), and active membership and leadership in student associations, as well as organisations of civil society off campus, in accounting for the development of citizenship competences and for graduates' more active and critical, democratic citizenship (Luescher-Mamashela et al., 2011, 2015; Mattes \& Luescher-Mamashela, 2012). This set of studies thus builds on earlier studies on the civic role of higher education in South Africa (e.g. Cross, Cloete, Beckham, Harper, Indiresan, \& Musil, 1999) as well as policy-related discourse on the public good dimension of higher education (Council on Higher Education, 2004, 2016; Department of Education, 1997). 
We can infer some further transformative experiences from the literature. Positively transformative experiences include students appreciating greater cultural and racial exposure; becoming more self-aware and articulate; learning to better form and express their opinions; learning to navigate their university in all its complexity (Cloete \& Duncan, 2016); and participating and taking charge in student organisations and student activism, on matters that personally affect them and in solidarity with others. This kind of 'student engagement' is also known to positively correlate with academic success (Kuh, 2009; Tinto, 2014). Conversely, negatively transformative experiences of university may include heightened anxieties about one's own race and identity; greater awareness of one's own economic and social disadvantage, compared to more wealthy students with whom one might never have mixed before, and how this class inequality continues to correlate with race; continued racial segregation on campus and in student life and personal experiences of discrimination; as well as indications that living in residence has some health and personal risks. Curiously, this also suggests that positive and the negatively transformative student experiences beyond the curriculum lie side by side.

Finally, an important counter-perspective to the predominantly pessimistic tone of the literature reviewed here is offered by Hodes (2016), who argues that the claim that universities are racist, classist, alienating places which have failed at transformation has become an orthodoxy that does not acknowledge the large body of South African scholarship that has been producing a sustained critique of the transition all along. Since the academics who write such critiques also teach and supervise in the universities, this then raises the question about the extent to which the critical capacities of the \#RhodesMustFall and \#FeesMustFall student campaigns were at least partially a product of the teaching of these same institutions. In other words, were students drawing both on their own experiences and on the critical discourses of the university when launching their rebellion against it?

\section{References}

Adams, J., Mabusela, M., \& Dlamini, E. (2013). Sexual harassment: The 'silent killer' of female students at the University of Ayoba in South Africa. South African Journal of Higher Education, 27(5), 1149-163.

Badat, S. M. (1999). Black student politics, higher education and apartheid: From SASO to SANSCO, 1968-1990. Pretoria: Human Sciences Research Council.

Badat, S. (2015). Deciphering the meaning and explaining the South African higher education student protests of 2015-2016. Pax Academica: African Journal of Academic Freedom, 1\&2, 71-106.

Badat, S. M. (2017). Theorising and researching university student politics in South Africa. Paper presented at the Ali Mazrui Centre for Higher Education Studies, Faculty of Education, University of Johannesburg, 6 April 2017.

Baragwanath, R. (2016). Social media and contentious politics in South Africa. Communication and the Public, 1(3), 362-366.

Bhana, D. (2014). Race matters and the emergence of class: Views from selected university students. South African Journal of Higher Education, 28(2), 355-367.

Booysen, S. (Ed.). (2016). Fees Must Fall: Student revolt, decolonisation and governance in South Africa. Johannesburg: Wits University Press.

Bosch, T. (2017). Twitter activism and youth in South Africa: The case of \#RhodesMustFall. Information, Communication \& Society, 20(2), 221-232. 


\section{HigheR EDUCATION PATHWAYS}

Bundy, C. J. (1989). South Africa. In P. G. Altbach (Ed.), Student political activism: An international reference handbook. Westport, Connecticut: Greenwood Press.

Cloete, N., \& Duncan, C. (2016). Shifting from orientation to disorientation: Reading student discourses of success. Perspectives in Education, 34(2), 33-42.

Cornell, J., Ratele, K., \& Kessi, S. (2016). Race, gender and sexuality in student experiences of violence and resistances on a university campus. Perspectives in Education, 34(2), 97-119.

Council on Higher Education (2004). South African higher education in the first decade of democracy. Pretoria: Council on Higher Education.

Council on Higher Education (2016). South African higher education reviewed: Two decades of democracy. Pretoria: Council on Higher Education.

Cross, M., Cloete, N., Beckham, E., Harper, A., Indiresan, J., \& Musil, C. (1999). Diversity and unity: The role of higher education in building democracy. Cape Town: Maskew Miller Longman.

Cross, M., \& Johnson, B. (2008). Establishing a space of dialogue and possibilities: Student experience and meaning at the university of the Witwatersrand. South African Journal of Higher Education, 22(2), 302-321.

de Jager, T. (2016). Traditional news platforms and citizens' reporting the news: The use of social media during the '\#feesmustfall' campaign in South Africa. Innovation: Journal of Appropriate Librarianship and Information Work in Southern Africa, Issue 52, 36-50.

Department of Education (1997). Education White Paper 3: A programme for the transformation of higher education. Government Gazette, No. 18207, 15 August 1997. Pretoria: Government Printers.

du Preez, R., Pentz, C., \& Lategan, B. (2016). Why students drink: A study of South African university students' drinking behaviour. South African Journal of Higher Education, 30(2), 73-93.

Durrheim, K., \& Mtose, X. (2006). Being-black-in-the-new-South-Africa. In G. Stevens, V. Franchi, \& T. Swart (Eds.), A race against time: Psychology and challenges to deracialisation in South Africa (pp. 153-170). Pretoria: Unisa Press.

Durrheim, K., Trotter, K., Piper, L., \& Manicom, D. (2004). From exclusion to informal segregation: The limits to racial transformation at the University of Natal. Social Dynamics, 30(1), 141-169.

Erasmus, Z., \& de Wet, J. (2003). Not naming 'race': Some medical students' experiences and perceptions of 'race' and racism at the Health Sciences Faculty of the University of Cape Town. Retrieved from https://open.uct.ac.za/bitstream/handle/11427/7571/not_naming_race.pdf?sequence=1

Essack, Z., \& Quayle, M. (2007). Students' perceptions of a university access (bridging) program for social science, commerce and humanities. Perspectives in Education, 25(1), 71-84.

Firfirey, N., \& Carolissen, R. (2010). 'I keep myself clean ... at least when you see me, you don't know I am poor': Student experiences of poverty in South African higher education. South African Journal of Higher Education, 24(6), 987-1002.

Gibson, N. C. (2017). The specter of Fanon: The student movements and the rationality of revolt in South Africa. Social Identities, 25(5), 1-21, (Online) DOI: 10.1080/13504630.2016.1219123

Gresse, A., Steenkamp, L., \& Pietersen, J. (2015). The influence of student accommodation on NMMU students' dietary patterns, activity and alcohol consumption. South African Journal of Higher Education, 29(6), 93-105.

Hodes, R. (2016). Questioning 'Fees Must Fall'. African Affairs, 116(462), 140-150.

Jackson, L, van der Vijver, B., \& Biela, R. (2013). Coping with diversity in dormitories in a historically white HEl in South Africa. South African Journal of Higher Education, 27(3), 607-626.

Jansen, J. (2017). As by fire: The end of the South African University. Cape Town: Tafelberg.

Karodia, A. M., Soni, D., \& Soni, P. (2016). Wither higher education in the context of the FeesMustFall campaign in South Africa. Research Journal of Education, 2(5), 76-80.

Kassier, S., \& Veldman, F. (2013). Food security status and academic performance of students on financial aid: The case of University of KwaZulu-Natal. Alternation, 9, 248-264.

Keet, A., \& Nel, W. (2016). Rights, regulation and recognition: Studying student leaders' experiences of participation and citizenship within a South African University. International Journal of Educational Sciences, 13(1), 129-144.

Kessi, S., \& Cornell, J. (2015). Coming to UCT: Black students, transformation and discourses of race. Journal of Student Affairs in Africa, 3(2), 1-16. 
Kiguwa, P., \& Langa, M. (2017). 'So I decided not to invade straight black men's space': Exploring heteronormative spaces on campus. South African Journal of Higher Education, 31(4), 53-71.

Koen, C., Cele, M., \& Libhaber, A. (2006). Student activism and student exclusions in South Africa. International Journal of Educational Development, 26, 404-414.

Kuh, G. D. (2009). What student affairs professionals need to know about student engagement. Journal of College Student Development, 50(6), 683-706.

Langa, M. (Ed.). (2017). \#Hashtag: Analysis of the \#FeesMustFall movement at South African universities. Johannesburg and Cape Town: Centre for the Study of Violence and Reconciliation.

Lategan, B., du Preez, R., \& Pentz, C. (2017). Socio-demographic insights into South African student drinking behaviour. South African Journal of Higher Education, 31(5), 90-115.

Lesch, E., Brits, S., \& Naidoo, N. (2017). 'Walking on eggshells to not offend people': Experiences of same-sex student couples at a South African university. South African Journal of Higher Education, 31(4), 127-149.

Luescher, T. M. (2009). Racial desegregation and the institutionalisation of 'race' in university governance: The case of the University of Cape Town. Perspectives in Education, 27(4), 415-425.

Luescher, T.M., \& Klemenčič, M. (2017). Student power in twenty-first century Africa: The character and role of student organising. In R. Brooks (Ed.), Student politics and protest: International perspectives. London: Routledge.

Luescher, T. M., Loader, L., \& Mugume, T. (2017). \#FeesMustFall: An internet-age student movement in South Africa and the case of the University of the Free State. Politikon: South African Journal of Political Studies, 44(2), 231-245.

Luescher-Mamashela, T. M. (2010). From university democratisation to managerialism: The changing legitimation of university governance and the place of students. Tertiary Education and Management, 16(4), 259-283.

Luescher-Mamashela, T. M., with Kiiru, S., Mattes, R., Mwollo-ntallima, A. M., Ng'ethe, N., \& Romo, M. (2011). The university in Africa and democratic citizenship: Hothouse or training ground? Wynberg: Centre for Higher Education Trust.

Lukhele, S. (2015). South Africa's student uprising signals wider social upheaval: Politicians' promises to end poverty ring hollow to a new generation of Africans. Africa Conflict Monitor, 2015(12), 68-72.

Machika, P., \& Johnson, B. (2015). Postgraduate students' experience of poverty and academic success at a University of Technology in South Africa. South African Journal of Higher Education, 29(6), 167-181.

Mangcu, X. (2015). The Rhodes debate - Early warning of racial civil war? University World News, 361, 1-2.

Maseko, S. S. (1994). Student power, action and problems: A case study of UWC SRC, 1981-92. Transformation, 24, 70-90.

Matshediso, K. (2010). Experiences of disabled students in South Africa: Extending the thinking behind disability support. South African Journal of Higher Education, 24(5), 730-744.

Mattes, R., \& Luescher-Mamashela, T. M. (2012). The roles of higher education in the democratization of politics in Africa: Survey reports from HERANA. Journal of Higher Education in Africa, 10(1), 139-170.

Mattes, R., \& Mozaffar, S. (2011). Education, legislators and legislatures in Africa. Paper prepared for the Higher Education Research and Advocacy Network in Africa (HERANA). Wynberg: Centre for Higher Education Trust.

Mattes, R., \& Mughogho, D. (2010). The limited impacts of formal education on democratic citizenship in Africa. Paper prepared for the Higher Education Research and Advocacy Network in Africa (HERANA). Wynberg: Centre for Higher Education Trust.

Mavhandu-Mudzusi, A., \& Sandy, P. (2017). Human rights violation: Its impact on the mental well-being of LGBTI students in a South African rural-based university. South African Journal of Higher Education, 31(4), 325-340

Mbembe, A. (2015). Decolonising knowledge and the question of the archive. http://wiser.wits.ac.za/system/ files/Achille.pdf (accessed on 21 January 2016).

Metz, T. (2016). The South African student/worker protests in light of just war theory. In S. Booysen (Ed.), Fees must fall: Student revolt, decolonisation and governance in South Africa. Johannesburg: Wits University Press. 
Molefe, T. O. (2016). Oppression must fall: South Africa's revolution in theory. Black lives matter everywhere. World Policy Journal, Spring, 30-37.

Msibi, T. (2013). Queering transformation in higher education. Perspectives in Education, 31(2), 65-73.

Mudaly, R., \& van Wyk, J. (2015). 'Pink collar' medicine: Medical students navigating the gendered landscape of a South African medical school. South African Journal of Higher Education, 29(4), 229-243.

Muller, J. (1991). South Africa. In P. G. Altbach (Ed.), International higher education: An encyclopedia. Chicago: St James Press.

Munro, N., Quayle, M., Simpson, H., \& Barnsely, H. (2013). Hunger for knowledge: Food insecurity among students at the University of KwaZulu-Natal. Perspectives in Education, 31(4), 168-179.

Munyuki, C., \& Vincent, L. (2017). 'It's tough being gay': Gay, lesbian and bisexual students' experiences of being 'at home' in South African university residence life. South African Journal of Higher Education, 31(4), 14-33.

Mutanga, O. (2017). Students with disabilities' experience in South African higher education - a synthesis of literature. South African Journal of Higher Education, 31(1), 135-154.

Naidoo, L-A. (2015). We shall not be moved or led astray: The emergence of the 2015 student movement. New Agenda, 60, 12-14.

Nduna, M., Mthombeni, A., Mavhandu-Mudzusi, A. H., \& Mogotsi, I. (2017). Studying sexuality: LGBTI experiences in institutions of higher education in Southern Africa. South African Journal of Higher Education, 31(4), 1-13.

Nel, C., Troskie-de Bruin, C., \& Bitzer, E. (2009). Students' transition from school to university: Possibilities for a pre-university intervention. South African Journal of Higher Education , 23(5), 974-991.

Nel, W. (2016). Student leadership: Challenges and possibilities. Journal of Student Affairs in Africa, 4(2), 55-60.

Nkomo, M. (1984). Student culture and activism in black South African universities: The roots of resistance. Westport, Connecticut: Greenwood Press.

Nkosi, S., \& Masson, F. (2017). Christianity and homosexuality: Contradictory or complementary? A qualitative study of the experiences of Christian homosexual university students. South African Journal of Higher Education, 31(4), 72-93.

Nyamnjoh, F. B. (2015). Black pain matters: Down with Rhodes. Pax Academica: African Journal of Academic Freedom, 1\&2, 47-70.

O'Halloran, P. (2016). The African university as a site of protest: Decolonisation, praxis, and the Black Student Movement at the university currently known as Rhodes. Interface: A Journal for and about Social Movements, 8(2), 184-210.

Pattman, R. (2010). Investigating 'race' and social cohesion at the University of KwaZulu-Natal. South African Journal of Higher Education, 24(6), 953-971.

Pillay, V., \& McLellan, C. (2010). Diverging on diversity and difference: The mask of inclusion. Perspectives in Education, 28(3), 13-22.

Pithouse-Morgan, K., Morojele, P., Pillay, D., Naicker, I., Chikoko, V., Ramkelawan, R., \& Rajpal, R. (2012). 'The air is hostile...': Learning from an African international postgraduate student's stories of fear and isolation within a South African university campus. Alternation, 19(2), 73-93.

Qambela, G. (2016). 'There is no such thing as a single-issue struggle': Xenophobia in the time of decolonisation, eRhini, 2015. Agenda, 30(2), 35-45.

Schreiber, B. (2007). Students and their presenting concerns at a Student Counselling Service at a South African university. South African Journal of Higher Education, 21(5), 527-535.

Schrieff, L., Tredoux, C., Dixon, J., \& Finchilescu, G. (2005). Patterns of racial segregation in university residence dining-halls. South African Journal of Psychology, 35(3), 433-443.

Shefer, T., Clowes, L., \& Vergnani, T. (2012). Narratives of transactional sex on a university campus. Culture, Health, \& Sexuality, 14(4), 435-447.

Singh, L., \& Francis, D. (2010). Exploring responses to xenophobia: Using workshopping as critical pedagogy. South African Journal of Higher Education, 24(3), 302-316.

Soudien, C. et al. (2008). Report of the ministerial committee on transformation and social cohesion and the elimination of discrimination in higher education institutions. Pretoria: Department of Education. 
Tinto, V. (2014). Tinto's South Africa lectures. Journal of Student Affairs in Africa, 2(2), 5-28.

van der Merwe, J. C., \& van Reenen, D. (2016). Transformation and legitimation in post-apartheid universities: Reading discourses from 'Reitz'. Bloemfontein: Sun Press.

van Zyl, G. M. (2014). The 'nervous conditions' of neo-liberated higher education students. South African Journal of Higher Education, 28(5), 1663-1679.

Wertheim, S. S. (2014). Can we become friends? Students' cross-racial interaction in post-apartheid South African higher education. Journal of Student Affairs in Africa, 2(1), 35-54.

Wilson-Strydom, M. (2014). Confronting contradiction: Diversity experiences at school and university. Perspectives in Education, 32(4), 56-73.

Wilson-Strydom, M., Strydom, F., \& Hen-Boisen, L. (2016). Institutional research and the student: The promise of mixed methods and intersectional analysis. In J. Botha \& N. J. Muller (Eds.), Institutional research in South African higher education. Stellenbosch: Sun Media. 


\title{
POST-GRADUATION TRAJECTORIES OF YOUNG SOUTH AFRICANS
}

\author{
Jennifer M. Case, Delia Marshall and Samuel Fongwa
}

\section{Introduction}

What graduates end up doing after they leave university has become of increasing concern and interest over the last few decades. In these times of increased participation in higher education, growing economic uncertainties and neoliberal politics, an increasing number of stakeholders are interested in graduate outcomes. While parents and students seek access to universities with better employment prospects, financial constraints continue to influence university access with increasing cost-sharing policies. University managers on their part have used graduate tracer studies as marketing tools and a proxy for academic or institutional quality. From the perspective of the employers, though, the notion of core employment skills is increasingly becoming a fluid concept due to changing technological advances and hence changing professional demands.

These combined effects mean that there has been a growing focus in the higher education literature on graduate employment - whether graduates are employed or not, and if so at what level. From a survey of UK research in this field, Behle et al. (2015) show how relatively recent is this concern - until the 1990s only a minority of UK university students had a clear sense of what they would do after graduation. This lack of knowledge did not significantly affect graduate outcomes, as a university degree or certificate provided an almost secure path to decent employment. An anticipated relationship between university participation and decent employment is now a significant policy driver, especially given that the introduction of tuition fees means that the choice to enter higher education is now linked to an ability to repay these fees through graduate earnings. In the UK the research focuses substantially on whether graduates are getting 'graduate jobs' and this enquiry is focused not only on whether graduates are able to use their skills and knowledge, but also, crucially, on whether the choice to enter higher education 'pays off' for the individual. 
Linked to the experience of graduates in the UK, there is increasing evidence also in the US context that the working aspirations of graduates are not always being met once they get into the world of work. Especially in large corporates, over half of graduates feel they are underemployed, with one in seven graduates saying they did not want to work in a large company (Smith, LaVelle, Lyons, \& Silverstone, 2016). In a context such as Australia, the notion of graduate employment is perceived slightly differently since there about $72 \%$ of undergraduate students are already in full-time employment. All the same, this literature does cite some concerns on graduate underemployment (Australian Government Department of Education and Training, 2018).

While researching graduate employability continues to be a critical issue across higher education systems globally, it can be argued that contextual realities shape and inform the focus and policy interventions. Based on the above introduction, it can be seen that graduate outcome research is strongly shaped by the higher education system, the socio-economic dynamics and even historical patterns.

In the South African context, as elsewhere, studies on graduate outcomes and students' postgraduation trajectories have tended to focus mostly on employment patterns, and less on other aspects such as whether graduates are self-employed or involved in other valuable pursuits (such as parenting, care-giving or further study) or on the wider civic purposes of higher education. This focus on employment patterns is not surprising in the South African context, with high levels of unemployment (van der Berg \& van Broekhuizen, 2012) and where graduates have some of the highest rates of return in the world on their personal investment in higher education (Montenegro \& Patrinos, 2014). Nevertheless, although this chapter focuses predominantly on the employment trajectories of graduates, it will also argue for the value of research into the other non-employment outcomes of higher education, such as the influence of higher education on graduates' dispositions and attitudes toward civic matters such as political activism, democratic citizenship and serving as role models for others in their various communities.

\section{An overview of the South African context}

The debate on graduate destinations in South Africa occurs within a different context, with its own distinct apartheid legacy of racialised participation in the economy and in the education system. Across the board, unemployment is a significant concern. Overall, South Africa has high levels of unemployment $-36.7 \%$ defined broadly (including those who have given up looking for work and $26.7 \%$ defined narrowly (only considering the population actively looking for work) (StatsSA, 2018). Youth unemployment is at $52 \% .{ }^{21}$ While South Africa industrialised faster than other African contexts from the late 1800s, colonial and apartheid policies meant that access to higher education and employment opportunities was racially stratified. The higher education system and the economy never accommodated the majority

21 https://tradingeconomics.com/south-africa/youth-unemployment-rate 
black and African population into the mainstream education system and subsequently into formal employment. Therefore, changing the post-apartheid socio-economic situation has not been an easy undertaking.

The apartheid education legacy also plays into this debate. Public schooling remains highly uneven, with the majority black population receiving education of a significantly inferior quality, even when compared across the continent. In the 2017 World Economic Forum's Global Competitiveness Report, South Africa's education system is ranked 134th out of 138, with quality of maths and science education ranked last of the 138 countries. During apartheid, universities were racially segregated, and while formally this system has been changed, historically black universities (HBUs) continue to suffer lower levels of resourcing and perceptions of quality of education. Walker and Fongwa (2017) note that the top six most preferred universities by major private sector employers are historically white advantaged universities. Considering the added complexities of access to these universities linked to academic quality, funding and institutional posture, interrogating graduate employment in South Africa becomes even more complex.

Thus the debate on graduate destinations in South Africa has been centred in the first instance on employment and unemployment for the masses who had been excluded from the mainstream labour force. There has been an anticipation in post-apartheid policy that the education system would be a major driver of social and economic redress (Department of Education, 1997), and that widened access to higher education would result in improved economic circumstances for the previously disenfranchised majority.

Concerns that black graduates were not moving as easily into the workplace as had been assumed arose in the early 2000s (Moleke, 2005), and this continues to be a focus for public concern almost two decades later. Social media frequently features university graduates standing on the side of the road with placards, in the manner of indigents asking for work. ${ }^{22}$ At the same time, there has been a substantial amount of research on this topic over the last two decades, and in this chapter we aim to provide a comprehensive overview of this work.

Two distinct modes of research have informed this debate: the Labour Force Surveys conducted on the broad working population, and Graduate Destination Surveys which target graduates from specific institutions. We start with an overview of the various studies that have been conducted in these domains.

\section{Key studies in the field}

Since the early 2000s there have been studies of graduate employment in South Africa that use the annual Labour Force Surveys ${ }^{23}$ (LFS) conducted by Statistics South Africa, the government's

22 See, for example, http://www.dispatchlive.co.za/news/2017/10/04/geology-honours-graduate-glen-will-persist-finds-job/

23 From 1995 to 1999 this was termed the October Household Survey; from 2000 to 2007 there was a twice-annual Labour Force Survey, and thereafter a Quarterly Labour Force Survey. 
statistics organ. It is important to note that these surveys are used to provide estimates around patterns in the full population that participates in the labour force. There are a few important issues to note upfront when using these analyses for information about graduate destinations which create limitations for the interpretations that can be made from their findings. Firstly, graduates form a small part of this overall population, and unemployed graduates a particularly small part, and so measurement errors get magnified - for example it is noted that estimates of graduate unemployment from these surveys have been made off raw data comprising 50-80 unemployed graduates (van der Berg \& van Broekhuizen, 2012). Secondly, it must be noted that these surveys are of the entire working age population; for graduates therefore this includes those who graduated up to four decades previously, and the impact of recent changes in higher education and in the youth population will be somewhat muted in overall statistics. These analyses do allow for some disaggregation by age cohort, but again small sample sizes start to become an issue at this level of analysis.

Early studies based on the LFS data suggested that graduate unemployment was a significant and growing problem (see, e.g. Bhorat, 2004; Kraak, 2010; Pauw, Oosthuizen, \& van der Westhuizen, 2008) with Bhorat (2004) suggesting that unemployment of those with tertiary qualifications increased by 139\% between 1995 and 2002 .

However, subsequent work by van der Berg and van Broekhuizen (2012) raised some important methodological questions regarding previous studies. Firstly, some studies have defined graduates as referring to all of those with post-school qualifications. This is a very wide definition including those with Technical and Vocational Education and Training (TVET) qualifications and in fact bachelors graduates are a minority in this group. Research shows very different employment trends across these categories and it is therefore suggested to hold to a narrower definition of a graduate as one with a bachelors degree. Secondly, some studies only use two data points from which to draw trends. It is also noted that the October 1995 LFS, which for some studies is the starting point, did show a surprisingly low rate of graduate unemployment.

For the purposes of this chapter therefore, we will focus on the more recent work by van der Berg and van Broekhuizen (2012) which utilises this narrower definition of graduate, and which also uses multiple data points over a longer term period (from 1995 till 2011) from which to elucidate trends. We also refer to subsequent work (van Broekhuizen, 2016) which draws on LFS data in combination with Higher Education Management Information System (HEMIS) data on graduate characteristics from the different institutions.

Compared to the Labour Force Surveys, in which graduates are a small proportion of the labour force surveyed and the focus is on the full working population, Graduate Destination Surveys (GDS) allow for a closer examination of the situation for graduates, since they target graduates from particular cohorts and institutions. Graduate Destination Surveys (also called Graduate Tracer Studies) are well established in developed countries, but are only more recently being used in developing countries, not least because of the resource and logistical implications to obtain these data. Thus in South Africa these surveys have been infrequent. Data in the 
GDS is dependent on who responds to the invitation to participate. The first issue is that these have tended to have low response rates, thus making statistical analyses difficult, but moreover it is hard to assess the bias inherent in the profile of respondents compared to the cohort (Branson \& Leibbrandt, 2017; du Toit, Kraak, Favish, \& Fletcher, 2014). A few of these GDS are described below.

In South Africa, the first national graduate destination studies were conducted by the Human Sciences Research Council (HSRC). Following on the work of Moleke (2005), the book by Letseka, Cosser, Breier, \& Visser (2010) reports a follow-up study by the HSRC which surveyed the 2002 cohort of both 'leavers' (drop-outs) and graduates at seven selected HEIs (University of the Witwatersrand, Tshwane University of Technology, Stellenbosch University, Cape Peninsula University of Technology, University of the Western Cape, University of Fort Hare and University of Limpopo). A 16\% response rate (based on the full cohorts of both leavers and graduates) was received on this postal survey. The detailed analysis of this survey is presented in the chapters of the book by Moleke (2010) and Bhorat, Mayet, \& Visser (2010).

In 2013, the Cape Higher Education Consortium (CHEC) published results from a study of 2010 graduates from all four universities in the Western Cape - University of Cape Town (UCT), Stellenbosch University (SU), the University of the Western Cape (UWC), and the Cape Peninsula University of Technology (CPUT); graduates were contacted in 2012 (Cape Higher Education Consortium, 2013). Using a combination of an online survey supplemented by telephonic interviews, they achieved a response rate of $22.5 \%$. To address the issue of potential skewedness in respondents, they adopted a statistical weighting procedure (du Toit et al., 2014), though Branson and Leibbrandt (2017) point out that this is only valid if the characteristics used for weighting are those most influential on employment outcomes.

More recently, Rogan and Reynolds (2015) conducted a graduate tracer study in another geographical area of South Africa, the Eastern Cape. The study approached a stratified random sample of all Rhodes University (RU) and University of Fort Hare (UFH) graduates who had completed a three- or four-year bachelors degree in either 2010 or 2011. As with the CHEC study, telephonic interviews were used to supplement an online survey - remarkable response rates were achieved (39\% for the UFH and $47 \%$ at RU).

Another recent study (Baldry, 2016) surveyed \#1175 graduates who graduated between 2006 and 2012, from a market survey database (15\% response rate) of graduates across all 23 public higher education institutions.

\section{Findings}

\section{Overall levels of graduate unemployment}

The concept of 'unemployment', as noted earlier, needs some definition. Economists differentiate between a 'narrow' concept which only focuses on those not in work and looking for work, while the 'broader' concept includes those who want work but have given up looking 
for it. In terms of graduates, it is noted that this group is relatively small in the overall population of the South African working age population, and thus the narrow definition tends to be utilised. Thus it must be noted that there is a group of graduates who are not employed or unemployed (narrowly defined). These include those in full-time study, but also those who for other reasons have chosen not to be working.

Using LFS data from nearly two decades, van der Berg and van Broekhuizen (2012) show that overall graduate unemployment did peak in 2001 - at $6.75 \% .{ }^{24}$ It reduced between 2001 and 2007 and has edged slightly upwards since 2008, although it is relatively stable at between 4 and 4.5\%. Taking statistical considerations into account, the peak in 2001/2002 can be verified, but over the broader period there has been no overall change in graduate unemployment, contrary to earlier studies on this topic drawing on more limited data as discussed above. The authors note that the response to worsening economic conditions has been muted for graduates compared to the overall population, where an increase in unemployment has been noted since 2008. Another important issue that this report emphasises is the dramatic increase in the total number of graduates in the labour force between 1995 (around 450 000) to 2011 (over a million), but that this has not resulted in an increase in graduate unemployment.

Van Broekhuizen (2016) offers a useful graphical overview of these findings, reproduced here as Figure 1.

Figure 1 Narrow unemployment rates from the LFS comparing graduates, diplomates and the overall working-age population (reproduced from van Broekhuizen 2016)

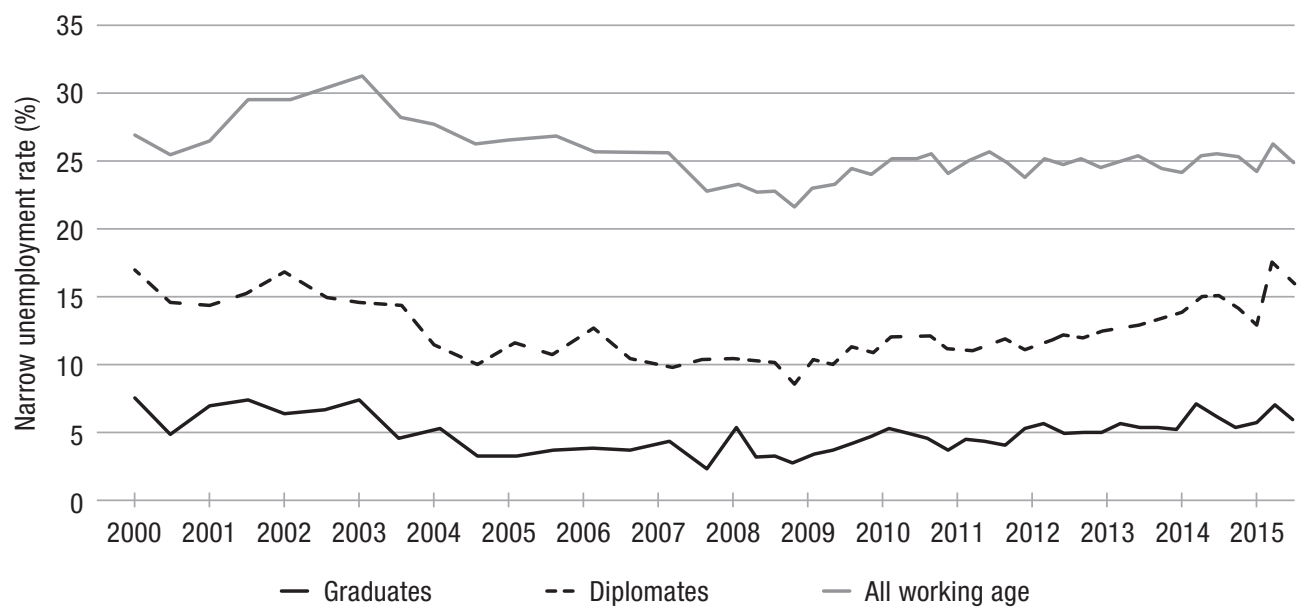

Note: Own estimations using StatsSA's March 2000 LFP - QLFS2015Q4 data. Estimates are weighted and are calcuated only for the working-age population (15-64 year-olds).

24 Measured in terms of the narrow definition, used through this section. For graduates it is noted that broad and narrow unemployment rates are close, given the small numbers of discouraged job seekers (due to low overall unemployment). 
Focusing on more recent graduates, the age cohort analysis in this study is important, although as noted earlier it suffers from small sample sizes. Here the study does note a concerning relative increase in unemployment levels for the cohorts aged 20-39 between 2008 and 2011 - from about 10\% (historical level) to about 15\%. This might be related to the global economic downturn of 2008 and its effect in subsequent years.

Moving to GDS findings, it becomes possible to get some sense of trajectories in employment as opposed to the LFS snapshot. Graduates get asked at some period after graduation about what has happened since then until the present. Thus, analysing the HSRC data, Moleke (2010) found that within one year of graduation, only $84 \%$ of graduates had found work, and looking over the whole two-year period since graduation, that $23 \%$ of their respondents had experienced unemployment at some point. The Baldry (2016) study with a market sample across all institutions found 8.3\% were unemployed and looking for work. The other GDS studies are discussed below, since their findings are pertinent to particular institutions.

\section{Disaggregation by race}

Overall, in terms of race, white graduates, irrespective of the field of study, seem to experience less unemployment (narrowly defined) compared to those from other population groups. Van der Berg and van Broekhuizen (2012) show that the overall labour force participation rates for black graduates are highest; this seems to be because across their life spans there are a fairly large number of white adults who choose not to work due to other financial resources.

Van der Berg and van Broekhuizen (2012) show a peak in black graduate unemployment of $14 \%$ in 2000 , reducing by half to about $7 \%$ by 2011 . The racial gap in graduate unemployment has substantially narrowed, although white graduate unemployment is still lower and has been relatively stable at under $2 \%$ over the whole period, as can be seen in Figure 2 below reproduced from van Broekhuizen (2016).

The findings across the GDS studies confirm the differential between black and white unemployment rates. In terms of descriptive statistics, for example, the CHEC study shows that unemployment was highest among black African graduates $(20 \%)$ compared to coloured $(7.8 \%)$ and white graduates (4\%). In short, there is no study that has not shown this differential in absolute employment rates. Further work has thus sought to look more closely at what this means. Not surprisingly, factors such as social capital and access to workplace networks are closely linked to race (to be discussed below). Another key issue, given South Africa's highly stratified higher education landscape, is to look at how employment rates correlate to institutions (and to field of study). 
Figure 2 Comparison of narrow unemployment rates from the LFS for black and white graduates

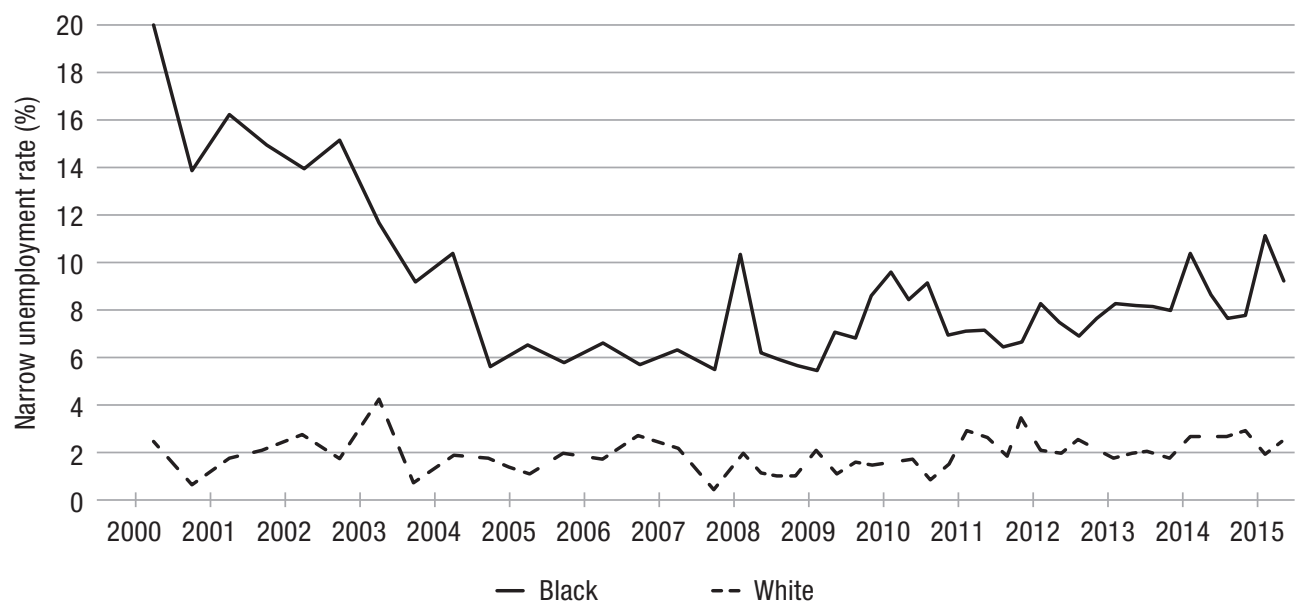

Note: Own estimations using Stats SA's March 2000 LFP - QLFS2015Q4 data. Estimates are weighted and are calcuated only for the working-age population (15-64 year-olds).

Source: Reproduced from van Broekhuizen (2016)

\section{Influence of institution and field of study}

Bhorat et al. (2010), analysing the HSRC data, show that while racially skewed unemployment did seem to track racially skewed institutional profiles (with HBUs having largely black enrolments and poorer employment outcomes compared to HWUs), unemployment rates were also racially skewed within institutions: $42 \%$ for black graduates from HWUs vs. $10 \%$ for whites at HWUs. This is linked to the historical context and is often poorly represented in public discussions over graduate employment.

The CHEC study found an overall unemployment rate of $10 \%$ two years after graduation for these Western Cape graduates, noting though that this differed significantly across institutions - 16\% for Cape Peninsula University of Technology graduates and 14\% for University of the Western Cape graduates compared to 5\% and 6\% for Stellenbosch University and University Cape Town respectively. Rogan and Reynolds (2015), surveying two to three years after graduation, found an unemployment rate of $7 \%$ for Rhodes graduates and 20\% for UFH graduates and understandably do not report an average unemployment rate across the study. Findings from the Walker and Fongwa (2017) study confirm the above mentioned findings as all graduates from the University of the Witwatersrand who wanted to work were employed, while about $50 \%$ of graduates from the University of Venda were still searching for work about one year after graduation.

Van Broekhuizen (2016) presents a new methodology that links LFS data to that in HEMIS. He offers a probabilistic estimate of employment based on race and institution 
attended, based on a statistical linking of characteristics of LFS respondents with individuals in the HEMIS database for given institutional types. This analysis confirms that for black graduates, employment is better for those who have attended an HWU. But contrary to other findings, it suggests that within an HWU, black graduates have better employment probabilities than white graduates.

Regarding field of study, there has long been a concern that Arts and Humanities have poor employment prospects (following the 'mismatch' or 'scarce skills' thesis (see, for example, Balwanz \& Ngcwangu, 2016), and early work by Moleke (2005) seemed to confirm this. While the GDS surveys have been limited in their capacity to explore the influence of field of study due to sample size, none of them have further confirmed this, and in fact the Rogan study explicitly shows that unemployment for humanities graduates is not significantly higher than for other fields of study. The only area with consistently better employment outcomes is education (Bhorat et al., 2010; Cape Higher Education Consortium, 2013; Rogan \& Reynolds, 2015).

\section{Socio-economic background and accessing the workplace}

Baldry's (2016) multivariate analysis showed that only three variables were statistically related to unemployment: race (12.7\% for black African participants compared to $2.5 \%$ for white participants), socio-economic status (26\% unemployment for those who responded that they struggled with money for basics such as food and clothes) and coming from a family in receipt of financial support (for the latter category, 28.5\% graduate unemployment was noted). While educational variables such as institution and field of study were associated with employment outcomes, when considered in conjunction with other variables these were found to be statistically non-significant.

The two recent GDS studies also sought to find out information on job search strategies. CHEC noted that the use of social networks was more prevalent amongst graduates from UCT and SU. Overall, 28\% of white graduates report benefitting from social capital in comparison with only $11 \%$ of black African graduates. The Rogan study found that for RU graduates, the most common strategy was through personal contacts/networks/social media (about 50\%); for UFH graduates, mostly through newspaper advertisements (36\%). Walker and Fongwa (2017) also identified the role of social capital as a critical factor in searching and securing employment before and after graduation.

These studies also compared private and public sector employment. CHEC found that $47 \%$ of all graduates were employed in the public sector - education; health and social work; provincial and municipal government; arts, culture and sport. Here again there were some institutional differences: UWC (64\%), SU (56\%), UCT (42\%), CPUT ( $41 \%)$. The Rogan study found that $73 \%$ of RU graduates are employed in the private sector, while $67 \%$ of UFH graduates are employed in government (public sector). 


\section{Discussion and conclusion}

The issue of graduate unemployment is a key matter for debate in South Africa and thus it is not surprising that research on graduate destinations tends to focus in the first instance on employment, and the literature reviewed in this chapter reflects that. This can also be linked to the government's drive to provide economic opportunities to the previously disadvantaged. Our focus has been especially on Labour Force Survey (LFS) and Graduate Destination Survey (GDS) findings.

A key distinction between the LFS data and the GDS data is that the former focuses on the full labour force, while the latter tend to focus on recent graduates from particular institutions. The LSF age cohort analysis notes that graduate unemployment is higher in younger cohorts and offers a range of reasons for this. Historically for the cohort aged 20-39 this was in the region of $10 \%$ graduate unemployment, nearly double that for the full labour force. Towards 2011 a substantial increase in unemployment towards 15\% was noted for this group. This finding needs to be borne in mind when considering the GDS studies. Here, looking at recent graduates, higher unemployment rates are noted. The recent studies are possibly worthy of more focus since some methodological issues have been ironed out. From these studies the impact of race on unemployment is clear. The CHEC study shows 20\% unemployment amongst black African graduates, the same level as that found in the Rogan study for UFH graduates (mostly black African). Both these studies note the impact of social capital, with white graduates more likely to get jobs through personal contacts, and black graduates through advertisements. The recent Baldry (2016) study takes this further, disaggregating beyond race to show the impact of socio-economic status on employment.

Overall, therefore, in South Africa a young person is generally better off if they manage to get a university degree, with graduates having substantially lower unemployment rates overall than non-graduates. But these studies also show that within graduates, race and socio-economic background (very much still correlated in South Africa) have a substantial differentiating effect: a white graduate with degree in hand having access to other crucial cultural and social capital to get a job is better off than a black graduate with the same degree, but without the additional social capitals coming from family and community background. Across the studies it is also suggested that this impact is far stronger even than field of study and institution, although the latter especially is of course also correlated with race and socio-economic background. Black graduates are more likely to look for work in the public than in the private sector. This is not surprising especially with government initiatives here, and a broader pattern in post-independence sub-Saharan Africa of the anticipated link between graduates and service in the public sector. However, this pattern might become a concern in South Africa as we face an impending constriction in this sector of employment.

Another critique of the current approach to researching graduate employment has been made by Koen (2006) who notes that this research seldom locates the observed 
outcomes within a broader understanding of the economic and political factors that shape opportunities for graduates. Bozalek and Boughey (2012) also characterise this research as 'misframing' the issues in that graduate outcomes are 'depoliticised' when taken out of the broader context.

Others have argued for an expanded conceptualisation of graduate outcomes research that accounts for the human development aspects of higher education within a context of inequality of opportunity and outcome (Fongwa, in press; Walker \& Fongwa, 2017). Specifically, students at historically black universities continue to experience under-resourced and lower quality higher education, which compounds what for many of them are poorer social backgrounds their employment outcomes cannot be analysed without a location within this broader context and its historical legacy.

Patterns of employment in the public and private sector also seem under-explored in GDSs. Graduate outcomes research in South Africa has noted the private sector employer bias towards a limited number of institutions (historically white advantaged universities), and this bias will likely increase with the advance of a globalised economy and global rankings in higher education. This raises further crucial questions for publicly funded higher education in South Africa and its connection to broader societal challenges.

In the South African context, as elsewhere, studies on graduate outcomes have tended to focus mostly on employment patterns, and less on the wider civic purposes of higher education. In this light we might need to reconsider the contents of the GDSs - while surveys are always limited, it might be useful to conceptualise a graduate tracer study that utilises survey items that gauge graduates' attitudes to key societal issues such as racial integration, income inequality, social justice etc. Such a study might draw on existing surveys, for example those that survey US college students' attitudes towards civic involvement (for example, Moely, McFarland, Miron, Mercer, \& Ilustre, 2002), or African-based studies on higher education's contribution to democracy (Mattes \& Luescher-Mamashela, 2012). These surveys measure civic skills, diversity and social skills, attitudes towards democracy and good citizenship.

Such survey questions would capture the broader, societal outcomes of higher education, emphasising higher education's role in promoting democratic citizenship and contributing to the public good. This would broaden the current, narrower focus of the graduate tracer surveys on employability, underpinned by human capital theory. Given the huge investment directed towards higher education by the state, such surveys would give an indication of the extent to which higher education was delivering on the public good aspect of its mission in terms of developing graduates with a commitment to critical citizenship and social justice.

In conclusion, then, it is suggested that much of the current research into graduate outcomes focuses on employment trajectories of graduates and rests on too narrow a conception of the purposes of higher education. While investment in human capital is part of the story, it doesn't tell us enough about the potential impact of higher education on society. There is a need for further graduate survey research into the broader, nonemployment outcomes of higher education. 


\section{References}

Australian Government Department of Education and Training (2018). Graduate outcomes survey. Retrieved from https://www.qilt.edu.au/about-this-site/graduate-employment

Baldry, K. (2016). Graduate unemployment in South Africa: Social inequality reproduced. Journal of Education and Work, 29(7), 788-812.

Balwanz, D., \& Ngcwangu, S. (2016), Seven problems with the 'scarce skills' discourse in South Africa. South African Journal of Higher Education, 30(2), 31-52.

Behle, H., Atfield, G., Elias, P., Gambin, L., Green, A., Hogarth, T., ... Warhurst, C. (2015). Reassessing the employment outcomes of higher education. In J. M. Case \& J. Huisman (Eds.), Researching higher education: International perspectives on theory, policy and practice (pp. 114-131). Oxford: Routledge.

Bhorat, H. (2004). Labour market challenges in the post-apartheid South Africa. South African Journal of Economics, 72(5), 940-977.

Bhorat, H., Mayet, N., \& Visser, M. (2010). Student graduation, labour market destinations and employment earnings. In M. Letseka, M. Cosser, M. Breier, \& M. Visser (Eds.), Student retention and graduate destination: Higher education \& labour market access and success (pp. 97-123). Cape Town: HSRC Press.

Bozalek, V., \& Boughey, C. (2012). (Mis)framing higher education in South Africa. Social Policy \& Administration, 46(6), 688-703.

Branson, N., \& Leibbrandt, M. (2017). Assessing the usability of the Western Cape Graduate Destination Survey for the analysis of labour market outcomes. Labour Market Intelligence Partnership. Retrieved from http://www.Imip.org.za/document/assessing-usability-western-cape-graduate-destination-survey-analysislabour-market

Cape Higher Education Consortium (2013). Pathways from university to work: A Graduate Destination Survey of the 2010 cohort of graduates from the Western Cape universities. Cape Town: Cape Higher Education Consortium.

Department of Education (1997). White paper on higher education. Pretoria: Department of Education, Government of the Republic of South Africa.

du Toit, J., Kraak, A., Favish, J., \& Fletcher, L. (2014). From study to work: Methodological challenges of a graduate destination survey in the Western Cape, South Africa. Assessment \& Evaluation in Higher Education, 39(7), 853-864.

Fongwa, S. (in press). Towards an expanded discourse on graduate outcomes in South Africa? Education as Change.

Koen, C. (2006). An analysis of research on graduate employment in South Africa. In C. Koen, Higher education and work: Setting a new research agenda. Pretoria: Human Sciences Research Council.

Kraak, A. (2010). The collapse of the graduate labour market in South Africa: Evidence from recent studies. Research in Post-Compulsory Education, 15(1), 81-102.

Letseka, M., Cosser, M., Breier, M., \& Visser, M. (2010). Student retention \& graduate destination: Higher education \& labour market access \& success. Cape Town: HSRC Press.

Mattes, R., \& Luescher-Mamashela, T. M. (2012). The roles of higher education in the democratisation of politics in Africa: Reports of HERANA Studies. Journal of Higher Education in Africa, 10(1), 139-170.

Moely, B. E., McFarland, M., Miron, D., Mercer, S., \& llustre, V. (2002). Changes in college students' attitudes and intentions for civic involvement as a function of service-learning experiences. Michigan Journal of Community Service Learning, 9(1), 18-26.

Moleke, P. (2005). Finding work: Employment experiences of South African graduates. Cape Town: HSRC Press.

Moleke, P. (2010). The graduate labour market. In M. Letseka, M. Cosser, M. Breier, \& M. Visser (Eds.), Student retention and graduate destination: Higher education \& labour market access and success (pp. 87-95). Cape Town: HSRC Press.

Montenegro, C. E., \& Patrinos, H. A. (2014). Comparable estimates of returns to schooling around the world. Washington, DC: The World Bank.

Pauw, K., Oosthuizen, M., \& van der Westhuizen, C. (2008). Graduate unemployment in the face of skills shortages: A labour market paradox. South African Journal of Economics, 76(1), 45-57. 
Rogan, M., \& Reynolds, J. (2015). Schooling inequality, higher education and the labour market: Evidence from a graduate tracer study in the Eastern Cape, South Africa. Pretoria: Labour Market Intelligence Partnership (LMIP) Project, HSRC.

Smith, D., LaVelle, K., Lyons, M., \& Silverstone, Y. (2016). The gig experience: Unleashing the potential of your talent and your business: Retrieved from Accenture Strategy website: https://www.accenture. com/us-en/ insight-2016-accenture-college-graduate-employmentresearch

StatsSA (2018). Quarterly Labour Force Survey. Quarterly 1: 2018. Retrieved from http://www.statssa.gov.za/ publications/P0211/P02111stQuarter2018.pdf

van Broekhuizen, H. (2016). Graduate unemployment and higher education institutions in South Africa. Bureau for Economic Research and Stellenbosch Economic Working Paper 08/2016.

van der Berg, S., \& van Broekhuizen, H. (2012). Graduate unemployment in South Africa: A much exaggerated problem. Stellenbosch: Centre for Development and Enterprise, Stellenbosch University.

Walker, M., \& Fongwa, S. (2017). Universities, employability and human development. New York: Springer. 


\section{EXPLORING DIFFERENCES IN SOUTH AFRICAN GRADUATE OUTCOMES}

Samuel Fongwa, Delia Marshall and Jennifer M. Case

\section{Introduction}

Interest in graduate employability tends to centre on the role of graduates in the workplace and the capacity of higher education to prepare them for the labour market (Tomlinson, 2012). Graduate employability has been argued to be a result of a combination of personal qualities, skills of various kinds and subject understanding (Yorke, 2001). These graduate skills are often referred to as 'employable skills', 'graduate attributes' or 'generic skills' (Barrie, 2006; Shivoro, Shalyefu, \& Kadhila, 2018). Moreau and Leathwood (2006) introduce another layer of complexity, relating to the nature of the labour market and related policies. They argue that the transition from university to employment is not a direct function of formal credentials, which are increasingly becoming a less reliable guide to success in the adaptable and changing labour market. Tomlinson (2012), similarly, notes that the massification of higher education may be amplifying class-cultural differences in access to higher education, as well as to economic outcomes in the labour market. For example, as Moreau and Leathwood (2006, p. 308) note, graduate skills are often socially constructed along gendered or racialised lines and most often 'the decision to appoint a candidate is not the result of a purely rational and neutral decision'. In a range of higher education contexts, university status, social class and access to social networks are also seen to be linked to employability outcomes (see, for example, Gonzalez-Roma, Gamboa, \& Peiro 2018; Morrison, 2014; Strathdee, 2011).

In the South African context the situation is not dissimilar. Graduate outcome has been observed to align, inter alia, with field of study, university graduated from, and race (Cape Higher Education Consortium, 2013; Letseka, Cosser, Breier, \& Visser, 2010). This chapter uses empirical evidence from two recent studies to interrogate the intersection between social background and graduate outcome in South Africa. 
Although many graduate outcomes studies focus predominantly on employment, we also argue that assessing graduate outcome within a framework of human development and social justice cannot be limited to employment alone. We need to consider graduate outcomes as encompassing the wider cultural and social benefits of higher education, and higher education's role in contributing to the broader development agenda and in developing critical citizens and public good professionals (Nixon, 2011; Singh, 2014; Walker \& McLean, 2013). Graduate outcomes should go beyond employment outcomes to encompass graduates' attitudes toward social justice, sustainability, diversity and democracy (McCowan, 2012).

\section{Theoretical framework}

In the field of human development, the capability approach (CA) has been widely regarded as an alternative framework for measuring economic growth and development (Nussbaum, 2001; Sen, 1999); see Chapter 8 for a detailed discussion). The CA provides a nuanced approach in measuring well-being based on individual circumstances and can be used to interrogate graduate outcome studies from an individual viewpoint. While approaches such as graduate destination studies and labour market surveys are important in understanding broad trends and making broader policies, they fail to provide an explanatory account of the differences that are found for graduates even from the same university and field of study. The capabilities approach, with its interest in individual people's ability to choose to live their lives in accordance with what they value, offers a rich conceptual framework to examine the impact of higher education on graduate outcomes.

Sen (1999, p. 235) asserts that 'the focus of the capability approach is thus not just on what a person actually ends up doing, but also on what she is in fact able to do, whether or not she chooses to make use of that opportunity'. Ilieva-Trichkova (2014) argues that these are not just abilities one possesses but also the freedoms or opportunities created by a combination of personal abilities and the external environment - political, social and economic. Sen (1999) introduces the term 'conversion factor' to indicate that each individual is differently positioned to convert his/her resources into capabilities. Individuals within the same system, country or region will convert goods and services into achievements differently (Crocker \& Robeyns, 2010). So, in the case of graduates, the ability of a graduate to convert his/her degree into gainful or valued employment depends on a number of factors which can be personal, social or environmental.

Firstly, personal conversion factors describe the personal characteristics or attributes such as physical conditions, gender, intelligence and reading ability, which assist or limit the ways in which a person converts a commodity or service into functionings. In our context, a degree that does not develop employability skills will not have the intended graduate outcome of employment, namely the functioning. Social conversion factors relate to the social structures including, inter alia, social norms, policies, hierarchies, perceptions and constructs which limit an individual from achieving desired or aspired functionings. If employers perceive that 
graduates from particular universities are not employable, then even some very employable graduates from these universities might be deprived of these opportunities. Lastly, environmental conversion factors such as climate and geographical location play a key role in enhancing or limiting graduate outcomes. The location of a university could determine the ultimate degree experience and graduate outcomes, through extracurricular activity or exposure to employment opportunities or social networks that a graduate might develop during her/his studies.

While achieving employment is a key graduate outcome within higher education and government policy, knowing the constraints and enablers related to such an outcome becomes important for any just and socially inclusive policy. Using the core tenets of opportunities and functionings, the notion of conversion factors within the capability approach provides for a more nuanced and expanded understanding of the graduate outcome process. Employment as a functioning, though important, does not become the ultimate normative measure of graduate outcome (Robeyns, 2003).

Within the capability approach, freedoms thus become critical in assessing one's well-being and functionings. This relates to 'the range of options a person [or student/graduate] has in deciding what kind of life to lead' (Dreze \& Sen, 2002, p. 10). Any assessment of graduate outcome needs to account for the effective opportunities linked to individual aspirations from the point of access, experience and employment outcome. Graduate outcome then moves beyond the preferred alternatives one currently enjoys or experiences after graduation to focus on the level of freedom to other alternatives or the freedom to choose (Saito, 2003). Capability freedom requires an evaluation of real educational or graduate advantage which identifies the disadvantages, constraints, marginalisation and exclusions which limit one person or group of persons from aspired functionings or functionings they have reason to value (Walker \& Unterhalter, 2007).

\section{The studies}

Evidence for this chapter was gathered from two different empirical studies both conducted between 2013 and 2015, and both aimed at interrogating graduate experience during university and after graduation. One of us was involved in the first study and two of us in the second study. In this chapter, we focus particularly on graduates' employment outcomes, but in moving beyond a human capital approach, we also look at the development of other, broader outcomes of higher education.

In the first study ${ }^{25}$ (British Council, 2016; Walker \& Fongwa, 2017) 115 final-year students were sampled across four universities (see Table 1 for details of the participants). The first university is the University of the Witwatersrand (WITS) which is a traditional, historically white, research-intensive institution (HWI) in Johannesburg, the economic heartbeat of the country. Second is the University of the Free State (UFS) which is a traditional, historically white institution in Bloemfontein, a secondary city. The third university is the University of

25 This study was funded by the British Council as part of a four country study. 
Venda (UNIVEN) which is a comprehensive, historically black institution (HBI) in the rural town of Thohoyandou in the Limpopo province. The fourth university is also a comprehensive university (though an HWI), now known as the Nelson Mandela University ${ }^{26}$ and located in Port Elizabeth, an urban city in the Eastern Cape Province. Senior students were recruited for interviews from the fields of Economic and Management Science (or Commerce), Law, Humanities, Arts and Natural Sciences, with a few engineering students. About a fifth of these students were also tracked one to two years after graduation to gain better insights into their graduate employment outcomes and some of the factors affecting them. A quantitative dimension involved the sampling of $17 \%$ of final-year students across the four institutions to provide further descriptive dimensions related to broad themes.

In the second study (Case, McKenna, Marshall, \& Mogashana, 2018), 73 young people from three research-intensive universities were sampled: the University of Cape Town (UCT), a traditional, historically white institution (HWI) in Cape Town, the University of the Western Cape (UWC), a traditional, historically black institution (HBI) also in Cape Town, and Rhodes University, a traditional HWI in the small town of Grahamstown. The study focused on students who had commenced higher education some six years ago at one of these three universities, and interviewed graduates, as well as those who had left university before completing their degrees (i.e. non-completers). Most of those who had graduated had entered the workforce at the time of the interview, but some were still studying either undergraduate or postgraduate, sometimes at other universities. The fields of study were in Natural Sciences and Humanities, including Arts (see Table 1 for details of the participants).

Table 1 Details of the participants in both studies

Study 1 Participant details:

\begin{tabular}{|c|c|c|c|c|c|c|c|c|c|c|}
\hline \multirow[t]{2}{*}{ Institution } & \multicolumn{4}{|c|}{ Race } & \multicolumn{2}{|c|}{ Gender } & \multicolumn{3}{|c|}{ Degree course } & \multirow[t]{2}{*}{ Tota } \\
\hline & 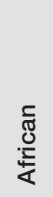 & 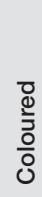 & 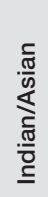 & $\stackrel{\frac{t}{2}}{\frac{4}{3}}$ & $\frac{0}{\frac{0}{\sigma}}$ & & 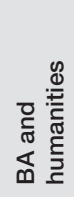 & 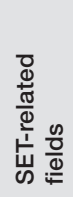 & 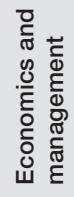 & \\
\hline NMU & 14 & 3 & 0 & 8 & 12 & 13 & 5 & 14 & 6 & 25 \\
\hline UFS & 26 & 0 & 0 & 2 & 15 & 13 & 10 & 11 & 7 & 28 \\
\hline WITS & 9 & 1 & 2 & 4 & 5 & 11 & 5 & 10 & 1 & 16 \\
\hline UNIVEN & 46 & 0 & 0 & 0 & 16 & 30 & 9 & 25 & 12 & 46 \\
\hline
\end{tabular}

26 NMU has recently changed its name from Nelson Mandela Metropolitan University which was the name when the study was taking place in 2013-2015. 
Study 2 Participant details:

\begin{tabular}{|c|c|c|c|c|c|c|c|c|c|}
\hline \multirow[t]{2}{*}{ Institution } & \multicolumn{4}{|c|}{ Race } & \multicolumn{2}{|c|}{ Gender } & \multicolumn{2}{|c|}{ Degree course } & \multirow[t]{2}{*}{ Total } \\
\hline & 宽 & 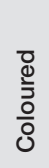 & 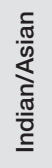 & 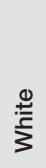 & $\frac{\frac{0}{\pi}}{\sum}$ & 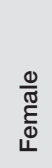 & ৫ & 兽 & \\
\hline Rhodes & 14 & 2 & 1 & 15 & 6 & 26 & 20 & 12 & 32 \\
\hline UCT & 10 & 11 & 1 & 13 & 9 & 26 & 15 & 20 & 35 \\
\hline UWC & 2 & 4 & 0 & 0 & 4 & 2 & 3 & 3 & 6 \\
\hline
\end{tabular}

Both studies used interviews to explore not only student experiences but also their aspirations, choices, perceptions of their graduate employment prospects and outcomes. Both studies provided opportunities for students to reflect on their university experiences, as well as graduate outcomes and factors affecting their outcomes.

Crucially, the research designs are centred on different comparisons. Study 1 deliberately chose four quite different institutions, one HWI with a strong research profile, one HWI with less of a research profile, one comprehensive HWI, and one comprehensive, rural HBI. Study 2 includes three institutions which are traditional universities, two HWIs and one HBI. These three institutions have significant institutional differences around history, size, geographical location and connections to the workplace.

The focus of Study 1 was on the employability perceptions of the graduates, based on what the university is doing through curriculum and pedagogy, while Study 2 was more interested on the formative BA and BSc degrees, and where relevant it draws distinctions between these different curricula. In both studies data was collected mainly through structured interviews and analysed thematically. In this chapter we bring these two studies in conversation with each other, looking for overlapping themes, and looking for similarities and differences within the findings. While Study 1 focused only on graduates one year after graduation, Study 2 also included students who had not completed their studies for one reason or another. Of key importance in this chapter is to note the points where these studies, coming from different empirical sites and with different theoretical orientations, converge on similar findings.

\section{Influences on employment outcomes}

As noted earlier, the graduate outcomes of students, from a capabilities approach perspective, relate directly and indirectly to the level of freedoms each graduate has experienced throughout their trajectory in getting into, getting through, and getting out of higher 
education. Both studies look at these full trajectories, but for the scope of this chapter we focus on their findings at the post-graduation stage of the trajectory.

From thematic analysis of data from student interviews, a number of factors emerged across both studies as strong determinants of entry to work. Interestingly, these factors had little to do with personal conversion factors (related to the qualities of the individual), but rather with social and environmental factors, most of which the students could not influence. These included the status of the university, the need for practical training and career guidance, field of study, family background or social capital, the geographical location of home and the university, and opportunities regarding public/private sector employment.

\section{Status and reputation of university}

Evidence from Study 1 suggests that the institution from which a degree was obtained was strongly related to employment outcomes - with all students from WITS in this sample having found work, while less than half of those from UNIVEN had (admittedly these were small sub-samples). A student from UNIVEN reflects as follows:

I don't think there's an advantage of being a graduate of UNIVEN.
Unlike most universities, the name itself, despite your grades, will speak
on your behalf to people who are going to employ you. If I did my degree
at WITS, obviously you are going to have a better advantage than a
person who has done a degree here. (Study 1, black female UNIVEN
BSc student)

From UNIVEN and UFS there were students who had resorted to postgraduate studies because they couldn't find work. Students also articulated the perception that the status of their university would affect their employment prospects, as noted by the UNIVEN student in the quote above.

In Study 1, there was a strong perception, supported by some feedback from employers, that employers in the private sector do prefer to employ from historically white institutions (HWIs) before considering candidates from the historically black institutions (HBIs). While such policies are sometimes indirectly influenced by the agreements or partnerships with departments, faculties or areas of specialisation in these universities, these practices continue to discriminate against students who, though academically qualified, are not able to access these universities.

It appears from these studies that graduates from $\mathrm{HBI}$ are therefore limited by institutional reputation in accessing the workplace, and this is further exacerbated for HBIs in rural areas, where graduates have less exposure to practical experience, internships and contact with employers. 


\section{Access to urban networks of employment and social capital}

... class, geographic background and race have huge, huge implications. If you are from a poorer background and black, you are unlikely to have the [right] contacts. It's ten times easier if you are white and advantaged - you are set from the get go regardless of what you are studying. (Study 1 , black female WITS BA student)

As noted by a black student from Study 1 in the quote above, the influence of family was felt to extend into employment prospects, with students from wealthier families having more contacts into the workplace. Study 2 also noted the significance of social networks in accessing the workplace, and in both studies, internships offered by the private sector were seen to play a significant role in this regard. In Study 1, most students from middle class backgrounds felt that they were well positioned to take up internship opportunities which they had access to, based on their social capital. This was the first job they obtained, often explicitly short term and relatively poorly paid. From students' accounts in Study 2, it seemed that the internship often functioned as a sort of extended interview in that a few months into the internship, the employee would be offered a better and more stable job. However, the internship model assumes that the graduate has access to other family or financial resources to survive on an intern salary. This increasing reliance on internships as a bridge between studies and the workplace raises equity questions in the South African context, where many graduates need to be earning money to support their families.

In both studies, geographical location played a key role in accessing the workplace, with most students finding work in the large cities. Study 1 noted that rural universities with limited industrial or commercial bases will be unable to provide their students with the same access to internships and practical experience as urban universities in close proximity to industry and business. This obviously has implications for employment outcomes once students graduate.

In Study 2, it was noted that participants who struggled to find work initially, or were unemployed for a period, were all students from small towns or rural villages. From a capabilities perspective, geographical location functions as an 'environmental conversion factor', enabling urban students to more successfully convert their degrees into employment opportunities than rurally based students. While the low status of the HBU was perceived by some to possibly be a better preparation for rural jobs, including small-scale entrepreneurship, there is not adequate support for such initiatives.

The role of social capital, then, emerged as a crucial constraining or enhancing factor in determining graduate outcome. Students from rural areas, or working class backgrounds, with little or no social capital from family and friends struggled to secure internship opportunities and subsequent employment after graduation, compared to their counterparts, mostly white and middle class who had families and friends in positions to enhance their graduate outcomes. 


\title{
Field of study and relevant experiences to access employment options
}

\begin{abstract}
They say that the problem with having a $B A$ is that you are not going to get a job, but actually the problem is that it opens up so many job opportunities that you actually just don't know which ones to choose. ... There are too many choices, you can go into journalism, into media, you can go into so many different industries and fields and you can find a job where you learn a new skill on the job as well. (Study 2, white male UCT BA Honours student)
\end{abstract}

This comment from a BA student in Study 2 runs counter to the popular perception that BA graduates struggle more than other graduates, such as BSc graduates, to get jobs. In terms of field of study, Study 1 found a perception that graduates from science, technology, engineering and mathematics (STEM) fields have better employment prospects, and that humanities degrees make one less employable, even though there was an acknowledgement of their being intrinsically valuable. However, Study 2 found a less clear pattern in this regard, with nearly all of the arts graduates in graduate-level work, even if not directly in the field of their major. Although several arts graduates in Study 2 felt that the degree had given them multiple employment options (as expressed in the quote above), it is likely that it was perhaps also the reputation of the particular universities from which they obtained their BA degree, and their stronger social capital, that opened employment options for them. This was also observed in Study 1, where BA graduates with stronger social ties could get employment, though not in their area of study. While graduates from STEM-related fields generally enjoy better employment prospects across both studies, Study 2 observed that the employment prospects of geology students were the most affected by labour market vagaries: the expectation that the BSc degree would lead to a good job in industry had been scuppered by the downturn in the mining sector.

The role of practical experience in enhancing job prospects was highlighted in Study 1, where students from all the universities in the study felt the need for more practical experience in the curriculum, through more practical work, internships or work integrated learning, in order to be more prepared for the workplace. Although students felt that their academic programmes were theoretically rigorous, they would have welcomed more opportunities to apply theory at practical level. They viewed this as a particularly important way of gaining work experience which, they felt, would open access to the workplace. This was seen as particularly pertinent for students from poorer backgrounds who lack the social capital to find vacation jobs or internships. Participants in Study 2 didn't talk explicitly about needing more practical skills in order to secure a job. It may be the case that some students see practical experience as a prerequisite for securing a job after graduation, whereas in fact it may be more the case that students at higher status, urban universities can rely more on institutional reputation and social networks, which act as social 'conversion factors' (Sen, 1999) in accessing employment. Students in this study mentioned the role of 
institutional career fairs and student organisations in helping them access the networks that could help them find employment.

Most students in Study 1, especially from HBUs and the humanities did not feel that their bachelors degree was going to be sufficient preparation for the workplace and felt that they were going to have to do postgraduate studies at least to the honours level. Study 2 followed trajectories post-bachelors graduation. Many of the young people interviewed had completed postgraduate studies at least until honours level. For the majority there was a clear narrative of how this fitted into their developing interests. In this study there was a minority for whom this seemed the only option due to difficulties in finding work.

Overall, then, these two studies show that field of study was seen as a less significant factor for employment than other conversion factors, such as university type and social connections.

\section{Work aspirations in relation to public-private sector employment}

Study 1 found that there were differences in students' work aspirations in relation to publicprivate sector employment. White graduates were more interested in being self-employed, or working in the private sector or academia compared to black graduates, who intended to seek work in the public sector. In Study 2, by contrast, very few graduates took up public sector jobs. This was not unexpected: national graduate destination studies show that most of the students from traditional HWIs (the focus in Study 2) head to the private sector. This preference for the public sector is shown in Study 1 to be linked to perceptions of job security, and to the social and economic capital often needed to access private sector jobs. However, there are indications that public sector employment is shrinking, and Study 1 notes that this may force universities to increase their focus on developing graduates' employability.

Furthermore, within both the public and private sectors, there have been a number of government policies within the labour market to give preference to graduates from previously disadvantaged groups. While such policies aim to address historic inequalities of the past, graduates in Study 1 increasingly feel that such policies constrain their abilities to gain employment in some sectors of the economy and hence their capacity to aspire to be and do what they value. These aspirations, even for white graduates, include their desire to use their engineering skills to work in the public sector. This concern about employment policies did not emerge in the interviews in Study 2, maybe not surprisingly, given that this study focused predominantly on traditional HWIs, where research has shown graduates have better employment prospects (Bhorat, Mayet, \& Visser, 2010).

In summary, both these studies show that obtaining a university degree is not fully determinant of job opportunities: the ease to which a degree led to job opportunities was significantly mediated by the graduate's urban/rural location, the type of institution attended and access to social networks. From a capabilities perspective, students were differently positioned in terms of being able to convert their university qualification to capabilities and functionings, and this led to varied graduate outcomes. 


\section{Graduate outcomes beyond employment outcomes}

I think it has definitely opened my mind to many things in terms of worldviews.... it helped me aspire for more and [also] to want to question things more, and not just be happy with the status quo. It has helped me form relationships and not only on a cultural level, but on more levels than that. It helped me develop a sense of 'who am I'and developed me academically and holistically... (Study 2, black male Rhodes MSc student)

This comment above from a student in Study 2 reveals some of the wider outcomes of higher education beyond employment prospects. In this section, we look at what the two studies reveal about these wider outcomes of higher education. As noted in the introduction, while graduate outcomes research is often focused mainly on employment, there is an emerging literature that signals the importance of contributions to the public good. In this framing we need to examine to what extent graduates identify with social justice and democratic commitments, and whether they hold the dispositions to make an impact in this regard. A simple comparison of the findings from the two studies is not straightforward, since their research foci were different. Study 1's focus was mainly on employability, whereas Study 2 was framed more broadly to encompass how university had influenced young people's life paths, both in terms of employment but also more broadly. Nevertheless, we can point to some interesting findings.

Both studies asked young people what they saw as the value of their degree. In Study 1, the students' focus was mostly on the employment outcome of university study, with little emphasis on wider development values. Only about $10 \%$ of the students surveyed rated the development of social citizenship as an important attribute. However, Study 1 found that - besides employment prospects - what students also valued from their degree was the ability to do hard work and to work with people, especially in culturally diverse contexts.

In Study 2, participants spoke more spontaneously about the intrinsic value of higher education. This may be because Study 2 was conducted several years later in the students' trajectory, when almost all the students had secured jobs, which perhaps enabled students to reflect more fully on the wider purposes of higher education.

The broad, intrinsic benefits of education for leading a flourishing life with a love of intellectual pursuits was particularly evident in Study 2, with many participants in this study expressing how they valued the exposure to the broad fields of knowledge at university - 'Ideas that you don't come across in a small town' (Study 2, white female Rhodes student, BA). They spoke about how this made them want to learn more; they had an even deeper sense of how much was 'out there'. Contrary then to a dominant discourse that sees higher education in fairly instrumental terms, Study 2 shows much evidence that many graduates from higher education have intrinsic and passionate motivations for academic endeavours, and that this is something they take with them after completing their studies. 
Besides the intrinsic value of higher education, students in both studies spoke about higher education fostering capacities that led to a sense of purpose in the world. In Study 1, students spoke of developing their self-confidence and a capacity for 'hard work'. In Study 2, capacities developed included becoming more independent and responsible, developing resilience and the confidence to move into the workplace or further study.

Students in Study 2 talked about how higher education had fostered their personal growth, developed a more analytical way of thinking, exposed them to greater diversity, and developed a more critical consciousness about society and social justice.

University ... it shapes your thinking. You really grow up a lot and I mean not like just like generally grow up, but university teaches you how to critically assess pretty much everything, and it makes you curious, it makes you sceptical ... (Study 2, black male UCT BSc student)

The students showed some evidence of the development of a social consciousness and nascent activism. Some of them talked about an idealism cultivated at university for doing worthwhile work and 'saving the world', and how this idealism sometimes is in tension with workplace expectations. This graduate in the advertising industry describes such tension:

What I studied was politics and journalism and obviously its ... very critical of the socio-economic sphere; ... So I find it's quite difficult [now working in advertising], ... to switch that off in your mind, to stop being so critical of what you are looking at all the time. I mean, I write copy for an oil company! (Study 2, white female Rhodes BA student)

These young people expressed dissatisfaction with inequality in society and clearly articulated the need for shifts in structural constraints. Graduates with these dispositions, termed by Walker and colleagues 'public good professionals' (Walker \& McLean, 2013), are going to be crucial in addressing the radical inequities in South African society, and in strengthening democratic culture (Mattes \& Luescher-Mamashela, 2012).

In both studies, there was some evidence around what students saw as the particular benefit of the institution they had attended. In Study 1, students at UNIVEN felt there was a genuine commitment to Ubuntu, ${ }^{27}$ and some also said they appreciated the strict 'morality code' on students' behaviour. These students also exhibited a stronger sense of wanting to 'give back' to their families and communities. This institution was also characterised by a fairly homogenous student population. In Study 2, Rhodes University stood out from the other two universities in the study in terms of students' perceptions of the institution facilitating a strong critical

27 'Ubuntu is an African philosophy on how human beings are intertwined in a world of ethical relations from the moment they are born ... We are born into a language, a kinship group, a tribe, a nation, and a family. ... We are mutually obligated to support each other on our respective paths to becoming unique and singular persons' (Cornell \& van Marle, 2015, p. 2). 
consciousness and awareness of social justice. Unlike the UNIVEN case, this way of thinking was not perceived to be based on a strict moral code; in fact students experienced considerable personal freedoms at this institution.

In terms of a capability approach, the two studies reveal how the different lived experiences of students at university provide them with different opportunities to develop various capabilities. So, students at a culturally homogenous, rural university may develop a greater sense of Ubuntu than the more individualistic attitudes of urban students, but they will not have the opportunities for exposure to diversity and working with peers across cultural differences. In Study 2, the three institutions were all culturally diverse, and this exposure to greater diversity of peers featured prominently in participants' reflections on the value of higher education. Similarly, Study 1 points to the value of exposure to diversity, and students developing what is referred to as 'diversity capital', which can be later converted into social capital when students enter the workplace or take on wider roles in society (British Council, 2016; Walker \& Fongwa, 2017). This student from Study 1 reflects on this as follows:
In the classroom, especially when we have to do things like group work ... then it exposes you to a person's life. You [tend to realise], this person is not that bad. Maybe I thought white people are like this, but this guy is different. So weve learned to appreciate other people. (Study 1, black female UFS BA student)

The studies also reveal how the structural arrangements of universities may serve to enable or hinder students' broader development. Study 2 found a wide variation among the three universities in how undergraduate programmes were structured, and that greater curriculum flexibility allowed students to explore disciplines for their intrinsic interest, and to find their academic strengths and passions. What is interesting in considering variations in programme structure is the implicit assumptions these differences reveal about different ideas on the purposes of higher education: a narrowly specified programme leading to a specific employment option implies a more instrumental, 'employability' perspective on higher education, whereas a more flexible programme seems to imply a greater focus on the intrinsic, personal developmental purposes of higher education. A student from Study 1 reflects on the lack of such opportunities in developing the social and moral dimensions of students from a university perspective as follows:

They [departments] are lacking in being involved in communities. So I think the University looks at people who are going to have more impact on the economic side but on the social front I think that is where we lack... In our course we are supposed to do a community-based project, and we did do it but now we didn't actually go to the local communities... We are lacking in making graduates socially aware of what is happening, especially in the local community. (Study 1, black male WITS BSc student) 
In summary, this section, which has touched on graduate outcomes beyond employment outcomes, has shown how structural arrangements of universities may act as a form of 'conversion factor', allowing some students greater exposure to diversity and cultural difference, as well as to develop their intrinsic interests and to support their study and career deliberations.

\section{Discussion and conclusion}

A key finding from Study 1 is that the graduate employment outcome is a product of complex factors and dynamics much beyond the quality of the degree, field of study and even the core skills acquired during the degree process. While the actual skills/attributes of the degree are important in terms of employment, with most students and staff subscribing to a human capital theory thinking, other aspects influence graduate employment outcomes. These include students' social capital, as well as the reputation of the university. The study also points to the impact of the externalities of the form of the labour market policies and practices. These factors, we argue, constrain or enhance the racial disparities in graduate destinations noted in the literature (Moleke, 2005). It therefore becomes vital to engage with a nuanced understanding of graduates, universities and the context of employment in understanding the apparent 'skills gap' dynamics.

As noted earlier, Study 2 surveyed students who had attended more high-status universities than some of those in Study 1, and their findings need to be interpreted in this light. Thus, overall, the graduates (and even non-completers) in Study 2 tend to have on average better employment outcomes (nearly all interviewees were either studying or employed six years after first year). All the same, similar trends explaining racial disparities in graduate outcomes are evident in this study, with more detail in this study on the actual trajectories into the workplace, since those interviewed had mostly been through this process. The findings of Study 2 also point to the significance of the social capital in the family in terms of accessing and succeeding in higher education. In terms of obtaining employment, university reputation was noted but was less prominent than in Study 1, possibly due to the institutions surveyed.

Using the notion of conversion factors, we argue that a student or graduate's capacity to convert resources such as university experience or a degree to functionings such as getting a job one has reason to value, is not only a function of the quality of the degree, but also depends on personal, social and environmental factors which can either be enhancing or constraining.

Bringing together the findings from the two studies, for the majority of students, graduate employability in South Africa is significantly linked to a number of factors: student background, personal attributes and student social capital and networks before, during and after university significantly determines graduate outcomes. We further argue that graduate outcome is more complex and demands looking beyond factors such as field of study, university graduated from, or even race. While students graduate from high school with admirable aspirations of becoming engineers, medical doctors or accountants, the reality is that the percentage of students whose aspirations are translated into actual socio-economic mobility is closely linked 
to social background and other capitals they can bring along to, or develop at, university. In particular, students from historically disadvantaged backgrounds, or dysfunctional secondary and high schools lack a huge amount of academic, social and personal capital which intersect in defining their university outcome. With most students not managing to enrol in their desired courses or universities, those who manage to access universities do sometimes find themselves studying in fields such as arts and humanities, which are often perceived as having lower employment rates (the national evidence for this perception is mixed - see Chapter 17 for a fuller discussion of this point). Furthermore, many of the students who do complete their studies do not have the social capital and networks to enhance their employment outcomes (Cape Higher Education Consortium, 2013; Walker \& Fongwa, 2017). The findings from both studies indicate that social capital from family and friends significantly influences graduate outcome, even when a student graduates with a degree perceived largely as less marketable. This echoes earlier studies (Shumba \& Naong, 2012) which show that family members are the most influential groups in enhancing student aspirations before and during their studies. Translating these aspirations to reality depends also on the type and level of support that students gain.

While we, in the main, do concur with earlier research globally and in South Africa that higher education enhances graduate employment outcomes, we suggest a more nuanced and human approach in assessing graduate outcome. We have shown from the evidence that the human capability approach provides one such nuanced approach. We have seen that, while there is a broader narrative of the key factors affecting graduate outcomes, these trends are entrenched by historical, personal, or social factors. The presence of these conversion factors or lack thereof will continue to silently and sometimes unwittingly influence graduate outcome within the South African context, hampering efforts towards social justice and redress.

\section{References}

Barrie, S. (2006). Understanding what we mean by generic attributes of graduates. Higher Education, 51(2), 215-241.

Bhorat, H., Mayet, N., \& Visser, M. (2010). Student graduation, labour market destinations and employment earnings. In M. Letseka, M. Cosser, M. Breier, \& M. Visser (Eds.), Student retention and graduate destination: Higher education \& labour market access and success (pp. 97-123). Cape Town: HSRC Press.

British Council (2016). Universities, employability and inclusive development: Repositioning higher education in Ghana, Kenya, Nigeria and South Africa. London: British Council.

Cape Higher Education Consortium (2013). Pathways from university to work: A Graduate Destination Survey of the 2010 cohort of graduates from the Western Cape universities. Cape Town: Cape Higher Education Consortium.

Case, J. M., McKenna, S., Marshall, D., \& Mogashana, D. (2018). Going to university: The influence of higher education on the lives of young South Africans. Cape Town: African Minds.

Cornell, D., \& van Marle, K. (2015). Ubuntu feminism: Tentative reflections. Verbum et Ecclesia, 36(2), 1-8.

Crocker, D. A., \& Robeyns, I. (2010). Capability and agency. Cambridge: Cambridge University Press.

Dreze, J., \& Sen, A. K. (2002). India: Development and participation. Oxford: Oxford University Press. 
Gonzalez-Roma, V., Gamboa, J. P., \& Peiro, J. M. (2018). University graduates' employability, employment status and job quality. Journal of Career Development, 45(2), 132-149.

llieva-Trichkova, P. (2014). A capability perspective on employability of higher education graduates in Bulgaria. Social Work \& Society, 12(2).

Letseka, M., Cosser, M., Breier, M., \& Visser, M. (2010). Student retention \& graduate destination: Higher education \& labour market access \& success. Cape Town: HSRC Press.

Mattes, R., \& Luescher-Mamashela, T. (2012). The roles of higher education in the democratization of politics in Africa: Survey reports from HERANA.

Morrison, A. (2014). A class act? Lecturers' views on undergraduates' employability. British Journal of Sociology of Education, 35(4), 487-505.

McCowan, T. (2012). Opening spaces for citizenship in higher education: Three initiatives in English universities. Studies in Higher Education, 37(1), 51-67.

Moleke, P. (2005). Finding work: Employment experiences of South African graduates. Cape Town: HSRC Press.

Moreau, M. P., \& Leathwood, C. (2006). Graduates' employment and the discourse of employability: A critical analysis. Journal of Education and Work, 19(4), 305-324.

Nixon, J. (2011). Higher education and the public good. London: Continuum.

Nussbaum, M. C. (2001). Women and human development: The capabilities approach (vol. 3). Cambridge: Cambridge University Press.

Robeyns, I. (2003). Is Nancy Fraser's critique of theories of distributive justice justified? Constellations, 10(4), 538-554.

Saito, M. (2003). Amartya Sen's capability approach to education: A critical exploration. Journal of Philosophy of Education, 37(1), 17-33.

Sen, A. K. (1999). Development as freedom. Oxford: Oxford University Press.

Shivoro, R., Shalyefu, R., \& Kadhila, N. (2018). Perspectives on graduate employability attributes for management science students. South African Journal of Higher Education, 32(1), 216-232.

Shumba, A., \& Naong, M. (2012). Factors influencing students' career choice and aspirations in South Africa. Journal of Social Sciences, 33(2), 169-178.

Singh, M. (2014). Higher education and the public good: Precarious potential? Acta Academica, 46(1), 98-118.

Strathdee, R. (2011). Educational reform, inequality and the structure of higher education in New Zealand. Journal of Education and Work, 21(5), 27-49.

Tomlinson, M. (2012). Graduate employability: A review of conceptual and empirical themes. Higher Education Policy, 25, 407-431.

Walker, M., \& Fongwa, S. (2017). Universities, employability and human development. New York: Springer.

Walker, M., \& McLean, M. (2013). Professional education, capabilities and the public good: The role of universities in promoting human development. London: Routledge.

Walker, M., \& Unterhalter, E. (2007). Amartya Sen's capability approach and social justice in education. London: Palgrave Macmillan.

Yorke, M. (2001). Employability in the first cycle higher education. A 'Skills plus' Project Working Paper. Liverpool: Liverpool John Moores University. 


\title{
DESTINATION AND OUTCOME TRENDS FOR GRADUATES FROM SUB-SAHARAN AFRICAN COUNTRIES: IMPLICATIONS FOR SOUTH AFRICA
}

\author{
Ibrahim Oanda and Siphelo Ngcwangu
}

\section{Introduction and context}

Higher education institutions in Africa have come under scrutiny in the last decade regarding the quality of their programmes and the capacity to equip graduates with skills required in the labour market. The demands on higher education systems have become intense as the institutions have grown in numbers and enrolments and diversified their curricula. Repeated calls to institutions are that they should produce graduates who are work ready or who can contribute to income-generating activities which can then develop into medium and large size enterprises.

While such data are available in the developed countries, and more increasingly in the developing countries of Asia (the ASEAN region), there is a dearth of such data in Africa. Ironically Africa is the region most deserving of such data tracking, given the emerging diverse narratives about its higher education system. There, however, does seem to be excitement, as seen from published literature and policy discourses, associated with the positive press that higher education in Africa is receiving from development partners, especially the World Bank, whose policy position led to a long period of underfunding in the 1990s. More recent optimism has been created by the inclusion of higher education as part of the post-2015 SDGs (Sustainable Development Goals Center for Africa, 2017). This change of attitude, it is argued, will spur more investments into the higher education system from national governments and international development partners, resulting in better accountability systems on the part of institutions, including better systems for collecting and reporting data on student learning outcomes. 
Two contradictory narratives exist side-by-side regarding higher education, graduate employability and outcomes in Africa. The first narrative concerns the twin crisis of a shortage of jobs and a shortage of skills in most countries due to various dysfunctions within the higher education system, as well as structural economic factors. The second is that an increasing supply of graduates has not resolved the problem of unfilled jobs in the public and private sector (see for example, Republic of Kenya, 2013). These assertions are however compounded by another reality; they are not based on any empirical data. This deficiency makes it difficult to even begin to identify which skills are better enablers of graduate employability, institutional practices that are most promising in training employable graduates, what graduates do after graduation and the academic programmes that offer faster transition to labour markets.

Graduate unemployment is however not experienced with the same intensity throughout sub-Saharan African countries. There are regional, national and institutional level differences which, if explored, would lead to a construction of what contribution higher education in Africa is making to stem or accentuate trends in graduate employability. An attempt by the African Union Commission (AUC) to centralise the collection and management of data, including crucial higher education-related statistics as part of its higher education strategy, has not worked. But there are regional and national level efforts that have produced data that if synthesized can enable initial comparisons on how higher education throughout the continent is functioning.

This chapter reflects on trends in graduate outcomes and destinations in a number of subSaharan African countries. Data and information for the chapter have been derived from a systematic review of existing literature, mostly of a historical nature. The overall objective is to contribute to a comparable understanding of the connections between higher education and postgraduation student trajectories in Africa and deepen understanding of the working of higher education institutions and graduate labour markets. Globally, the marketisation of higher education has witnessed various aspects of the system subjected to metrics intended to measure the level of value derived from outputs to the system and the fit of outcomes to various economic imperatives.

\section{Conceptual and methodological note}

This chapter is based on a comparative survey and analysis of secondary data from a number of sub-Saharan African countries. In our conclusion, we consider the implications for South African higher education and graduate outcomes for South African students, which have also been discussed in Chapters 17 and 18 of this book. The sub-Saharan African countries we focus on are those whose higher education systems were founded on almost a similar logic to that of South Africa. Universities in these countries were established towards the end of the colonial period. The institutions were elitist and focused on the needs of the colonial economy. The surge in the expansion of the institutions increased after about two decades of independence as the economy changed in response to 
indigenisation policies. South Africa seems to be undergoing the same experiences, with policies for more indigenisation of the economy and broadening access for black students to universities characterising higher education and the employability debate. The difference is that compared to other sub-Saharan African countries, South Africa has a better funded and developed higher education system. The other countries did not have this advantage even after two decades of independence, and expansion and access have required the establishment of physical infrastructure from scratch. Methodologically, our comparative approach will have some constraints related to the availability of data and the extent to which such data would provide a useful basis for drawing conclusions. In many respects there are significantly different higher education contexts within Africa, especially in terms of the overall size of the system, participation and completion rates and general perceptions about the quality of the higher education system. However, concerns that the higher education system does not fulfill various expectations from society seem to be uniform throughout the continent. Such uniform concerns provide sufficient justification for a comparative synthesis of available secondary data.

The overall aim in this chapter is to contribute to the debates going on in different contexts in Africa regarding the contribution of higher education institutions to graduate outcomes. The scope of the chapter will therefore be limited to providing arguments and analysis based on secondary data in order to develop conceptual frames to guide further studies in the area. North Africa and South Africa in this respect tend to have near up-to date data and related studies that give a sense of the operations of the higher education system, graduate destinations and outcomes. South Africa for example has bodies such as the Council on Higher Education (CHE) that monitor and report on the state of the higher education system, including assessing whether, how, to what extent and with what consequences the vision, policy goals and objectives for higher education are being realised.

North Africa is similar to the rest of sub-Saharan Africa in terms of offering higher education focused on producing skills for the public sector, with the state being the employer of first and last resort. Another similarity is the provision of free higher education, based on the notion that poor people should have access to higher education as a means of escaping poverty (Devarajan, 2016). An ongoing intervention by the World Bank is contributing to the adoption of benchmarking practices to identify strengths and weaknesses at individual institutions; trends at the national level, and by type of institution; and is generating interest to initiate reforms at institutional, national and regional levels. Studies and data documenting ways in which universities are seeking to find meaningful ways to compare themselves with other institutions around the world, including graduate destinations and outcomes provide a useful basis for comparison across the continent (World Bank, 2012).

The rest of sub-Saharan Africa provides a mixed picture that unfortunately tends towards unlikely availability of quality data. The AUC initiative to develop a centralised system known as EMIS (Education Management Information System) for the whole of the continent has so far not yielded positive results. By 2012, 30 of 46 countries had provided 
less than $30 \%$ of the internationally required data; with data related to higher education, quality management and TVET the least reported at less than $40 \%$ of the required data (African Union Commission, 2014). The AUC, though, under the initiative continues with efforts to focus on collection of data at national levels and transmit the same through regional economic communities to help create African-based continental databases. Much effort is also being expended in creating regional EMIS capacity to enhance policy, resource allocation, statistical processes and staff development. The outcome has been that regional higher education councils, such as the Inter-University Council of East Africa (IUCEA), have partnered with the private sector to undertake studies on various aspects of the higher education sector related to graduate outcomes.

\section{The sub-Saharan African context}

Higher education institutions in most of sub-Saharan Africa were established during late colonialism in order to train the workforce for the public sector. The most interesting aspect during the initial period revolved around whether to establish universities focused on vocational and technical skills to serve the entrepreneurial and capitalist needs of the colonial economy or those focused on elite professions (see, for example, discussions by Lilford, 2012). In the case of East Africa, Makerere University College, established in 1892 as a technical college, developed into a liberal art leaning institution due to pressure for such an education from the emerging African elite. The Royal Technical College (later University of Nairobi) was established with an initial focus on the colonial needs of settler agriculture (Mngomezulu, 2012). Higher education continued to expand, based on the logic of the 'human capital approach' until well into the 1990s, when circumstances forced countries and institutions to slowly begin questioning this model. The focus on developing skills in the university sector is therefore a recent development that has arisen as a response to increasing rates of graduate unemployment. The focus of universities is perceived to be the training of skilled professionals. The preparation of vocational workers was left to a well-developed middle tier of tertiary colleges that offered vocational skills and trades at different levels.

Interest in graduate destinations and learning outcomes is associated with the outcomes of the structural adjustment period, which led to a subsequent downsizing of the public sector, which had been a significant employer of university graduates. A study by Hughes (1987) pointed to the dilemma that most African countries were then facing: the pressure to continue expanding higher education institutions within the logic of the 'workforce development approach' with a contracting public sector. The study noted that in most sub-Saharan African countries, the increasing supply of highly educated graduates had exceeded the demand for university level jobs available in the economy, making graduates face a highly competitive labour market. In the case of Kenya, the study shows that the then only university, the University of Nairobi, had expanded its enrolment in excess of $15 \%$ while private sector employment only grew at $2.5 \%$ annually. The result was that the employment prospects of the 
1983 cohort of graduates differed significantly from the 1970, 1975 and 1979 cohorts in terms of ability to find work, likelihood of accepting temporary employment, and willingness to accept employment with less responsibility and with less relevance to their undergraduate training (Hughes, 1987).

In the case of Malawi, a similar tracer study covering the period 1987-1994 showed that the period of seeking employment had increased from an average of 2.5 months in 1987-1989 to an average of 4.3 months in 1994-1995. The number of contacts that a graduate had to make before securing a job increased from an average of seven contacts in 1987-1989 to an average of seventeen contacts in 1994-1995. Instances of graduates changing jobs had also increased because most graduates are employed initially in jobs not linked to their training due to job scarcity and only later move to jobs related to their training (Zembere \& Chinyama, 2008).

The conclusions from both studies in Kenya and Malawi have come to mirror the circumstances of university graduates throughout most of the continent; graduates are neither as fortunate nor as few as were their counterparts of the first two decades of independence. The main reason explaining this trend was the fast rate in the growth of university enrolments at the same time as the public sector of most countries was shrinking due to structural adjustment dynamics. Despite these early observations, universities have continued to expand throughout the continent based on the initial logic of a supply-driven public sector labour market. However, the formal private sector is too small to absorb the growing labour force and transition between formal and informal work seems limited. Studies suggest that in the 1960s-1980s, somewhere in the order of $65-90 \%$ of all working university and college graduates were employed by the public sectors in most African countries, especially within East Africa. By the late 1980s the supply of highly educated graduates had exceeded the demand generated by most African economies (Hughes, 1987). The problem with the manpower (workforce) approach is that most countries operated a system of guaranteed jobs for graduates, which made it difficult to discern whether the high employment rates of graduates were due to the efficiency of higher education or the unresponsiveness of the labour market.

\section{Trends and determinants of graduate destinations}

The higher education sector has the least available comparable data in Africa compared to other priority areas that have been outlined by the African Union Commission (2014). Establishing clear trends in higher education enrolments and the transition to labour markets is in most respects anecdotal. Data from the African Economic Outlook (AEO) (African Development Bank et al., 2012) indicates that it is not just a question of poor quality skills but also a general mismatch. However other scholars such as Balwanz and Ngcwangu (2016) argue that there are several problems with the skills mismatch thesis as it is anchored on poor conceptual and empirical bases, which are premised on human capital theory assumptions. The AEO data from 36 countries suggest that graduation rates in sub-Saharan Africa are broadly similar to those in other parts of the world (with the exception of engineering fields). 
The degrees awarded by African institutions do not however align with promising career paths such as telecommunications, engineering, agriculture, information technology, health, banking and education, most likely due to poor career guidance (African Development Bank et al., 2012).

Table 1 University graduation rates in Africa and the world - 2008-2010

\begin{tabular}{|c|c|c|c|c|c|c|c|c|}
\hline & $\begin{array}{c}\text { Education, } \\
\text { Humanities } \\
\text { and Arts }\end{array}$ & $\begin{array}{c}\text { Social } \\
\text { Sciences, } \\
\text { Business } \\
\text { and Law }\end{array}$ & Science & $\begin{array}{l}\text { Engineering, } \\
\text { Manufacturing } \\
\text { and } \\
\text { Construction }\end{array}$ & Agriculture & $\begin{array}{l}\text { Health } \\
\text { and } \\
\text { Welfare }\end{array}$ & Services & Other \\
\hline $\begin{array}{l}\text { Sub- } \\
\text { Saharan } \\
\text { Africa }\end{array}$ & $26 \%$ & $44 \%$ & $\begin{array}{c}12 \% \\
(3 \% \mathrm{ICT})\end{array}$ & $4 \%$ & $2 \%$ & $5 \%$ & $0 \%$ & $7 \%$ \\
\hline $\begin{array}{l}\text { North } \\
\text { Africa }\end{array}$ & $22 \%$ & $51 \%$ & $\begin{array}{c}8 \% \\
(1 \% \mathrm{ICT})\end{array}$ & $10 \%$ & $1 \%$ & $6 \%$ & $1 \%$ & $1 \%$ \\
\hline Asia & $23 \%$ & $30 \%$ & $6 \%$ & $20 \%$ & $4 \%$ & $9 \%$ & $4 \%$ & $4 \%$ \\
\hline $\begin{array}{l}\text { Latin } \\
\text { America }\end{array}$ & $23 \%$ & $38 \%$ & $7 \%$ & $9 \%$ & $2 \%$ & $13 \%$ & $3 \%$ & $5 \%$ \\
\hline OECD & $25 \%$ & $37 \%$ & $\begin{array}{c}10 \% \\
(3 \% \text { ICT) }\end{array}$ & $11 \%$ & $2 \%$ & $11 \%$ & $4 \%$ & $1 \%$ \\
\hline
\end{tabular}

Source: African Development Bank et al. (2012)

Though comparatively, the number of graduates across the disciplines from African universities does not show much divergence from those of the other regions, it is argued here that the situation in Africa should not be tied to that of other regions. Rather, universities should focus on offering skills that are directly related to the development needs of the continent. Much would be gained if, for example, universities focused on offering higher-level skills in agriculture and in the extractive industries, as well as the legal expertise needed to gain control of these industries. Instead, a continent with much more arable land compared to other regions of the world continues to rely on food imports and the importation of skilled labour into well-paying but unfilled technical and engineering occupations in the extractive sector.

What is not clear is where the graduates proceed to after graduation, the quality of jobs they perform and the contribution of the skills they have to overall development. 2012 data by the AEO show that the number of African university students increased from 3.53 million in 1999 to 9.54 million in 2012, the latest year for which full figures are available (African Development Bank et al., 2012). A recent World Bank study puts the percentage enrolment increase between 1998 and 2012 at 3.1\% for the bottom $80 \%$ of the income quintile and $7.9 \%$ for the top $20 \%$ income quintile (Darvas, Gao, Shen, \& Bawany, 2017). At the same time, expansion of universities has led to declining expenditures and enrolments in technical, industrial and vocational education and training (TIVET), which offers alternative post- 
secondary training opportunities for students from low-income groups. Data show that the period 1999 to 2012 that witnessed a surge in enrolments at university-level institutions in the continent also recorded a drop in TIVET enrolments from 7\% in 1999 to 6\% in 2012 (African American Institute, 2015). TIVET skills are frequently cited as lacking in graduates, thus exacerbating unemployability. The problem is that higher education in most of the continent has not developed vocational curricula that focus on the development of technical skills. South Africa's recent focus on skill development represents one attempt to introduce such an approach. What this means is that the higher education and employability challenge in most of Africa goes beyond what universities can do. It is more a question of political policy choices that lead to a situation in which the majority of students from low-income groups cannot access opportunities for skill development.

More recently, data by the Africa Centre for Economic Transformation indicate that half of the 10 million graduates from over 668 universities in Africa yearly do not get jobs (African Center for Economic Transformation, 2016). More generally, data seem to suggest that the transition from tertiary degree graduation into employment seems to take longer in SSA than in other regions.

Table 2 Employment status of higher education graduates by age in 23 SSA countries, $2003^{28}$

\begin{tabular}{l|c|c|c}
\hline Employment Status & $\mathbf{2 5 - 3 4}$ years & $\mathbf{3 5 - 4 9}$ years & $\mathbf{5 0 - 5 9}$ years \\
\hline Formal Sector & $55 \%$ & $76 \%$ & $74 \%$ \\
\hline Informal Sector & $20 \%$ & $19 \%$ & $22 \%$ \\
\hline Unemployed & $26 \%$ & $6 \%$ & $4 \%$ \\
\hline Not Active & $3 \%$ & $3 \%$ & $9 \%$ \\
\hline Total & 100 & 100 & 100 \\
\hline
\end{tabular}

Source: Summarised from Maajgard and Mingat (2012, Table 7.4, p.183)

Data from the table above, though a little dated, seem to suggest fairly high levels of graduate employment, especially in the formal sector. The fact that $55 \%$ of the $25-34$-age cohort compared to $76 \%$ and $74 \%$ for the $35-49$ and 50-59 age cohorts are in formal employment suggests that it takes graduates slightly longer to secure formal employment after graduation. Indeed, studies do indicate that higher levels of education seem to have very little return before age 30 (African Development Bank et al., 2012), which is indicated by the lower percentage of people over 34 who are unemployed. The data are consistent with more recent data covering Kenya, Nigeria, Ghana and South Africa which indicate that, on average, it takes a university graduate at least five

28 The 23 countries covered in the study are Benin, Burkina Faso, Burundi, Cameroon, Central African Republic, Chad, DRC, Côte d' Ivoire, Ethiopia, Ghana, Guinea, Guinea-Bissau, Lesotho, Madagascar, Malawi, Mali, Mauritania, Mozambique, Rwanda, Senegal, Sierra Leone, Uganda and Zambia. 
years to secure a job in the formal sector, with the graduate unemployment rate in Nigeria as high as $23.1 \%$ (British Council, 2016). Much of the reason for this inability to quickly transition into the job market is no fault of the students or universities; it is the structural nature of most African economies, where only $16 \%$ of jobs are in the formal sector, and the rest in family-owned firms and the informal sector (Trust Africa/Mail \& Guardian Africa, 2015). Widespread concern about the work readiness of graduates also abounds, with employers in Ghana, Nigeria, Kenya and South Africa generally satisfied with the academic knowledge of students, but concerned about their lack of adequate IT skills, personal qualities (e.g. reliability) and transferable skills (e.g. team working and problem solving) (British Council, 2016).

Despite policies promoting the informal sector as a viable possible alternative to redressing graduate unemployment, it does not seem to attract a majority of graduates as the 2003 data from Maajgard and Mingat (2012) show. However, the literature seems to suggest a number of graduates in formal employment also engaged in informal sector activities as a strategy to supplement low public sector wages that have been plummeting over time. The underside to this is that all over Africa, the motivation, commitment and standards of professional conduct of public servants have been eroded by their engagement in the informal sector to the extent that ethical conduct as an outcome of university level training remains in doubt (Bennell, 1983).

In an effort to revitalise the university sector in Africa, tracer studies began to emerge from the year 2000 examining the education levels and employment status of a large number of university graduates in a number of African countries (see for example, Kadzamira, 2003; Kirumira \& Bateganya, 2003; Mukyanuzi, 2003; Ncube, 2003). The studies were part of an international research project evaluating the education and employment experiences of large representative samples of secondary school leavers and university graduates in four countries in SSA: Malawi, Tanzania, Uganda, and Zimbabwe (Al-Samarrai \& Bennell, 2007). The university graduate sample was drawn from the main national university in each country (University of Malawi, University of Dar es Salaam, Makerere University and University of Zimbabwe), and equally divided between individuals who completed their undergraduate education in 1980,1987/1988, 1994, and 1999. The overall conclusions from these studies are interesting to note as they point to contradictions that have persisted in most of subSaharan Africa with regard to outcomes from university expansion and the fate of graduates. Findings from the four countries agreed that:

- International migration among graduates (the so-called 'brain drain') was less than expected.

- The incidence of unemployment among university graduates was very low, disregarding the initial high unemployment due to the time taken to secure a job, as seen in Table 2 (the persistence of the notion of high graduate unemployment levels was also recently confirmed in Kenya by the British Council (2016) study).

- Self-employment among graduates was fairly rare (with the exception of 1980's graduates in Zimbabwe), while self-employment among school leavers tended to be 
quite high and growing over time. (Again, university expansion policies in most African countries have continued to transform middle level vocational colleges to universities, even when it is evident university education is not producing entrepreneurial graduates. This contradiction goes back to when African nationalists opted for a white-collar university education approach as opposed to the technically focused education that had been preferred by the colonial authorities.)

- Despite persistent concerns that large numbers of university graduates are unable to effectively utilise the knowledge and skills they acquired while at university, nearly all the traced graduates in the four countries were in professional occupations that were directly related to their university training.

- The activity profiles for university graduates in the tracer studies showed wage employment dominating and this has not changed a great deal over the years.

- University graduate employees were less likely to be working for the private sector than secondary school leavers. However, the share of private sector wage employment was higher among the 1990s graduates, especially in Tanzania and Uganda.

- The incidence of secondary employment, both wage and self-employment, was generally much higher among university graduates who were in full-time wage employment than it was among school leavers. Nearly three-quarters of 1980 s graduates in Uganda had secondary incomes, over $60 \%$ in Zimbabwe, and nearly $45 \%$ in Tanzania. The percentages were much lower among 1990s graduates, suggesting that it takes time before a graduate is able to exploit secondary employment activities. (In Kenya, the government supported this approach from 1972, when senior public servants were allowed to engage in private businesses. This is now blamed for the high level of economic crimes committed by the elite.)

- The most noticeable feature of further education and training (FET) among graduates from the tracer studies was that so many have studied for postgraduate degrees. Among the 1980s graduates, approximately half had enrolled in $\mathrm{PhD}$ and masters degree programmes. In all four countries, relatively more female graduates have studied for these degrees than males. The investment in postgraduate degree training is the result of a number of factors: strong demand to study at overseas universities, as well as for high-value qualifications (most notably MBAs), which are marketable, in both national and international labour markets.

Since 1990, discipline- and institutional-specific tracer studies examining graduate outcomes have been conducted. From 1990 to 2000, a number of discipline-specific studies were undertaken in the context of the post-adjustment period and what implications this had in the quality of training and graduate outcomes (see for example Anyanwu \& Iloeje, 1999; Baldauf \& Lwambuka, 1993; Batse \& Gyekye, 1992; Mayanja, Nakayiwa-Mayega, Adebua, Kabuye, \& Kaase-Bwanga, 1999; Winkler, Hartmann, \& Schomburg, 1992). Many studies noted the theoretical, rather than practical, nature of graduate training. Universities, even in 
professionally orientated degree programmes, had tended to produce job seekers and not entrepreneurs who could create their own jobs or effectively help the private sector develop. A persistent mismatch between the knowledge and skills acquired by graduates and what is required by employers began to emerge. For example, the curricula and teaching methods in agricultural institutions tended to neglect the development of soft skills such as critical thinking and problem solving which would allow graduates to adapt easily to changing demands in the job market. There has also been a continued mismatch in the number of graduates produced in various fields and what is required in the market, due to inadequate labour market information. The findings pointed to the underfunding that most universities had faced in the previous decade. The studies provide useful indications on how the economic circumstances of African countries affected the financial health of universities and the employment options of graduates in the changing social and economic situation in the late 1980 s and the early 1990 s.

Since 2000, institutional-specific tracer studies have been conducted, largely focused on profiling the institutions as better training alternatives in the face of competition for students and the emergence of a private higher education sector. The positive international press for higher education in Africa had changed following the World Bank's report in 2000 (Task Force on Higher Education \& Society, 2000) and the attempt by African countries to have higher education institutions benefit the countries by training in skills focused on the knowledge economies. Higher education institutions had also improved in terms of their funding levels, given the semi-privatisation of most public universities.

A recent tracer study was undertaken by the Regional Universities Forum for Capacity Building in Agriculture (RUFORUM, 2014). RUFORUM is a consortium of 32 universities in 18 countries in Eastern, Central and Southern Africa (ECSA), established in 2004. The study aimed to trace their graduates covering the period 2004 to 2014. The main objective of the tracer study was to establish the location of the graduates, the institutions in which they are employed, how they are performing in respect to the RUFORUM outcomes and in respect to the needs of employers, the competitiveness of the graduates, retention rates after employment, regional distribution, and other relevant factors. The study indicated a higher transition rate of graduates to the labour market and a positive impact of the agricultural skills on local small-scale farmers in all the countries.

Findings from a number of these studies point to the emergence of the private sector, including self-employment, as the major destination of graduates from public institutions. The outcome of this trend is that the public sector began to be stripped of critical skills. Countries such as Kenya have been forced to offer private sector level wages in the public sector to attract some high-level skills from the private sector. 


\section{The return of the vocational logic}

Policies to increase the vocational content and orientation of universities have included those tailored to increasing articulation between higher education institutions and secondary level schooling, and between the different levels of the overall tertiary education sector. Designing qualification frameworks showing pathways and skills requirements between upper secondary school and related technical and vocational institutions and the variety of tertiary or higher education institutions has been the preferred strategy (Mohamedbhai, 2013). While the main emphasis has been on the transition from academic secondary schools to university, attention has also been paid to other possible transitions, notably from upper secondary equivalent programmes. There have also been attempts to 'modernise' the content and focus of training in information and communication technologies, research and innovation as the key drivers not only in the development of new knowledge and skills, but also in the adaptation of new ideas, products and innovative approaches in business, management, processes of production and marketing of goods and services (Hoppers, 2009). These policies aim at achieving better articulation between university and non-university institutions and enhanced access to higher education opportunities and choices available to upper secondary graduates in academic and vocational tracks. Accompanying the design of qualification frameworks has been the establishment of accreditation and quality assurance authorities, and student loan programmes; governance and management reforms at the institutional level; diversification of funding sources and increased investment of time and resources in research and innovation. But these just remain promises and anticipations and their capacity to cause real transformation and the quality and rate of graduate transitions have not been confirmed.

More broadly, teaching of entrepreneurship courses has been introduced as part of the basic skills courses for undergraduate students. The focus is that such courses be reformed to offer students the opportunity to develop the personal skills that help them identify work opportunities and transform these into business-creation possibilities. In addition, the courses should enable students to learn the technical and managerial knowledge and skills needed for self-employment or to start a business. Countries such as Kenya are urging the University of Nairobi to go back to its origins in the Royal Technical College and to build technical skills and ensure the education system meets contemporary economic and social needs (Juma, 2017).

However, there have also been concerns that the turn to entrepreneurship and vocationalisation has made graduates more unemployable. This is because universities turned to entrepreneurship activities in the first instance not to improve graduate skills but to generate operational revenues (Mamdani, 2007). A survey by the Inter-University Council for East Africa (IUCEA) has established that 51\%-63\% of graduates from East African universities are unfit for jobs and 'lacking job market skills'; the worst records were in Uganda (63\%) and Tanzania (61\%) (Inter-University Council for East Africa \& East African 
Business Council, 2014). The survey sought the views of employers in the five East Africa Community (EAC) countries (Kenya, Uganda, Tanzania, Rwanda and Burundi), on the employability of graduates from universities in East Africa.

\section{Conclusion}

This chapter has tried to show that the focus on higher education institutions as the single explanatory factor for graduate employability is misplaced. Trends from a number of subSaharan African countries two to three decades after independence suggest that changes in the structural dynamics of the economy and labour markets may better explain the graduate employability crisis than the inability of the institutions to teach relevant skills. Changes in the structure of the economy can be fast and rapid and outpace the capacity of higher education institutions to respond as fast.

In applying these insights to the South African context, it is clear that as in the case in the rest of sub-Saharan Africa, graduate unemployment in South Africa is affected mainly by structural changes in the economy, as well as practices in the labour market that still reflect the apartheid legacy of racial, gender and geographical disparities. The core issue is that South African higher education still demonstrates a division between historically black and historically white universities, which is often an indicator of labour market success for graduates. This is caused by the subjective perceptions of 'quality' by employers and professional associations within the economy. This raises critical questions for the South African higher education sector: as the South African higher education sector continues to grow, will graduate unemployment rates eventually begin to increase as has been the case in sub-Saharan Africa? What can South Africa learn from other sub-Saharan African countries regarding private higher education? As the public service was downsized in sub-Saharan Africa (due to structural adjustment), graduate unemployment increased. Will the same occur in South Africa with budgetary constraints increasing and talks in some quarters about a need to reduce the public sector which is said to be 'bloated'?

\section{References}

African Center for Economic Transformation (2015). State of education in Africa report. The African American Institute, African Center for Economic Transformation (2016). Retrieved from http://acetforafrica.org/acet/ wp-content/uploads/publications/2016/06/ATF_March2016_Summary_Report.pdf

African Development Bank, Development Centre of the Organisation for Economic Co-operation and Development, United Nations Development Programme, \& United Nations Economic Commission for Africa (2012). African economic outlook 2012. Retrieved from http://www.undp.org/content/dam/rba/docs/ Reports/African\%20Economic\%200utlook\%202012\%20En.pdf

African Union Commission (2014). African education outlook.

Al-Samarrai, S., \& Bennell, P. (2007). Where has all the education gone in sub-Saharan Africa? Employment and other outcomes among secondary school and university leavers. The Journal of Development Studies, 43(7), 1270-1300. 


\section{HigheR EDUCATION PATHWAYS}

Anyanwu, G. A., \& Iloeje, I. C. (1999). Graduates' employment survey: A tracer study of the graduates of the Faculties of Arts and Agriculture at the University of Nigeria, Nsukka (unpublished report).

Baldauf, B., \& Lwambuka, L. (1993). Findings of the graduates' and employers' surveys 1989. In University of Dar es Salaam, Faculty of Engineering (Ed.), University education and engineering profession in Tanzania. Dar es Salaam.

Balwanz, D., \& Ngcwangu, S. (2016). Seven problems with the 'scarce skills' discourse in South Africa. South African Journal of Higher Education, 30(2), 31-52.

Batse, Z. M. K., \& Gyekye, O. (1992). Graduate tracer study: A study of employed and unemployed graduates in Ghana. Report of the Institute for Statistical, Social and Economic Research, University of Ghana, Legon for the Ministry of Education, Higher Education Division.

Bennell, P. S. (1983). The colonial legacy of salary structures in Anglophone Africa. Journal of Modern African Studies, 20(1), 127-154.

British Council (2016). Universities, employability and inclusive development: Repositioning higher education in Ghana, Kenya, Nigeria and South Africa. London: British Council.

Darvas, P., Gao, S., Shen, Y., \& Bawany, B. (2017). Sharing higher education's promise beyond the few in subSaharan Africa. New York: The World Bank.

Devarajan, S. (2016). The paradox of higher education in the MENA. Retrieved from https://www.brookings.edu/ blog/future-development/2016/06/27/the-paradox-of-higher-education-in-mena/

Hoppers, W. (Ed.). (2009). Post-primary education in Africa: Challenges and approaches for expanding learning opportunities. Synthesis prepared for and lessons learned from the ADEA 2008 Biennale on Education in Africa (Maputo, Mozambique, May 5-9, 2008). Association for the Development of Education in Africa (ADEA).

Hughes, R. (1987). Revisiting the fortunate few: University graduates in the Kenyan labor market. Comparative Education Review, 31(4), 583-601.

Inter-University Council for East African Business Council (2014). Regional higher education qualification gaps: Vol II. Situation Composite EAC Report. Kampala. IUCEA.

Juma, C. (2017). Universities' future lies in innovation. Updated Sun. Retrieved from https://www.standardmedia.co.ke/article/2001227566/universities-future-lies-in-innovation

Kadzamira, E. (2003). Where has all the education gone in Malawi? Brighton: IDS and KSD.

Kirumira, E., \& Bateganya, F. (2003). Where has all the education gone in Uganda? Brighton: IDS and KSD.

Lilford, G. (2012). The liberal arts in Anglophone Africa. Journal of General Education, 61(3), 189-210.

Majgaard, K., \& Mingat, A. (2012). Education in sub-Saharan Africa: A comparative analysis. Washington, DC: World Bank.

Mamdani, M. (2007). Scholars in the marketplace. The dilemmas of neoliberal reform at Makerere University, 1989-2005. Dakar: Council for the Development of Social Science Research in Africa.

Mayanja, M. K., Nakayiwa-Mayega, F., Adebua, A., Kabuye, M. K., \& Kaase-Bwanga, E. (1999). A comparative study of Makerere University graduates from the faculties of Arts \& Science (unpublished report).

Mngomezulu, B. R. (2012). Politics and higher education in East Africa: From the 1920s to 1970. Bloemfontein: African Sun Media.

Mohamedbhai, G. (2013). Towards an African higher education and research space. A summary report. Association for the Development of Education in Africa (ADEA), Working Group on Higher Education (WGHE).

Mukyanuzi, F. (2003). Where has all the education gone in Tanzania? Brighton: IDS and KSD.

Ncube, M. (2003). Where has all the education gone in Zimbabwe? Brighton: IDS and KSD.

Regional Universities Forum for Capacity Building in Agriculture (2014). Tracer study on RUFORUM alumni. Final report.

Republic of Kenya (2013). National workforce survey, 2010/2011.

Sustainable Development Goals Center for Africa (2017). Mobilizing higher education for SDGs. Retrieved from http://sdgcafrica.org/wp-content/uploads/2017/03/sdgca-mobilizing-higher-education-for-sdgs.pdf

Task Force on Higher Education \& Society (2000). Higher education in developing countries: Peril and promise (No. 440). New York: World Bank.

Trust Africa/Mail and Guardian Africa (2015). Graduating in Africa. Retrieved from http://trustafrica.org/images/ graduating-in-africa.pdf 


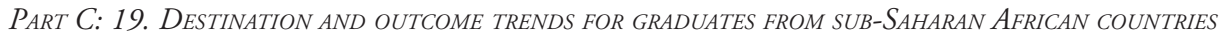

Winkler, H., Hartmann, K., \& Schomburg, H. (1992). Engineers in Tanzania. A secondary Analysis - Graduate and Employer Survey 1985. Faculty of Dar es Salaam. Eschborn: Deutsche Gesellschaft für Technische Zusammenarbeit (GTZ) GmbH.

World Bank (2012). Universities through the looking glass: Benchmarking university governance to enable higher education modernization in MENA. Washington, DC: World Bank. Retrieved from https://openknowledge. worldbank.org/handle/10986/12535

World Education Services (2017). Education in South Africa. Retrieved from http://wenr.wes.org/wp-content/ uploads/2017/05/May17_SAfCP_enrollment-race.png

Zembere, S. N., \& Chinyama, M. P. M. (2008). The University of Malawi graduate tracer study 1996. Retrieved from http://rc.aau.org/files/ZEMBERE.pdf 


\title{
ENGINEERING GRADUATES IN SOUTH AFRICA AND BRAZIL: A COMMON GOOD PERSPECTIVE
}

\author{
Renato H. L. Pedrosa and Bruce Kloot
}

\section{Introduction}

This chapter examines relationships between engineering education and the common good, by comparing how they relate to each other in South Africa and Brazil. According to Deem and McCowan in Chapter 5, South Africa's higher education system can be seen to be quasimarketised, with relevant participation of government but increasingly subjected to market rules and demands. Despite this, they propose approaching the theme of the common good and higher education in South Africa from a broader perspective, by exploring the various roles higher education institutions play in society that involve significant public benefit, going beyond the assumptions that returns from higher education are largely private and economic and that society is simply made up of discrete individuals with separate interests.

Engineering is an interesting case to consider from a public good perspective because private returns for its graduates are seen as being among the highest in higher education, thus making it a good test for the perspective proposed above. Moreover, engineers play important roles in most industrial activities, including knowledge-intensive innovation (Gordon, 2016; Landes, 2003) and management strategies (Chandler, 1980; Mowery, 1984), important activities in modern economies. From a direct common good perspective, they 'can be part of the struggle to reduce poverty in many ways. Improvements in public services and the building of infrastructure for both commercial and social ends cannot take place without skilled engineers' (Walker, McLean, Dison, \& Peppin-Vaughan, 2010, p. 53).

Our task is complicated, and enriched, by the inclusion of Brazil as a comparison country, since its higher education system is comprised of a public state-funded subsystem, and two private ones, composed of private for-profit and non-profit higher education institutions (McCowan, 2007; Pedrosa, Amaral, \& Knobel, 2013), all of them providing engineering education. Moreover, for-profit higher education institutions in Brazil receive large amounts 
of public funds dedicated to supporting low-income students, so that its characterisation as a private good provider must be discussed with care. We will see that these structural differences give rise to some of the main differences between the two countries with respect to engineering education and its relation to common good themes, such as social inclusion in higher education and employment. Our comparative approach will help distinguish which issues are specific to South Africa and which are shared by other emerging economies, and important differences may help identify country-related specific causes. The choice of Brazil as the comparison country follows from relevant commonalities, as Brazil and South Africa experienced transitions from authoritarian to democratic rule in the early 1990s and still are, despite recent progress, very unequal societies, in which race continues to play an important role. Furthermore, they are economic powers in their respective regions (World Bank, 2016) and leaders in terms of higher education and research (Leiden Ranking, 2018). Despite that, their economies have lagged behind those of other emerging economies and figured relatively low in international innovation lists (Cornell University, INSEAD, \& WIPO, 2017), an area in which engineers are expected to play central roles.

The chapter is organised as follows: we start by discussing relationships between engineering education and the common good, from both conceptual and factual perspectives, then use that to develop a comparison of the two countries, discussing the following aspects: (a) institutional structure of engineering education and profession; (b) engineering degrees conferred, including those at postgraduate level; and (c) transition to employment, bringing forward common good issues. The conclusion will discuss how the chapter may have contributed to the understanding of the relationships between engineering education and the common good for the two countries.

\section{Engineering education and the common good}

The relationship between higher education and the common good has been developed in broader terms by various authors (cf. Marginson, 2016 and Chapter 5 by Deem and McCowan for discussion and references). About specific fields, which may require focusing on some aspects of that relationship in more depth, there is a general lack of discussion and research, with some few exceptions (discussed below). We will see, in this section, that this is the case for engineering, as the profession has strong ties to industry and markets, which requires a broader view of how higher education impacts the lives of graduates and the society where they live, expanding how public and private interests relate to each other.

\section{Common good, public and private goods}

In general terms, common good refers to 'social solidarity, social relations based on universal human rights and equality of respect' (Marginson, 2016, p. 16). Definitions of public and private goods usually imply zero-sum results, one excluding the other, but, as Marginson 
(2016, pp. 19-20) argues: 'The private interest is nested in the public interest, and although they are not the same, they work together rather than against each other.' He adds that 'the existence of a positive-sum relation between public good and private good is itself one of the common goods that society should provide to all'. Since much of the engineer's activity is related to market organisations, and to industry in particular, and since it is considered a field with high private returns, an important ingredient as youngsters choose their college field (Jawitz \& Case, 1998; Reed \& Case, 2003), we consider the positive-sum approach to publicprivate good interactions especially appropriate when discussing engineering education. We will come back frequently to that basic idea along the chapter.

\section{Instrumental and intrinsic relationships between engineering and the common good}

One may identify an instrumental or extrinsic relationship between higher education and the common good, where its various aspects 'are perceived to lead to particular manifestations of public good, delineated as economic, social, political or cultural', or an intrinsic one, 'where the intellectual, physical and cultural experiences ... express and enact the public good e.g. prejudice reduction, democratisation, critical thinking, active citizenship' (Unterhalter, Allais, Howell, McCowan, Morley, Oanda, \& Oketch, 2018). In multi-country studies, even when information is available for intrinsic relationships, it usually comes from studies involving different methodologies or specific contexts, which limit their use for direct comparison purposes. The distinction is also important in the case of engineering education, as much of the relationship between the field and the common good tends to focus on instrumental aspects, even when students are exposed to social themes while in university (Walker et al., 2010).

\section{Engineering and known impacts on intrinsic common good aspects}

Mayhew, Rockenbach, Bowman, Seifert, Wolniak, Pascarella, \& Terenzini, (2016, citing Ishitani \& McKitrick, 2013) observe that there is evidence that majoring in engineering has long-term negative effects on civic engagement. But that is also true for some other fields, for example mathematics, physical sciences, arts and humanities, applied social sciences, and business, and they mention a series of other studies for which majoring in engineering is shown to be neutral regarding various other intrinsic aspects of the common good, also in a long-term perspective. They report on one study (Sax, 2008) showing that, during college years, majoring in engineering reduced students' commitment to promoting racial understanding (Mayhew et al., 2016). These studies dealt with the US higher education system, so that one cannot assume that they would hold for other countries and systems. Nevertheless, one should keep their results in mind when discussing the common good as related to specific fields/programmes. Mayhew et al. (2016) also list various studies providing evidence of the positive effects of higher education activities on students' attitudes and values, without reference to particular majoring fields. 


\section{Reduction of inequalities, expansion policies and stratification}

Expansion policies do not guarantee effective reduction of social inequalities, as the newly included groups may be diverted to sectors of higher education considered of less quality or of less prestige, resulting in the social stratification of higher education systems (Shavit, Arum, \& Gamoran, 2007). Marginson (2016, p. 77) observes that

in too many countries these (higher education) systems are so stratified as to reduce sharply - sometimes empty out - the value of participation for the majority of students. This abandons the potential for higher education as a common good, substituting for the notion of a common good system that of a higher education system organised primarily as a provider of private goods of unequal value.

We will see examples of stratification of higher education in both countries.

\section{Engineering education and gender}

Engineering, among the major educational/professional fields, is one in which women show some of the lowest participation rates, about $25 \%$ of graduates and $15 \%$ of the employed, across the world (Huyer, 2015; Mills, Ayre, \& Gill, 2010). Despite efforts in many countries to make engineering more attractive to women, the rate of change has been very slow (Mills et al., 2010), and we will see the same is true for Brazil and South Africa. Studies about the engineering workplace in both South Africa (Nel \& Meyer, 2016) and Brazil (Lombardi, 2017) indicate that the low participation of women in some subfields of engineering may be linked to the highly gendered environment they find in the workplace. Also, critical mass studies indicate that below $25 \%$ of participation, the chances of identity groups to drop out of college tends to increase significantly (Huyer, 2015).

\section{Pedagogical, curriculum aspects and the intrinsic impacts}

There are various aspects of engineering training that are designed to improve graduates' chances of success in the profession. Even for undergraduate students, internships in industry and other private organisations, sometimes quite early in their programmes, may be seen as directly related to private interests. Institutions may try to counteract that by developing engineering-specific awareness courses. One such programme (Walker et al., 2010) has shown limited results, with students and graduates still seeing the role of engineers as that of simply being technically skilled professionals and developing ethically oriented careers. Government programmes may also help in developing social awareness in higher education. 
In Brazil, a government programme, Projeto Rondon, organises 2-3 week-long stays of groups of undergraduate students in poor communities, where they work in various areas, including engineering. Studies show that participation in the programme has a positive impact on students' awareness of social inequalities (de Souza et al., 2017). A mix of both special courses and intensive short-term internship programmes such as Projeto Rondon could help foster greater social awareness among students, in all fields, thus counteracting the possible negative effects of engineering education on that, as mentioned above.

\section{Engineering, the origins of mass higher education and instrumental impacts}

Marginson (2016) observes that the land grant colleges, launched by the Morrill Act (1862) with the support of Abraham Lincoln, may be considered the origin of modern mass higher education. One important aspect of the new system was that it should focus on construction and mechanical engineering (and agriculture). From three engineering schools in existence in 1862, the system had expanded by 2017 to over 120 institutions developing engineering programmes, most in the newly founded state systems. By then, the US had overtaken Germany as the country graduating the largest number of engineers (Mann, 1918). Today, land grant institutions are responsible for over $75 \%$ of engineering degrees granted yearly in the country (Brantley, 2012). The impact of that decision on US industrialisation and on the improvements in the quality of life that new products brought to households, is wellestablished (Gordon, 2016). This is another example of the nesting of private interests in public ones.

\section{A broader perspective on engineering education and the common good}

We have seen earlier that Marginson's proposal for developing a positive-sum relationship between public and private interests, as they relate to higher education, is the most appropriate approach to the theme, especially in the case of engineering education. This includes his view that private interests be considered nested in public ones. The conceptual distinction between instrumental and intrinsic relationships between higher education and the common good also assisted us in detailing some of the important points under discussion. That broader perspective is present in the concluding remarks in Walker et al. (2010, p. 94), when they observe that their project's

early conceptual shift from an emphasis on pro-poor professionalism to something we have called "buman development public good professionalism" might enlarge the scope for the kinds of identities and commitments engineering students might form at university. The more expansive concept of public good might allow for valuing both direct and indirect contributions to poverty reduction and human development in South Africa and enlarge the reach and responsiveness of the capability approach. 


\section{Engineering education, profession and employment in South Africa and Brazil}

\section{Institutional aspects of engineering education and profession}

Regarding how professions have developed, Brazil and South Africa have very different backgrounds. Brazil started developing and regulating professions in the 1930s, influenced by continental European models, while colonial times had strong influences in South Africa (Kloot \& Rouvrais, 2017), so it is not surprising to find similarities between the UK's and South Africa’s systems.

In South Africa, there are three types of engineers recognised by the Engineering Council of South Africa (ECSA): engineers, engineering technologists and technicians. In the case of Brazil, the Federal Engineering and Agronomy Council (CONFEA) only registers engineers in the full sense. Technologists are not considered for registration by CONFEA. In both countries, engineers are the most elite group, graduating from four-year bachelors programmes at universities in South Africa, and from five-year ones, in Brazil, where all types of institutions may grant them. In South Africa, technicians/technologists qualify at a lower level compared to engineers, which is also the case of technologists in Brazil. Elite higher education institutions do not offer technologist degree programmes in Brazil, while in South Africa universities do, an indication of a system with less academic differentiation. In the rest of the chapter we will focus on full engineering degrees (BEng or BScEng). In South Africa, engineers are required to undergo a professional development programme in industry, lasting for at least three years, after which, if successfully completed, they may register as Professional Engineers. In Brazil, once the student graduates from an accredited programme, registration is automatic and does not require any development plan or any further assessment process, and only registered engineers may work as such, which is not the case for South Africa.

Summarising this section, it seems, at least formally, that Brazil's professional registration system is less strict than South Africa's, in the case of BEng/BScEng degrees, the only criterion being that the programme granting it must be authorised and accredited by government. Accreditation also seems to be laxer in Brazil, which may account for a much larger system of engineering education, in comparison to South Africa's, as we will see next.

\section{Degrees granted in engineering}

In South Africa, undergraduate engineering education has been expanding consistently since the year 2000, while in Brazil the expansion started earlier, in 1995, but picked up speed after 2000 as well, as indicated in Table 1 by figures for enrolment and degrees granted. 
Table 1 Enrolment and degrees granted in engineering at the undergraduate level, Brazil and South Africa (BEng/BScEng)

\begin{tabular}{l|l|r|r|r|r|r|r}
\hline & Country & \multicolumn{1}{c|}{1995} & \multicolumn{1}{c|}{2000} & \multicolumn{1}{c|}{2005} & \multicolumn{1}{c}{2010} & 2015 & $\begin{array}{c}\text { Yearly rate of change } \\
\text { 2015/1995 (2015/2000) }\end{array}$ \\
\hline Enrolment & Brazil & 150006 & 179598 & 263231 & 492779 & 1041646 & $10.2 \%(12.4 \%)$ \\
\hline & South Africa & 8288 & 7362 & 11392 & 15735 & 20735 & $4.7 \%(7.1 \%)$ \\
\hline Degrees & Brazil & 16224 & 17634 & 26331 & 40921 & 82363 & $8.5 \%(10.8 \%)$ \\
\hline & South Africa & 1527 & 1292 & 1519 & 2239 & 2934 & $3.3 \%(5.6 \%)$ \\
\hline
\end{tabular}

Sources: http://portal.inep.gov.br/microdados; DHET (2016)

The differences between the two countries are striking, even taking into account their populations, as the number of degrees conferred per 100000 population in 2015 were 5.3 for South Africa and 40 for Brazil. Most of this difference is due to the existence of a large private system in Brazil, which expanded much faster than the public one in all fields and types of programmes (see McCowan, 2004, 2007; Pedrosa, Simóes, Carneiro, Andrade, Sampaio, \& Knobel, 2014). This was a consequence of important federal government policies supporting students in private higher education institutions (McCowan, 2007; Pedrosa et al., 2014), which have no counterparts in South Africa's system.

Regarding gender and ethnicity of graduates, Table 2 shows that women were the recipients of $24 \%$ of all degrees in South Africa, but participation depended on the population group. The $24 \%$ figure is in line with the international level of participation of women among engineering graduates (Huyer, 2015; Mills et al., 2010), but it is interesting to observe that the level of participation of women is lower amongst whites, which is not the case for Brazil (see Table 3).

Table 2 Degrees granted in engineering (BEng/4 years), South Africa, by population group and sex, 2015. Includes representation of race groups in general population

\begin{tabular}{l|c|c|c|c|c}
\hline Population group & Degrees & $\%$ of degrees & Female & $\%$ female & $\begin{array}{c}\% \text { population group } \\
\text { in population }\end{array}$ \\
\hline Black African & 886 & $30.2 \%$ & 256 & $28.9 \%$ & $79.2 \%$ \\
\hline Coloured & 106 & $3.6 \%$ & 34 & $31.8 \%$ & $8.9 \%$ \\
\hline Indian or Asian & 314 & $10.7 \%$ & 85 & $26.9 \%$ & $2.5 \%$ \\
\hline White & 1555 & $53.0 \%$ & 325 & $20.9 \%$ & $8.9 \%$ \\
\hline No race/other & 73 & $2.5 \%$ & 17 & $23.3 \%$ & $0.5 \%$ \\
\hline Total & $\mathbf{2 9 3 4}$ & $\mathbf{1 0 0 . 0 \%}$ & $\mathbf{7 1 7}$ & $\mathbf{2 4 . 4} \%$ & \\
\hline
\end{tabular}

Sources: DHET (2016); Statistics South Africa (2012) - with elaboration by the authors 
Table 2 also shows that whites are highly over-represented among graduates in engineering, with more than six times more participation than in the overall population. Indians/Asians also show higher participation among graduates than among the population, while black Africans and the coloured group are under-represented as graduates by large margins.

Table 3 Degrees granted in engineering (BScEng), Brazil, by population group and sex, 2016. Includes representation of race groups in general population

\begin{tabular}{l|c|c|c|c|c}
\hline Population group & Degrees & $\begin{array}{c}\text { \% of degrees } \\
\text { (w/o not informed) }\end{array}$ & Female & \% female & $\begin{array}{c}\text { \% population group } \\
\text { in population }\end{array}$ \\
\hline White & 47583 & $47.5 \%(65.4 \%)$ & 14517 & $30.5 \%$ & $47.7 \%$ \\
\hline Pardo & 18603 & $18.6 \%(25.6 \%)$ & 5896 & $31.7 \%$ & $43.1 \%$ \\
\hline Black & 4072 & $4.1 \%(5.6 \%)$ & 1132 & $27.8 \%$ & $7.6 \%$ \\
\hline Asian & 2074 & $2.1 \%(2.9 \%)$ & 708 & $34.1 \%$ & $0.6 \%$ \\
\hline Native Brazilian & 406 & $0.4 \%(0.6 \%)$ & 104 & $25.6 \%$ & $0.4 \%$ \\
\hline Not informed & 27500 & $27.4 \%$ & 7878 & $28.6 \%$ & $0.0 \%$ \\
\hline Total & $\mathbf{1 0 0 2 3 8}$ & $\mathbf{1 0 0 . 0 \%}$ & $\mathbf{3 0 2 3 5}$ & $\mathbf{3 0 . 2} \%$ & \\
\hline
\end{tabular}

Sources: http://portal.inep.gov.br/microdados - with elaboration by the authors

In the case of Brazil, $30 \%$ of graduates were women and their participation does not follow any tendency along population groups, as for South Africa. Whites' participation among graduates, without counting those without information, is about $50 \%$ higher than their participation in the population, while pardos ${ }^{29}$ and black graduates, together, for $31 \%$ of graduates, lower than their $51 \%$ share in the total population. Asians show a very high participation level, compared to their share of the population, as for South Africa.

Given the high degree of system differentiation in Brazil, one must address the possibility of social and/or gender stratification. First of all, the public higher-education institutions are not allowed to charge students in any form, which already raises issues of equity, as they are also more selective and tend to show a higher share of high-income students, in comparison to private higher education institutions (McCowan, 2007; Pedrosa et al., 2014). In the case of gender, there was, in 2016, a relative advantage for women, as their participation is higher in public higher education institutions (36\%), followed by that in non-profit higher education institutions (29\%), then in for-profit higher education institutions (26\%) (see http://portal.inep.gov.br/microdados), exactly the ordering from higher to lower prestige in the system. In the case of ethnic/racial groups, the participation of black, pardo, and native

29 Pardo is the Brazilian denomination used in national statistics for those of mixed ancestry involving European and African and/or Native Brazilian. It means, literally, of brown/gray colour. 
Brazilian students put together, was 30\% in public higher education institutions, $29 \%$ in non-profit and $37 \%$ in for-profit higher education institutions, for the same year. Thus, there is diversion in this case, with the largest participation of historically disadvantaged groups being absorbed by the sector of lowest prestige (for-profit higher education institutions), which has been also providing education at unacceptably low levels of quality (Pedrosa et al., 2013). On the other hand, in the federal system, participation of historically disadvantaged groups was highest among public higher education institutions, reaching $32 \%$ of all graduates, due in great part to a federal law, passed in 2012, imposing quotas for students who graduated from public high-schools and for black, pardo, and native Brazilian students (Pedrosa et al., 2014). In the case of South Africa, we will see that there is indication of stratification between historically white and black universities with regard to employment.

Regarding postgraduate education, the data available show smaller differences in numbers of degrees between the two countries, more in line with population totals. In South Africa, the number of women who completed doctorate degrees in 2015 represented only $18 \%$ of the total, lower than the $24 \%$ for undergraduate degrees. For masters programmes, women's participation was 25\%. In Brazil, participation of women was slightly higher than that for undergraduate education. We do not compare the ethnicity of postgraduate students because these data are not available for Brazil.

\section{Engineering graduates and employment}

Engineers' participation in the total workforce in South Africa varied between 0.61 and 0.46\% between 1994 and 2001 (Steyn, \& Daniels, 2003), not much different than their participation in Brazil's formal workforce, which varied between 0.52 and $0.58 \%$ between 2003 and 2013 (Federação Nacional dos Engenheiros [FNE], 2015). This is likely related to the participation of the economic sectors that hire engineers in the economies of both countries (which have similar levels of economic development).

Regarding the participation of women in the workforce, ECSA (2016) reported that only $4.7 \%$ of a total of 16526 registrations of professional engineers (BEng), in the period covered by the report, were female. Despite not being a direct estimate of employment, this indicates a much lower participation of women in the engineering working force in comparison to that among BEng/BScEng degree holders (24\%). The 2013 skills survey (ECSA, 2014) showed a larger proportion of female participation, at $12 \%$, and also that their age profile was substantially lower than that of men, implying that participation of women in the lower age cohorts has been growing. In Brazil, women constituted $18 \%$ of the total engineering (BEng) formal workforce in 2013 (Salerno, de Toledo, Gomes, \& Lins, 2014). This has not changed more recently (Relação Anual de Informaçóes Sociais [RAIS], 2016) and is much lower than the $30 \%$ participation among BEng degree holders. It is not as extreme as in South Africa in engineering, but neither has it shown any recent improvement. Thus, in both countries, the transition of women from college to the working place shows 
signs of relevant obstacles, possibly related to negative aspects of the engineering workplace in relation to women engineers (Lombardi, 2017). International figures show large variations as well, with some countries reporting figures around $50 \%$, while others, $10 \%$ or less (Huyer, 2015), with differences not necessarily related to regional or economic level groupings.

Regarding race, ECSA (2016) reports that among registrations of professional engineers for the period, $10 \%$ were by black Africans, $6.1 \%$ by Indians and $1.1 \%$, by coloured individuals. As in the case of women's participation, these are much lower than the levels of participation among recipients of recent engineering degrees, for the same groups $(30 \%$, $11 \%$ and $3.6 \%$, respectively). The skills survey report (ECSA, 2014) shows, as in the case of women, that black Africans form a very large part of the younger group of respondents, actually matching numbers of whites below age 40, which denotes a positive recent trend. In Brazil, only $10 \%$ of employed engineers were neither white nor Asian (RAIS, 2016), also a much lower rate than that found among BEng degree holders (30\%), but the situation is also better for younger cohorts. So, for both countries, despite recent advances, historically disadvantaged groups have a lower participation rate in the engineering workforce than expected from the proportion of graduates. This is an indication that there are serious obstacles in engineering to the inclusion of historically disadvantaged groups in the transition between college and employment.

Regarding the chances of graduates to find a job, Moleke (2005) reports that $77 \%$ of engineering graduates in South Africa had the experience of finding employment immediately. Black African graduates reported a higher incidence of immediate employment compared to whites, at $89 \%$, but he also observed that the chance of being employed immediately was higher for those graduating from historically white than from historically black universities, that is $78 \%$ compared to $60 \%$. Moreover, $20 \%$ of those graduating from HBUs had to wait at least one year to find a job, whereas in the case of HWUs, only $1 \%$ fell in that category. This shows that, despite no formal differentiation within the system of universities, there are stratification effects in the transition from college to employment in South Africa, certainly inherited from the apartheid period. In Brazil, Maciente, Nascimento, Servo, Vieira, \& Silva, (2015) reported that, of the 42000 students who had graduated in 2011, 28\% were either unemployed or working informally at the end of 2012, and only $32 \%$ were formally employed in engineering or other jobs requiring a higher education degree, thus leaving more than half of those employed in the underemployed category. All this followed about eight years of continuous economic growth, a period for which employment of engineers showed a significant growth (FNE, 2015). As the economy has slowed down severely since, and the number of graduates has continued to increase reaching 100000 in 2016 (see http://portal.inep.gov.br/microdados), while there are only 270000 formally employed engineers (FNE, 2015) - young engineers will certainly face a worsening employment scenario for years to come. 


\section{Conclusions}

Despite recent advances in the inclusion of historically disadvantaged groups in engineering programmes in both countries, the transition to employment has not kept pace. In the case of South Africa, this occurs despite the evidence that black Africans show a higher than average chance of finding a job immediately in the general field of engineering. However, those graduating from an HBU take longer to find jobs, which indicates that social/racial stratification is at work in the system, which still reflects the structural aspects of the system inherited from the apartheid period. Brazil seems to be ahead in the reduction of race-related inequalities in engineering education due to, in part, the very fast rate of expansion of higher education, engineering in particular, in the last two decades. This was stimulated by strong government policies, which has not been the case for South Africa. Secondly, there have been affirmative action policies in Brazil dedicated to increasing opportunities for historically disadvantaged groups to be admitted to higher education, with some success in the federal public system. Still, the issue of social stratification and the stubbornly low participation of historically disadvantaged groups in the engineering labour force indicate that there are still obstacles that must be overcome before the goal of an equitable system is achieved. Underemployment of graduates is also an issue in Brazil, aggravated recently by a lasting economic recession and the rapid growth in the number of graduates in recent years.

Regarding the participation of women, Brazil's engineering education is slightly more inclusive, as they constitute about $30 \%$ of BEng degree recipients, while, in South Africa, the figure is $24 \%$, which is about the average world participation. But this does not seem a distinctive aspect between the systems, as there is no stratification in Brazil for women and, in the case of South Africa, the number of women among historically disadvantaged groups is larger than among whites. Therefore, it seems that, at least regarding higher education itself, gender differences in both countries are in line with world tendencies (which is not to say that the situation is acceptable). However, women's participation in the engineering workplace is at a much lower level, for both countries, than expected given the proportion of women gaining degrees. Part of the problem is certainly that, in both countries, the engineering workplace is plagued by gender discrimination, which is likely to have strong discouraging effects on women's attitudes towards professional development and their likelihood to study engineering. Thus, even if higher education itself may not be directly responsible for the low participation of women in engineering programmes, the external negative professional environment ends up impacting women's choices as they go to university. This is certainly true for other countries.

As for the possibility of higher education itself working in favour of developing social awareness and civic engagement among engineering students, there is evidence in the literature (Mayhew et al., 2016) that majoring in engineering may have negative impacts on students' and graduates' attitudes and values, compared to other fields. However, many studies also showed neutrality for engineering education in that respect and this is a sign that results are still in a preliminary stage and that more research is needed, including other 
countries and systems. Walker et al. (2010) observed that even those who participated in a social awareness course at a South African university still kept a perspective of getting a wellpaying job as one of their main objectives and thought that engineers would serve society well by being competent and ethical professionals. This is a strictly instrumental view of the relationship between engineering and the common good. Also, graduates surveyed by Walker and her team reported difficulties of obtaining commitment from government authorities to effective poverty reduction programmes that would include engineers as relevant actors for their development. Despite these restrictions, many studies (Mayhew et al., 2016) confirm that higher education plays important roles in developing common goodrelated attitudes and values of students, irrespective of majoring field. Thus, to counterbalance the possible negative effect of specific disciplinary areas, including engineering, academics and institutional leaders need to develop courses and degree programmes that achieve these objectives. Finally, one must recognise that the relationships between engineering education and the common good require an expanded vision, including all aspects of the profession, an approach related to the idea of nesting private interests in public ones, as proposed by Marginson (2016), in order to bring a positive-sum perspective to public-private good relationships to higher education.

In conclusion, engineers work for the common good by making lives of people better, by helping societies develop means of providing all sorts of important goods to members and helping countries achieve their full economic potential. However, the way the profession works in modern societies, with strong ties to private and market interests, impose restrictions on the role it could play in relation to broader common good interests, especially in regard to development of graduates' values and attitudes. Here is where engineering education comes in, as it may work to counteract some of those restrictions, and also by making it possible for disadvantaged groups and for women to have access to a profession that has been, and will continue to be, part of the ongoing process of scientific, technological and social development across the world. That being the case, we have seen that Brazil and South Africa, despite some advances in the last couple of decades, still have a long way to go, and need to develop a focused approach in overcoming many types of obstacles. Whilst some of these obstacles are outside the control of higher education, it has an important role to play in providing opportunities for the development of skilled and engaged citizens and increasing participation by historically disadvantaged groups and women, both of which would contribute to the development of more equitable and sustainable societies.

\section{Acknowledgements}

We would like to thank Joana Santa-Cruz and Nadia Dini at Fapesp, for their help regarding data collection about Brazilian engineering education and profession. R. Pedrosa acknowledges partial support from Fapesp Grant N. 2017/17329-6. 


\section{References}

Brantley, C. (2012). Engineering's debt to the Morrill Act. Today's Engineer, IEEE. Retrieved from http://www. todaysengineer.org/2012/Jul/Morrill-Act.asp

Chandler, A. D. (1980). The growth of the transnational industrial firm in the United States and the United Kingdom: A comparative analysis. The Economic History Review, 33, 396-410.

Cornell University, INSEAD, \& WIPO (2017). The Global Innovation Index 2017: Innovation feeding the world. Ithaca, Fontainebleau, and Geneva. Retrieved from http://www.wipo.int/edocs/pubdocs/en/wipo_pub_ gii_2017.pdf

de Souza, C. V., Faganello, C. P., Diego Almeida dos Santos, D. A., Felipe de Oliveira Gonçalves, F. O., Penteado, L. P., Xavier, M. F. R., ... Dasso Jr., A. E. (2017). O impacto do Projeto Rondon na atividade profissional de ex-rondonistas. III Congresso Nacional do Projeto Rondon, Brasília, 2017.

Department of Higher Education and Training (2016). Table 2.13 for all institutions, 2000, 2005, 2010, 2015. Department of Higher Education and Training, South Africa. Retrieved from http://www.dhet.gov.za/HEMIS/ Graduates/Graduates\%20Table\%202.13(2015)/2015\%20Table\%202.13\%20for\%20all\%20institutions.zip (Access: 2018/04/23).

Engineering Council of South Africa (2014). National engineering skills survey - December 2013. Pretoria: Engineering Council of South Africa. Retrieved from https://www.ecsa.co.za/news/Surveys\%20 PDFs/200215_ECSA_National_Engineering_Skills_Survey_Report_April_2014.pdf

Engineering Council of South Africa (2016). ECSA annual report 2015/2016. Pretoria: Engineering Council of South Africa. Retrieved from https://www.ecsa.co.za/news/Annual\%20Reports/Annual_Report_2015-2016.pdf

Federação Nacional dos Engenheiros (2015). Perfil Ocupacional dos Profissionais de Engenharia no Brasil. Federação Nacional dos Engenheiros/Dieese. Brasília, DF, Brasil. https://www.seesp.org.br/site/images/ documentos/PerfilFNE_net.pdf

Gordon, R. J. (2016). The rise and fall of American growth - The US standard of living since the civil war. The Princeton Economic History of the Western World Series. Princeton, NJ: Princeton University Press.

Huyer, S. (2015). Is the gender gap narrowing in science and engineering? In Unesco Science Report: Towards 2030. Paris: UNESCO. Retrieved from https://en.unesco.org/unesco_science_report https://en.unesco.org/ sites/default/files/usr15_is_the_gender_gap_narrowing_in_science_and_engineering.pdf

Ishitani, T. T., \& McKitrick, S. A. (2013). The effects of academic programs and institutional characteristics on postgraduate civic engagement behaviour. Journal of College Student Development, 54(4), 379-396.

Jawitz, J., \& Case, J. M. (1998). Exploring the reasons South African students give for studying engineering. International Journal of Engineering Education, 14(4), 235-240.

Kloot, B., \& Rouvrais, S. (2017). The South African engineering education model with a European perspective: History, analogies, transformations and challenges. European Journal of Engineering Education, 42(2), 188-202.

Landes, D. S. (2003). The unbound Prometheus: Technological change and industrial development in Western Europe from 1750 to the present. Cambridge, UK: Cambridge University Press.

Leiden Ranking (2018). CWTS Leiden ranking. Retrieved from http://www.leidenranking.com/ranking/2018/list

Lombardi, M. R. (2017). Engenheiras na construção civil: a feminização possível e a discriminação de gênero [Women engineers in construction: the feminizatio possible and gender discrimination]. Cad. Pesquisa, v. 47 no. 163. Fund. Carlos Chagas, São Paulo, Brasil. English version: Retrieved from https://www. researchgate.net/publication/316176609_Engenheiras_na_construcao_civil_a_feminizacao_possivel_e_a_ discriminacao_de_genero

Maciente, A. N., Nascimento, P. A. M. M., Servo, L. M. S., Vieira, R. S., \& Silva, C. A. (2015). A inserção de recém-graduados em engenharias, medicina e licenciaturas no mercado de trabalho formal. Radar 38 , Brasília, DF, Brasil: IPEA.

Mann, Charles R. (1918). A study of engineering education. Carnegie Foundation for the Advancement of Teaching Bulletin No. 11. Boston, Merrymount Press. Retrieved from http://web.mit.edu/ jwk/www/docs/ Mann\%201918\%20Study_of_Engineering_Educ.pdf

Marginson, S. (2016). Higher education and the common good. Melbourne, Australia: Melbourne University Publishing. 
Mayhew, M. J., Rockenbach, A. N., Bowman, N. A., Seifert, T. A, Wolniak, G. C., Pascarella, E. T., \& Terenzini, P. T. (2016). How college affects students - volume 3. San Francisco, CA: Jossey-Bass, John Wiley, \& Sons.

McCowan, T. (2004). The growth of private higher education in Brazil: Implications for equity and quality. Journal of Education Policy, 19(4), 453-472.

McCowan, T. (2007). Expansion without equity: An analysis of current policy on access to higher education in Brazil. Higher Education, 53(5), 579-598.

Mills, J., Ayre, M., \& Gill, J. (2010). Gender inclusive engineering education. New York, NY: Routledge.

Ministério do Trabalho e Emprego, Brazil (2016). Relação Anual de Informações Sociais 2016 (Annual Report of Social Information). Ministério do Trabalho e Emprego, Brazil.

Moleke, P. (2005). Finding work: Employment experiences of South African graduates. Cape Town: HSRC Press.

Morrill Act (1862). A century of lawmaking for a new nation: US Congressional Database and Debates, 1774-1875, Chap. CXXX, pp. 503-505, The Library of Congress, Washington, DC, USA. Retrieved from http://memory.loc.gov/cgi-bin/ampage?collld=Ils|\&fileName=012/Is|012.db\&recNum=534

Mowery, D. (1984). Firm structure, government policy, and the organisation of industrial research: Great Britain and the United States, 1900-1950. Business History Review, 58(4), 504-531.

Nel, H., \& Meyer, J. (2016). Attraction, education and retention of technical women in South Africa. Proc. IEEE IEEM, pp. 174-178.

Pedrosa, R. H. L., Amaral, E., \& Knobel, M. (2013). Assessing higher education learning outcomes in Brazil. Higher Education Management and Policy, 24 (2), 55-71, Paris, France: OECD.

Pedrosa, R. H. L., Simões, T. P., Carneiro, A. M., Andrade, C. Y., Sampaio, H., \& Knobel, M. (2014). Access to higher education in Brazil. Widening Participation Lifelong Learning, 16(1), 5-33(29).

Reed, B., \& Case, J. M. (2003). Factors influencing learners' choice of Mechanical Engineering as a career. African Journal of Research in Mathematics, Science and Technology Education, 7(1), 73-83.

Sax, L. J. (2008). The gender gap in college: Maximizing the development potential of women and men. San Francisco, CA: Jossey-Bass, John Wiley, \& Sons.

Salerno, M. S., de Toledo, D. G. C., Gomes, L. A. V., \& Lins, L. M. (2014). Tendências e Perspectivas da Engenharia no Brasil - 2013. Observatório da Inovação e Competitividade, IEA, USP, São Paulo, Brasil. Retrieved from http://www.iea.usp.br/pesquisa/grupos/observatorio-inovacao-competitividade/ publicacoes/online/engenhariadata-tendencias-e-perspectivas-da-engenharia-no-brasil-relatorio-2014/view

Shavit, Y., Arum, R., \& Gamoran, A. (Eds.). (2007). Stratification in higher education: A comparative study. Stanford CA: Stanford University Press.

Statistics South Africa (2012). Census 2011 - Census in brief. Retrieved from http://www.statssa.gov.za/ census/census_2011/census_products/Census_2011_Census_in_brief.pdf

Steyn, G., \& Daniels, R. C. (2003). Engineers and technicians. In R. Devey, C. Skinner, \& I. Valodia (Eds.), Human resources development review 2003: Education, employment and skills in South Africa. Cape Town: HSRC Press.

Unterhalter, E., Allais, S., Howell, C., McCowan, T., Morley, L., Oanda, I., \& Oketch, M. (2018). Conceptualising higher education and the public good in Ghana, Kenya, Nigeria and South Africa. Preprint, 2018 (paper delivered at CIRES Conference, Mexico City, Mexico, March 2018). Retrieved from http://discovery.ucl. ac.uk/10050089/

Walker, M., McLean, M., Dison, M. A., \& Peppin-Vaughan, R. (2010). Higher education and poverty reduction: The formation of public good professionals in universities. Case Study: Engineering, Arcadia University. School of Education, University of Nottingham, UK. Retrieved from https://assets.publishing.service.gov.uk/ media/57a08b0240f0b652dd000a38/60622_Case_Studies_Final.pdf

World Bank (2016). GDP, PPP (current international \$). Retrieved from https://data.worldbank.org/indicator/ NY.GDP.MKTP.PP.CD 

PART D

CONCLUSION 



\section{WHAT HAVE WE LEARNED ABOUT PATHWAYS TO THE PUBLIC GOOD FROM SOUTH AFRICAN UNDERGRADUATE EDUCATION?}

Paul Ashwin, Vincent Carpentier, Jennifer Case, Delia Marshall, Tristan McCowan, Sioux McKenna, Rajani Naidoo, Rebecca Schendel and Melanie Walker

In this book, we have explored the contribution of South African undergraduate education to the public good, looking at the pathways to the public good that arise from students' access to higher education, their experiences of higher education and their outcomes from higher education. With the high expectations placed on higher education and its potentially transformative influence on students and societies, in a time of heightened contestation, this issue has some urgency. We recognise that the potential public good purposes of higher education go well beyond its undergraduate function, but it was this aspect of higher education that was the focus of our project.

In this conclusion, we want to examine what is highlighted when the individual chapters of this book are considered as a whole. In doing so, it is important to remember that the project that underpinned this book was not primarily focused on generating new empirical data about South African undergraduate education. Rather, we wanted to bring together and reflect on what is currently known and to consider what implications this has for higher education research, policies and practices in the future. Our work began looking at the distinctive literatures on access, student experiences, and graduate outcomes, but in putting together this book we sought to bring together literatures that are often developed in silos and are seldom connected to each other. Rather than push ahead with new empirical projects, we wanted to take stock on what we can learn from the immense amount of research that has already been conducted across this domain, noting also where there are gaps. As Tight (2018) argues, higher education internationally would benefit from these kinds of conversations that aim for synthesis in the field. 
In this chapter, we first examine what we have learned about the difficulties in conceptualising undergraduate education. We then examine what we have learned from the project about researching higher education and finally we explore how we see the implications of the project for policies and practices in higher education. Although the book focuses its attention on the South African context, it also engages with international comparative contexts and literature. In this conclusion, rather than separating these literatures, each section brings together the South African specific and internationally relevant aspects of the outcomes from this project.

\section{Tensions in conceptualising undergraduate education}

Across all of the chapters, what is most evident is the diversity and complexity of students' experiences of accessing, engaging in, and graduating from, their undergraduate studies. Such diversity and complexity stems from a wide range of factors including socio-economic background, institutional context, curriculum choice, student aspirations, teaching and learning, and opportunities for employment. We have identified multiple barriers experienced by students, but also opportunities for personal and societal transformation. These are not straightforward paths, and rather than drawing definitive conclusions, we feel it is more helpful to highlight a range of tensions that underpin our understanding of these pathways. There are no simple answers to any of the key questions we have grappled with in this project, and, given this, these tensions are intended to act as provocations to further work, rather than summaries of what has been achieved.

\section{Tension 1: Between individual institutions and (differentiated) bigher education systems}

Much of the popular debate on higher education internationally tends to be dominated by a focus on individual institutions, particularly universities (Millot, 2015; Williams, de Rassenfosse, Jensen, \& Marginson, 2013) at the expense of considering higher education systems. In recent times this has been exacerbated by the rise of global rankings, whereby universities are pitted against each other as competitive organisations. In the South African context, however, this tension between institutions and the system seems to take a particular form. First, as discussed in the introduction, the higher education system is explicitly positioned as having a key role to play in transforming society. Moreover, in the desire to move from a differentiated system based on race, there has been an avoidance of conceptualising other forms of differentiation in the system. There are good reasons for this, particularly because such a move could simply entrench the low status and poor resource levels in historically disadvantaged institutions. Thus, as in other higher education systems, there have been patterns of 'academic drift' in mission across institutional types. However, in this South African attempt to move past inherited inequalities with a homogenised policy, there is also the risk of overlooking institutions' distinct institutional histories, cultures and values, and resources and needs. As we discuss in more detail when looking at research into higher education, 
this tendency to think of a single undifferentiated system in South Africa obscures the fact that we know far more about higher education in historically advantaged institutions than we do about historically disadvantaged institutions. There is a distinct gap in the literature regarding these historically disadvantaged institutions, despite the crucial role they can play in transforming who gains access to and benefits from an undergraduate education.

\section{Tension 2: Between transformation and reproduction}

The second tension has similarities to the first as it is embedded in the clear expectations that were placed on higher education in South Africa in the transition to a democracy. Higher education was explicitly expected to play a key role in alleviating the inequalities inherited from the apartheid era. However, it is also important to be clear that much of the attraction of higher education for students and their families is the 'graduate premium' that they expect to receive from engaging with higher education. The experience of studying at university and the subsequent access it can provide to a graduate career can clearly be hugely personally transformative for individuals and their families. However, graduate premiums are also a clear indicator of inequality because they signal the differences in income between graduates and non-graduates (Marginson, 2016). Thus much of the popular support for higher education, in South Africa and globally, is related to its role in reproducing existing inequalities in society, even if some individuals hope to experience social mobility. In this way much of its popularity, comes from its role in personal rather than societal transformation (for example, see Southall, 2016 on the emerging black middle class in South Africa). Indeed if higher education was successful in supporting the transformation of society in the way envisaged in policy, then it is likely that graduate premiums would fall. For this not to lead to a sense of disillusion with higher education, it would appear to be crucial that societal transformation is underpinned by a personal transformation in students that ensures a commitment to a transformed society.

A focus on this tension highlights that, rather than seeing reproduction and transformation in opposition to each other, the important question is about what aspects of existing systems are to be transformed and what elements are to be reproduced. For example, how would we view a higher education system that helps to transform racial inequalities in South Africa but reproduces the overall levels of economic and gender inequality? This awkward question is helpful because it also highlights the importance of thinking intersectionally when considering the relationship between transformation and reproduction.

\section{Tension 3: Between homogenisation and differentiation}

At the heart of the first two tensions, is a conceptual tension between homogenisation and differentiation. Whilst there is something inclusive about positioning higher education as a single system, the danger of this is that it underplays the inequalities between institutions; moreover, it does not allow for the potential strengths inherent in systems that are differentiated 
deliberately according to mission. Institutions have different (actual or aspirational) identities and material resources (and staff, etc.) which are 'flattened' (and even ignored) by homogenising discourses of institutional excellence. This project highlighted the need to find a more inclusive 'both/and' way of discussing the higher education system in South Africa so that the common mission of making transformative knowledge accessible to as many people as possible is recognised, but so too is the value of distinctive institutional missions, providing there are the resources available to make each of these different missions achievable.

\section{Tension 4: Between local and universal concepts of the public good}

As Deem and McCowan recognise in Chapter 5, the public good was a concept developed in the Global North. A question driving the explorations in this book is the extent to which this concept needs to change to fit with contexts in the Global South and how much needs to remain the same in order for the concept to be recognisably focused on what has originally been termed the public good. For example, Walker (2018) argues for a capability approach for conceptualising the public good of higher education in South African universities because it has an ethic that is humanising, focuses on whether opportunities are fairly distributed and foregrounds participation by considering what students are able to do and become through their engagement with higher education. Such an approach can be seen to highlight a version of the public good that is focused on creating a democratic public good.

In thinking about how the notion of the public good applies in the South African context, it is also important to recognise the relative openness of South African society and the value that is assigned to academic freedom. The importance of these conditions in underpinning a productive notion of the relation between higher education and the public good suggests that perhaps it is more helpful to focus on the conditions required for universities to support the public good, rather than seeking a universal notion of the public good. To develop this further requires further comparative research examining how higher education contributes to the public good in a range of national settings. It also raises the question of whether there is a way of understanding higher education's relationship to the public good internationally, rather than simply at a national level.

\section{Tension 5: Between complex research ideas and simple dominant discourses}

We began this section by discussing the tension between engaging with the complexity of higher education and the need to provide accessible ways of understanding that complexity. In our reviews of the existing bodies of knowledge, the importance of finding better ways of engaging with these tensions became even more urgent. This is because we found many conceptually rich studies, but we also found many studies that were based on simplified conceptualisations of higher education practices that served to reinforce problematic ways of understanding students and higher education. We need to engage directly with the attractiveness 
and appeal of these discourses so that we can move discussions in a more productive direction. This final tension brings us to the next section of this chapter, in which we examine what we have learned in this project about higher education research in South Africa and beyond.

\section{Implications for researching higher education}

\section{A rich but partial literature}

The chapters in this book have shown that there is a rich literature on higher education in South Africa but that it is in some ways a partial literature. The rather homogenised conceptualisation of the higher education system plays a role in this partiality. We noted that we know far more about access, student experiences and graduate outcomes in historically advantaged institutions than we do in other institutions, dramatically skewing this overall picture. It is also worth noting that there is a particularly limited literature on access, regardless of institutions. There is also a tendency to treat the experiences of poor, black and rural students as a single set of experiences, rather than exploring the diversity of experiences that are brought together under these different descriptors.

\section{Limits on publicly available system-wide data}

It is clear from the reviews of existing research presented in this book that higher education research in South Africa would benefit from access to more publicly available data on higher education, especially in relation to the limited statistical data presently available for economic or sociological analyses of South African society. As it stands, the higher education literature is dominated by single institution studies. As we have already discussed, one concern is the very limited information on historically disadvantaged institutions. These data are needed in order to develop a clearer picture about processes and inequalities across the whole system.

However, we also need to be careful to avoid suggesting that having access to such data will necessarily provide the insights needed to better understand the full complexity of this system. All such data are by their nature proxies for the complex practices and processes they are intended to measure. As such, they can only provide a broad outline of what is occurring across the sector. This means that such data need to represent the beginning of a conversation within and beyond the higher education sector about the relationships between the picture portrayed by analysis of these data and the potential of higher education to contribute to the personal and public good.

\section{The importance of comparative research}

Some of the chapters in this book have also highlighted the importance of comparative research in developing a better understanding of higher education systems, both in South Africa and 
internationally. Here we note that comparison can operate at different scales (for example, comparing institutions or comparing higher education systems) and that comparisons can focus on different dimensions of higher education. As already mentioned, what was striking about the South African research that we examined was that it was nearly always - with notable exceptions - conducted in a single institution.

The problem with this lack of comparative research is that it tends to limit our thinking to a particular context and so makes it more difficult to discern how things might be different than they are. It can also lead to a tendency to compare what is currently happening with an ideal rather than understanding how similar challenges are managed in different settings. It seems possible that the tendency for South African research to see the South African higher education context as unique ('South African exceptionalism') is more a product of this lack of comparative studies, rather than the uniqueness of the challenges faced in South African higher education.

The value of comparative research is that it allows us to develop a more nuanced account of what is happening in different contexts. Thus, for example, comparative research into the underresearched historically disadvantaged sector would allow us to gain a richer sense of the diversity of experiences in these institutions, rather than positioning them as a homogenous group.

\section{Collective networks and bodies of literature}

In arguing for more comparative studies of higher education both within South Africa and internationally, it is important to be clear that the value of individual projects comes from their relationship to collective bodies of literature. That is to say, it is not the outcomes of any single project that are important but the ways in which this further develops our collective knowledge.

For this to happen, we need spaces in which to bring bodies of knowledge together, and this book is an attempt in that direction. The tendency for literatures to exist in silos is a major barrier to developing a shared sense of what we know about higher education in South Africa and internationally. Bringing these bodies of knowledge together requires stronger research networks because they do not exist simply in research texts, but also in the partnerships between researchers that lead to the development of collective practices. In the work undertaken in producing this book, the collective discussions that were had in face-to-face settings played a key role in developing shared collective understandings that moved beyond any individual perspective over the course of our meetings. The space to develop such collective thinking is important if higher education research is to do more than critique existing arrangements and instead move to offering alternative arrangements that can help to address the challenges facing higher education in South Africa and globally.

\section{Talking back to the Global North?}

One of the challenges within this project was to examine the extent to which ideas originating in the Global North could do useful work in the context of South African higher education. 
This is linked to the previous point about the importance of comparative work because the power of internationally comparative work is that it alerts us to the similarities and differences between contexts. It highlights the ways in which any ideas need to be transformed in order to be relevant in new contexts. One of the problems with the notions of 'best practice' or 'teaching excellence' is that they imply that the same practices are effective regardless of the context in which they are operating. What this book makes clear is that international higher education has as much to learn from the South African case, as South Africa might learn from the international collective body of knowledge about higher education. It also highlights the ways in which the differences between international and local knowledge are misleading because all knowledge is in some way local. The issue is whether that knowledge is positioned in relation to a collective body of knowledge that is international or local in its scope. In focusing on South African research talking back to the Global North, the intention is to highlight that South African research has an important contribution to make to international bodies of knowledge about higher education.

\section{What are the implications for policies and practices in South Africa and internationally?}

In exploring the implications for policies and practices in South Africa, we focus on three areas of higher education: research practices, educational practices and policies.

In terms of research practices, it is clear that for higher education research in South Africa to develop further, there is a need for spaces for researchers to come together and reflect on how South African research into higher education relates to research conducted in other contexts. Here we gratefully acknowledge the support from the ESRC and NRF which made this project possible. Such spaces for reflection need to be based on a common commitment to developing collective and high-quality bodies of knowledge about South African higher education that tell us about the whole system and the diversity of student experiences and are in conversation with international bodies of knowledge.

In terms of educational practices, this project highlighted the ways in which institutional cultures, admission practices, curricula and pedagogies are central to possibilities of the kind of personal transformation that contributes to the public good. A key element of this is for institutions and curricula to recognise students as they are, rather than by some notions of what they ought to be. For example, enhanced curricula and pedagogies need to start from students' current knowledge and understanding and be designed intentionally to help students to critically engage with collective bodies of knowledge that change their understanding of the world and themselves. Such enhancement work requires a diverse body of professional, qualified and committed academics, supported by scholarly academic development and student involvement in university governance, curricula and pedagogies. It also requires research that helps us to better understand whether and how different forms of student experience contribute directly (positively or negatively) to the public good. 
In terms of educational policies, higher educational practices need to be supported by policies and assessment regimes that value and prioritise the creation of a more equal society. The transformative potential of the South African higher education sector depends on contextualised governance and funding measures, rather than the kind of superficial engagement that is valued and promoted by the rhetoric of global competition, rankings and metrics.

\section{Concluding remarks}

This project set itself the challenging task of drawing together the extensive literature on undergraduate education in South Africa, to examine how it contributes to the public good. We were particularly interested in grappling with how this works systemically, to describe how positive transformations work, but maybe even more importantly, to identify the barriers that currently limit the public good outcomes of South African higher education. The literature that we have allows us to fill in part of this picture; for example, we know quite a lot about the experiences of a diverse group of students at historically advantaged institutions. But we have a relatively limited sense of the sector overall, and this is a concern at a time when higher education policy is in flux. If South African undergraduate education is to play a key role in transforming society, as envisaged in policy, then this will involve significant changes to current practices that support access to, student experiences of, and outcomes from undergraduate education. To make these changes will not only require more evidence about how the whole of the system operates, but will also require intense public debate about the ways in which higher education should contribute to the transformation of society.

\section{References}

Marginson, S. (2016). The dream is over: The crisis of Clark Kerr's California idea of higher education. Oakland, California: University of California Press.

Millot, B. (2015). International rankings: Universities vs. higher education systems. International Journal of Educational Development, 40, 156-165.

Southall, R. (2016). The new black middle class in South Africa. Suffolk, UK: Boydell, \& Brewer.

Tight, M. (2018). Higher education journals: Their characteristics and contribution. Higher Education Research \& Development, 37(3), 607-619.

Walker, M. (2018). Dimensions of higher education and the public good in South Africa. Higher Education, 1-15.

Williams, R., de Rassenfosse, G., Jensen, P., \& Marginson, S. (2013). The determinants of quality national higher education systems. Journal of Higher Education Policy and Management, 35(6), 599-611. 


\section{INDEX}

Notes: Locators in italics refer to figures and tables.

Acronym used: $\mathrm{HE}=$ higher education

\section{A}

A programme for the transformation of higher education (White Paper 3, 1997) 30, 137, 192, 193-195

Abdulla, M. J. 180, 181, 185

academic development 87

defined 204

rationale and focus 195-197, 205-206

theoretical approaches and critical concerns 157-158, 207-213

academic staff

and curriculum reform 196, 198

and development programmes 206, 208-209, 211-213

and institutional culture 140, 142-144

access

epistemic 196, 197, 199-200, 205

factors influencing $85-89,91-92,96-99$, 180-184

meaning of $82-84,178$

see also massification; registration fees

activism, impact of participation in 224-225, 226-227

'adaptive preferences' 114

admissions programme score (APS) 90-91, 90

African Economic Outlook (EOC) report (2012) 264-265, 265

African National Congress (ANC), development policies $10-14$

African Union Commission (AUC) 260, 262 263, 264

agriculture, education in Africa 263, 265, 265, 269
Akoojee, S. 208

Anders, J. 82

apartheid 27, 28-30, 35, 83n8, 192, 233-234

APS (admissions programme score) 90-91, 90

Archer, M. 167, 170

Arustei, C. C. 168

Ashton, D. 22, 49, 52

Ashwin, P. 127, 138

attainability of higher education 89-99

AUC (African Union Commission) 260, 262-263, 264

availability of higher education $84-85,98$

\section{B}

baccalauréat (Bac) and access to HE 101-103, 102, 107

Badat, S. 17

Baldry, K. 236, 238, 240

Ball, S. J. 82, 89

Balwanz, D. 264

Barnsely, H. 222

Bauling, A. 126

Bednarek, A. 82

Behle, H. 232

Bernstein, B. 199

Bhana, D. 220

Bhorat, H. 46, 236, 239

Biela, R. 220

'black tax' 173, 181, 181n19

Boliver, V. 104

Boughey, C. 155, 209, 211, 242

Bozalek, V. 117-118, 242

Brazil see engineering 
Brennan, J. L. 104

Britain, availability of HE 98, 103-105, 108, 232

Brown, P. 22, 49, 52

Budd, R. 61

Bunting, M. B. 28-30, 35-36

\section{C}

Calhoun, C. 66-67

capability approach and access to higher education $83-84,92$, 169, 175

applied to graduate outcomes research 246-247, 249, 251, 253, 256

higher education and personal transformation 114-119, 131, 132

key concepts 113-114, 114n12

and public good 119-121, 294

research community 112

Cape Higher Education Consortium, (CHEC) study 236-241

Carpentier, C. 22

Case, J. M. 91, 173

Cele, S. 183

Centre for Research on Violence and Reconciliation 177, 183, 188

CHE (Council on Higher Education) see Council on Higher Education (CHE)

CHEC (Cape Higher Education Consortium), study 236-241

Chetty, R. 185

Chile, availability of HE 98

citizenship

capability approach to 118,119

research on $\mathrm{HE}$ and 242, 254

and role of higher education 45, 72, 136, 226-227

Clark, B. R. 27, 139

Cloete, N. 17, 33, 46-47

Clowes, L. 223

collective skill formation systems 55

colonialism and higher education 233, 261, 263, 268

Commission of Inquiry into Higher Education and Training (2017) 34, 38-39

commodification of higher education see privatisation of higher education

common good see public good

'commons', the 64

community service programmes 119

CONFEA (Federal Engineering and Agronomy Council), Brazil 279 'conversion factors'/structural constraints 113 , $117,118,246-247,252,257$

Cooper, D. 89

Cornell, J. 219

Council on Higher Education (CHE) on extended degree programmes 194, 197 functions 15, 262

on higher education funding 29-30, 38

on higher education transformation 16, 17, $137,141,186$

Cowen, R. 39

curriculum

attempts at transformation 193-195

considerations in transforming the 18-22, 297

and knowledge 199-201

restructuring the 195-198, 256

D

decolonisation of curriculum

meaning of 198-201

and student protests $18,62,186,188$,

194-195, 225

decontextualised learners 155-158, 209

'deficit discourse' 157, 196, 208-209, 210, 211-213

democracy and higher education 68, 125, 226

Deneulin, S. 64

Department of Education see Department of Higher Education and Training (DHET)

Department of Higher Education and Training (DHET)

funding policies 30-34, 37, 165

transformation policies 193-195, 201-202, 298

and widening access $18,53,85,88,179-180$

developmental role of higher education 45, 47, $52,53,56-57$

developmental state, South Africa as 10-16

Dewey, J. 68

DHET see Department of Higher Education and Training (DHET)

Dill, D. D. 67, 74

disabilities, students with 159, 223

Disemelo, K. 186

diversity and homogenisation 20, 292, 293-294, 295-296

Dreze, J. 92

Dubet, F. 131-132

Durrheim, K. 218 


\section{E}

Economic Social Research Council (ESRC), UK 3-5

economy and higher education

in Africa 261-262, 263, 271

ANC government policies $12-15,194$

impact of slow economic growth 33-34, 34, $36,38-39$

issue of skills needs 19, 21-22, 44, 46-49

see also funding higher education; labour market

ECSA (Engineering Council of South

Africa) 279, 282, 283

EDP (extended degree programme) 193, 194, 195-197

Education Management Information System (EMIS) 262-263

employment see graduate un/employment

engineering

education and accreditation $279-282,280$, 281

employment in $282-283$

and public good 120, 274, 275-278, 285

Engineering Council of South Africa

(ECSA) 279, 282, 283

enrolment

in engineering 279,280

globally 98, 102-103, 105, 106, 264, 265-266

and public funding $6,17-18,28-33,85$

South African statistics 4, 179-180

entrepreneurship, training in $251,263,268,269$, 270

epistemic access 196, 197, 199-200, 205

equity/equality, concepts of 96-97

Espinoza, O. 96

ESRC (Economic Social Research Council), UK 3-5

Evans, P. 18

exclusion 82, 90-91, 158-159, 182-184, 186-187

extended degree programme (EDP) 193, 194, 195-197

\section{$\mathbf{F}$}

Federal Engineering and Agronomy Council (CONFEA), Brazil 279

\#FeesMustFall

access and tuition fees $38,179-182$

and media $178-179,187-188$

origin and visibility $177-178$

responses to $165-166,167,185$ and role of higher education 5, 62

student concerns raised 182-184, 186, 188, 207, 216, 225, 227

see also curriculum

field of study and employment 50, 239-240, $245,252-253$

Finland, availability of HE 97, 99-101, 108

flexible degrees 193, 194, 195, 197-198, 201, 256

Fongwa, S. 234, 239, 240

food insecurity, students and 116, 171-172, 222-223

Fossberg, C. H. 49

Foundation Grant 194, 195

France, increasing availability of HE 98, 101103,108

Fraser, N. 193

Fredriksen, B. 49

free higher education $38-39$, 47, 62, 69, 165$166,167,177-178$

'freedoms', capability approach definition 247

'functionings' 113, 246-247

funding higher education

cost-sharing/tuition fees 34-38, 36, 52-54, $61,87-88,87,232$

during apartheid $28-30$

and fee-free higher education $38-39,47,62$, 69, 165-166, 167, 177-178

global trends 39-41, 100, 102-103, 105, 262

post-apartheid 6, 30-34, 32, 34

public good considerations 62-63, 66-69, $68,73-74$

students' own plans for 172-174

see also NSFAS (National Student Financial Aid Scheme)

G

GEAR (Growth, Employment and

Redistribution) policy 12, 13, 19

gender

education and employment 50,73

and educational performance 86

in engineering 277, 280-283, 280, 281, 284

participation in higher education 101

and sexism on campus 158, 221-222

Global Competitiveness Report (WEF, 2017) 234

graduate destination/tracer studies (GDS) 44-51, 232, 234-236, 241-242, 246, 264-269

graduate outcomes

capability approach to $118-119,246-247$, 253, 256, 258 
other than employment 72-73, 254-258

research on 44-51, 232-233, 242, 245-246, 247-249, 268

see also graduate un/employment

graduate premium $61,81,293$

graduate skills 48-49, 232, 263, 270

graduate un/employment

in Africa 260-261, 263-269, 266

factors influencing 52, 238-242, 239, 250, 252-253, 282-284

research on 45-51, 232-236, 241-242

socio-economic/geographic factors 240, 247, 251

statistics on 81, 236-238, 237

graduates' contribution to public good 70-73, 120, 274, 275-278, 285

graduation rates, South Africa and globally 5, 33, 264, 265

Growth, Employment and Redistribution (GEAR) policy $12,13,19$

Guta, A. L. 168

\section{H}

Habermas, J. 64-65

Hall, P. A. 56

Hargreaves, A. 209

health of students 222-223

HEFCE (Higher Education Funding Council for England) 98

HESA (Higher Education South Africa, now Universities South Africa) 18, 37, 166

Higgins, J. 143

higher education

conclusions on South African research in 295-298

number of South African institutions 5, 207

higher education and economy see economy and higher education

Higher Education Funding Council for England (HEFCE) 98

Higher Education South Africa (HESA, now Universities South Africa) 18, 37, 166

higher education and the state see state and higher education

Highes, R. 263

historically black/disadvantaged universities (HBUs/HDIs)

apartheid legacy 17, 234

employment of graduates from 50, 239-240, 250-251, 271, 283

research at $143,144,151,151,225,292-293$ resource constraints $5,29,30-31,83 \mathrm{n} 8$,

$$
\text { 167-168 }
$$

student experiences at 129, 159, 242

historically white/advantaged universities (HWUs/ HAIs)

black academics at $142-144$

black students' experiences at $183,218,220$, 225

Hodes, R. 227

Hofmeyr, H. 47, 84, 85-86, 89

homogenisation and diversity 20, 292, 293-294, 295-296

horizontality 83, 83n7, 89-91, 92

see also Finland, availability of $\mathrm{HE}$

HSRC (Human Sciences Research Council) 236, 238,239

human capital theory 14, 22, 48, 113, 257, 263

Human Sciences Research Council (HSRC) 236, 238, 239

Husén, T. 97

I

Ilieva-Trichkova, P. 246

informal sector, graduate employment in 264 , 266, 267, 268, 283

Institute for Fiscal Studies (UK) 71

institutional culture

and \#FeesMustFall 182-184, 186

meaning of 138-140

in postgraduate research 156-159

South African research on 140-146

transformation of 18-19, 22, 136-138

see also exclusion

institutional mergers 5, 17, 142-143, 145, 194

institutional stratification

access and inequality 6, 22-23, 82, 89-90, 90, 91-92, 292-294

global models addressing access and 99-105, 108-109

importance of 50-52, 242

see also engineering, education and accreditation

Inter-University Council of East Africa

(IUCEA) 263, 270

internships 250, 251, 252, 277-278

Ismail, S. 183, 184, 185

\section{J}

Jackson, L. 220

Jansen, J. D. 15, 198

Jary, D. 127 
Jordaan, M. 88

justice see social justice

\section{K}

Kapp, R. 91, 117, 209

Keep, E. 21

Keet, A. 224

Kenya, graduate employment study 263-264

Kessi, S. 219

Kezar, A. 139

Knaus, C. B. 185

knowledge curriculum and identity 195-202

and curriculum transformation 193-195

impact of lack of 88-89, 168

and personal transformation 127, 131, 132

as a public good 63-64, 66-67, 209

and the transformation debate 18-22, 297

Koen, C. 50, 241

\section{$\mathbf{L}$}

labour force surveys (LFS)

key studies and findings of $8,46,234 \mathrm{n} 23$, $236-240,237,239,241$

uses and limitations of 234-235, 246

labour market

graduate outcomes and 45-51, 56-57, 71

and graduate output in sub-Saharan

Africa 260-261, 263-269, 265, 266, 270, 271

and institutional ranking/status 51-54, 242, 245, 250, 251, 252

land grant colleges, United States 278

Langa, M. 223

Lange, L. 192-193, 195, 196

language, impact on student experience 130, 144, 219-220

Lauder, H. 22, 49, 52

Leathwood, C. 245

Lebeau, Y. 127

LFS see labour force surveys (LFS)

LGBTI students' experiences 221

Lloyd, C. 22

Locatelli, R. 70

Loots, S. 119

Lötter, H. P. P. 168

Luckett, K. 197

\section{M}

Maciente, A. N. 283

McKenna, S. 155, 209
McLellan, C. 219

McMahon, W. 72-73

Macrae, S. 82

Maguire, M. 82

Magwedze, H. 166

Makerere University College 263

Malawi, graduate employment 264

Mandela presidency and redress $12,16,19$

Manolescu, I. 168

Manyonga, B. 88

Marginson, S.

on higher education access 97, 108, 165, 277, 278

on postgraduate studies 21

on public good $63,64,68-69,68,74,192$, 275-276

Marshall, D. 91

massification

global trends 55-56, 95, 99-105, 108

origin 278

in South Africa 4, 179-180

and stratification 6, 65, 99, 106, 245, 277

in sub-Saharan Africa 105-108, 263-264

as transformation 16-18

Maton, K. 200, 211

Maxim, E. 168

Mbeki presidency 13-14

Mbembe, A. J. 184, 198, 200

mental health of students 222-223

Miratho project $118 \mathrm{n} 14$

Mkwananzi, F. 88

Moja, T. 17

Moleke, P. 236, 283

Moreau, M. P. 245

Morrow, W. 205

Msibi, T. 221

Mtawa, N. 119

Mtolo, V. 173

Munro, N. 222

\section{$\mathbf{N}$}

Naidoo, R. 12, 90-91

National Development Plan (NDP) 11, 14, 17-18, 19

National Research Foundation (NRF, SA) 3-5, 152

National Student Financial Aid Scheme see NSFAS (National Student Financial Aid Scheme)

Nattrass, N. 12, 13

NDP (National Development Plan) 11, 14, $17-18,19$ 
NEETs (youth not in education, employment or training) 5,180

Nel, W. 224

Nelson Mandela University (NMU) 222, 247$249,248,248 \mathrm{n} 26$

Ngcwangu, S. 264

Nigeria, access to HE 105-108, 109

Nixon, J. 66

Nkomo, M. 208

Nordic societies/model see Finland, availability of HE

North Africa, higher education and employment in 262

North, E. 88

NSFAS (National Student Financial Aid Scheme) concerns regarding $38,168,172,173$, 180-182, 223

government funding to 37

Nussbaum, M. 112, 114, 114n12, 115

\section{o}

OECD (Organisation for Economic Co-operation and Development) 82, 100, 265

Onishi, N. 183-184

online news as secondary data $187-188$

organisational saga 139

\section{$\mathbf{P}$}

parental education, impact of 82, 100, 101, 205 'parity of participation' 193, 194, 195-198, 200-201

Pattman, R. 219

Payne, J. 22

pedagogies

enabling student capabilities 117, 120, 297

research on impact of institutional culture 140-146

and social transformation 136-137, 139

Peppin-Vaughan, R. 120

personal transformation of students

critical thinking and social awareness 226-227, 254-257

international perspectives $125-127$

models of $130-133$

overview of South African research on 127-130

Pillay, Pundy 17, 28

Pillay, V. 219

Pitman, T. 82

postgraduate research

approaches to student experiences in 154-159

findings on theoretical framing of 152-154, 160

overview of South African 149-152, 151 poverty

capability approach to reducing 113-114, 120

defining 168-169

powerful knowledge 20, 200-201

private sector employment see public/private sector employment

privatisation of higher education

consequences 71,261

expanding access 39-40, 95, 104, 107, 109

and public good $66-67$

students as consumers $51-52,61-62,154-155$

Prodan, A. 168

Projeto Rondon, Brazil 278

prostitution 174, 223

PSET (Post-school School Education and

Training, White Paper, 2013) 180

public good

contribution of graduates to $70-73,119-121$, 242, 254-257, 285

instrumental/intrinsic aspects of 276

meaning of 63-64, 192-193, 275-276, 278, 294

and universities 64-70, 68, 209, 226-227

public/private sector employment

in sub-Saharan Africa 261, 262, 263-264, 268-269

trends in South Africa 240-242, 250-251, 253

Pym, J. 117, 209

quality assurance $44-45,51-54,168$

Quayle, M. 222

$\mathbf{R}$

race

in engineering 280-282, 280, 281, 283, 284

and graduate employment 8, 238-240, 239, 241

and 'home'/'academic' identity 130-131

and institutional culture 136-137, 158, 182-184

and segregation on campus 218-220

in South African research 141-143

and university enrolment 84-86, 89-91, 180-181, 205

Ramaphosa presidency 14-15

ranking systems 45, 51-52, 242, 292

rape culture on campus 221

Reay, D. 82

Reconstruction and Development Programme (RDP) $11,12,14$ 
Regional Universities Forum for Capacity

Building in Agriculture (RUFORUM) 269

registration fees and accessing higher

education $83 \mathrm{n} 7,171-174,177,180-181$, 182,185

return (on investment) studies 45-47

Reynolds, J. 236, 239, 240

Rhodes University

fallist movements at 185, 220, 221

graduate experiences studies 50, 239, 247-249, 249, 254-258

\#RhodesMustFall

and decolonisation 18, 198, 200, 219, 225, 227

and role of higher education 5, 62

Rogan, M. 236, 239, 240

Ross, A. 104

RUFORUM (Regional Universities Forum for Capacity Building in Agriculture) 269

\section{$\mathbf{S}$}

SAJHE (South African Journal of Higher Education), review of 137-138, 140-146

Samuelson, P. 63, 68

SAPSE (South African Post-Secondary Education) funding formula 29-30

schooling

global views on HE access and 100-101, 104 impact on HE access in South Africa 50, 84n9, 85-86, 88-89, 115, 258

Scott, I. 211

Scott, P. 108

screening/sorting role of higher education 45 , $47-48,53,54,57$

Seekings, J. 12, 13

self-employment $233,253,267,268,269,270$

Sen, A. 92, 112, 114, 119, 169, 246

Senegal, access to HE 105-108, 109

sexism see gender

Shay, S. 197

Shefer, T. 223

Sheppard, C. 33

Simpson, H. 222

Singh, M. 66, 168

Smith, S. 126

social capital 219, 240, 241, 251, 256, 258

social justice

in Mandela era 16

meanings of 69-70, 113-114, 193

role of higher education $115,119,125$, 200-201, 242, 254-257

social media, uses of $178-179,187,240$ social realism 169,200

socio-economic background

and employment 240, 241-242

and exclusion 116, 183-184

impact on education $50,82,102-103,104$, 211, 222-223

study on students' experience of 167-175

socio-economic mobility 5-6, 21, 81, 92, 181, 293

Soskice, D. 56

Soudien report 217

South Africa as developmental state 10-16

South African Journal of Higher Education

(SAJHE), review of 137-138, 140-146

South African Post-Secondary Education (SAPSE) funding formula 29-30

Spaull, N. 86

Spiegler, T. 82

state and higher education

ensuring equitable access 55, 99-101, 108

funding issues 15-16, 22-24, 28, 38

Stellenbosch University (SU) 87, 180, 220, 239, 240

Student Representative Council (SRC) 173, 174-175, 183

students

choosing a university $81-82,88-89,116$

as consumers/customers $51-52,61-62$, 154-155

overcoming adversity $171-174$

study field and employment 50, 239-240, 245, 252-253

sub-Saharan Africa

data availability $260-263$

graduate employment/employability 265-269, 266, 270-271

graduation rates in 264-265, 265

tracer studies in $262-263$

Sustainable Development Goals 63, 260

systemic evaluation 44-45, 51-54, 168

\section{$\mathbf{T}$}

Technical and Vocational Education and Training Colleges (TVET) 34, 47, 48, 54-57, 180, 265-266

see also engineering, education and accreditation; Finland, availability of HE

Terzi, L. 115

Thaver, B. 143-144

Tierney, W. G. 138

Tilak, J. B. 115

Tomlinson, M. 245 
Townsend, N. 64

tracer/graduate destination studies 44-51, 232, 234-236, 241-242, 246, 264-269

transactional sex 174,223

transformation, meaning of 16-19, 22, 194

transformation, personal see personal transformation of students

Trowler, P. 139

tuition fees 34-38, 36, 52-54, 61, 87-88, 87, 232

see also funding higher education

TVET see Technical and Vocational Education and Training Colleges (TVET)

\section{$\mathbf{U}$}

Ubuntu 255, 255n27

unemployment among South African youth 5, 46, 180, 233

see also graduate un/employment

United States of America, promoting engineering 278

universities

factors influencing choice of $81-82,88-89$, 116

and geographical location of 98, 101, 247, 251, 256

and graduate employment 47, 239-240, 245, 250

and improving ranking 21, 51-52, 232

and public good $64-70,68,209,226-227$

status and enrolment 82, 89-91, 90

see also institutional culture

Universities South Africa (was HESA) 18, 37, 166

University Access Programme (UAP) 87

University of Cape Town (UCT)

accessibility 84,87

graduate outcomes studies 239, 240, 247-249, 249, 250-258

racism 183-184, 219

student mental health study 223

University of the Free State (UFS)

admission policies 87,90

graduate outcomes study 247-249, 248, 250-258

Miratho project $118 \mathrm{n} 14$

racism 219, 220, 221

University of Johannesburg (UJ) 84, 87

University of Nairobi 263-264, 270

University of South Africa (UNISA) 166

University of Venda (UNIVEN) 90, 239, 247-249, $248,250-258$
University of the Western Cape (UWC) 117-118, $223,239,240,247-249,249,250-258$

Unterhalter, E. 115

V

Van Broekhuizen, $\mathrm{H}$. on accessibility $47,84,85-86,89$ on graduate employment 235, 237, 238, 239

Van den Berg, S. 47, 84, 85-86, 89, 235, 237, 238

Van der Vijver, B. 220

Van Harte, M. 34-35

Van Heerden, Y. 88

Van Schalkwyk, F. 33

Van Zyl, G. M. 223

Vandeyar, S. 143

Vergnani, T. 223

Vincent, C. 89

vocational training in Africa 263, 265-266, 268-271

challenges 5, 20, 23, 34, 54-57

in Europe 99-103

as part of higher education system 17-18, 33, 46-48

\section{W}

Walker, M.

on capability approach $112,115,119-120$, 294

on graduate employment 234, 239, 240

on institutional culture 146

on public good 71, 278, 285

research on higher education access and experiences $88,118 \mathrm{n} 14$

Watson, D. 125

Wazar, M. 180, 181, 185

Wertheim, S. S. 219

White Paper 3: A programme for the transformation of higher education (1997) 30, 137, 192, 193-195

White Paper on Post-school School Education and Training (PSET, 2013) 180

Wiese, N. 88

Wilson-Strydom, M. 83, 119, 220

WITS (University of the Witwatersrand)

discrimination 183, 221

fees and admission 87,90

graduate outcomes study 239, 247-249, 248, 250-258

World Bank 260, 262, 265, 269

World Economic Forum Global Competitiveness Report (2017) 234 
$\mathbf{X}$

xenophobia $158,221-222$

$\mathbf{Y}$

youth not in education, employment or training

(NEETs) 5, 180

$\mathbf{Z}$

Zuma presidency 14-15, 22, 166, 178 

- In what ways does access to undergraduate education have a transformative impact on people and societies?

- What conditions are required for this impact to occur?

- What are the pathways from an undergraduate education to the public good, including inclusive economic development?

These questions have particular resonance in the South African higher education context, which is attempting to tackle the challenges of widening access and improving completion rates in in a system in which the segregations of the apartheid years are still apparent.

Higher education is recognised in core legislation as having a distinctive and crucial role in building post-apartheid society. Undergraduate education is seen as central to addressing skills shortages in South Africa. It is also seen to yield significant social returns, including a consistent positive impact on societal institutions and the development of a range of capabilities that have public, as well as private, benefits.

This book offers comprehensive contemporary evidence that allows for a fresh engagement with these pressing issues. 